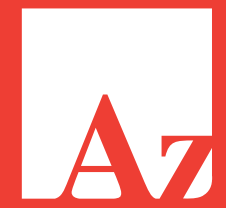

Alzheimer's Disease International

The global voice on dementia

\title{
World Alzheimer Report 2014
} Dementia and Risk Reduction AN ANALYSIS OF PROTECTIVE AND MODIFIABLE FACTORS

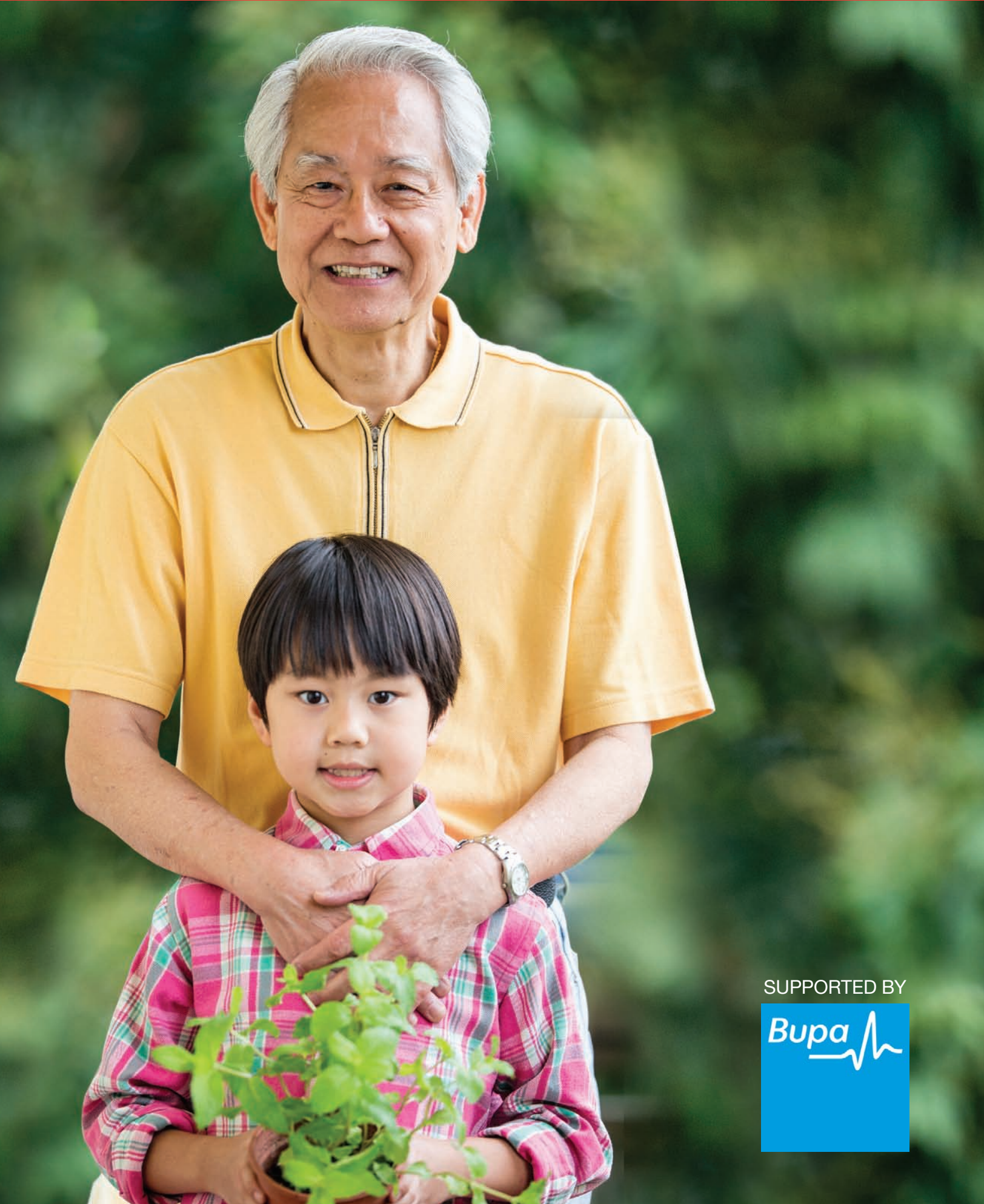




\section{Authors}

Prof Martin Prince

The Global Observatory for Ageing and Dementia Care, King's College London

Prof Emiliano Albanese

University of Geneva, Switzerland

Dr Maëlenn Guerchet

The Global Observatory for Ageing and Dementia Care, King's College London

Dr Matthew Prina

The Global Observatory for Ageing and Dementia Care, King's College London

\section{Contributors}

Richard Pender

The Global Observatory for Ageing and Dementia Care, King's College London

Dr Cleusa Ferri

Universidade Federal de Sao Paulo, Department of Psychobiology, Brazil Institute of Education and Health Sciences at the Hospital Alemao Oswaldo Cruz, Brazil

Dr Diego R. Mazzotti

Universidade Federal de Sao Paulo, Department of Psychobiology, Brazil

Dr Ronaldo D. Piovezan

Universidade Federal de Sao Paulo, Department of Psychobiology, Brazil

Ivan Padilla

Universidade Federal de Sao Paulo, Department of Psychobiology, Brazil

Prof José A. Luchsinger

Columbia University Medical Center, New York, USA

\section{Chapter 1}

Dr Maëlenn Guerchet

Prof Emiliano Albanese

\section{Chapter 2}

Richard Pender ${ }^{1}$

Dr Maëlenn Guerchet *2

Prof Martin Prince 1,2

${ }^{1}$ Education, Occupation;

${ }^{2}$ Leg length and head circumference, early-life events

\section{Chapter 3}

Dr Matthew Prina 1,2

Richard Pender ${ }^{2}$

Dr Cleusa Ferri ${ }^{3}$

Dr Diego R. Mazzotti 3

Prof Emiliano Albanese 4

${ }^{1}$ Depression; ${ }^{2}$ Anxiety disorders; ${ }^{3}$ Sleep disorders;

4 Psychological distress: personality and life events

\section{Chapter 4}

Dr Cleusa Ferri

Dr Ronaldo D. Piovezan ${ }^{1}$

Ivan Padilla ${ }^{1}$

Prof Martin Prince 1,3

Prof Emiliano Albanese 2,3

Dr Matthew Prina ${ }^{3}$

${ }^{1}$ Smoking and alcohol;

${ }^{2}$ Physical activity and cognitive stimulation; ${ }^{3}$ Diet

\section{Chapter 5}

Prof Martin Prince 1,2,3,4

Prof José A. Luchsinger 4

Prof Emiliano Albanese 2

${ }^{1}$ Hypertension; ${ }^{2}$ Obesity; ${ }^{3}$ Cholesterol; ${ }^{4}$ Diabetes

\section{Chapter 6}

Prof Martin Prince

Dr Maëlenn Guerchet

Dr Matthew Prina

Prof Emiliano Albanese

Published by Alzheimer's Disease International (ADI), London,

September 2014.

Copyright (C) Alzheimer's Disease International.

Reprinted with minor corrections October 2014

\section{Acknowledgements}

Chapter 1 photo - Adela Hernandez, Federacion Mexicana de

Alzheimer (FEDMA)

Chapter 2, 3, 4 photos - Bupa

Chapter 6 photo - Hong Kong Alzheimer's Disease Association

Cover and chapter 5 photos - iStock

Design - David O'Connor - www.daviddesigns.co.uk 


\section{Foreword}

Dementia, including Alzheimer's disease, remains one of the biggest global public health challenges facing our generation. The number of people living with dementia worldwide today is estimated at 44 million, set to almost double by 2030 and more than triple by 2050 . The global cost of dementia was estimated in 2010 at US $\$ 604$ billion, and this is only set to rise.

Given this epidemic scale, and with no known cure, it's crucial that we look at what we can do to reduce the risk or delay the onset of developing the disease. We believe that Alzheimer's disease and other forms of dementia must become a national and international public health priority. Governments must develop adequate strategies to deal with the epidemic holistically - including tackling both reduction in risk for future generations, and adequately caring for people living with the condition and supporting their friends and family.

As the only worldwide international federation of Alzheimer associations and global voice on dementia, and the largest international provider of specialist dementia care, we are committed to changing the way the world thinks about dementia. One way we will do this is by campaigning for national dementia plans which have greater emphasis on improved brain health, as well as enabling those who have dementia to live well.

To make this happen, and lessen the impact of dementia on individuals and society, there is enormous possibility in a comprehensive approach from all sectors, including health, business, academia, foreign affairs, NGOs and others, to work together to reduce the risks associated with dementia, as well as promote the interventions to manage the quality of life of those living with it and their relatives.

Our World Alzheimer Report 2014 examines the latest existing evidence associated with dementia risk factors, ranging from smoking to socialising, and provides an analysis of interventions that have been trialled to create change around the world. We believe this is an invaluable resource. It provides the basis upon which to campaign for change, and opens the door for more research in the area.

We're committed to addressing global dementia risk reduction and care - tackling one of the toughest challenges in healthcare, together.
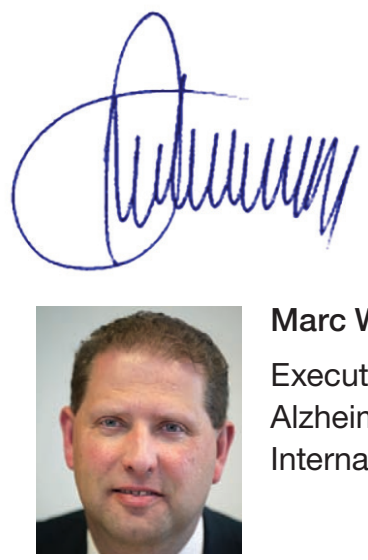

Marc Wortmann

Executive Director Alzheimer's Disease International

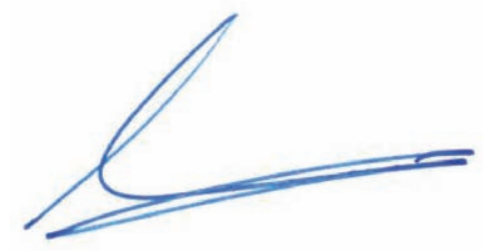

Stuart Fletcher

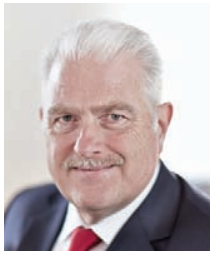




\title{
Alzheimer's Disease International \\ World Alzheimer Report 2014 Dementia and Risk Reduction
}

\author{
AN ANALYSIS OF PROTECTIVE AND MODIFIABLE FACTORS
}

\section{The Global Observatory for Ageing and Dementia Care}

The Global Observatory for Ageing and Dementia Care, hosted at the Health Service and Population Research Department, King's College London, was founded in 2013.

Supported by Alzheimer's Disease International, and King's College London, the Observatory has a tripartite mission:

1 To build upon ADI's 10/66 Dementia Research Group program of population-based and intervention research in low and middle income countries, maximising the impact that research findings from our data can have upon policy and practice.

2. To developing, evaluate, and promote primary care and community interventions for people with dementia.

3. To synthesise global evidence for policymakers and public, in particular, continuing and developing our role in the preparation of high impact evidence-based reports for Alzheimer's Disease International (World Alzheimer Reports 2009, 2010, 2011 and 2013, and Nutrition and dementia), the World Health Organization (Dementia: a public health priority, 2012) and other relevant intergovernmental organisations.

The World Alzheimer Report 2014 was independently researched and authored by Prof Martin Prince, Prof Emiliano Albanese, Dr Maëlenn Guerchet and Dr Matthew Prina on behalf of the Global Observatory for Ageing and Dementia Care, with contributions from others as listed. The evidence reported in Chapters 1-6, and the inferences drawn, are the responsibility of the authors alone. The key messages were developed by Alzheimer's Disease International and the Global Observatory. 


\section{A message from Dr Dennis Gillings, World Dementia Envoy}

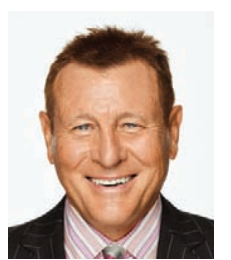

I am delighted to be asked to introduce the World Alzheimer Report 2014. Since 2009, these annual reports have yielded the best available data on dementia worldwide, providing a global framework for public policy and best practice on the international stage.

The establishment of the World Dementia Council was one of the main commitments made at the G8 dementia summit in December 2013. The council aims to stimulate innovation and development of treatments and care for people with dementia. This year we welcomed two members of the ADI family onto the Council; Dr Daisy Acosta, Honorary Vice President of ADI, and Harry Johns, CEO of the Alzheimer's Association, ADI's member organisation in the USA.

The World Dementia Council has four main areas of focus. These include promoting integrated development - enhancing or innovating the drug development pathway for dementia - with increased research budgets and financial incentives, as well as encouraging a culture of open science, unleashing the enormous potential for sharing information and knowledge.

Crucially, we will also look at how public health programmes can be used to help to reduce the incidence of dementia. We will shortly publish an evidence review into existing research on how risk factors such as diabetes and heart disease relate to dementia, and how effective public health messaging can affect the prevalence of this disease.

While we look for a cure, we must do everything we can to help reduce the risk of dementia. This report demonstrates that there is persuasive evidence that the population risk of dementia can be modified through a reduction in tobacco use and increased physical activity, alongside better treatment for hypertension and high cholesterol.

By 2050, 135 million people around the world will live with dementia. In 2010, the global cost of dementia care was estimated at US $\$ 604$ billion. Based on current estimates, this figure is expected to rise to US $\$ 1$ trillion by 2030 . With this in mind, we can't afford to do nothing. If research is not currently delivering the results we need, doing our best to live a healthy lifestyle is a sound investment for the future.

I very much welcome the findings of the report and look forward to continuing to work with $A D I$ in the future.

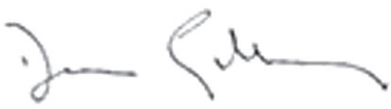

Dr Dennis Gillings

World Dementia Envoy 


\section{Contents}

Key messages 5

CHAPTER 1

Background 6

Dementia 6

Epidemiological concepts 7

Prevention 9

Life course approach 10

References 11

CHAPTER 2

Developmental and early-life risk factors 12

Leg length and head circumference 12

Early-life events 15

Education and occupation 17

References 24

CHAPTER 3

Psychological factors 26

Depression 26

Anxiety disorders 30

Psychological distress: personality and life events 30

Sleep disorders 35

References 39

CHAPTER 4

Lifestyle 42

Smoking 42

Alcohol 49

Physical activity 51

Cognitive stimulation 57

Diet 59

References 63

CHAPTER 5

Cardiovascular risk factors 66

Hypertension 67

Obesity 70

Cholesterol (Dyslipidaemia) 72

Diabetes 75

Overall conclusion 81

References 83

CHAPTER 6

Summary and conclusion 87

Summary of findings 87

Contextualising these findings with other research 88

Implications - Where do we go from here? 92

References 98 


\section{Key messages}

This report has been produced to inform health promotion and disease prevention strategies. We have examined critically the evidence for the existence of modifiable risk factors for dementia. We have focused upon sets of potential modifiable risk factors in four key domains; developmental, psychological and psychosocial, lifestyle and cardiovascular risk factors.

\section{In summary}

- There is persuasive evidence that the dementia risk for populations can be modified through reduction in tobacco use and better control and detection for hypertension and diabetes, as well as cardiovascular risk factors. A good mantra is "What is good for your heart is good for your brain".

- Based on the evidence, brain health promotion messages should be integrated in public health promotion campaigns such as anti-tobacco or non-communicable disease (NCD) awareness campaigns, with the message that it's never too late to make these changes.

- This report strongly suggests that dementia needs to be included on World Health Organization (WHO) and national NCD planning.

\section{In detail}

- The strongest evidence for possible causal associations with dementia are those of low education in early life, hypertension in midlife, and smoking and diabetes across the life course.

- Improved detection and treatment of diabetes and hypertension, and smoking cessation, should be prioritised, including for older adults who are rarely specifically targeted in prevention programs. Increased physical activity and reduction in levels of obesity are also important.
- There is considerable potential for reduction in dementia incidence associated with global improvements in access to secondary and tertiary education. There is also consistent evidence from several studies for an inverse association between cognitive activity in laterlife and dementia incidence. However, this association may not be causal, and the benefits of cognitively stimulating activities need to be tested in randomised controlled trials.

- While cardiovascular health is improving in many high income countries, it is deteriorating elsewhere. Many low and particularly middle income countries show a pattern of increasing cardiovascular conditions, hypertension and diabetes. The largest increase in dementia prevalence in the coming decades will be in the low and middle income countries, where the risk factors identified in this report present an increasing problem.

- There is no evidence strong enough at this time to claim that lifestyle changes will prevent dementia on an individual basis. However, combining efforts to tackle the global burden and threat of NCDs is important.

- Research should test hypotheses on lifestyle and control of risk in randomised controlled trials when feasible, and explore other sources of evidence when it is not. The quality and relevance from observational studies should be enhanced (include any dementia as an outcome, harmonise exposure/outcomes, careful reviewing of systematic reviews and creation publicly accessible archives of data).

- The future course of the global dementia epidemic is likely to depend crucially upon the success or otherwise of continuing efforts to improve global public health. Combining efforts to tackle the increasing global burden of NCDs will be strategically important, efficient and costeffective.

- If we can all enter old age with better developed, healthier brains we are likely to live longer, happier and more independent lives with a much reduced chance of developing dementia. With an estimated global societal economic cost of dementia of over US $\$ 600$ billion, and rising, the stakes could hardly be higher. 


\section{CHAPTER 1 \\ Background}

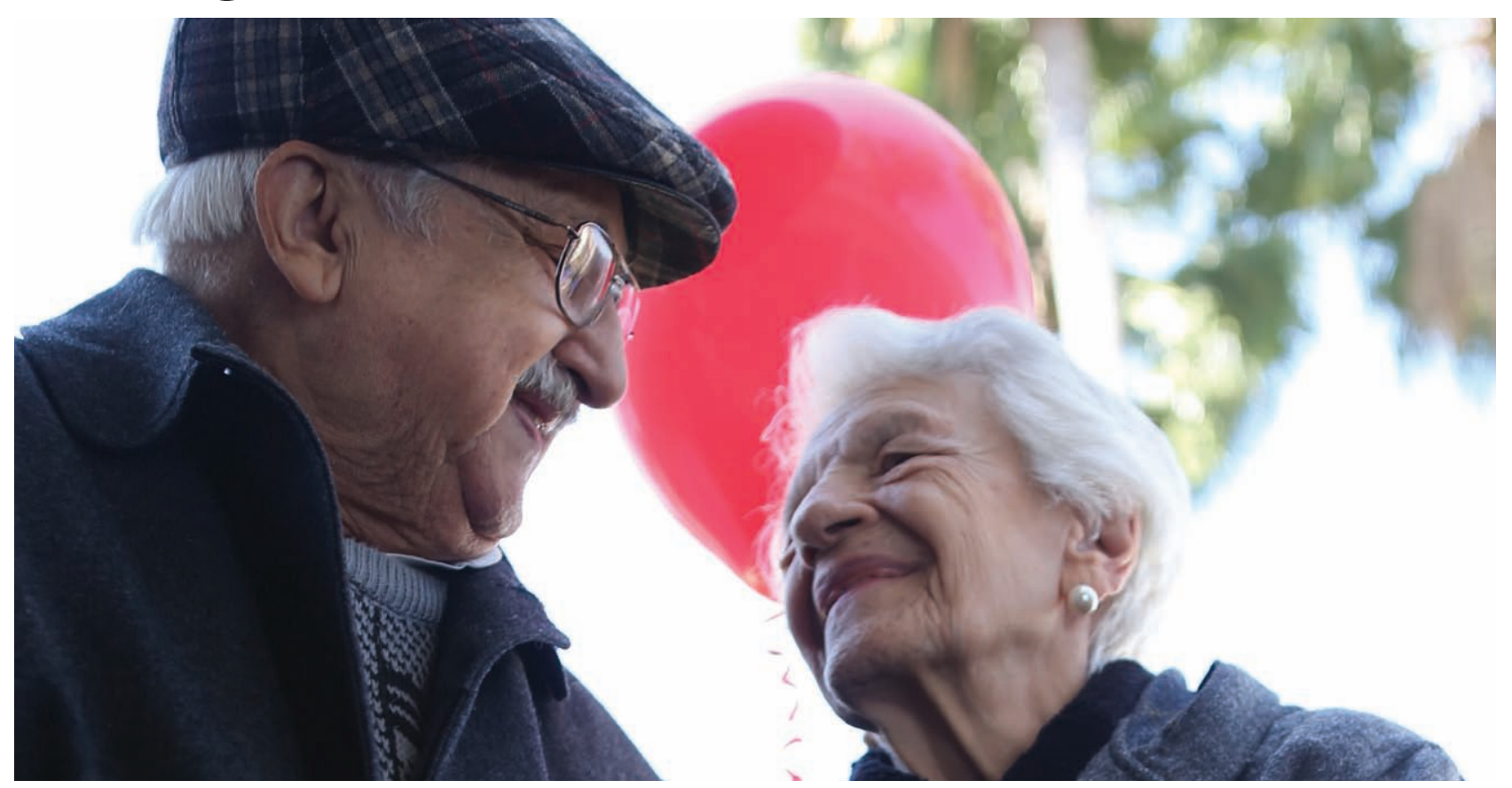

\section{Dementia}

Dementia is a syndrome caused by a number of progressive illnesses that affect memory, thinking, behaviour and the ability to perform everyday activities. It mainly affects older people but 2 to $10 \%$ of all cases are estimated to start before the age of 65 years. After this, the prevalence doubles with every five year increment in age. Dementia is one of the main causes of dependence and disability at older ages.

\section{Brain pathology and dementia syndrome}

Dementia syndrome is linked to a large number of underlying brain pathologies. Alzheimer's disease (AD), vascular dementia $(\mathrm{VaD})$, dementia with Lewy bodies and frontotemporal dementia are the most common

(Table 1.1).

In 1906, a German physician, Dr Alois Alzheimer first described an agglomeration of pathologic abnormalities in the autopsied brain of a woman who was affected for years by memory problems, confusion and language dysfunction. He reported the presence of a collection of dense deposits or plaques outside the neurons and bands of fibres or tangles within the brain cells. These senile plaques and neurofibrillary tangles have been recognised to be the two core pathological hallmarks of Alzheimer's disease. Plaques are composed of amyloid beta $(A \beta)$ and are called amyloid plaques, and the tangles consist of hyperphosphorylated tau protein. Associated with these changes are increased levels of inflammation, oxidative stress, and nerve cell death ${ }^{1}$.
Both senile plaques and neurofibrillary tangles are associated with the progressive loss of neurons and synapses, brain atrophy and dilatation of the lateral ventricles due to loss of brain tissue, which are the broad features of brain damage in dementia.

A further important cause of the brain damage in $A D$ is ischaemia, which may be caused by cerebral amyloid angiopathy (amyloid deposits forming in blood vessels), cerebral atherosclerosis ('hardening of the arteries') and small vessel disease.

Brain changes underlying AD probably develop over a period of at least 20-30 years before the onset of symptoms, with earliest signs around the base of the brain in the fifth decade of life, and plaques and tangles later spreading up to the cortical regions ${ }^{2}$.

The second most common form of dementia, vascular dementia $(\mathrm{VaD})$, has different neuropathological signs. Multifocal and/or diffuse lesions (lacunes to microinfarcts) resulting from systemic, cardiac, and local large and small vessel disease, which affect neural networks ${ }^{3}$. Vascular dementia may be the result of a single strategic infarct, multiple cortical or lacunar infarcts, or microvascular insults detectable with brain imaging. However, the mere presence of multiple (or strategic single) infarcts on imaging is neither sufficient nor necessary for the presence of vascular dementia. The time course and pattern of development of cerebrovascular pathology is likely to be more variable than in AD. As the brain pathology develops, gradually so do the symptoms and signs that may, with progression, ultimately lead to the diagnosis of dementia. 
Table 1.1

Characteristics of dementia subtypes ${ }^{4}$

\begin{tabular}{|l|l|l|l|}
\hline Dementia subtype & Early characteristic symptoms & Neuropathology & $\begin{array}{l}\text { Proportion of } \\
\text { dementia cases }\end{array}$ \\
\hline Alzheimer's Disease (AD)* & $\begin{array}{l}\text { Impaired memory, apathy and depression } \\
\text { Gradual onset }\end{array}$ & $\begin{array}{l}\text { Cortical amyloid plaques and } \\
\text { neurofibrillary tangles }\end{array}$ & $50-75 \%$ \\
\hline Vascular Dementia (VaD)* & $\begin{array}{l}\text { Similar to AD, but memory less affected, } \\
\text { and mood fluctuations more prominent } \\
\text { Physical frailty } \\
\text { Stepwise onset }\end{array}$ & $\begin{array}{l}\text { Cerebrovascular disease } \\
\text { Single infarcts in critical regions, } \\
\text { or more diffuse multi-infarct } \\
\text { disease }\end{array}$ & $20-30 \%$ \\
\hline Dementia with Lewy Bodies & $\begin{array}{l}\text { Marked fluctuation in cognitive ability } \\
\text { Visual hallucinations } \\
\text { Parkinsonism (tremor ad rigidity) }\end{array}$ & $\begin{array}{l}\text { Cortical Lewy bodies (alpha- } \\
\text { synuclein) }\end{array}$ & $<5 \%$ \\
\hline Frontotemporal dementia & $\begin{array}{l}\text { Personality changes } \\
\text { Mood changes } \\
\text { Disinhibition } \\
\text { Language difficulties }\end{array}$ & $\begin{array}{l}\text { No single pathology - damage } \\
\text { limited to frontal and temporal } \\
\text { lobes }\end{array}$ & $5-10 \%$ \\
\hline
\end{tabular}

* Post mortem studies suggest that many people with dementia have mixed Alzheimer's disease and vascular dementia pathology, and that this 'mixed dementia' is underdiagnosed

Clinico-pathological correlation studies examining the agreement between the diagnosis made in life and the pathology evident in the brain post-mortem have tended to indicate that mixed pathologies are much more common than 'pure' forms of dementia (particularly for $\mathrm{AD}$ and $\mathrm{VaD}$, and $\mathrm{AD}$ and dementia with Lewy bodies) ${ }^{5}$. Post-mortem measurement of these classic pathological hallmarks only explains to a limited extent the presence and severity of cognitive, behavioural and psychological symptoms of dementia in the population ${ }^{6}$.

Brain pathology likely starts decades before the onset of clinical dementia, which could be seen as a transition point in the accumulation of brain damage over time. Modifiable risk factors may influence the rate of development of the underlying neuropathologies, or they may counteract in various ways the detrimental effects of brain pathology on cognitive function. Hence, the presence or absence of these factors may advance or delay the clinical onset of dementia. The role of many of these factors can be investigated empirically in epidemiological studies. The present report on 'preventing dementia' is based upon a critical and systematic appraisal of the available evidence. It is worth noting that the term prevention is used in this report to refer to the effect of preventive interventions which are targeted to the general public or a whole population group. This does not imply that an individual receiving an intervention can necessarily avoid dementia, but that their risk may be reduced as a result. The background concepts and methodological challenges of epidemiological studies of dementia are here briefly presented.

\section{Epidemiological concepts}

Epidemiology is the discipline that studies the distribution, the causes and impact of health and ill health in populations. Epidemiology is mainly concerned with the estimation of the number of those affected by a certain health condition or trait in the population, and with the identification of risk factors for disease. Prevalence is the proportion of those with the disease in a given population and is a broad measure, or a snapshot, of the impact of the disease at a given point in time. Incidence is the rate at which new cases occur in that population and is therefore a measure of risk of developing the disease. Prevalence and incidence are closely linked, prevalence being the product of incidence and duration of the disease episode. Because late-life dementia cannot be treated, duration essentially corresponds to survival. In other words, the number of those with dementia (i.e. dementia prevalence) depends on risk of developing the disease (i.e. incidence) and on the length of survival among those who are affected in the general population.

Epidemiology is considered the cornerstone of public health because it is aimed at informing health policy decisions including providing preventive strategies based on knowledge about causes. There are two main types of study designs in epidemiology that are used to investigate the aetiology of diseases (i.e. the causes). In observational studies, like prospective population-based studies of representative cohorts of individuals, the incidence of a disease in the cohort is studied as a function of the observed level of exposure 
to a hypothesised cause. At the simplest level disease incidence is compared between those who are, and are not, 'exposed' to a risk factor such as smoking. The incidence rate in the exposed, divided by the incidence rate in the non-exposed gives rise to an indicator called the relative risk (RR). An RR of 2, indicates that those who are exposed have double the risk of developing dementia than those who are not exposed.

Conversely, experimental studies, like randomised controlled trials (RCTs), are conducted by exposing, or not, two groups of people to an intervention (typically a treatment, like a drug, or the removal of a risk exposure, for example by smoking cessation programs), where the allocation of the exposure is completely at random, to determine whether disease incidence varies under experimentally controlled conditions. Since randomisation matches the two exposure groups for all characteristics other than the exposure of interest, experimental studies are considered to provide much stronger evidence about causes than observational studies. Observational studies, although prone to error from bias and confounding (see below), are an indispensable investigational tool, not least because in many cases it would not be ethical or practical to manipulate a potential risk exposure under experimental conditions.

The ability to anticipate or predict disease occurrence, through identification of causal relationships is central to the development of evidence-based prevention strategies and to improve our mechanistic knowledge of diseases. This process relies on the assumption that observations are true, or valid. But what does validity mean? We say that the results of a study are internally valid when they are not an artefact, either of the study design or of its conduct. When results can also be applied to other samples and settings they are also considered to be externally valid (or generalisable).

Methodological differences between studies and differences in the populations under study may each contribute to inconsistent findings across epidemiological studies. Such inconsistencies are referred to as heterogeneity in the size of the effect (for example the relative risk) that is being measured. These discrepancies are often a reason of concern and may insinuate a generic distrust in epidemiologic research. As elegantly argued by Professor Mary Ganguli in a recent editorial, "epidemiologists themselves must shoulder some of the blame" for the existing confusion that limits the translation of epidemiological findings, because "they are responsible for the excessive simplification of epidemiological concepts"7.

Associations between a putative cause (exposure) and dementia (outcome) may be explained by bias in the way that participants are sampled (selection bias), or the way that measurements and data are collected (information bias). Some examples of biases that should be carefully considered when appraising the validity of epidemiological studies of dementia are listed in Box 1.1 ${ }^{8}$. The observed association between an exposure and dementia may be explained by a third, unaccounted factor (a confounder) that is independently associated with both. For instance, over a follow-up period, dementia incidence may be higher in those who are, compared to those who are not, obese. However, obesity is strongly associated with diabetes, which in turn may cause dementia. If data on diabetes has also been collected, then it is technically possible to adjust or control for the effect of this confounder in the statistical analysis, such that we focus on the independent effect of the risk factor of interest. Socio-demographic characteristics (like sex, age and educational level) are the minimum set of covariates that should be controlled for in the analysis, since these are determinants of dementia risk, and may well be associated with other potential risk factors. Others adjustments will be determined by the study hypothesis and the association under investigation.

Even when confounding and bias can be excluded, exposures found to predict dementia in observational studies may be an early marker of the disease itself and not a causal risk factor. The two things need not to be confused because the early marker is part (or a consequence) of dementia, and not a possible cause. Ideally, one should be sure to have measured exposure status in dementia-free individuals. However, this may be difficult because the neurodegenerative and cerebrovascular changes that underlie late-life dementia begin decades before the symptomatic, clinical onset. Therefore measuring exposure status even years before the manifestation of dementia symptoms, and allowing a long follow-up between exposure and outcome assessments may only reduce the potential confusion between risk factors and prodromal signs. As discussed in this report, dementia may cause a seeming paradoxical reduction in some potential risk and protective factors including blood pressure, body weight, and physical and cognitive activity, through mechanisms linked to the disease symptoms and/or and its underlying neuropathology. The term 'reverse-causality' is used to describe this phenomenon, in which the direction of the association observed between a hypothesized risk factor and dementia is 'reversed', that is, it goes in fact from dementia to the putative risk factor. For this reason, ideally, epidemiological studies designed to investigate risk and protective factors for dementia should not only count on long follow-ups, but also on baseline assessment of exposure status obtained before old age. The possible influence of dementia on exposure will be discussed in the next chapters when we review the evidence for the specific risk and protective factors.

Chance is the final alternative explanation to be considered for an association that is not causal. Chance arises from sampling error, that is an association is observed in a sample, when it is not present in the population from which the sample is 
Box 1.1

\section{Examples of biases in epidemiological studies of dementia}

\section{Participation Bias}

Consent/refusal to participate in a study is sometimes related to exposure status. For instance those who are APOE $\varepsilon 4$ positive may be more likely to participate because they may have relatives with $A D$ in their family which is a common reason to take part into research; the proportion of APOE $\varepsilon 4$ carriers would be artificially high and reduce the representativeness of the sample (external validity).

\section{Survival Bias, and other forms of attrition}

Because dementia and mortality share a number of known and unknown risk factors those who are exposed to these shared risk factors are less likely to be observed developing dementia in late-life, simply because they have died prematurely. This 'competing risk' of dementia-free death, may bias estimation of the true effect of the risk exposure. Loss to follow-up ('attrition') may occur for other reasons and may also bias the study findings, for example if those who have the risk factor, but do not develop the disease, are more likely to drop out.

\section{Information Bias}

This occurs when the exposure status influences the assessment of the outcome, or vice versa; a measurement error that does not happen randomly across the comparison groups. For instance, if dementia diagnosis in the study is determined using routine hospital records, subjects who make a limited use of health services because they have less comorbidity and better risk factors profiles may be less likely to receive a timely dementia diagnosis. The consequence of their underrepresentation in the study sample could inflate the observed associations.

taken. The bigger the sample, the greater the precision of the risk estimate. The precision is conveyed by the 95\% confidence intervals $(95 \% \mathrm{Cl})$, and if these do not include the relative risk that would be observed if there was no association $(R R=1)$, then the association is considered to be statistically significant, that is, that it is unlikely to be accounted for by chance alone.

\section{Prevention}

Dementia has an insidious onset typically characterised by an initial subtle decline in one or more cognitive functions including memory and reasoning.

Although brain damage accumulates and cognitive function declines progressively with age, dementia is not a normal part of ageing and most older adults will never develop the disease up to the time of death. However, marked inter-individual differences in cognitive health in late-life are observed at a population-level. These differences may in part be a function of the level of exposure to a number of factors across the entire life course and are usually termed risk or protective, depending on whether, in general, they are associated with an increased or reduced future likelihood of cognitive impairment and dementia in populations.

Because there are no established diagnostic biomarkers of dementia-related brain damage ${ }^{11}$, and because the mechanisms that link this damage to the expression of dementia symptoms are not fully understood $^{12}$, prevention of dementia is commonly conceived as the delay of the clinical onset of the disease rather than a slowing or avoidance of the development of the underlying neuropathology. Similar to other chronic diseases primary prevention of dementia corresponds, ideally, to 'delay until death' of symptomatic onset, or, failing that, a delaying or deferring of onset to older ages than that at which it would otherwise have occurred. An average five year delay in the age of onset would tend to reduce population prevalence by $50 \%$, hence greatly reducing its impact in the general population.

A large variety of potential risk and protective factors for dementia and cognitive impairment have been investigated in epidemiological studies and some of these have also been tested in experimental studies ${ }^{13}$. The current focus on modifiable risk factors is justified by their potential to be targeted for prevention. However, non-modifiable risk factors (eminently age, gender and genetic factors) are also very important. The apolipoprotein E (APOE) gene that lies on chromosome 19 is the only common genetic risk factor for non-familial, late-onset Alzheimer's disease (AD) identified to date as having a major impact on disease risk $^{14}$. The APOE gene has three alternative forms ('alleles'), the $\varepsilon 4$ allele increases and $\varepsilon 2$ allele decreases risk ${ }^{15}$. APOE genotype is a marker of susceptibility not an autosomal deterministic gene. It is neither necessary nor sufficient to cause disease. Although at present genetic factors cannot be modified they can be used to identify those at higher risk who may be targeted for subgroup prevention programs; and because complex gene-environment interactions likely exist the actual expression of these genes might be modified too. Moreover, our knowledge of the disease mechanisms can be improved through the 
Figure 1.1

Hypothesized model of the origins and life course of brain aging - From Muller M et al. 2014

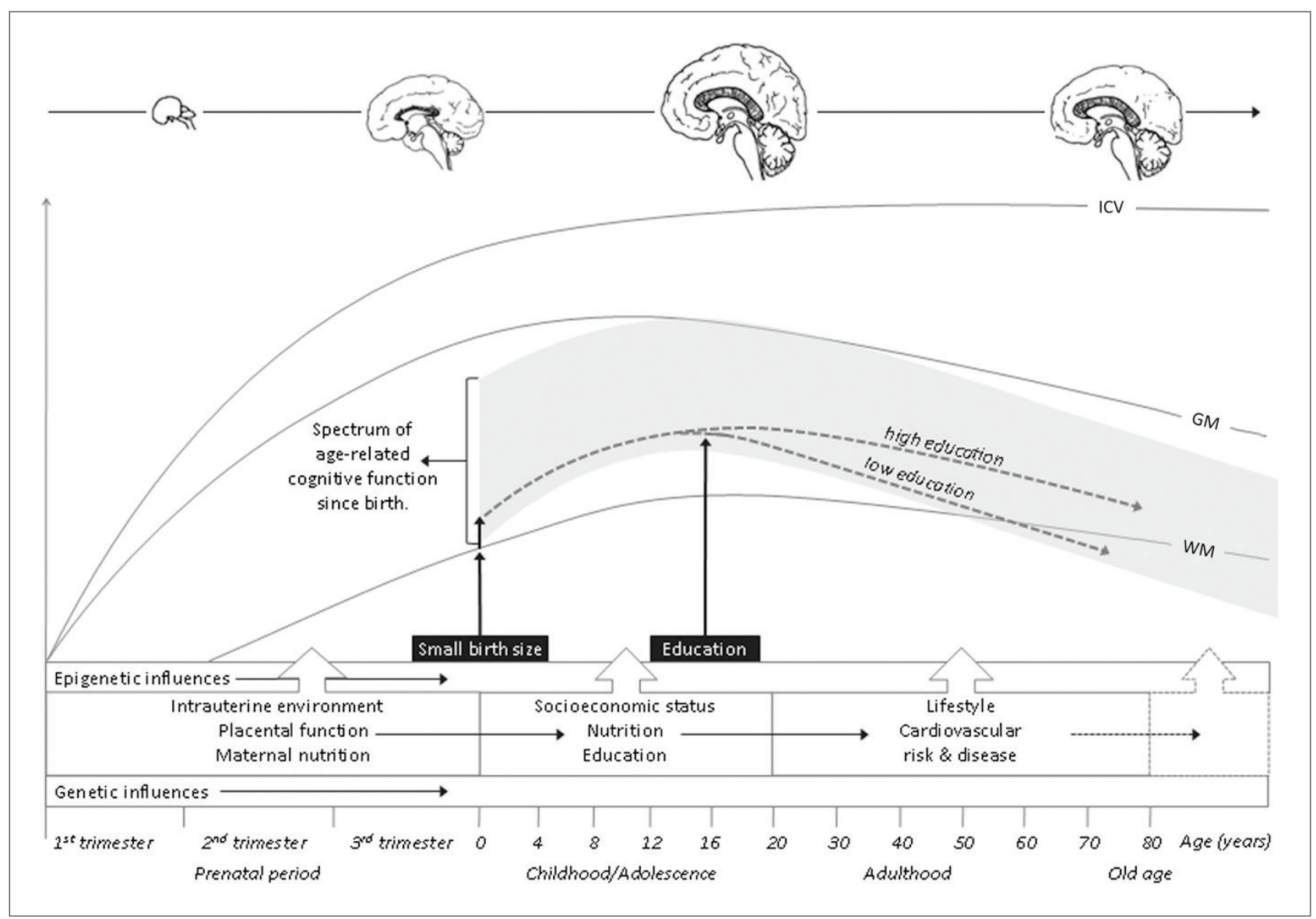

investigation of the function of the products of those genes that are found to be associated with dementia.

\section{Life course approach}

There is accumulating evidence from observational and experimental studies on how modifiable risk/protective factors may relate to the pathological hallmarks of AD (i.e. extracellular amyloid- $\beta$ plaques and intracellular microtubule $p$-tau protein neurofibrillary tangles) as well as to the inflammatory and vascular components ${ }^{13}$ of all types of dementias.

A life course approach to the study of dementia supports the notion that certain risk factors may operate at critical periods with varying strength of association observed at different time periods, and that even the direction of association can vary over time, as a factor that was a risk factor for the onset of dementia in turn becomes influenced by the dementia disease process (reverse causality) before and after the clinical onset of the condition.

Brain and cognitive reserve, developed early in life, and consolidated in midlife may buffer the expression of symptoms of dementia in the presence of neurodegenerative disease ${ }^{16}$. Early life growth and development, higher educational achievement, mentally-stimulating activity, social engagement, and physical exercise may all contribute to this process, and help to ward off the development and clinical manifestations of dementia in later-life. Vascular risk factors (i.e. high blood pressure, cholesterol, diabetes, and overweight/obesity) become more prevalent in midlife, and are plausibly linked to risk for dementia through a variety of cerebrovascular disease, inflammatory and neurodegenerative pathways ${ }^{17}$. However, the associations of social and behavioural factors with cognitive function markedly vary with age, and the period before the onset of dementia may be characterised by declining values of vascular risk factors, and reductions in engagement in physical and cognitive stimulating activities after midlife. As discussed earlier, these changes are more likely early (prodromal) manifestations rather than independent predictors of the disease. Moreover, evidence shows that maintenance of cognitive health through old age depends also on development and optimal achievement of cognitive level throughout life, which would contribute to greater structural (brain) and functional (cognitive) reserve in late-life, which in turn would counteract the effects of brain damage on cognitive function ${ }^{18}$.

In recent years a growing consensus has emerged that dementia risk and protective factors are best studied using a life course approach ${ }^{19}$, and a comprehensive 
model has been proposed by Muller et al.

(Figure 1.1) ${ }^{20}$. Life course epidemiology is a theoretical model used to study the effects of exposures (like social and biological factors) throughout life on later outcomes. The key purpose of life course epidemiology is to provide clues to the aetiology of diseases, building and testing theoretical models of complex pathways between exposures across the life course and outcomes in late life. The timing and duration of exposures are considered key. Risks may cluster at specific ages, as early as in uterus and in childhood, during time windows defined as sensitive (or critical), when their effects are stronger compared to other periods in the life course. Risk factors may also cause damage to biological systems (or lead to suboptimal development) as a function of the number, severity and duration of the exposures. Chains of risks, lifelong long trajectories of individual characteristics deviating from putative norms, chronological age and time in history, location and year of birth may also be considered ${ }^{21}$. Because the clinical onset of dementia is likely to be the end stage of the accumulation of neuropathological damage over several years, the latency between the initiation of the process and detection of the onset of dementia is likely to be very long. Borrowing from concepts developed in cancer research, it may be important to distinguish factors into those that initiate, promote, proliferate, and advance the disease; better model specifications are needed to address the implications of this lifelong trajectory approach.

Particularly long follow-ups are certainly needed in order to relate lifelong exposures to dementia risk in late-life, which complicates the conduct of such research. For instance only very recently was the foetal origins of adults disease hypothesis that relates suboptimal foetal development to cardiovascular disease in late life ${ }^{22}$ successfully tested with respect to cognitive function and brain damage in late life ${ }^{20}$. Design and methodological difficulties limit the feasibility of life course epidemiological studies, and some controversies on the actual interpretation of life course findings remain unresolved ${ }^{23,24}$.

Nevertheless, the implications for prevention of a life course approach to dementia could be remarkable. The observation that exposure to an environmental factor or a certain lifestyle may increase dementia risk may not suffice; when, and for how long the exposure should be modified may be as much, or even more important in order to achieve the aimed prevention goal.

In the next chapters we will review current evidence on a selection of modifiable risk and protective factors for late-life dementia. Central to our critical appraisal of existing studies will be the methodological issues discussed in this chapter that may explain inconsistent observations and/or prompt cautious interpretations of findings of possible risk and protective factors before these can be targeted for dementia prevention. In doing so we consider in particular whether reverse- causality, and/or the possibility that some observed exposures may in fact also be early markers of dementia, can explain reported associations.

\section{References}

1. Ballard C, Gauthier S, Corbett A, Brayne C, Aarsland D, Jones E. Alzheimer's disease. Lancet 2011; 377(9770): 1019-31.

2. Braak H, Braak E, Bohl J, Bratzke H. Evolution of Alzheimer's disease related cortical lesions. Journal of neural transmission Supplementum 1998; 54: 97-106.

3. Jellinger KA. The pathology of "vascular dementia": a critical update. Journal of Alzheimer's disease : JAD 2008; 14(1): 107-23.

4. International AsD. World Alzheimer Report 2009. London: Alzheimer's Disease International, 2009.

5. Neuropathology Group. Medical Research Council Cognitive $\mathrm{F}$, Aging S. Pathological correlates of late-onset dementia in a multicentre, community-based population in England and Wales. Neuropathology Group of the Medical Research Council Cognitive Function and Ageing Study (MRC CFAS). Lancet 2001; 357(9251): 169-75.

6. Matthews FE, Brayne C, Lowe J, McKeith I, Wharton SB, Ince P. Epidemiological pathology of dementia: attributable-risks at death in the Medical Research Council Cognitive Function and Ageing Study. PLoS medicine 2009; 6(11): e1000180.

7. Kukull WA, Ganguli M. Generalizability: the trees, the forest, and the low-hanging fruit. Neurology 2012; 78(23): 1886-91.

8. Ganguli M, Kukull WA. Lost in translation: epidemiology, risk, and alzheimer disease. Archives of neurology 2010; 67(1): 107-11.

9. Kukull WA, Ganguli M. Generalizability The trees, the forest, and the low-hanging fruit. Neurology 2012; 78(23): 1886-91.

10. Jack CR, Jr., Knopman DS, Jagust WJ, et al. Tracking pathophysiological processes in Alzheimer's disease: an updated hypothetical model of dynamic biomarkers. Lancet neurology 2013; 12(2): 207-16.

11. Frisoni GB, Bocchetta $M$, Chételat $G$, et al. Imaging markers for Alzheimer disease Which vs how. Neurology 2013; 81(5): 487-500.

12. Savva GM, Wharton SB, Ince PG, et al. Age, neuropathology, and dementia. The New England journal of medicine 2009; 360(22): 2302-9.

13. Hughes TF, Ganguli M. Modifiable Midlife Risk Factors for Late-Life Cognitive Impairment and Dementia. Curr Psychiatry Rev 2009; 5(2): 73-92.

14. Corder E, Saunders A, Strittmatter W, et al. Gene dose of apolipoprotein $E$ type 4 allele and the risk of Alzheimer's disease in late onset families. Science 1993; 261(5123): 921-3.

15. Raber J, Huang Y, Ashford JW. ApoE genotype accounts for the vast majority of AD risk and AD pathology. Neurobiology of aging 2004 25(5): 641-50.

16. Stern $Y$. What is cognitive reserve? Theory and research application of the reserve concept. Journal of the International Neuropsychological Society : JINS 2002; 8(3): 448-60.

17. Reitz C, Brayne C, Mayeux R, Medscape. Epidemiology of Alzheimer disease. Nat Rev Neurol 2011; 7(3): 137-52.

18. Stern Y. Cognitive reserve in ageing and Alzheimer's disease. Lancet neurology 2012; 11(11): 1006-12.

19. Launer LJ. The epidemiologic study of dementia: a life-long quest? Neurobiology of aging 2005; 26(3): 335-40.

20. Muller M, Sigurdsson S, Kjartansson O, et al. Birth Size and Brain Function 75 Years Later. Pediatrics 2014.

21. Ben-Shlomo Y, Kuh D. A life course approach to chronic disease epidemiology: conceptual models, empirical challenges and interdisciplinary perspectives. Int J Epidemiol 2002; 31(2): 285-93.

22. Barker DJ, Eriksson JG, Forsen T, Osmond C. Fetal origins of adult disease: strength of effects and biological basis. International journal of epidemiology 2002; 31(6): 1235-9.

23. De Stavola BL, Nitsch D, dos Santos Silva I, et al. Statistical issues in life course epidemiology. American journal of epidemiology 2006 163(1): 84-96.

24. Mishra G, Nitsch D, Black S, De Stavola B, Kuh D, Hardy R. A structured approach to modelling the effects of binary exposure variables over the life course. Int J Epidemiol 2009; 38(2): 528-37. 


\section{CHAPTER 2 \\ Developmental and early-life risk factors}

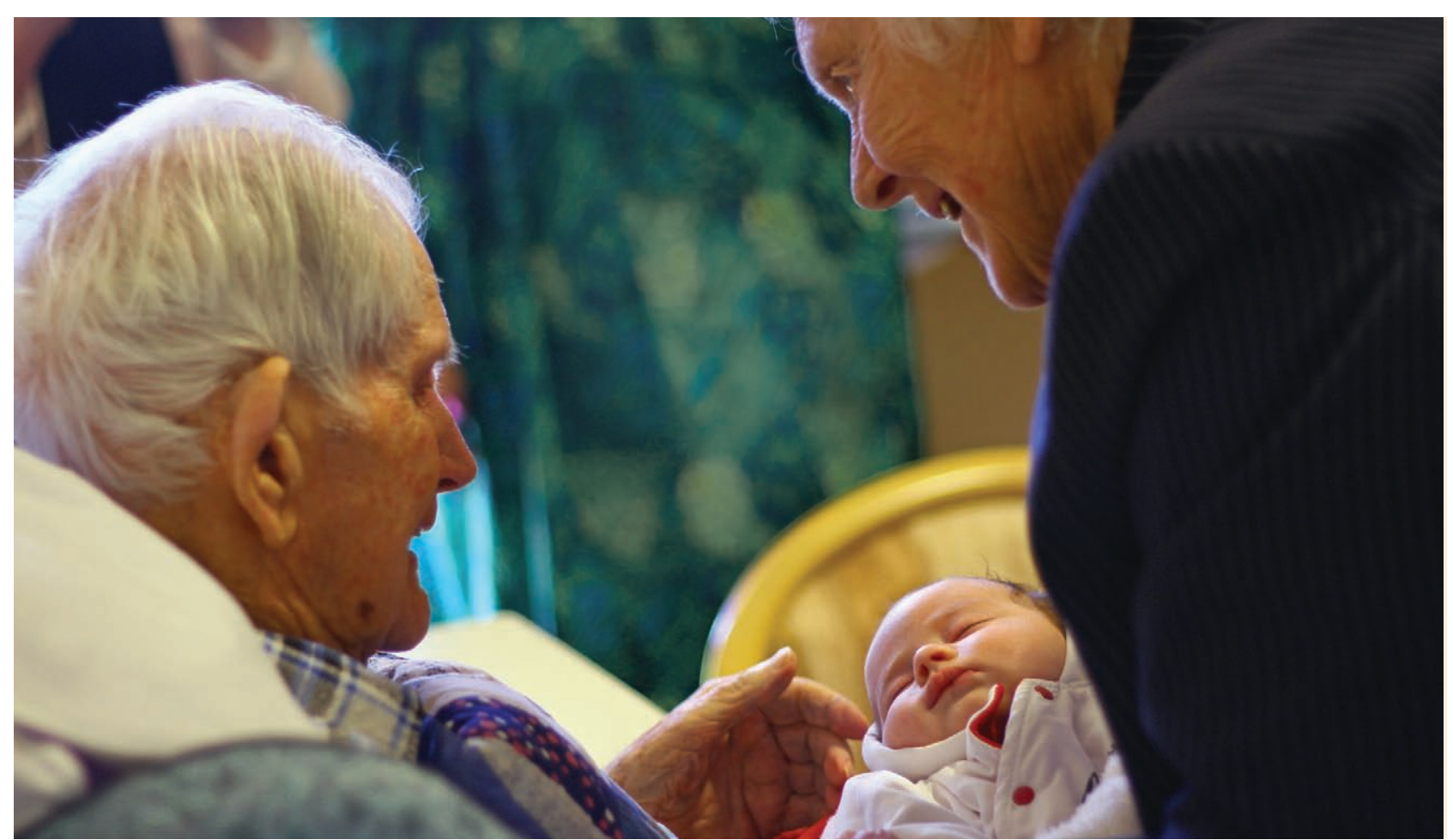

Research findings suggest that dementia has a lifelong trajectory, with risk clustering around specific developmental periods and often accumulating in its effect, sometimes even decades before the onset of clinical symptoms of dementia 1 . While some risk factors may have an effect in early-life, others may have an influence later in life and interact with the environment over the life course. Early-life risk factors include factors related to perinatal circumstances (like birth weight, intrauterine environment, number of siblings and birth order) and also factors influencing the growth and development of the brain or body, such as nutrition. Socioeconomic conditions, environmental enrichment and education in the first years of life have also been suggested as having an effect on the risk of dementia ${ }^{2}$. As improving nutrition of children improves their cognitive function ${ }^{3}$, adequate nutrition during childhood may also enhance children performances at school and participate to a better education.

In this chapter, we will review the evidence on the association of several of these early life factors with the onset of dementia, from a life course and developmental perspective. We focused on factors where evidence was available from longitudinal studies or where relevant and unbiased markers of early-life environment and experiences were available.

\section{Leg length and head circumference}

\section{Introduction}

Conditions during foetal life and the first two years after birth are important for determining final brain size. Between the $35^{\text {th }}$ and the $40^{\text {th }}$ weeks of gestation, micronutrients and fat stores are key for brain and nervous system maturation and development, occurring up to the age of five ${ }^{4}$. Brain development may, in turn, influence the risk of dementia and cognitive impairment in old age ${ }^{5}$. Some studies have found a discrepancy between the degree of brain pathology and the clinical symptomatology of Alzheimer's disease (AD) ${ }^{6}$. Therefore, brain reserve, the number of neurons and synapses (for which brain size might be a marker, see Box 2.1), may buffer the effects of dementia related neuropathology and explain the variability of the expression and severity of dementia clinical symptoms in people with the same levels of neuropathology. The brain and skull grow rapidly, with $95 \%$ of growth achieved by the age of six years ${ }^{7}$. Up to this age there is an almost perfect correlation between brain size and skull circumference ${ }^{8}$; after the maximal brain proportions are reached between 11 and 15 years old ${ }^{7}$ brain size decreases while skull dimensions remain constant. Thus, measurement of skull circumference made in adulthood reflects the size of the brain in early-life, and skull dimensions can be considered a stable marker. 
A low birth weight can affect brain development through its association with undernutrition and may be associated with lower cognitive level in childhood and adulthood $^{9}$. Persistent insufficient nutrient intake in early infancy slows growth and causes low height for age that results in shorter legs for total height. Previous findings from a British cohort study suggested that leg length in adults is particularly sensitive to diet in infancy (breastfeeding and energy intake at age 4) while trunk length may be more associated with factors occurring during longer periods between infancy and puberty (childhood serious illness or parental separation) ${ }^{10}$. Therefore having shorter legs relative to total height in adulthood is a valid proxy of early life inadequate nutritional level.

We will now summarize the evidence on the association between dementia (or AD) and skull/head circumference and leg length, as reliable markers of development in early-life.

\section{Evidence}

The association between head circumference, leg length and dementia has been investigated in few studies to date.

In cross-sectional studies, a shorter leg length, indicating inadequate nutrition in early life, was associated with an increased prevalence of dementia in Brazil ${ }^{11}$, among women in South Korea ${ }^{12}$, and with cognitive impairment in a population of Afro-Caribbean in South London ${ }^{13}$ (see Table 2.1). In a later wave of the study in South Korea, a shorter leg length was associated with dementia, independently of age, education, early life residence, head circumference and cardiovascular factors, but only reached statistical significance in women. In a longitudinal study from the United States, Huang et al. ${ }^{14}$ found that knee height was inversely associated with incident dementia in women for both dementia and $A D$, whereas it was non significant for men, and the interaction between

Table 2.1

Characteristics of epidemiological studies on the association between leg length and dementia, Alzheimer's disease and cognitive impairment

\begin{tabular}{|c|c|c|c|c|c|}
\hline $\begin{array}{l}\text { Authors, Year, } \\
\text { Location }\end{array}$ & $\begin{array}{l}\text { Population (size, } \\
\text { mean age at } \\
\text { baseline [years } \\
\pm \text { sd]) }\end{array}$ & Exposure & Outcome & $\begin{array}{l}\text { Crude Effect } \\
\text { Size (95\% CI) }\end{array}$ & Adjusted Effect Size (95\% Cl) \\
\hline $\begin{array}{l}\text { Kim et al., } 2003 \\
\text { South Korea }{ }^{12}\end{array}$ & $\begin{array}{l}\mathrm{N}=746,72.2 \\
\text { years }\end{array}$ & $\begin{array}{l}\text { Leg length (knee } \\
\text { height, per } 5 \mathrm{~cm} \\
\text { decrease) }\end{array}$ & $\begin{array}{l}\text { Dementia } \\
\text { (DSM-IV) }\end{array}$ & $\begin{array}{l}\mathrm{OR}=1.93(1.56 \\
-2.39)\end{array}$ & $\mathrm{OR}=1.42(1.12-1.81)$ \\
\hline $\begin{array}{l}\text { Mak et al., } 2006 \\
\text { Afro-Carribean in } \\
\text { South London }{ }^{13}\end{array}$ & $\begin{array}{l}\mathrm{N}=290,55-75 \\
\text { years }\end{array}$ & $\begin{array}{l}\text { Leg length (iliac crest } \\
\text { to lateral malleolus, } \\
\text { lowest quartile) }\end{array}$ & $\begin{array}{l}\text { Cognitive } \\
\text { Impairment }\end{array}$ & $\begin{array}{l}\mathrm{OR}=2.1 \\
(1.0-4.4)\end{array}$ & $\mathrm{OR}=1.7(0.7-4.2)$ \\
\hline $\begin{array}{l}\text { Huang et al., } 2008 \\
\text { United States } \\
{ }^{14}\end{array}$ & $\mathrm{~N}=2798,72$ years & $\begin{array}{l}\text { Knee height (per } 1 \\
\text { inch increase) }\end{array}$ & $\begin{array}{l}\text { Dementia } \\
\text { (DSM-IV) } \\
\text { AD (NINCDS- } \\
\text { ADRDA) }\end{array}$ & - & $\begin{array}{l}\text { Dementia: } \\
\text { Women, } \mathrm{HR}=0.84(0.74-0.96) \\
\text { Men, } \mathrm{HR}=0.93(0.81-1.07) \\
\text { AD: } \\
\text { Women, } \mathrm{HR}=0.78(0.65-0.93) \\
\text { Men, } \mathrm{HR}=0.89(0.72-1.10)\end{array}$ \\
\hline $\begin{array}{l}\text { Scazufca et al., } 2008 \\
\text { Sao Paulo (Brazil) }{ }^{11}\end{array}$ & $\begin{array}{l}\mathrm{N}=2005, \\
72.2 \pm 6.3 \text { years }\end{array}$ & $\begin{array}{l}\text { Leg length (iliac crest } \\
\text { to lateral malleolus, } \\
\text { 4th quartile as a } \\
\text { reference) }\end{array}$ & $\begin{array}{l}\text { Dementia } \\
\text { (DSM-IV) }\end{array}$ & - & $\begin{array}{l}\text { 3rd quartile: } 0 \mathrm{R}=1.64 \text { (0.82- } \\
\text { 3.29) } \\
\text { 2nd quartile: } 0 \mathrm{R}=2.19(1.11- \\
\text { 4.30) } \\
\text { 1st quartile: } \mathrm{OR}=2.58 \text { (1.34- } \\
\text { 4.93) }\end{array}$ \\
\hline $\begin{array}{l}\text { Kim et al., } 2008 \\
\text { South Korea }{ }^{17}\end{array}$ & $\begin{array}{l}\mathrm{N}=916,73.1 \pm 5.2 \\
\text { years (without } \\
\text { dementia) } \\
/ 79.9 \pm 6.8 \\
\text { (dementia) }\end{array}$ & $\begin{array}{l}\text { Leg length (iliac crest } \\
\text { to lateral malleolus, } \\
\text { per } 7 \mathrm{~cm} \text { decrease) }\end{array}$ & $\begin{array}{l}\text { Dementia } \\
\text { (DSM-IV) }\end{array}$ & $\begin{array}{l}\mathrm{OR}=1.44 \\
(1.23-1.70)\end{array}$ & $\mathrm{OR}=1.13(0.94-1.37)$ \\
\hline $\begin{array}{l}\text { Prince et al., } 2011 \\
\text { China, India, Cuba, } \\
\text { Dominican Republic, } \\
\text { Venezuela, Mexico } \\
\text { and Peru }{ }^{15}\end{array}$ & $N=14960$ & $\begin{array}{l}\text { Leg length (iliac crest } \\
\text { to lateral malleolus, } \\
\text { (highest vs lowest } \\
\text { quartile) }\end{array}$ & $\begin{array}{l}\text { Dementia } \\
(10 / 66)\end{array}$ & - & Pooled OR=0.82 $(0.68-0.98)$ \\
\hline
\end{tabular}


Table 2.2

Characteristics of epidemiological studies on the association between head circumference and dementia and Alzheimer's disease

\begin{tabular}{|c|c|c|c|c|c|}
\hline $\begin{array}{l}\text { Authors, Year, } \\
\text { Location }\end{array}$ & $\begin{array}{l}\text { Population } \\
\text { (size, mean } \\
\text { age at } \\
\text { baseline } \\
\text { [years } \pm \text { sd]) }\end{array}$ & Exposure & Outcome & $\begin{array}{l}\text { Crude Effect } \\
\text { Size ( } 95 \% \text { CI) }\end{array}$ & $\begin{array}{l}\text { Adjusted Effect Size ( } 95 \% \\
\text { CI) }\end{array}$ \\
\hline $\begin{array}{l}\text { Schofield et al., } \\
1997 \\
\text { United States }^{16}\end{array}$ & $\begin{array}{l}\mathrm{N}=649 \\
78.3 \pm 6.4 \\
\text { years }\end{array}$ & $\begin{array}{l}\text { Head } \\
\text { circumference }\end{array}$ & $\begin{array}{l}\text { AD (NINCDS- } \\
\text { ADRDA) }\end{array}$ & - & $\begin{array}{l}\text { Lowest quintiles: } \\
\text { Women: } \mathrm{OR}=2.9(1.4-6.1) \\
\text { Men: } \mathrm{OR}=2.3(0.6-9.8) \\
\text { Continuous: } \\
\text { OR= } 0.8(0.7-0.9)\end{array}$ \\
\hline $\begin{array}{l}\text { Mortimer et al., } \\
2003 \\
\text { Nun Study, United } \\
\text { States }^{18}\end{array}$ & $\begin{array}{l}\mathrm{N}=294 \\
\text { (females), } 89.3 \\
\text { years }\end{array}$ & $\begin{array}{l}\text { Head } \\
\text { circumference } \\
\text { (lowest } \\
\text { two tertiles) }\end{array}$ & $\begin{array}{l}\text { Dementia } \\
\text { (assessed by the } \\
\text { CERAD and IADL) }\end{array}$ & $\begin{array}{l}\text { OR }=4.3(1.9- \\
9.6) \text { when fewer } \\
\text { than } 16 \text { years of } \\
\text { education } \\
\text { OR }=1.0 \\
(0.5-1.7) \\
\text { when } 16 \text { years } \\
\text { of education } \\
\text { completed }\end{array}$ & $\begin{array}{l}\mathrm{OR}=4.1(1.7-9.9) \text { when fewer } \\
\text { than } 16 \text { years of education } \\
\mathrm{OR}=1.0(0.6-1.8) \text { when } 16 \\
\text { years of education completed }\end{array}$ \\
\hline $\begin{array}{l}\text { Borenstein et al., } \\
2005 \\
\text { United States }^{20}\end{array}$ & $N=1859$ & $\begin{array}{l}\text { Head } \\
\text { Circumference } \\
(\leq 54.4 \mathrm{~cm})\end{array}$ & $\begin{array}{l}\text { AD (NINCDS- } \\
\text { ADRDA) }\end{array}$ & $\begin{array}{l}\text { Adjusted in age } \\
\text { only: } \\
\text { APOE } \varepsilon 4 \\
\text { positive: } \\
\text { HR=2.77 (1.12- } \\
6.82) \\
\text { APOE } \varepsilon 4 \\
\text { negative: } \\
\text { HR=1.16 (0.47- } \\
2.87)\end{array}$ & $\begin{array}{l}\text { Adjusted on the number of } \\
\text { children in home at age } 2-3 \\
\text { and gender: } \\
\text { APOE } \varepsilon 4 \text { positive: } H R=1.92 \\
(0.66-5.57) \\
\text { APOE } \varepsilon 4 \text { negative: } H R=1.16 \\
(0.43-3.07)\end{array}$ \\
\hline $\begin{array}{l}\text { Scazufca et al., } \\
2008 \\
\text { Sao Paulo } \\
\text { (Brazil) }^{11}\end{array}$ & $\begin{array}{l}\mathrm{N}=2005 \\
72.2 \pm 6.3 \\
\text { years }\end{array}$ & $\begin{array}{l}\text { Head } \\
\text { circumference } \\
\text { (4th quartile as a } \\
\text { reference) }\end{array}$ & $\begin{array}{l}\text { Dementia (DSM- } \\
\text { IV) }\end{array}$ & - & $\begin{array}{l}\text { 3rd quartile: } 0 R=1.03 \\
(0.52-2.03) \\
\text { 2nd quartile: } 0 R=1.69 \\
\text { (0.91-3.12) } \\
\text { 1st quartile: } 0 R=1.64(0.88- \\
\text { 3.04) }\end{array}$ \\
\hline $\begin{array}{l}\text { Kim et al., } 2008 \\
\text { South Korea }{ }^{17}\end{array}$ & $N=916$ & $\begin{array}{l}\text { Head } \\
\text { circumference } \\
\text { (per } 3 \mathrm{~cm} \\
\text { decrease) }\end{array}$ & $\begin{array}{l}\text { Dementia (DSM- } \\
\text { IV) }\end{array}$ & $\begin{array}{l}\mathrm{OR}=1.66(1.29- \\
2.13)\end{array}$ & $\mathrm{OR}=1.13(0.84-1.52)$ \\
\hline $\begin{array}{l}\text { Prince et al., } 2011 \\
\text { China, India, } \\
\text { Cuba, Dominican } \\
\text { Republic, } \\
\text { Venezuela, Mexico } \\
\text { and Peru }{ }^{15}\end{array}$ & $N=14960$ & $\begin{array}{l}\text { Head } \\
\text { circumference } \\
\text { (highest vs lowest } \\
\text { quartile) }\end{array}$ & Dementia $(10 / 66)$ & - & Pooled $\mathrm{OR}=0.75(0.63-0.89)$ \\
\hline
\end{tabular}

DSM-IV: Diagnostic and Statistical Manual of Mental Disorders - 4th edition; NINCDS-ADRDA: National Institute of Neurological and Communicative Disorders and Stroke and the Alzheimer's Disease and Related Disorders Association; OR: odds ratio; HR: hazard ratio; CERAD: Consortium to Establish a Registry for Alzheimer's Disease; IADL = Instrumental Activities of Daily Living 
gender and knee height was not significant. For each gender, knee height was not associated with VaD. Findings from the large 10/66 study in low and middle income countries ${ }^{15}$, the pooled fixed effect comparing the quarter with the longest with the quarter with the shortest legs was 0.82 , and dementia prevalence declined with each centimetre increase in leg length (Prevalence Ratio = 0.988, 95\% Cl: 0.981-0.995).

Regarding head circumference, six cross-sectional studies showed an inverse association with prevalent Alzheimer's disease. Three population-based studies were carried out in the US ${ }^{16}$, Brazill ${ }^{11}$ and South Korea $^{17}$, and two on communities of Catholic Nuns in the States ${ }^{18}$ and in Germany ${ }^{19}$. In the States, the association with dementia was only significant among people with fewer than 16 years of educational attainment ${ }^{18}$ while in Brazil, head circumference was associated with prevalent dementia (OR $=0.74,95 \%$ Cl: 0.69-0.93), but the effect was reduced when full adjustments were made $(\mathrm{OR}=0.80,95 \% \mathrm{Cl}$ : 0.63 $1.01)^{11}$. As for leg length, in the large population based study from the 10/66 Dementia Research Group, the prevalence of dementia decreased with each centimetre increase of head circumference (Prevalence Ratio $=0.961,95 \% \mathrm{Cl} 0.940-0.986)^{15}$.

The only longitudinal study, from the US, found a nonsignificant trend towards a twofold increased risk for dementia with smallest skull circumferences (HR 2.3, 95\% Cl: 0.7-6.9) even after adjustment for gender and the number of children in home at age $2-3^{20}$.

\section{Conclusion}

The little evidence available on head circumference and leg length seems consistent, showing an association with prevalent and incident dementia in diverse geographical regions of the world. Early-life development therefore appears to be of possible relevance to the risk of dementia and Alzheimer's disease. Weaknesses in the current evidence base include the paucity of prospective studies (since reverse causality is also possible, the onset of dementia leading to apparent reduced leg length, and shrunken heads due to loss of fat), and lack of longterm cohort studies with contemporary assessment of skull circumference (or preferably brain volume) and leg length in childhood.

\section{Early-life events}

\section{Introduction}

The occurrence of stressful events across the lifespan has been one of the psychosocial risk factors suggested for dementia and Alzheimer's disease. In essence, experiencing negative events might cause stress reactions, which could affect the brain structure through a complex neuro-endocrine process regulated by the 'HPA axis' (Hypothalamic-Pituitary-Adrenal axis; see also Chapter 3, Psychological distress: personality and life events). While those events have been generally studied across the lifespan, the evidence is less extensive for the first period of life, and often focused on the death of a parent during childhood.

Parental death during childhood (or 'early parental death') is an unexpected and traumatic event which commonly causes an adaptive challenge for the child and initiates new stress into his or her life ${ }^{21}$. It is consequently often an event affecting long-term emotional, cognitive, social, spiritual and physical wellbeing. Increased risk for psychiatric disorder, including depression and post-traumatic stress disorder (an anxiety disorder caused by very stressful, frightening or distressing events), and alcohol or substance abuse after parental death, has been showed in bereaved children and adolescents ${ }^{22-24}$. Childhood stressors have been shown to impact health into adulthood, with an increased risk for poorer cardiovascular health ${ }^{25}$ and pulmonary disease ${ }^{26}$, and to predict decreased longevity ${ }^{27}$.

Although early-life adversity cannot be easily modified, showing its association with the development of dementia in later life could help target people at risk, for relevant interventions ${ }^{21}$.

\section{Evidence}

The first prospective study that focused on the association between late-onset dementia and a range of stressful life events was carried out in Sweden ${ }^{28}$ (Table 2.3). A representative sample of 374 people aged 70 and over, living in Goteborg, was followed for 9 years. The diagnosis of dementia was made according to the DSM-III-R criteria during the follow-up period while psychosocial risk factors had been collected at baseline. Five potential stressors before the age of 16 were gathered (death of a parent, divorce of parents, growing up with one parent, different guardians, extreme poverty). When comparing participants who were exposed to individual events to those who had not been exposed to any, participants who had lost a parent before the age of 16 had a greatly increased risk of developing dementia after 70 years $(R R=6.3,95 \%$ $\mathrm{Cl}: 1.8-21.1)$.

The association between dementia and early parental death has also been investigated in cross-sectional and case-control studies ${ }^{21,29,30}$, where the risk variable was collected at the same time as dementia was ascertained and the events of interest were mostly reported by the participants themselves or a caregiver. Consequently, those studies are subject to an unknown degree of recall bias in reported dates of parental death, and the strength of the evidence showed by those studies is uncertain.

In the Cache-County Study, the effect of early parental death and remarriage of widowed parents was reexamined when parental death dates were extracted from records and certificates and compared to the participant's birth date ${ }^{31}$. After adjustments, the 
Table 2.3

Characteristics of epidemiological studies on the association with parental death and dementia and Alzheimer's disease

\begin{tabular}{|c|c|c|c|}
\hline 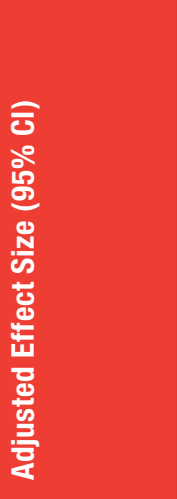 & & 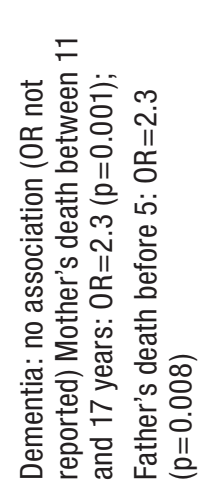 & 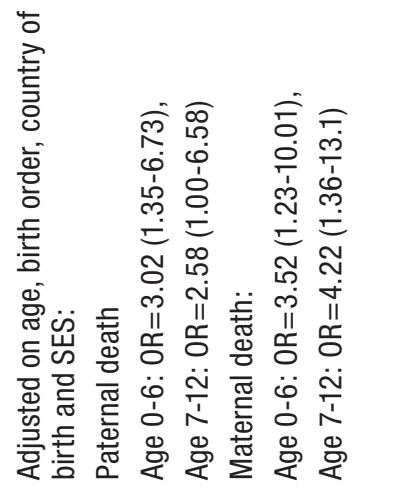 \\
\hline 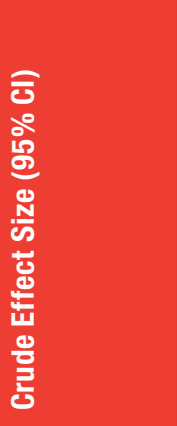 & 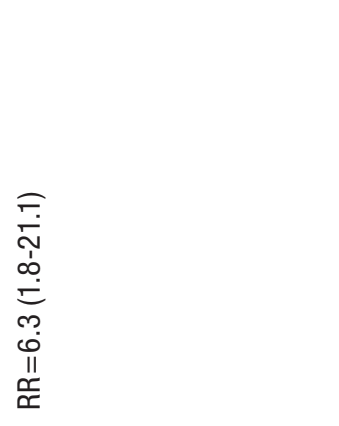 & ' & 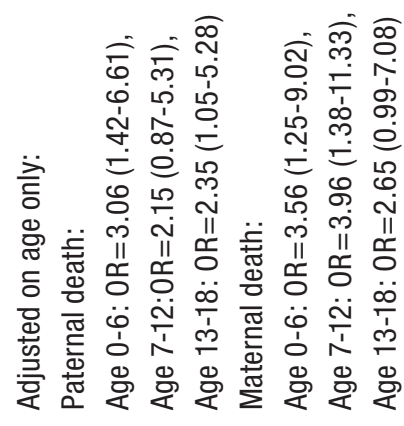 \\
\hline 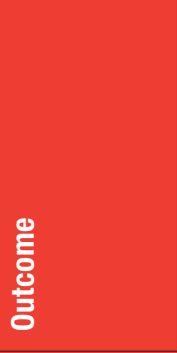 & 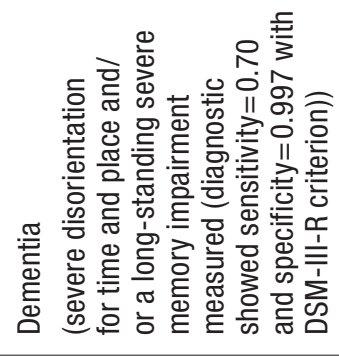 & 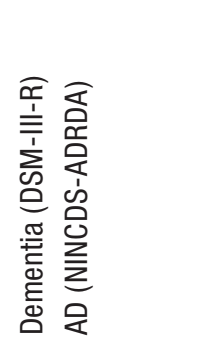 & 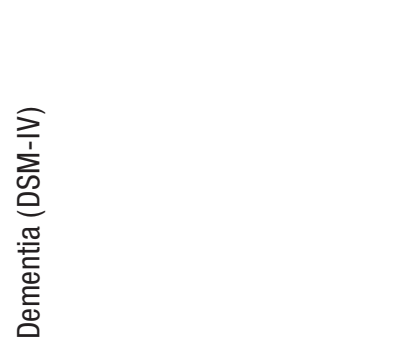 \\
\hline & 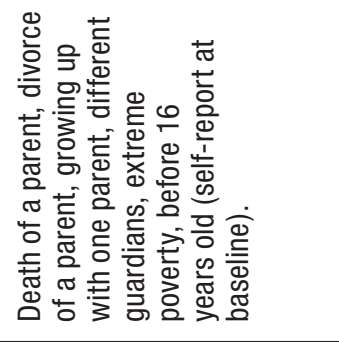 & 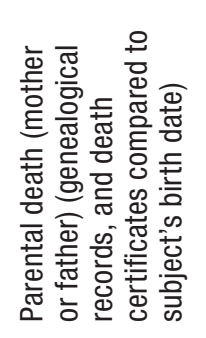 & 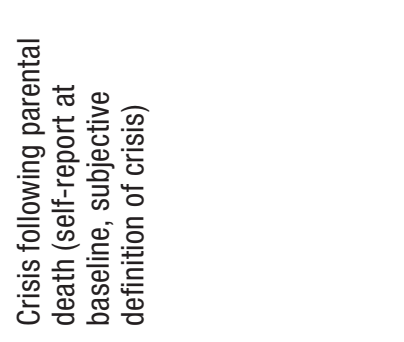 \\
\hline 言 & $\sigma$ & ' & 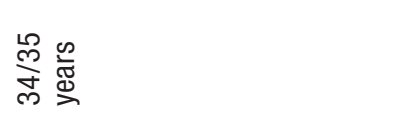 \\
\hline 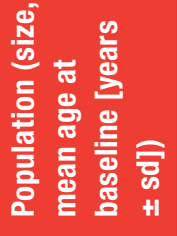 & 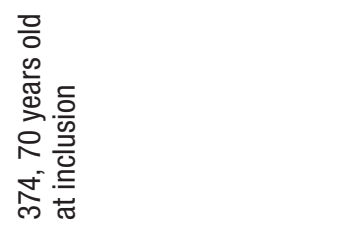 & 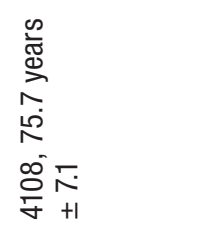 & 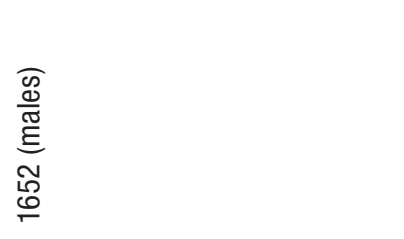 \\
\hline 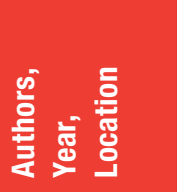 & 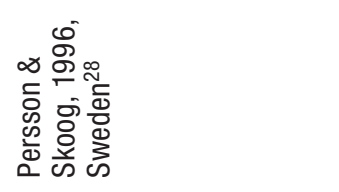 & 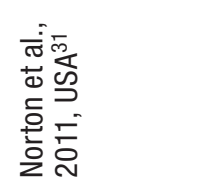 & 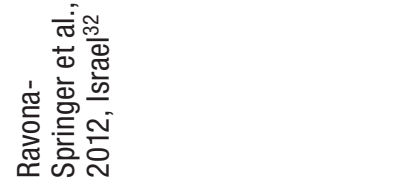 \\
\hline
\end{tabular}

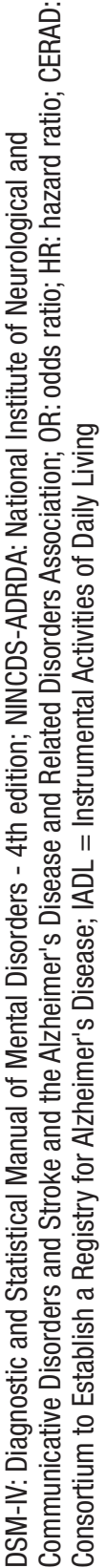


overall association between early paternal death and $A D$ diagnosis in late life was marginal, with paternal death before the age of five years and maternal death during adolescence associated with a doubling of the prevalence of $A D$. These associations were not modified by gender or the presence of an APOE e4 allele. Neither maternal or paternal death were associated with non-AD dementia risk. When the remarriage of widowed parent during the remaining years of childhood was included in the analysis, paternal death was no longer associated with $A D$ while maternal death during adolescence was associated with a higher rate of $A D(O R=2.41, p=0.003)$ when the widowed father did not remarry. A third study has examined the relationship between crisis following parental death in male children and the risk of dementia in late-life in Israel ${ }^{32}$. After adjustment for age, birth order, country of birth and socio-economic status, those who reported a crisis after paternal death before the age of 12 (detailed results Table 2.3) were at increased risk of dementia. A similar effect was found for those who reported a crisis after maternal death before 12 years.

\section{Conclusion}

Evidence from longitudinal studies shows an increased risk of dementia or Alzheimer's disease for people who experienced early-parental death (and/or a crisis after early parental death), with the possibility of different critical periods for paternal and maternal death. The association seems to be attenuated when the widowed parent remarries during the index person's childhood. However, the evidence relies for now on very few longitudinal studies. As early-life events can easily be subject to recall bias, linkage of clinical data with population database could allow more rigorous testing of this hypothesis in large epidemiological populationbased studies.

\section{Education and Occupation}

\section{Introduction}

Since Mortimer ${ }^{33}$ suggested that years of formal education may raise one's level of "intellectual reserve" and thus exert a protective effect against developing dementia, a large number of studies have investigated this association. Following the demonstration, in a New York cohort study ${ }^{34}(n=593)$, that those with low educational attainment had around 2.25 times the risk of dementia of those with a low educational level, a weight of evidence has accumulated from high-quality prospective cohort studies showing higher levels of education significantly protecting against dementia risk.

Several possible mechanisms have been proposed to explain this effect (Box 2.1). As Mortimer noted, the observation that pathological lesions are often present prior to the emergence of clinical symptoms strongly
Box 2.1

\section{How can we explain} the association between education and dementia?

Brain reserve: A larger brain volume may be related to a delay in onset of clinical symptoms despite the presence of neuropathology, due to physical resources which can compensate. This may take the form of a greater number of neurons or synapses, for example ${ }^{35}$. People with larger brains may be more likely to stay in education for longer.

Cognitive reserve: It may be brain function, rather than size, which helps protect against dementia. People with higher levels of education may develop a greater complexity and/or efficiency of neural networks, meaning as dementia-related pathology occurs in the brain, they can actively compensate by drawing on a greater reserve of cognitive processing approaches.

The 'use it or lose it' hypothesis: Lifelong cognitive activity may be necessary to help prevent cognitive decline, and those with higher education may be more highly motivated to pursue intellectual stimulation throughout the life course.

The 'brain-battering' hypothesis: People with higher educational attainment are likely to have a higher socio-economic status, to enjoy a healthier and more advantaged lifestyle, and to have greater access to superior healthcare. They may be exposed to fewer toxins, and their brains may be protected from insults such as cerebral infarct that contribute to dementia.

Ascertainment bias: Some authors ${ }^{36,37}$ have suggested that individuals with lower educational attainment may simply perform more poorly on cognitive tests, and the apparent relationship between education and dementia would be an artefact of measurement.

Education is a proxy for third variables: Education may be a marker for innate intelligence, which could be related genetically or environmentally to other protective factors. 
suggests that there are two sets of risk factors: one for brain pathology and one for development of symptoms. Indeed Meng and D'Arcy ${ }^{38}$ have observed that $10-40 \%$ of individuals with mild to moderate brain pathology at death did not manifest clinical symptoms.

Hence it seems some people are able to compensate for neuropathology and forestall symptom onset. As showed in the EClipSE collaborative studies ${ }^{39}$ including more than 800 people with brain autopsies in Europe, more education did not protect individuals from developing neurodegenerative and vascular neuropathology by the time they died, but it appeared to mitigate the impact of pathology on the clinical expression of dementia before death. It is the discrepancy between the observed and expected impairment associated with a given degree of pathology that constitutes the "reserve" model. This can be divided into a passive, quantitative conceptualisation ("Brain Reserve"), in which greater brain volume helps compensate for pathology, and an active, qualitative conceptualisation ("Cognitive Reserve") in which it is more complex and efficient cognitive processing that performs this role 35,40 . Cognitive Reserve has become the dominant explanatory framework for education and risk of dementia, to the point where education is now widely used as a proxy for Cognitive Reserve ${ }^{41}$.

Higher occupational attainment has also been highlighted as a potentially protective factor against risk of developing dementia ${ }^{41}$. This could either be a result of lifelong opportunity to build Cognitive Reserve; a result of the "use it or lose it" principle whereby continued mental exercise helps forestall cognitive decline, or as a result of higher socioeconomic status being associated with superior health care and health behaviours. Education and occupational status are likely to be closely related, and adjusting for educational level in studies on occupational status may help clarify to what extent effects operate independently of one another.

An important complexity in studies of occupational and educational attainment relates to the way that these exposures are operationalised and defined, and what constitutes a high "dose" of education in particular. This problem becomes especially acute in studies in low and middle income countries where formal education systems may be less developed, and yet informal and traditional systems of instruction ensure that children are well trained to understand and cope with the environmental and socioculturally determined demands that they will encounter in later life.

\section{Evidence from systematic reviews}

Early reviews ${ }^{42,43}$ identified that education was likely to be a risk factor for dementia. Gilleard ${ }^{36}$ in a review of 32 international studies across nine countries, argued that methodological and ascertainment biases were in fact driving the relationship. This review was rightly critical of potential sources of bias in the studies it included, particularly case-control studies, and also of reliance on tests of cognitive impairment to make diagnoses.

A 2006 review $^{44}$ included a meta-analysis of 19 studies - 13 cohort and six case-control studies. Ten cohort studies reported outcomes for all dementia types. Dementia was shown to be moderately increased in participants with low education, and this was consistently reported across designs and outcome definitions. The pooled relative risk of all dementia types comparing lowest to highest educational categories in cohort studies was 1.62 (95\% Cl: 1.262.09). The authors concluded that education fulfilled Bradford-Hill criteria as a likely causal risk factor for dementia.

Valenzuela and Sachdev ${ }^{41}$ included both education and occupational status as risk factors for dementia in their review. Despite some inconsistencies, cohort studies from the developed countries included in the review showed that higher levels of education and occupational attainment were associated with a lower incidence of dementia than were limited education and manual or unskilled professions. Fifteen cohort studies were included examining the incidence of dementia and education history, reporting a pooled Odds Ratio of 1.88 (95\% Cl: 1.61-2.32) for low compared with high education. Twelve cohort studies examined incidence of dementia and occupational status, contributing to a pooled Odds Ratio of 1.78 (95\% Cl: 1.54-2.04) for low compared with high occupational attainment. However, of the eight cohort studies that controlled for age and education, only four remained significant, suggesting that education might have been an important confounder of the association between occupational attainment and incident dementia.

Fratiglioni and Wang 45 reviewed studies reporting the effect of education, socioeconomic status and work complexity on dementia incidence and prevalence. Eleven cohort studies reporting associations of education with dementia were considered, but no meta-analysis was conducted. Heterogeneity in measurement of exposure was noted, but all eleven studies reported a positive outcome. The association between socioeconomic status and incident dementia was reported in five cohort studies, four of which investigated adult status. Two of these reported an association, and two did not after controlling for education. Only one cohort study and three casecontrol studies investigating work complexity were reviewed, and all found a reduced risk of dementia for more complex work activities even after controlling for confounders.

Sharp and $\mathrm{Gatz}^{46}$ did not conduct a meta-analysis, but reviewed fifteen cohort studies on education and dementia, eight of which reported significant results. The authors concluded that education was well-established as a risk factor for dementia, was not unique to Alzheimer's disease, and was not only 
significant when the lowest category was no or very low education.

Meng and D'Arcy ${ }^{38}$ carried out a meta-analysis of 18 cohort studies and four case-control studies. The pooled Odds Ratio for low education compared with high was 1.88 (95\% Cl: $1.51-2.34)$, with significant heterogeneity. The Odds Ratio for cohort studies alone was actually higher at $1.96(95 \% \mathrm{Cl}: 1.54-2.51)$; the association for case-control studies alone was not significant.

Beydoun et al ${ }^{47}$ identified 27 cohort studies for education and dementia, 18 of which were reported an association between lower education level and a worse cognitive outcome, including cognitive decline. Only four cohort studies were entered into a meta-analysis restricted to an exposure of greater or fewer than eight years of education, and an outcome of incident Alzheimer's disease. The pooled Risk Ratio was 1.99 (95\% Cl: 1.30-3.04).

An individual participant meta-analysis of 11 prospective cohort studies $^{48}(n=86,508)$ examining lifetime socioeconomic factors and risk of dementia death found that leaving full-time education at an early age was a significant risk factor for women $(H R=1.76$, 95\% Cl: 1.23-2.53) but not for men. Occupational social class was not statistically significantly associated with dementia death in men or women.

\section{Updated evidence from longitudinal studies (including those published since previous systematic reviews)}

\section{Methods}

\section{Education}

We conducted a literature search on Ovid MEDLINE using the MeSH headings Education, Educational Status and Dementia, and using the search terms education*, school, dement* and Alzheimer*. Papers dating from October 2011 were retrieved, based on the last period covered by Sharp and Gatz's review ${ }^{46}$. We retrieved 1779 abstracts, which were screened for relevance, and 24 full papers were reviewed. Of these, five meeting our inclusion criteria had not been included in any previous reviews (Table 2.4). New studies were included based on the following criteria: 1 . Cohort study design; 2. Study based in the community; 3. Absence of dementia at baseline; 4. Educational achievement measured at baseline; 5 . Incident dementia reported as outcome. We excluded studies based on the following criteria: 1. Study focuses exclusively on Alzheimer's disease, vascular dementia or other dementia subtypes; 2 . Outcome is dementia or probable dementia diagnosed according to MMSE cutpoint or other measures of cognitive decline; 3 . Cross-sectional or nested case-control analysis conducted on cohort data; 4. Literacy/illiteracy used as a proxy for education as the exposure measure.

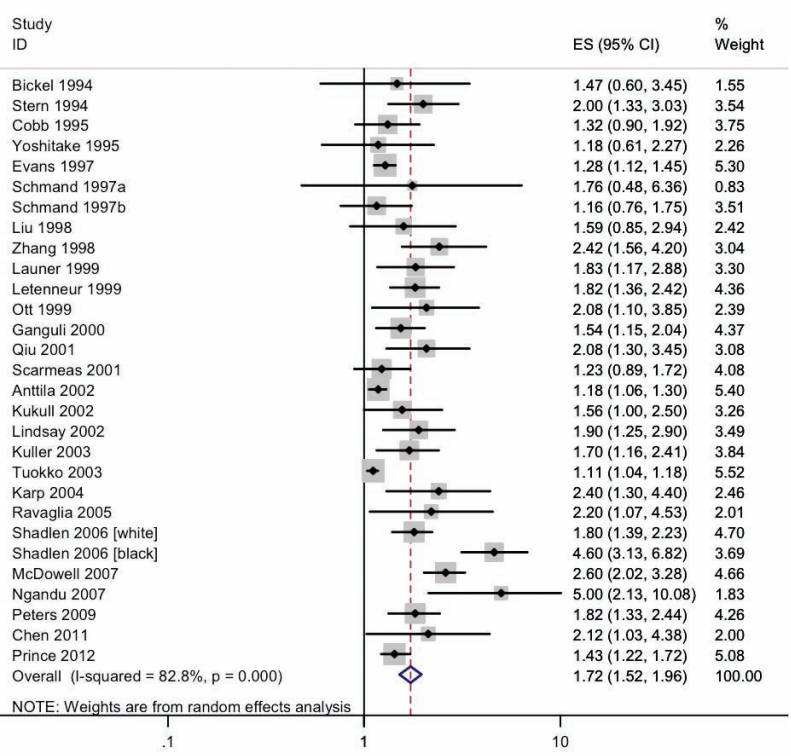

Figure 2.1

Meta analysis for the adjusted effect of education on the risk of incident dementia

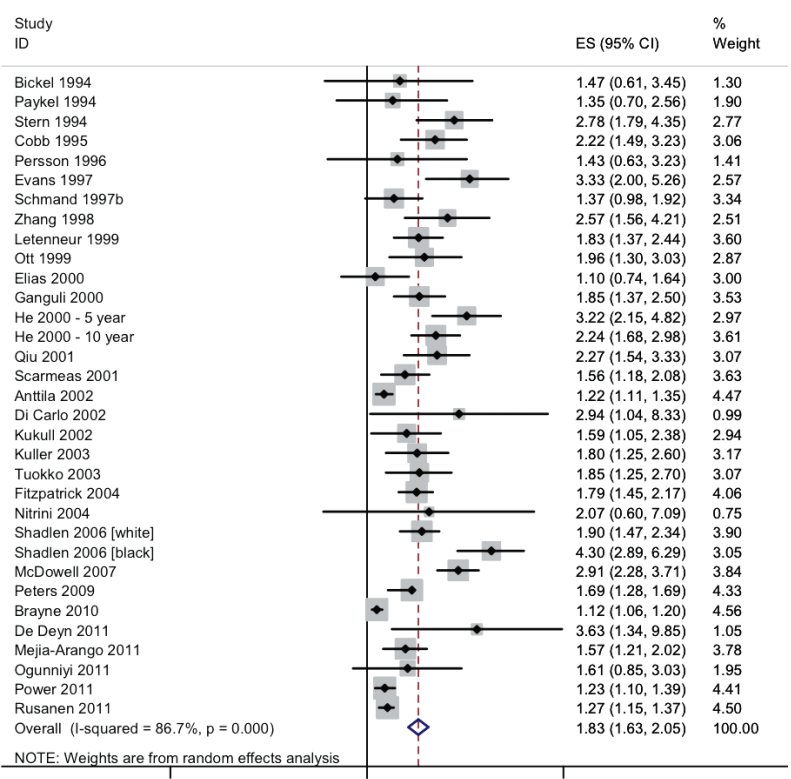

Figure 2.2

Meta analysis for the unadjusted effect of education on the risk of incident dementia

The five new papers retrieved were put together with 36 papers that met inclusion criteria and had been included in previous reviews. Of the combined pool, 10 only reported effect sizes that had been adjusted for confounders (age and sex in the majority of cases). Unadjusted effect sizes only were reported in 13 studies, and both adjusted and unadjusted effect sizes were reported in 18 studies.

The new papers reporting adjusted effect sizes were entered into a random effects meta-analysis alongside 26 other cohort studies reporting adjusted 
Table 2.4

Characteristics of epidemiological studies on the association between education or occupation and incident dementia, which were not included in previous reviews

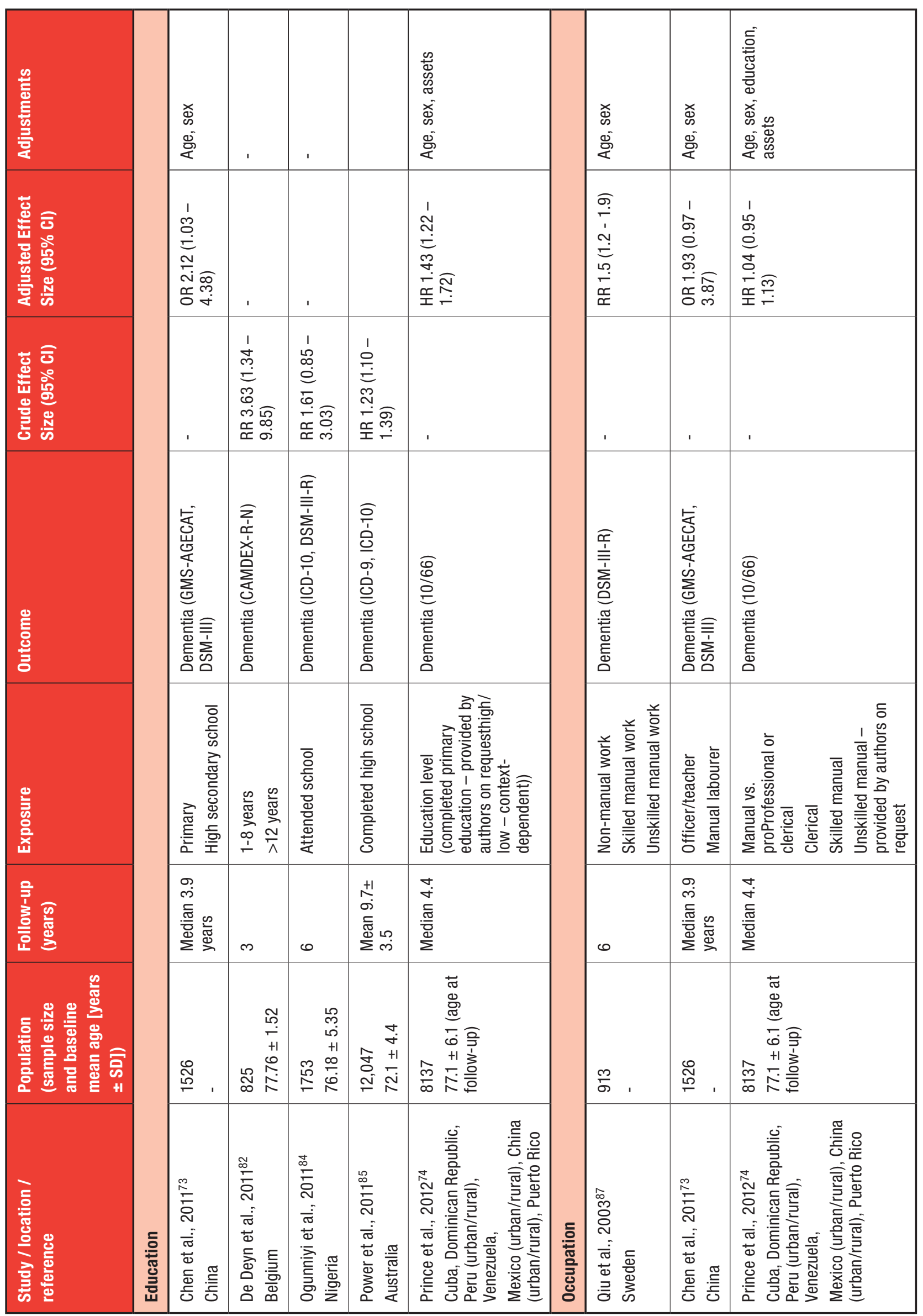




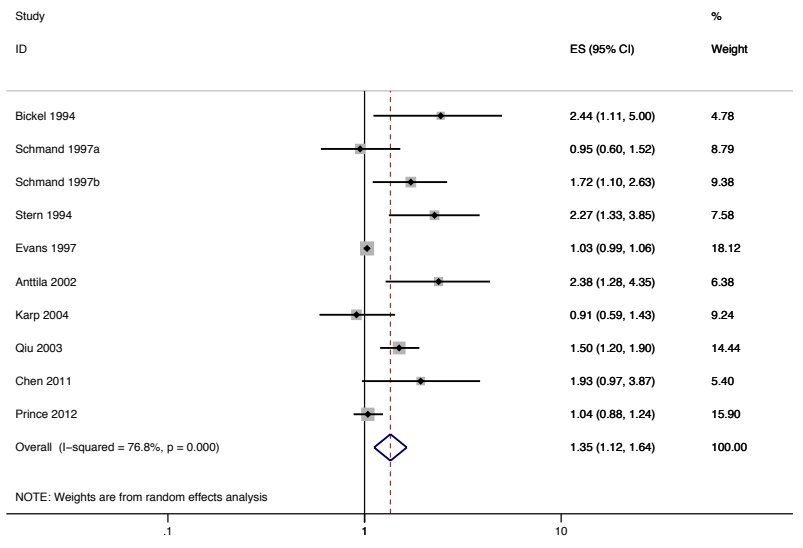

Figure 2.3

Meta analysis for the adjusted effect of occupation on the risk of incident dementia

outcomes $^{34,37,49-74}$. We log-transformed the adjusted Risk, Odds and Hazard Ratios and the associated 95\% Confidence Intervals for each study, and then grouped and meta-analysed them (Figure 2.1).

Another random effects meta-analysis was conducted using the three new papers reporting unadjusted effect sizes, along with the 28 other relevant cohort studies $28,34,37,49,50,52,53,56,58-64,69,70,72,75-86$. Unadjusted effect sizes and Confidence Intervals were log-adjusted, grouped and meta-analysed (Figure 2.2).

\section{Occupational attainment}

We conducted an Ovid MEDLINE literature search using the MeSH headings Occupations, Social Class, Employment and Dementia along with the search terms occupation*.tw, ses.tw, socioeconomic.tw, employ*. tw, attainment.tw, job*.tw, work.tw, dement ${ }^{*} . t w$ and Alzheimer*.tw. The same inclusion and exclusion criteria were applied as in the search for educational attainment, except that the literacy exclusion criterion was no longer relevant. A total of 1050 papers were retrieved, of which 104 were screened in depth based on abstracts and full papers. Of these, 28 were cohort studies reporting an occupation-related outcome and risk for incident dementia. Five new papers not included in Valenzuela and Sachdev's 2006 review ${ }^{41}$ were identified. Three of these reported on occupational attainment (Table 2.4), and two on occupational complexity. One large meta-analysis reported on occupational status and risk of dementia death, which is discussed in a paragraph below. The three new studies all reported effect sizes adjusted for confounders of age and sex, and these were entered into a random effects meta-analysis alongside six other cohort studies reporting adjusted outcomes $^{34,49,52-54,63,67,73,74,87}$. We log-transformed the adjusted Risk, Odds and Hazard Ratios and the associated 95\% Confidence Intervals for each study, and then grouped and meta-analysed them

(Figure 2.3).

\section{Results}

\section{Education}

Our random effects meta-analysis of 28 cohort studies examining the effect of low education as a risk factor for incident dementia which reported adjusted effect sizes for age, gender and other confounding variables produced a pooled effect size of 1.72 (95\% Cl: 1.521.96). Our additional random effects meta-analysis of 31 cohort studies reporting unadjusted effect sizes produced a pooled effect size of 1.83 (95\% Cl: $1.63-$ 2.05). Higgins I squared tests revealed substantial heterogeneity in studies in both meta-analyses. However, sensitivity analyses removing one study at a time to test effects on the pooled effect sizes revealed no individual studies significantly biased results in either meta-analysis. Funnel plots suggested significant publication bias was unlikely.

Two of the new studies included in the meta-analysis reported effects adjusted for age and sex, and three reported unadjusted outcomes. There was no obvious difference between adjusted and unadjusted effect sizes; rather, it was noticeable that the larger cohort studies (12,047 and 8,137 respectively) found more conservative effect sizes (RR 1.61 and HR 1.23 respectively), while the smallest studies also reported the largest effects. Effect sizes ranged from 1.43 to 3.63.

The result from the Nigerian cohort ${ }^{84}$ was not statistically significant. Almost all previous studies showing a protective effect of higher education on dementia were conducted in high-income countries. For this reason the Nigerian cohort study and the 10/66 multicentre study ${ }^{74}$ are particularly interesting.

The 10/66 study pooled data from 10 centres (Cuba, Dominican Republic, urban and rural Peru, Venezuela, urban and rural Mexico, urban and rural China, and Puerto Rico). In the original publication, educational attainment was measured as a trend across five categories (none, did not complete primary, completed primary, completed secondary, tertiary education). A fixed effects meta-analysis found a significant protective effect of increasing levels of education against risk of incident dementia (RR 0.89, 95\% $\mathrm{Cl}: 0.81-0.97)$, with modest heterogeneity (50\%). Repeating the original analysis reported in the paper, including the new data from Puerto Rico, yielded a fixed effect of 0.88 (RR 95\% Cl: 0.81-0.95) and a random effect of 0.85 (95\% Cl: $0.75-0.97)$, with $57 \%$ heterogeneity. These estimates provide robust evidence for a protective effect of higher levels of education against incident dementia in middle income countries. For the purposes of our meta-analysis which required a dichotomised education exposure (low versus high), the original 10/66 data were dichotomized (not completing vs. completing primary education) yielding a pooled $\mathrm{RR}$ of 1.43 (95\% Cl: 1.22-1.72). While the dichotomised analysis was essential for our meta- 
analysis, the evidence from the original paper was both more homogenous and robust.

\section{Occupational attainment}

Our random effects meta-analysis of nine cohort studies that reported effect sizes adjusted for age, sex and other confounders produced a pooled effect size of 1.35 (95\% Cl 1.12 - 1.64). Higgins' I squared test revealed substantial heterogeneity between studies. Our meta-analysis followed the pragmatic approach of Valenzuela and Sachdev ${ }^{41}$ in dichotomising occupational attainment (low versus high).

Three new studies were identified that assessed low occupational attainment and risk for developing dementia. A Swedish cohort study of 913 participants ${ }^{87}$ was not included in Valenzuela and Sachdev's 2006 review ${ }^{41}$ despite meeting inclusion criteria. The study showed unskilled manual workers had a 50\% greater risk of incident dementia compared with non-manual workers (RR 1.5, 95\% Cl: 1.2-1.9) after controlling for age and gender. Relative Risks remained similar when manual work was split into skilled and unskilled categories, and was larger for manual workers involved in goods production (RR 1.8, 95\% Cl: 1.2-2.7) than in service production (RR 1.4, 95\% Cl: 1.1-1.8). However, none of these effects were statistically significant after controlling for education.

Chen et $\mathrm{al}^{73}$ reported Odds Ratios for incident dementia comparing manual labourers with professionals, using data from a Chinese cohort study of 1526 participants. The odds were not significantly different; nor were they in another analysis comparing professionals with peasants.

Prince et al's multisite study ${ }^{74}$ across lower and middle income studies also failed to find a significantly different effect between occupational status categories (HR 1.04, 95\% Cl: 0.95-1.13), after controlling for age, sex, education and assets. Again, in order to include the 10/66 data in our meta-analysis, we dichotomised occupational attainment (low versus high), and carried out a fixed effects meta-analysis. The overall effect size remained the same as between categories, albeit the confidence intervals were wider $(1.04,95 \% \mathrm{Cl}$ : 0.881.24).

The three studies included in Valenzuela and Sachdev's review ${ }^{41}$ that reported effects controlling for educational attainment all showed non-significant results after making this adjustment.

Two cohort studies were identified that examined occupational complexity and risk of incident dementia. Occupational complexity could be considered to be a more direct operationalisation of cognitive demands than occupational attainment. Complexity of work with data, people and things is rated for each occupation and entered into the model with the outcome of interest. Kroger et al ${ }^{88}$ evaluated occupational complexity and risk of incident dementia in a Canadian cohort of 3,557 participants over a 10-year follow-up.
High complexity with data (HR 0.75, 95\% Cl: 0.59 0.94) and people (HR 0.65, 95\% Cl: 0.51-0.83), but not with things, exerted a significant protective effect against incident dementia. After adjusting for education and sex however, neither of these remained significant. Karp et al ${ }^{67}$ also reported significant effects for occupational complexity with data (RR $0.85,95 \% \mathrm{Cl}$ : $0.77-0.95$ ) and people (RR $0.88,95 \% \mathrm{Cl}: 0.80-0.97$ ) from a Swedish cohort of 931 participants. These effect sizes were adjusted for age and sex; however, when education was added to the model, neither of these remained significant.

\section{Conclusions}

This review synthesised and updated the previous evidence detailing the relationship between education, occupational attainment and incident dementia.

Overall there appears to be a protective effect of education against developing dementia later in life, with our meta-analysis suggesting the reduction in risk may be around $40 \%$ (RR for high vs. low educational level $=1 / 1.72=0.58$ ). Our meta-analysis of adjusted and unadjusted effect sizes yielded results comparable to those reported in previous reviews. Previous metaanalyses produced pooled effect sizes ranging from 1.62 to 1.88 , and both our pooled effect sizes lay within this range. The majority of individual studies found a protective effect for higher levels of education, even after controlling for important confounders.

It is interesting to note that the Nigerian cohort study ${ }^{84}$ did not find a significant protective effect of school attendance for dementia. The 10/66 multisite study provided fairly robust evidence however that higher educational attainment exerted a protective effect against incident dementia. It is noteworthy that all the centres in the 10/66 incidence study were from middle-income countries, and further high-quality evidence from cohort studies in lower-income countries is needed to establish the extent to which the same effect applies. This is especially important given that the prevalence of lower education is much higher in low and middle income countries, and hence the Population Attributable Fraction, and the potential for reduced incidence in successive birth cohorts proportionally greater. The mechanism by which education operates as a protective effect, and how this might relate to the quality and quantity of education, as well as the culture and context in which it is received, remain to be clarified.

Valenzuela and Sachdev's $2006^{41}$ meta-analysis of occupational attainment and incident dementia found a pooled OR of 1.78 (95\% Cl: 1.54-2.04), suggesting an $80 \%$ increase in odds of developing dementia for those in low-status jobs. These studies were exclusively conducted in high-income countries, however, and two new studies located in our search conducted in lower and middle income countries did not report statistically significant effects. Furthermore, when 
studies' effect sizes were adjusted for education, the effect was reduced so as to no longer be statistically significant; this also applied to studies on occupational complexity. Clearly we would expect educational and occupational attainment in life to be highly correlated, and both could be related to other factors such as innate intelligence and life-long health behaviours. Our meta-analysis of all cohort studies with adjusted effect sizes produced a pooled effect size of 1.35 (95\% $\mathrm{Cl}: 1.12-1.64)$. Therefore, while there appears to be some association between occupational attainment and dementia, adjustment for confounders appears to substantially reduce the effect size. There was heterogeneity in the confounders adjusted for in our meta-analysis, and residual confounding may well account for the remaining effect.

In terms of public health implications of these findings, education in particular appears to be an important potential protective factor against dementia. Cognitive reserve seems to be the best current model for explaining this effect, but the role that the quality and quantity of education play remains to be clarified, as well as how this might operate in low-income countries.

\section{Overall conclusions}

There is tentative evidence that early life experiences, during the period of brain development and maturation, may influence the risk of developing dementia in late life. Those with larger skulls (an index of brain development) and longer legs (an index of early life nutrition) in late-life have a lower prevalence of dementia. Parental death in early life is associated with a higher risk of incident AD and dementia. Lower levels of education appear to be consistently associated with an increased incidence of dementia, with heterogeneity among studies largely relating to variability in the size, rather than the direction of the association. This heterogeneity may well arise from the relatively crude and variable nature of the dichotomized (low vs. high) education exposure. The much weaker associations with occupational status in adult life, and their tendency to attenuate after controlling for education, suggests that early life may represent a critical period for the benefits of brain and/or cognitive reserve to accrue.

Evidence remains tentative because of the lack of true long-term life course studies, and the consequent use of late-life proxies (skull circumference and leg length) or recall in late-life (parental bereavement, education and occupation) to establish early life exposures, even in those (late-life) cohort studies that relate these exposures to incident dementia. These deficiencies will be addressed when 'birth cohorts' studied intensively from birth, such as the UK MRC National Survey of Health and Development (with participants all born in one week in 1946) reach old age, and can be studied for the incidence of dementia. Such studies have the potential not only to clarify early life developmental risk factors for dementia in late life, but also to elucidate the mechanisms over the life course that may account for their effect. In the meantime, it seems reasonable to hypothesise that secular improvements in neonatal and infant health and nutrition, and educational experience, may lead to a substantial decline for coming generations of older people in the age-specific incidence of dementia. 


\section{References}

1. Whalley LJ, Dick FD, McNeill G. A life-course approach to the aetiology of late-onset dementias. The Lancet Neurology 2006; 5(1): 87-96.

2. Borenstein $\mathrm{AR}$, Copenhaver $\mathrm{Cl}$, Mortimer JA. Early-life risk factors for Alzheimer disease. Alzheimer disease and associated disorders 2006; 20(1): 63-72.

3. Freeman HE, Klein RE, Kagan J, Yarbrough C. Relations between nutrition and cognition in rural Guatemala. American journal of public health 1977; 67(3): 233-9.

4. Cunnane SC, Crawford MA. Survival of the fattest: fat babies were the key to evolution of the large human brain. Comparative biochemistry and physiology Part A, Molecular \& integrative physiology 2003; 136(1): 17-26.

5. Mortimer JA. Brain reserve and the clinical expression of Alzheimer's disease. Geriatrics 1997; 52 Suppl 2: S50-3.

6. Stern Y. What is cognitive reserve? Theory and research application of the reserve concept. Journal of the International Neuropsychological Society : JINS 2002; 8(3): 448-60.

7. Lenroot RK, Giedd JN. Brain development in children and adolescents: insights from anatomical magnetic resonance imaging Neuroscience and biobehavioral reviews 2006; 30(6): 718-29.

8. Bartholomeusz HH, Courchesne E, Karns CM. Relationship between head circumference and brain volume in healthy normal toddlers, children, and adults. Neuropediatrics 2002; 33(5): 239-41.

9. Richards M, Hardy R, Kuh D, Wadsworth ME. Birth weight and cognitive function in the British 1946 birth cohort: longitudinal population based study. Bmj 2001; 322(7280): 199-203.

10. Wadsworth ME, Hardy RJ, Paul AA, Marshall SF, Cole TJ. Leg and trunk length at 43 years in relation to childhood health, diet and family circumstances; evidence from the 1946 national birth cohort. International journal of epidemiology 2002; 31(2): 383-90.

11. Scazufca M, Menezes PR, Araya R, et al. Risk factors across the life course and dementia in a Brazilian population: results from the Sao Paulo Ageing \& Health Study (SPAH). International journal of epidemiology 2008; 37(4): 879-90

12. Kim JM, Stewart R, Shin IS, Yoon JS. Limb length and dementia in an older Korean population. Journal of neurology, neurosurgery, and psychiatry 2003; 74(4): 427-32.

13. Mak Z, Kim JM, Stewart R. Leg length, cognitive impairment and cognitive decline in an African-Caribbean population. International journal of geriatric psychiatry 2006; 21(3): 266-72.

14. Huang TL, Carlson MC, Fitzpatrick AL, Kuller LH, Fried LP, Zandi PP. Knee height and arm span: a reflection of early life environment and risk of dementia. Neurology 2008; 70(19 Pt 2): 1818-26.

15. Prince $M$, Acosta $D$, Dangour $A D$, et al. Leg length, skull circumference, and the prevalence of dementia in low and middle income countries: a 10/66 population-based cross sectional survey. International psychogeriatrics / IPA 2011; 23(2): 202-13.

16. Schofield PW, Logroscino G, Andrews HF, Albert S, Stern Y. An association between head circumference and Alzheimer's disease in a population-based study of aging and dementia. Neurology 1997; 49(1): 30-7.

17. Kim JM, Stewart R, Shin IS, Kim SW, Yang SJ, Yoon JS. Associations between head circumference, leg length and dementia in a Korean population. International journal of geriatric psychiatry 2008; 23(1): 41-8.

18. Mortimer JA, Snowdon DA, Markesbery WR. Head circumference, education and risk of dementia: findings from the Nun Study. Journal of clinical and experimental neuropsychology 2003; 25(5): 671-9.

19. Bickel H, Riemenschneider M, Kurz A. [Associations between dementia and head circumference as a measure of brain reserve-results from the Bavarian School sisters study]. Psychiatrische Praxis 2006; 33(3): 138-44.

20. Borenstein AR, Wu Y, Mortimer JA, et al. Developmental and vascular risk factors for Alzheimer's disease. Neurobiology of aging 2005; 26(3): 325-34.

21. Norton MC, Ostbye T, Smith KR, Munger RG, Tschanz JT. Early parental death and late-life dementia risk: findings from the Cache County Study. Age and ageing 2009; 38(3): 340-3.

22. Kirwin KM, Hamrin V. Decreasing the risk of complicated bereavement and future psychiatric disorders in children. Journal of child and adolescent psychiatric nursing : official publication of the Association of Child and Adolescent Psychiatric Nurses, Inc 2005 18(2): 62-78.

23. Melhem NM, Walker M, Moritz G, Brent DA. Antecedents and sequelae of sudden parental death in offspring and surviving caregivers. Archives of pediatrics \& adolescent medicine 2008; 162(5): 403-10
24. Brent D, Melhem N, Donohoe MB, Walker M. The incidence and course of depression in bereaved youth 21 months after the loss of a parent to suicide, accident, or sudden natural death. The American journal of psychiatry 2009; 166(7): 786-94.

25. Lehman BJ, Taylor SE, Kiefe CI, Seeman TE. Relationship of early life stress and psychological functioning to blood pressure in the CARDIA study. Health psychology : official journal of the Division of Health Psychology, American Psychological Association 2009; 28(3): 338-46.

26. Anda RF, Brown DW, Dube SR, Bremner JD, Felitti VJ, Giles WH. Adverse childhood experiences and chronic obstructive pulmonary disease in adults. American journal of preventive medicine 2008; 34(5): 396-403.

27. Schwartz JE, Friedman HS, Tucker JS, Tomlinson-Keasey C, Wingard DL, Criqui MH. Sociodemographic and psychosocial factors in childhood as predictors of adult mortality. American journal of public health 1995; 85(9): 1237-45.

28. Persson G, Skoog I. A prospective population study of psychosocial risk factors for late onset dementia. International journal of geriatric psychiatry 1996; 11(1): 15-22.

29. Whalley LJ, Staff RT, Murray AD, Deary IJ, Starr JM. Genetic and environmental factors in late onset dementia: possible role for early parental death. International journal of geriatric psychiatry 2013; 28(1): 75-81.

30. Wei CJ, Cheng Y, Zhang Y, Sun F, Zhang WS, Zhang MY. Risk factors for dementia in highly educated elderly people in Tianjin, China. Clinical neurology and neurosurgery 2014; 122: 4-8.

31. Norton MC, Smith KR, Ostbye T, et al. Early parental death and remarriage of widowed parents as risk factors for Alzheimer disease: the Cache County study. The American journal of geriatric psychiatry : official journal of the American Association for Geriatric Psychiatry 2011; 19(9): 814-24.

32. Ravona-Springer R, Beeri MS, Goldbourt U. Younger age at crisis following parental death in male children and adolescents is associated with higher risk for dementia at old age. Alzheimer disease and associated disorders 2012; 26(1): 68-73.

33. Mortimer J. Do psychosocial risk factor contribute to Alzheimer's disease? Etiology of dementia of Alzheimer's type 1988

34. Stern Y, Gurland B, Tatemichi TK, Tang MX, Wilder D, Mayeux R. Influence of education and occupation on the incidence of Alzheimer's disease. Jama 1994; 271(13): 1004-10.

35. Stern Y. Cognitive reserve in ageing and Alzheimer's disease. The Lancet Neurology 2012; 11(11): 1006-12.

36. Gilleard C. Education and Alzheimer's disease: a review of recent international epidemiological studies. Aging \& Mental Health 1997 1(1): 33-46

37. Tuokko H, Frerichs R, Graham J, et al. Five-year follow-up of cognitive impairment with no dementia. Archives of neurology 2003 60(4): 577-82.

38. Meng X, D'Arcy C. Education and dementia in the context of the cognitive reserve hypothesis: a systematic review with metaanalyses and qualitative analyses. PLoS One 2012; 7(6): e38268.

39. Members ECC, Brayne C, Ince PG, et al. Education, the brain and dementia: neuroprotection or compensation? Brain : a journal of neurology 2010; 133(Pt 8): 2210-6.

40. Stern Y. Cognitive reserve. Neuropsychologia 2009; 47(10): 2015-28.

41. Valenzuela MJ, Sachdev P. Brain reserve and dementia: a systematic review. Psychological medicine 2006; 36(04): 441-54.

42. Katzman R. Education and the prevalence of dementia and Alzheimer's disease. Neurology 1993.

43. Mortimer JA, Graves AB. Education and other socioeconomic determinants of dementia and Alzheimer's disease. Neurology 1993.

44. Caamaño-Isorna F, Corral M, Montes-Martínez A, Takkouche B. Education and dementia: a meta-analytic study. Neuroepidemiology 2006; 26(4): 226-32.

45. Fratiglioni L, Wang $\mathrm{H}-\mathrm{X}$. Brain reserve hypothesis in dementia. Journal of Alzheimer's disease 2007; 12(1): 11-22.

46. Sharp ES, Gatz M. The Relationship between Education and Dementia An Updated Systematic Review. Alzheimer disease and associated disorders 2011; 25(4): 289.

47. Beydoun MA, Beydoun HA, Gamaldo AA, Teel A, Zonderman AB Wang $Y$. Epidemiologic studies of modifiable factors associated with cognition and dementia: systematic review and meta-analysis. BMC public health 2014; 14(1): 643.

48. Russ TC, Stamatakis E, Hamer M, Starr JM, Kivimaki M, Batty GD. Socioeconomic status as a risk factor for dementia death: individua participant meta-analysis of 86508 men and women from the UK. The British journal of psychiatry : the journal of mental science 2013 203(1): 10-7. 
49. Bickel $\mathrm{H}$, Cooper $\mathrm{B}$. Incidence and relative risk of dementia in an urban elderly population: findings of a prospective field study. Psychological medicine 1994; 24(01): 179-92.

50. Cobb J, Wolf PA, Au R, White R, D'agostino R. The effect of education on the incidence of dementia and Alzheimer's disease in the Framingham Study. Neurology 1995; 45(9): 1707-12.

51. Yoshitake T, Kiyohara Y, Kato I, et al. Incidence and risk factors of vascular dementia and Alzheimer's disease in a defined elderly Japanese population The Hisayama Study. Neurology 1995; 45(6): 1161-8.

52. Evans DA, Hebert LE, Beckett LA, et al. Education and other measures of socioeconomic status and risk of incident Alzheimer disease in a defined population of older persons. Archives of neurology 1997; 54(11): 1399-405.

53. Schmand B, Smit J, Geerlings M, Lindeboom J. The effects of intelligence and education on the development of dementia. A test of the brain reserve hypothesis. Psychological medicine 1997; 27(06): 1337-44.

54. Schmand B, Smit J, Lindeboom J, et al. Low education is a genuine risk factor for accelerated memory decline and dementia. Journal of Clinical Epidemiology 1997; 50(9): 1025-33.

55. Liu H-C, Fuh J-L, Wang S-J, et al. Prevalence and subtypes of dementia in a rural Chinese population. Alzheimer Disease \& Associated Disorders 1998; 12(3): 127-39.

56. Zhang M, Katzman R, Yu E, Liu W, Xiao SF, Yan H. A preliminary analysis of incidence of dementia in Shanghai, China. Psychiatry and clinical neurosciences 1998; 52(S6): S291-S4.

57. Launer L, Andersen K, Dewey M, et al. Rates and risk factors for dementia and Alzheimer's disease Results from EURODEM pooled analyses. Neurology 1999; 52(1): 78-.

58. Letenneur L, Gilleron V, Commenges D, Helmer C, Orgogozo J, Dartigues J. Are sex and educational level independent predictors of dementia and Alzheimer's disease? Incidence data from the PAQUID project. Journal of Neurology, Neurosurgery \& Psychiatry 1999; 66(2): 177-83.

59. Ott A, Van Rossum C, Van Harskamp F, Van de Mheen H, Hofman A, Breteler M. Education and the incidence of dementia in a large population-based study: the Rotterdam Study. Neurology 1999; 52(3): 663-

60. Ganguli M, Dodge H, Chen P, Belle S, DeKosky S. Ten-year incidence of dementia in a rural elderly US community population The MoVIES Project. Neurology 2000; 54(5): 1109-16.

61. Qiu C, Bäckman L, Winblad B, Agüero-Torres H, Fratiglioni L. The influence of education on clinically diagnosed dementia incidence and mortality data from the Kungsholmen Project. Archives of Neurology 2001; 58(12): 2034-9.

62. Scarmeas N, Levy G, Tang M-X, Manly J, Stern Y. Influence of leisure activity on the incidence of Alzheimer's disease. Neurology 2001; 57(12): 2236-42.

63. Anttila T, Helkala E-L, Kivipelto M, et al. Midlife income, occupation, APOE status, and dementia A population-based study. Neurology 2002; 59(6): 887-93

64. Kukull WA, Higdon R, Bowen JD, et al. Dementia and Alzheimer disease incidence: a prospective cohort study. Archives of Neurology 2002; 59(11): 1737-46.

65. Lindsay J, Laurin D, Verreault R, et al. Risk factors for Alzheimer's disease: a prospective analysis from the Canadian Study of Health and Aging. American journal of epidemiology 2002; 156(5): 445-53.

66. Kuller LH, Lopez OL, Newman A, et al. Risk factors for dementia in the cardiovascular health cognition study. Neuroepidemiology 2003; 22(1): 13-22.

67. Karp A, Kåreholt I, Qiu C, Bellander T, Winblad B, Fratiglioni L. Relation of education and occupation-based socioeconomic status to incident Alzheimer's disease. American journal of epidemiology 2004; 159(2): 175-83

68. Ravaglia G, Forti P, Maioli F, et al. Incidence and etiology of dementia in a large elderly Italian population. Neurology 2005; 64(9): 1525-30.

69. Shadlen MF, Siscovick D, Fitzpatrick AL, Dulberg C, Kuller LH, Jackson S. Education, Cognitive Test Scores, and Black-White Differences in Dementia Risk. Journal of the American Geriatrics Society 2006; 54(6): 898-905.

70. McDowell I, Xi G, Lindsay J, Tierney M. Mapping the connections between education and dementia. Journal of clinical and experimental neuropsychology 2007; 29(2): 127-41.

71. Ngandu T, von Strauss E, Helkala E-L, et al. Education and dementia What lies behind the association? Neurology 2007; 69(14): 1442-50.

72. Peters R, Beckett N, Geneva M, et al. Sociodemographic and lifestyle risk factors for incident dementia and cognitive decline in the HYVET*. Age and ageing 2009: afp094.
73. Chen R, Hu Z, Wei L, Ma Y, Liu Z, Copeland JR. Incident dementia in a defined older chinese population. PloS one 2011; 6(9): e24817.

74. Prince M, Acosta D, Ferri CP, et al. Dementia incidence and mortality in middle-income countries, and associations with indicators of cognitive reserve: a 10/66 Dementia Research Group populationbased cohort study. The Lancet 2012; 380(9836): 50-8.

75. Paykel ES, Brayne C, Huppert FA, et al. Incidence of dementia in a population older than 75 years in the United Kingdom. Archives of General Psychiatry 1994; 51(4): 325-32.

76. Elias MF, Beiser A, Wolf PA, Au R, White RF, D'Agostino RB. The preclinical phase of Alzheimer disease: a 22-year prospective study of the Framingham Cohort. Archives of Neurology 2000; 57(6): 80813.

77. He Y, Zhang X, Zhang M. Psychosocial risk factors for Alzheimer's disease. Hong Kong J Psychiatry 2000; 10(2): 2-7.

78. Di Carlo A, Baldereschi M, Amaducci L, et al. Incidence of dementia, Alzheimer's disease, and vascular dementia in Italy. The ILSA Study. Journal of the American Geriatrics Society 2002; 50(1): 41-8.

79. Fitzpatrick AL, Kuller LH, Ives DG, et al. Incidence and prevalence of dementia in the Cardiovascular Health Study. Journal of the American Geriatrics Society 2004; 52(2): 195-204.

80. Nitrini R, Caramelli P, Herrera Jr E, et al. Incidence of dementia in a community-dwelling Brazilian population. Alzheimer Disease \& Associated Disorders 2004; 18(4): 241-6.

81. Brayne C, Ince PG, Keage HA, et al. Education, the brain and dementia: neuroprotection or compensation? EClipSE Collaborative Members. Brain : a journal of neurology 2010; 133(8): 2210-6.

82. De Deyn P, Goeman J, Vervaet A, Dourcy-Belle-Rose B, Van Dam D, Geerts E. Prevalence and incidence of dementia among 75-80-yearold community-dwelling elderly in different districts of Antwerp, Belgium: the Antwerp Cognition (ANCOG) Study. Clinical neurology and neurosurgery 2011; 113(9): 736-45

83. Mejia-Arango S, Gutierrez LM. Prevalence and Incidence Rates of Dementia and Cognitive Impairment No Dementia in the Mexican Population Data From the Mexican Health and Aging Study. Journal of aging and health 2011; 23(7): 1050-74.

84. Ogunniyi A, Lane K, Baiyewu O, et al. Hypertension and incident dementia in community-dwelling elderly Yoruba Nigerians. Acta Neurologica Scandinavica 2011; 124(6): 396-402.

85. Power BD, Alfonso H, Flicker L, Hankey GJ, Yeap BB, Almeida OP. Body adiposity in later life and the incidence of dementia: the health in men study. PloS one 2011; 6(3): e17902.

86. Rusanen M, Kivipelto M, Quesenberry CP, Zhou J, Whitmer RA. Heavy smoking in midlife and long-term risk of Alzheimer disease and vascular dementia. Archives of internal medicine $2011 ; 171(4)$ : 333-9.

87. Qiu C, Karp A, von Strauss E, Winblad B, Fratiglioni L, Bellander T. Lifetime principal occupation and risk of Alzheimer's disease in the Kungsholmen project. American journal of industrial medicine 2003; 43(2): 204-11.

88. Kroger E, Andel R, Lindsay J, Benounissa Z, Verreault R, Laurin D. Is complexity of work associated with risk of dementia? The Canadian Study of Health And Aging. American journal of epidemiology 2008; 167(7): 820-30. 


\section{CHAPTER 3}

\section{Psychological factors}

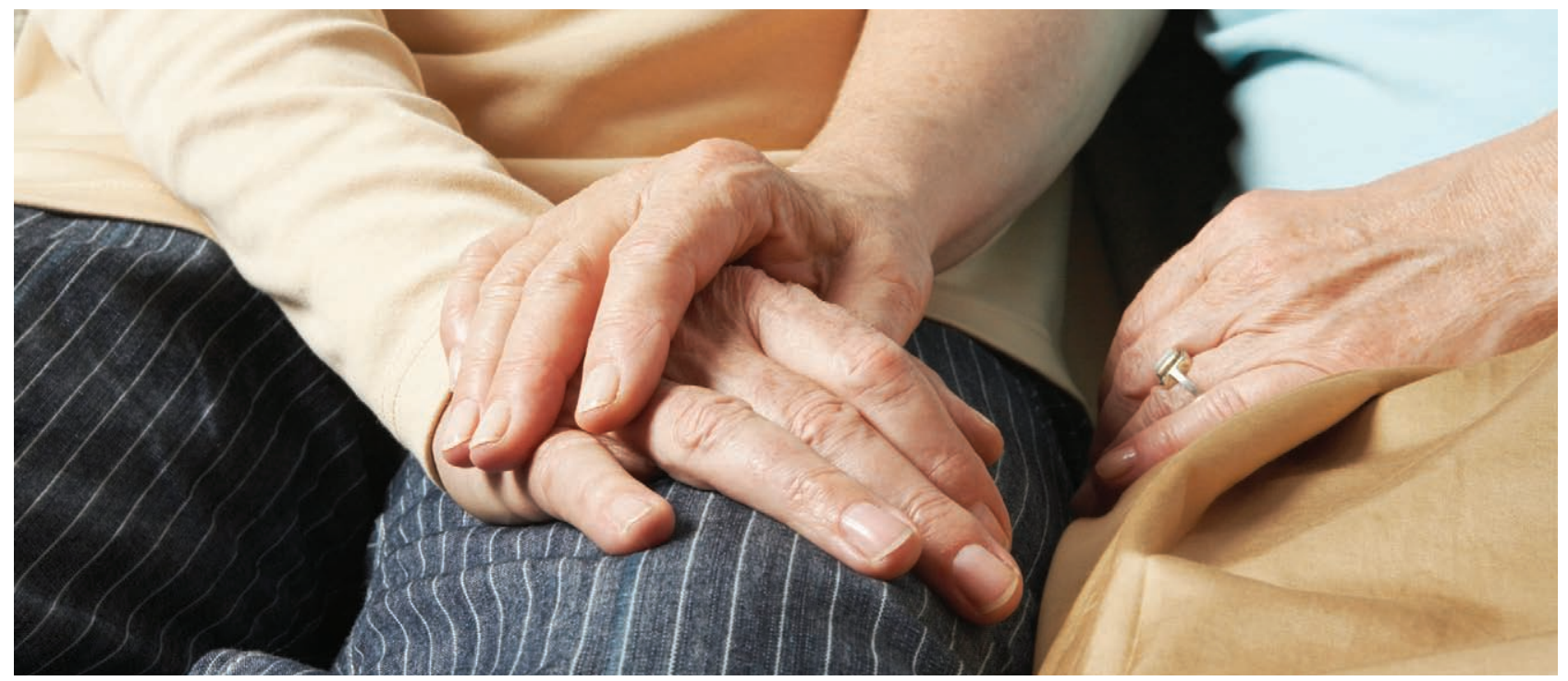

In this section we present the latest evidence on psychological factors and their relationship with dementia. We decided to focus specifically on depression and anxiety disorders, psychological distress (including personality traits as a proxy for this exposure), and sleep disorders. There are other potential psychological factors that are not covered in this section. We limited our review to those factors amenable of being targeted for prevention, and for which there is large enough literature that has neither been comprehensively nor recently reviewed.

\section{Depression}

\section{Introduction}

Depression is one of the most common mental conditions in adults. Its prevalence remains high throughout lifetime, with almost $14 \%$ of older adults living in the community estimated to have clinically relevant symptoms of depression ${ }^{1}$. It is associated with high levels of disability, reduced quality of life and adverse hospital outcomes ${ }^{2-5}$. The impact of depression on disability adjusted life-years (DALYs), a time-based measure that combines the sum of years lived with disability (in states of less than full health) and the years of lost life due to premature mortality, is greater than that of any other mental disorder ${ }^{6}$. Major depressive disorder was ranked as the $11^{\text {th }}$ leading contributor to the global burden of disease (GBD), but with some relevant geographical variations. For instance, it was ranked as high as third or fourth in Latin America, North Africa and the Middle East, Western Europe and Australasia ${ }^{7}$.

Cognitive disorders and depression often co-occur, however, the nature of this association is still not entirely understood. Various explanations for the association have been proposed, and these are summarised in Box 3.1.

Depression could be a consequence of dementia. Conversely, it may represent a very initial phase (or prodrome) of, or an independent risk factor, for dementia. It should also be noted that depression is highly co-morbid with a wide range of communicable and non-communicable chronic physical disorders ${ }^{14}$, and with other mental conditions, particularly anxiety, and alcohol and substance use disorders ${ }^{12,15}$.

Therefore, in assessing the independent contribution of depression to the incidence of dementia, it is important to control for the potential confounding effects of other associated conditions.

We will now summarise the evidence for depression as a risk factor for dementia.

\section{Evidence from the latest reviews}

In the last few years, several systematic reviews have been published which explore the relationship between depression and dementia; few among them focused specifically on epidemiological studies with a longitudinal design.

The two most recent systematic reviews and metaanalyses of longitudinal studies were published in 2013. One of these seems seriously flawed with few studies identified, faulty citation, incorrect application of inclusion and exclusion criteria, and incorrect data extraction ${ }^{16}$. The other, with a much stronger methodology, reported a pooled-analysis of the risk of depression in later life on incident dementia based on 23 studies, covering a total of 49,612 participants and with a median follow up of 5 years ${ }^{17}$. The OR (odds ratio, which quantifies the strength of association) pooled estimate from these studies was 1.85 (95\% 
Box 3.1

\section{How can we explain a relationship between depression and dementia?}

\section{Possible explanations include:}

Depression is the result of early cognitive deficits. Depressive symptoms may arise as a result of increasing awareness of diminishing cognitive function or in response to a diagnosis of dementia $^{8}$. This relationship could also arise from biological mechanisms (e.g. limbic and cortical atrophy, white matter lesions), which are common in both dementia and late onset depression ${ }^{9}$.

\section{Depression is a prodromal syndrome of} dementia. Depression may represent a predementia syndrome, which marks the beginning of an underlying disease process. The appearance of depression may then be driven by changes in brain structure and function that are part of the neuropathological course of dementia. In this case, symptoms of depression should appear just before or together with the onset of dementia ${ }^{10-12}$

\section{Depression is an independent risk factor} for dementia. Depression preceding dementia may be a causal risk factor for its onset. Several biological mechanisms have been proposed for such a relationship. These include depressionrelated predisposition to vascular disease, release of pro-inflammatory cytokines and chemokines, increased glucocorticoid production, amyloid deposition and neurofibrillary formation, all of which can lead to hippocampal injury ${ }^{9}$. For a detailed account of potential pathways to explain these relationships see Butters et $\mathrm{al}^{13}$.

Cl: 1.67-2.04). This study also reported a subanalysis, including only those studies that presented confounder-adjusted associations. The pooled risk of dementia was reduced, but still significant $(\mathrm{OR}=1.59$, 95\% Cl: 1.41-1.80).

Another systematic review, published in 2006, included 11 longitudinal studies and 9 case-control studies, and focused specifically on the risk of developing Alzheimer's disease as a function of having a diagnosed history of depression ${ }^{18}$. The overall OR was 2.02 with a $95 \%$ confidence interval of $1.80-2.26$.

\section{New studies (not included in previous systematic reviews)}

\section{Methods}

We carried out a literature search from February 2012, the latest date covered by the Diniz review ${ }^{17}$. We identified 1563 potential papers searching PubMed using the terms Depress* AND Dement* OR Cognition OR Alzheimer* in July 2014. Inclusion criteria were: 1- longitudinal cohort or case-control study design; 2study based in the community; 3-absence of dementia at the baseline assessment; 4- information on incident dementia; 5- information of the association reported by Odds or Hazard ratio with $95 \% \mathrm{Cl}$. We excluded studies which: 1- focused solely on Alzheimer's disease, vascular dementia or other dementia subtypes; 2- measured depression concomitantly with dementia; 3- assessed depression or depressive symptoms without using validated scales or clinical diagnoses.

We then carried out a random effect meta-analysis combining the new studies with those previously identified by Diniz and colleagues ${ }^{17}$. We logtransformed the unadjusted ORs or HRs (hazard ratios) and their $95 \% \mathrm{Cl}$ for each study, and then grouped all studies and meta-analysed them. Higgins $1^{2}$ test was used to measure the heterogeneity of the pooled estimate. A funnel plot was used to explore the possibility of publication bias, and a sensitivity analysis was carried out to estimate whether the pooled estimate was biased by the effect of any individual study by removing one study at a time and recalculating the pooled estimate each time. Finally, a meta-regression was conducted to explore the effect that publication year and length of follow up (the interval between ascertainment of depression among dementia free individuals, and the ascertainment of the outcome, dementia onset) had on the effect sizes for the association between depression and dementia onset.

\section{Results}

We identified 12 new studies that met our inclusion criteria. Their characteristics are reported in Table 3.1. These included three types of depression assessments: brief assessment scales (Geriatric Depression Scale - GDS - or the Centre for Epidemiologic Studies Depression Scale - CES-D), clinical diagnoses or ICD (International Classification of Diseases) codes on medical registers, or a combination of brief scale and clinical diagnoses.

All the included studies were carried out in high income countries (Europe, USA, and Hong Kong) and most controlled for potential confounding factors on the effect estimates. Depressive symptoms were associated with an increased risk of incident dementia in most studies, and most of these associations remained significant after adjustment for confounding variables, which in most cases were socio- 
Table 3.1

Study characteristics. * Effect size reported for adjusted models

\begin{tabular}{|c|c|c|c|c|c|c|c|c|c|c|c|c|}
\hline 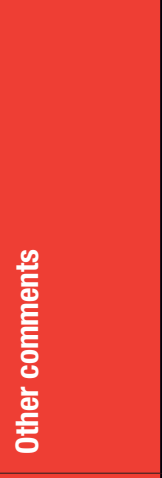 & 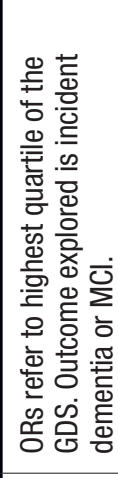 & 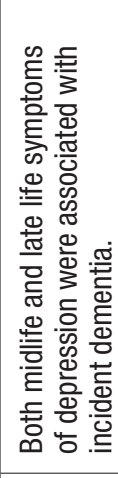 & 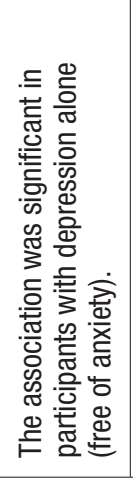 & & 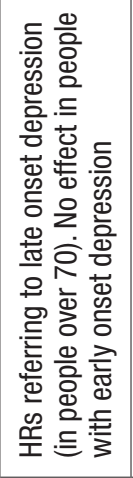 & 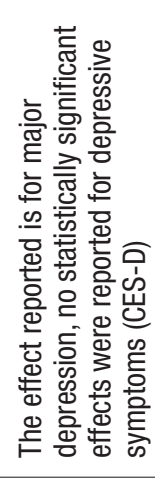 & 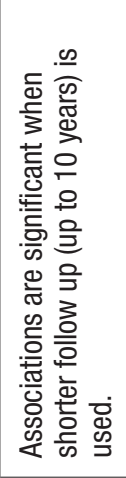 & 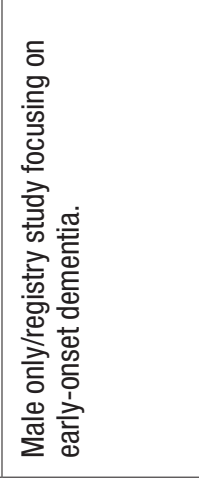 & & & 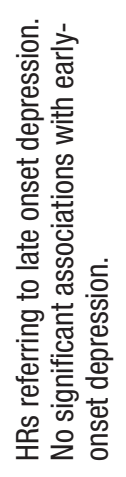 & \\
\hline $\begin{array}{l}\text { 号 } \\
\text { 兽 } \\
\text { 营 }\end{array}$ & 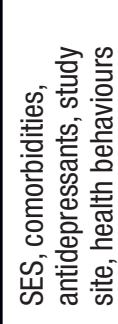 & 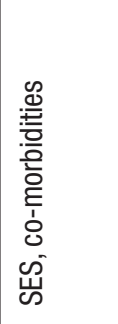 & 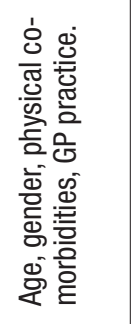 & 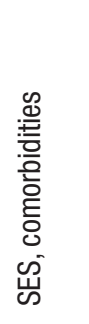 & 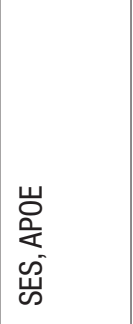 & 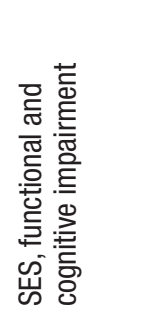 & 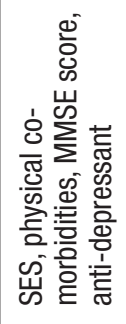 & 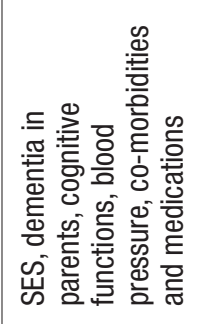 & 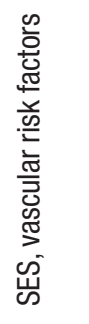 & ' & 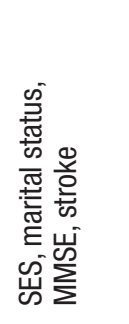 & 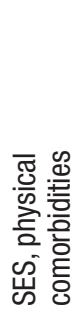 \\
\hline $\begin{array}{l}\text { 惫 } \\
\text { 言 }\end{array}$ & 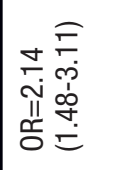 & 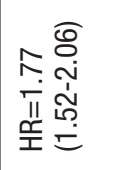 & 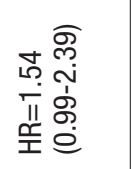 & 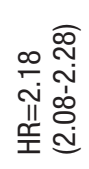 & 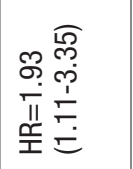 & 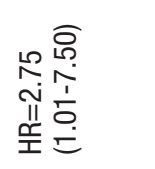 & 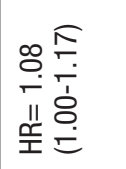 & 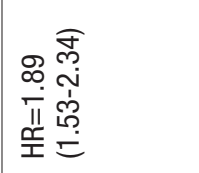 & 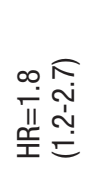 & 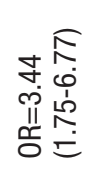 & 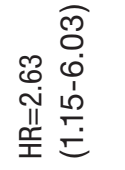 & 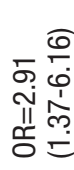 \\
\hline 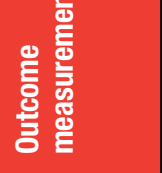 & $\sum_{\text {\& }}$ & 离 & 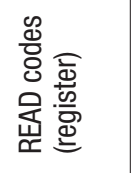 & 离 & 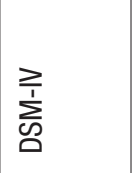 & $\sum_{\substack{1 \\
0}}^{3}$ & 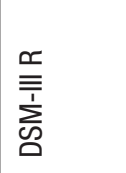 & 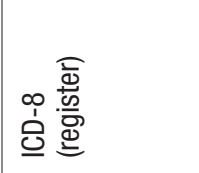 & 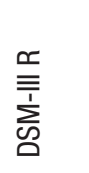 & 愛 & $\sum_{\substack{1 \\
0}}^{\geq}$ & $\sum_{\substack{i \\
0}}^{\geq}$ \\
\hline 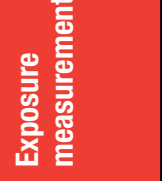 & 总 & 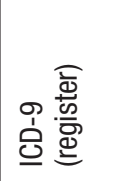 & 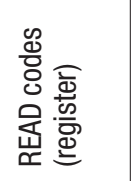 & 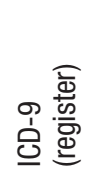 & 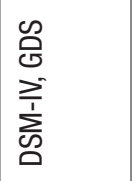 & 点 & 奌 & $\begin{array}{l}\infty \\
\grave{1} \\
\underline{0}\end{array}$ & $\begin{array}{l}\text { 点 } \\
\text { 岁 }\end{array}$ & 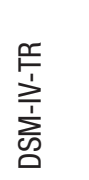 & $\sum_{\substack{1 \\
0}}^{\geq}$ & 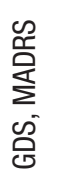 \\
\hline 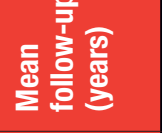 & $\stackrel{\sim}{\underset{\mathrm{N}}{*}}$ & 0 & $\begin{array}{l}\infty \\
0 \\
0 \\
0 \\
0\end{array}$ & $\stackrel{\Upsilon}{\sim}$ & $\stackrel{\llcorner}{+}$ & $\stackrel{m}{\sim}$ & $\stackrel{m}{m}$ & ले & to & $\sim$ & ما & $\stackrel{\vec{m}}{\dot{m}}$ \\
\hline 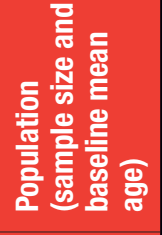 & 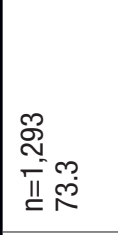 & 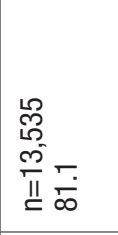 & 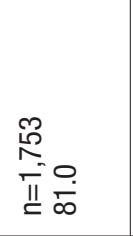 & $\begin{array}{l}\text { 早 } \\
\text { D. } \\
\text { o. } \\
\text { II } \\
\text { II }\end{array}$ & 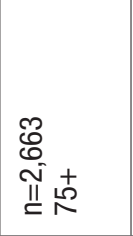 & 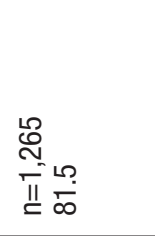 & 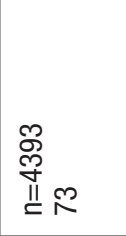 & 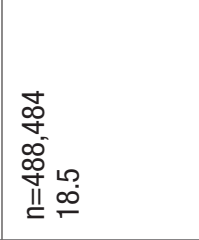 & 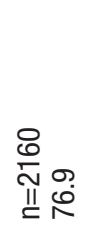 & ָֻ & 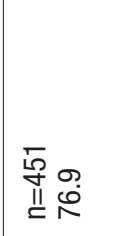 & $\begin{array}{l}\underset{N}{N} \infty \\
\stackrel{N}{I} \infty \\
\infty\end{array}$ \\
\hline 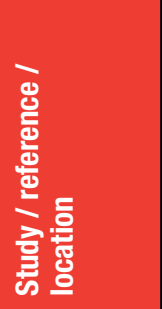 & 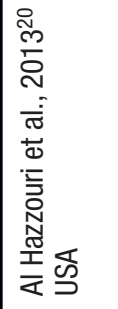 & 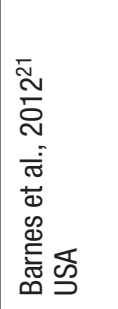 & 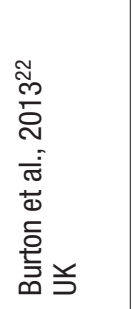 & 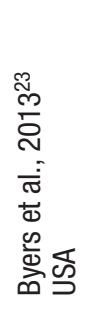 & 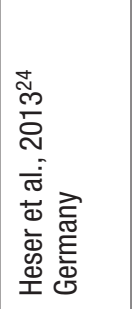 & 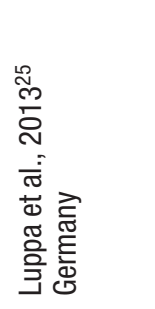 & 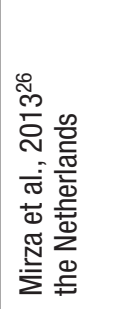 & 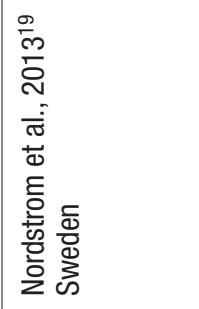 & 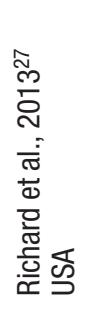 & 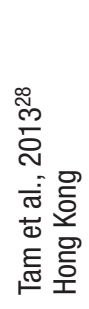 & 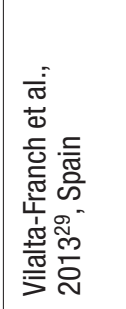 & 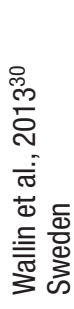 \\
\hline
\end{tabular}


demographic characteristics and physical co-morbid conditions. Most studies assessed depression in later life, with a mean age at baseline ranging from 69.7 to 88.8 years. The exception was a study that assessed depression in late male teenagers (mean age $=18.5$ ) as a risk factor for young-onset dementia ${ }^{19}$. Depression or antidepressant usage were reported to be the second most important risk factors for young-onset dementia (Population attributable risk $=0.28,95 \% \mathrm{Cl}$ : 0.09-0.28) in the 488,484 participants who were followed up through medical registers for a median of 37 years.

The results reported in four ${ }^{19,21-23}$ of the 12 newly identified studies were not included in our metaanalysis because the exposures and outcomes of interest were based on registry data only. This typically leads to the identification and inclusion of more severe cases, which may bias results and overestimate the true effect size. We were therefore able to synthesise evidence from 32 studies; the 24 included in an earlier review ${ }^{17}$ and the 8 further studies that we had identified were published subsequently. The total sample size of the 32 studies included in our meta-analysis was 62,598 participants, with a median follow up of 5 years (range $=2-17$ ). Those with depression or depressive symptoms at baseline were twice as likely to have experienced an onset of dementia by follow-up (pooled effect size 1.97, 95\% Cl 1.67-2.32) (Figure 3.1). On inspection of the funnel plot, there was no evidence of publication bias amongst the available studies.

In the sensitivity analyses, no single study had a significant influence on the overall estimate. We also found no significant differences when we stratified the analyses, either by year of publication or length of follow up. However, in the meta-regression, there was a non-significant trend for the association between depression and incident dementia to be weaker when the length of follow-up was longer (pooled effect size 1.97, 95\% Cl 1.67-2.32) (Figure 3.2). This is consistent with findings reported by Mirza and colleagues, who ran several statistical models for different interval times of follow up ${ }^{26}$, and found a higher risk of dementia onset associated with depression in studies with short and intermediate follow ups (up to 10 years), but no apparent effect beyond 10 years.

\section{Conclusions}

This review updates previously meta-analysed evidence ${ }^{17}$ on the relationship between depression and subsequent onset of dementia. The latest published studies seem consistent with earlier work, and accordingly strengthen the evidence that depression may increase dementia risk, with a pooled estimate of 1.97 (95\% Cl: 1.67-2.23). This is slightly higher than that of the most recent systematic review, which reported an effect size of 1.85 (95\% Cl: 1.67-2.04) ${ }^{17}$. Most studies, with only a few exceptions, reported positive associations, even after adjusting for potential confounding variables. Although we did not carry out a separate meta-analysis of the effect sizes from the
Figure 3.1

Meta analysis for the unadjusted effect of depression on the risk of incident dementia

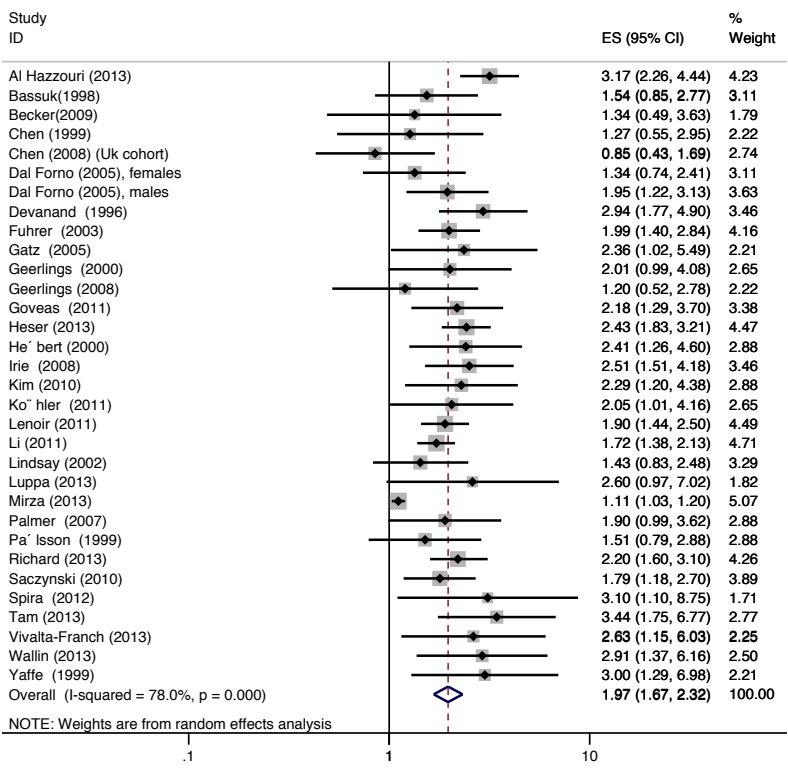

Figure 3.2

Meta regression exploring the effect of length of follow-up on the risk of incident dementia

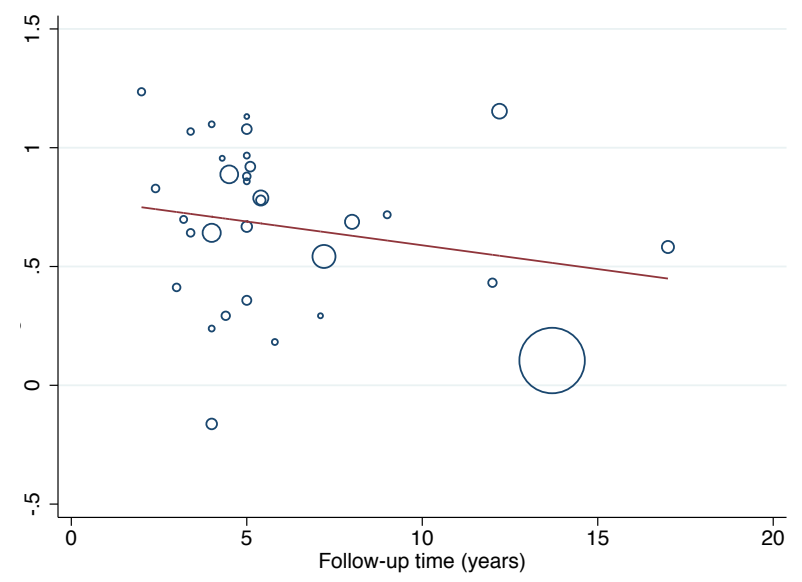

adjusted models, we would expect to find a similar magnitude of associations as found by Diniz and colleagues in their sensitivity analysis ${ }^{17}$.

While our analysis clarifies the strength of the association between depression and the subsequent onset of dementia, it still does not distinguish clearly between the two most plausible explanations for this association - that is, whether depression is a prodrome of dementia, or an independent causal risk factor. Unfortunately, as indicated in the meta-regression graph, relatively few studies (4 of 32) carried out follow-ups of longer than 10 years. There is a trend towards smaller effect sizes in studies with longer follow-up, which would be consistent with expectations if depression were part of the prodrome of dementia (a manifestation of neurodegenerative processes underlying dementia, or a consequence of the very 
early preclinical symptoms of cognitive impairment). The lack of statistical significance for the trend may be explained by lack of power to detect such an effect, given the paucity of studies with longer follow-up periods. Studies that have specifically focused on late-onset depression and explored latency in the onset of dementia reported positive associations only with shorter follow-ups, in line with the prodromal hypothesis ${ }^{26}$. A study that was not included in the meta-analysis as it was based on medical registers ${ }^{21}$ reported that the risk of dementia was increased in both people with midlife or late life symptoms, but that risk of Alzheimer's disease was only increased in participants with late-life depressive symptoms (whether or not in combination with midlife symptoms), but not in those with midlife symptoms alone.

The incidence and prevalence of depression may be reduced through population primary prevention ${ }^{31}$, and improved coverage of evidence-based pharmacological and psychological treatments should be effective in shortening episodes of depression and reducing relapse ${ }^{32-34}$. Whether more effective implementation of these strategies will be effective in slowing cognitive decline and reducing and delaying dementia onset is open to doubt. However, these approaches are rightly considered public health priorities, because of the individual and societal burden of depression. Also regardless of whether depression is an independent risk factor or a prodromal manifestation of dementia, depression is associated with increased disability, physical comorbidities and hospital costs, all of which worsen dementia prognosis.

\section{Anxiety disorders and dementia}

The relationship between anxiety disorders and dementia has been under-researched, particularly given the extensive co-morbidity with depression. Nevertheless we have tried to summarise what is known about this relationship below.

\section{What are anxiety disorders?}

The American Psychiatric Association describe anxiety as "the apprehensive anticipation of future danger or misfortune accompanied by feeling of dysphoria or somatic symptoms of tension"35. Anxiety disorders were introduced as a separate nosological group in the third edition of the Diagnostic and Statistical Manual of Mental Disorders (DSM) ${ }^{36}$. Anxiety disorders include panic disorders, agoraphobia, social phobias, specific phobias, generalised anxiety disorder, obsessive-compulsive disorder and post-traumatic stress disorder. Generalised anxiety disorder (GAD), the most common form of anxiety, is characterised by excessive anxiety and worry, occurring most days, about a number of events and activities. Anxiety has been associated with an increased risk of mortality ${ }^{37}$ and disability ${ }^{38}$.

\section{What is known about the relationship between anxiety and dementia?}

Few studies have explored the relationship between general anxiety and the future onset of dementia. In the Welsh Caerphilly prospective study, anxiety was measured in 1160 people aged between 48 and 67 who were followed up for 17 years ${ }^{39}$. Anxiety was associated with an increased risk of incident dementia at follow up $(\mathrm{OR}=2.89,95 \% \mathrm{Cl}: 1.27-6.54)$, but the relationship was not statistically significant after full adjustment for vascular risk factors, and general health. In a UK "case-control" study a diagnosis of anxiety was associated with a dementia diagnosis $(\mathrm{OR}=2.76,95 \% \mathrm{Cl}: 2.11-3.62)^{22}$, but anxiety comorbid with depression did not increase the risk of dementia, compared to having a diagnosis of anxiety alone. In the Rotterdam Study there was no significant association between dementia and either anxiety symptoms (HR=1.05, 95\% Cl: 0.77-1.43) or anxiety disorder $(\mathrm{HR}=0.92,95 \% \mathrm{Cl}: 0.58-1.45)^{40}$.

\section{Conclusions}

There is currently too little evidence on the relationship between anxiety and incident dementia to conclude whether this may be an independent risk factor. Further research is required, particularly exploring the impact of the extensive comorbidity with depression.

\section{Psychological distress: personality and life events}

\section{Introduction}

Psychological distress is a state or feeling of pressure or strain. Although some degree of arousal is usually considered to be beneficial, for instance to motivate and improve response to challenges and demanding situations, too much of it is invariably considered detrimental for health and wellbeing. Psychological distress is very common in most populations, and because it can be modified and improved with lifestyle, environmental and even pharmacological interventions, it may be a target for preventive strategies. The potential association of psychological distress with dementia and cognitive impairment may therefore have significant public health implications.

Acute stress, the 'fight-or-flight' response, is a positive adaptation evolutionarily linked to survival. It is mainly regulated by the involuntary part of the peripheral nervous system (specifically the sympathetic nervous system) that controls functions like heart rate and breathing, and mediated by catecholamines, which temporarily increase the delivery of oxygen and glucose to all tissues including the brain. Sustained psychological distress is accompanied by a more complex neuro-endocrine process regulated by the so-called 'HPA axis'. The hypothalamus $(\mathrm{H})$ initiates a cascade secreting a hormone (the corticotrophin releasing hormone, or $\mathrm{CRH}$ ) that stimulates the nearby 
pituitary gland $(\mathrm{P})$ to secrete a second hormone (the adrenocorticotropic hormone, or ACTH), to which the adrenal gland $(A)$ responds secreting glucocorticoids, mainly cortisol. Through cortisol, psychological distress may lead to a number of physiologic responses including vascular, metabolic and immunologic, and may impact health in various ways ${ }^{41,42}$. For instance, psychological distress is associated with worse cardiovascular risk profile, unhealthy adaptive/coping lifestyles ${ }^{43}$, and depressive symptomatology 44,45 . While these outcomes may in themselves be risk factors for dementia (as illustrated in other chapters of this report), psychological distress may also have a direct effect on dementia neuropathology 46,47 by impacting the structure and function of the hippocampus, a brain region rich in cortisol receptors ${ }^{48,49}$. The association of prolonged psychological distress with dementia seems therefore biologically plausible and may have significant public health implications because both exposure to stressors and stress itself may be reduced in populations and in individuals.

Indirect measures of sustained psychological distress may be used in epidemiological studies. For instance, self-reported exposure to stressors, negative life events and difficulties has been found to be associated with cognitive impairment and increased dementia risk in large population-based samples ${ }^{50,51}$. Investigators have also compared survivors of extremely physically and psychologically stressful circumstances in early life with suitable controls, for the outcomes of cognitive impairment and dementia in late life. Such studies, for example of holocaust and concentration camp survivors ${ }^{52}$, and Australian prisoners of war of the Japanese ${ }^{53}$, do not indicate any association with cognitive impairment or dementia in late-life. However, these negative findings may be explained by the ability to survive such extreme circumstances later conferring protection against frail ageing and neurodegeneration.

One of the problems of research in this area is that the duration and intensity of stressful experiences are difficult to measure. Moreover, psychological distress depends also on how and individual perceives and responds to life events when these occur ${ }^{42}$. This has led to an interest in personality as a proxy for individual lifelong proneness to experience psychological distress ${ }^{54}$. Individual perception and response to stressors are closely linked to personality, which encapsulates the stable behavioural, cognitive and emotional patterns of an individual. Cross-culturally validated personality questionnaires have been widely used in epidemiological studies, and measures of personality traits like neuroticism and agreeableness have been used in dementia research as proxies of the cumulative level of psychological distress experienced throughout life 55 .

In the next paragraphs we will summarise the available evidence from epidemiological studies that explored the prospective association of personality traits with subsequent risk of dementia or Alzheimer's disease.

\section{Available evidence from epidemiological studies}

\section{Personality}

Personality traits, which tend to remain stable throughout adult life, are assumed to capture individuals' 'proneness to psychological distress'55. Thus, people with higher scores of neuroticism (the tendency to experience negative emotions) are more likely to be exposed to stressors ${ }^{56}$, have less efficient coping strategies ${ }^{57}$, report greater personal distress in the face of difficulties ${ }^{58}$ and experience a higher number of negative life events ${ }^{59}$. They may, therefore, capture sustained psychological distress also in the absence of actual direct measures of lifelong exposure to life stressors and difficulties.

Questionnaires commonly used to assess personality in studies of dementia risk are illustrated in Box 3.2.

The Neuroticism Extraversion Openness Personality Inventory revised (NEO-PI-R), which profiles five dimensions that are considered to be the key personality types (neuroticism; extraversion; openness; agreeableness and conscientiousness) is the most widely used ${ }^{60}$. While definitions and measures vary across studies; the simple taxonomy of relevant personality traits presented in Box $\mathbf{3 . 3}$ is consistent with the studies presented below.

\section{Evidence from latest systematic reviews}

We retrieved only one systematic review of longitudinal studies on the association between personality and dementia/Alzheimer's disease. This was published in 2014 along with original results from the Baltimore Longitudinal Study of Aging (BLSA) ${ }^{64}$. The authors included in their meta-analysis the results of longitudinal studies that used the NEO-PI questionnaire to assess personality and that studied the incidence of Alzheimer's disease ${ }^{54,64-67}$. The main characteristics of the five included studies are reported in Table 3.2. Sample sizes in the studies included in the meta-analysis were between 648 and 1672, and follow-up years between assessment of personality and Alzheimer's diagnosis ranged between 3 and 12 years. Personality was generally assessed at the inception of the study, in late-life. The sole exception was the Baltimore Longitudinal Study on Aging where personality was assessed at a mean age of 57 years ${ }^{64}$. With the exception of extraversion, all of the personality traits were significantly associated with risk of Alzheimer's disease at follow-up. Namely, risk of Alzheimer's disease was 32\% higher for neuroticism, and 23, 14, 12 and 5\% lower for conscientiousness, openness, agreeableness and extraversion respectively.

The authors of the meta-analysis combined the reported estimates from the least adjusted models 
Box 3.2

Personality questionnaires frequently used in epidemiologic research

\begin{tabular}{|c|c|c|}
\hline Questionnaire name & $\begin{array}{l}\text { Number of items and } \\
\text { administration }\end{array}$ & Personality dimensions/traits measured \\
\hline $\begin{array}{l}\text { NEO Personality Inventory (NEO- } \\
\text { PI) (revised) }\end{array}$ & $\begin{array}{l}\text { Typically self-administered } \\
240 \text { items (long version) } \\
60 \text { items (short version) }\end{array}$ & $\begin{array}{l}\text { Six sub-facets for each of the five main domains (or factors) of } \\
\text { personality: Neuroticism (anxiety, angry hostility, depression, self- } \\
\text { consciousness, impulsiveness, vulnerability); } \\
\text { Extraversion (warmth, gregariousness, assertiveness, activity, } \\
\text { excitement seeking, positive emotions); Openness (fantasy, } \\
\text { aesthetics, feelings, actions, ideas, values); Agreeableness (trust, } \\
\text { straightforwardness, altruism, compliance, modesty, tender } \\
\text { mindedness); Conscientiousness (competence, order, dutifulness, } \\
\text { achievement striving, self-discipline, deliberation) }\end{array}$ \\
\hline $\begin{array}{l}\text { Eysenck Personality Inventory } \\
\text { (EPI-Q) }\end{array}$ & $\begin{array}{l}\text { Uni-dimensional self-report } \\
\text { questionnaire } \\
57 \text { items }\end{array}$ & Extraversion/introversion; Neuroticism/stability \\
\hline $\begin{array}{l}\text { Goldberg's adjective rating } \\
\text { scale }\end{array}$ & $\begin{array}{l}\text { Self- or administered to a next- } \\
\text { of-kin of the subject. } \\
100 \text { items (adjectives) }\end{array}$ & $\begin{array}{l}\text { Five personality traits ('Big-Five'): distress proneness; extraversion; } \\
\text { intellect; agreeableness; conscientiousness }\end{array}$ \\
\hline Cook-Medley Hostility Scale & $\begin{array}{l}\text { Self-administered } \\
50 \text { items }\end{array}$ & Hostility, and Cynical Distrust Scale (subset) \\
\hline
\end{tabular}

Box 3.3

Definitions of personality traits used in dementia epidemiologic studies

\begin{tabular}{|l|l|l|}
\hline Personality trait & Definition & Questionnaire \\
\hline Neuroticism & $\begin{array}{l}\text { Tendency to experience negative emotions like anxiety, anger } \\
\text { and sadness. }\end{array}$ & NEO-PI \\
\hline Extraversion & $\begin{array}{l}\text { Inclination towards being sociable, assertive, enthusiastic and } \\
\text { energetic. }\end{array}$ & NEO-PI \\
\hline Openness & $\begin{array}{l}\text { Tendency to be imaginative, unconventional, curious, and } \\
\text { emotionally and artistically sensitive. }\end{array}$ & NEO-PI \\
\hline Agreeableness & $\begin{array}{l}\text { Interpersonal dimension characterized by altruism, trust, } \\
\text { modesty and cooperativeness. }\end{array}$ & NEO-PI \\
\hline Conscientiousness & $\begin{array}{l}\text { Tendency to be organized, strong-willed, persistent, reliable, } \\
\text { followers of rules and ethical principles. }\end{array}$ & NE0-PI \\
\hline Hostility & $\begin{array}{l}\text { Negative orientation toward interpersonal dealings, including } \\
\text { cynicism, anger, mistrust, and aggression. }\end{array}$ & $\begin{array}{l}\text { Cook-Medley Scale or } \\
\text { Facets of the NE0-PI }\end{array}$ \\
\hline Cynical distrust & Belief that others are mainly motivated by selfish interests. & Sub-set of the Cook-Medley Scale \\
\hline
\end{tabular}

NEO-PI = Neuroticism Extraversion Openness Personality Inventory revised 55

and the pooled estimates are for the associations of each personality trait with risk of Alzheimer's disease not controlling for the other four personality traits. However, in the primary studies included in the metaanalysis the effects of depressive symptomatology, socio-demographic and health characteristics were minimal and the results did not change when personality measures were mutually adjusted for. This seems to support the interpretation that the association between personality and dementia/Alzheimer's disease may be direct, that is not mainly mediated by lifestyle and health characteristics, although these are independently related to both personality and dementia risk.

\section{Evidence from other studies}

Given the relatively narrow focus of this review, we conducted a further systematic review to identify studies of the prospective association between all relevant measures of personality and a wider range of outcomes; cognitive function or decline, dementia and Alzheimer's disease. We retrieved seven further publications that reported findings from six populationbased studies on the prospective association between personality and cognitive function or decline ${ }^{68-70}$, dementia ${ }^{71-74}$, and Alzheimer's disease ${ }^{70}$. We also identified three studies of the association of personality assessed in vivo with dementia-related 
Table 3.2

Characteristics of the studies included in Terraccianno et al.'s 2014 systematic review of longitudinal studies on personality and Alzheimer's disease

\begin{tabular}{|c|c|c|c|c|c|}
\hline $\mathscr{g}$ & 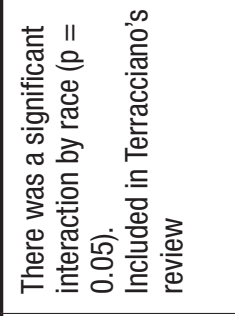 & 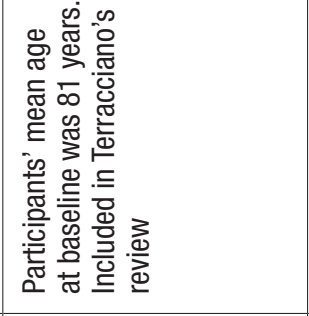 & 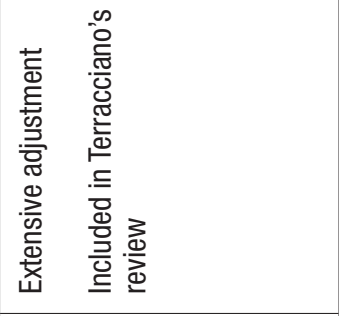 & 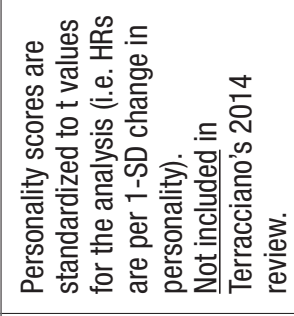 & 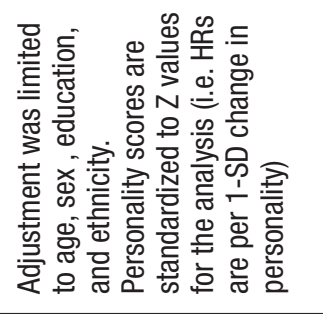 \\
\hline $\begin{array}{l}\text { 号 } \\
\text { 言 } \\
\text { 晋 } \\
\text { 돋 }\end{array}$ & 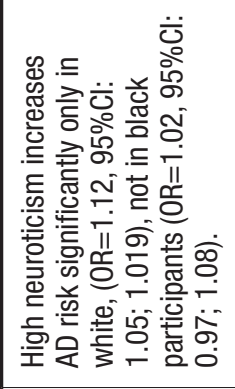 & 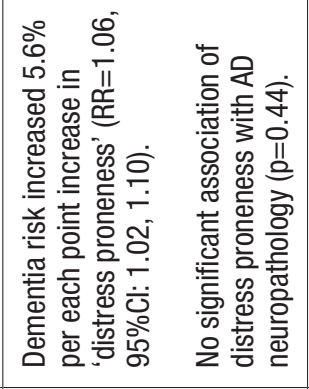 & 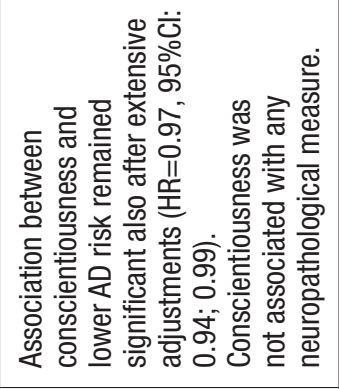 & 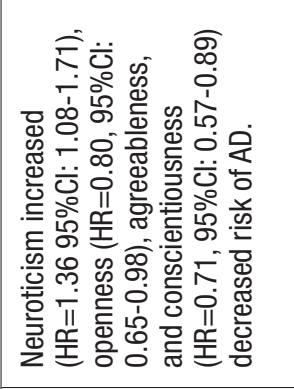 & 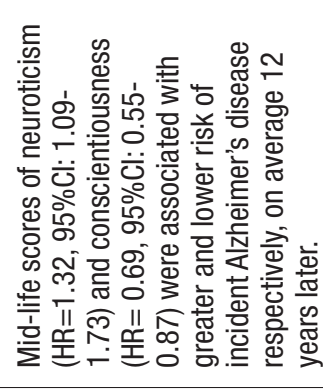 \\
\hline 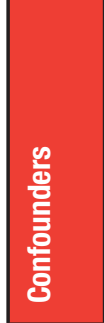 & 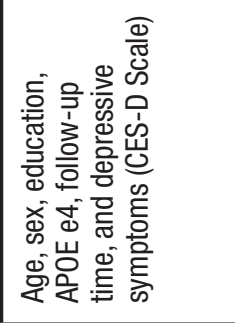 & 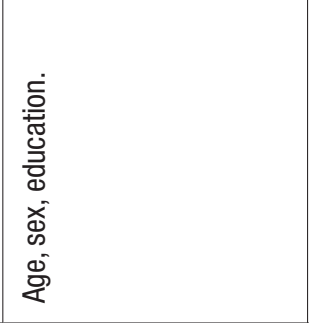 & 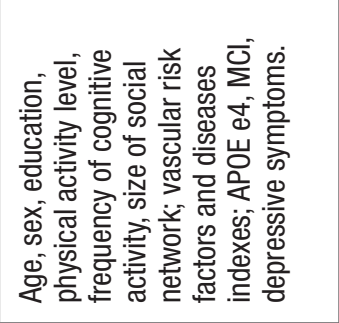 & 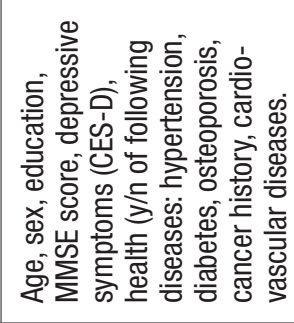 & 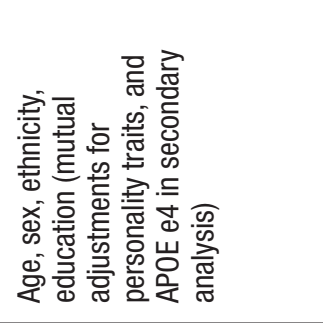 \\
\hline 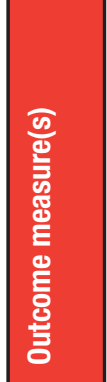 & 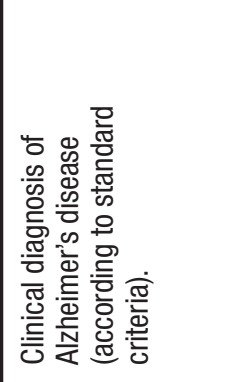 & 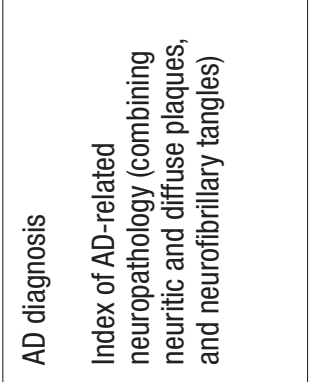 & 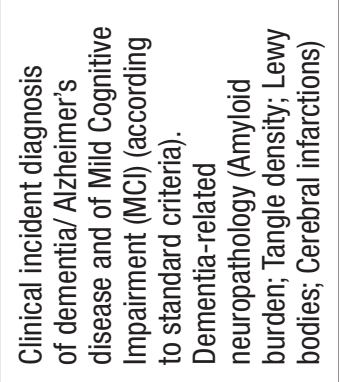 & 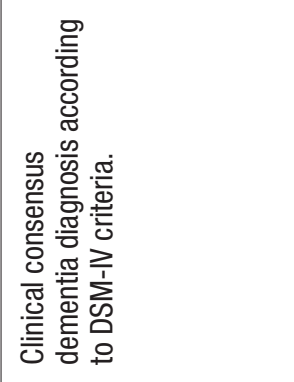 & 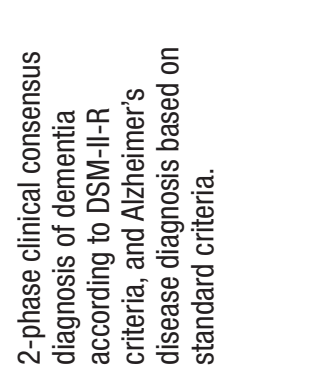 \\
\hline 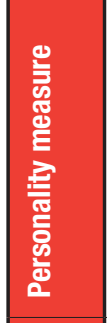 & 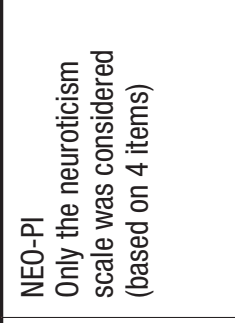 & 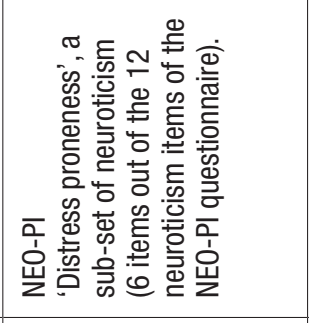 & 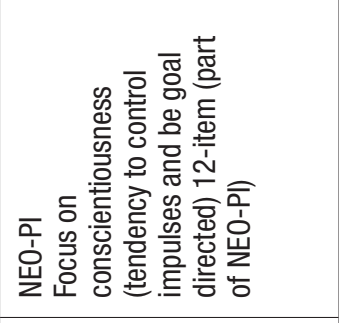 & 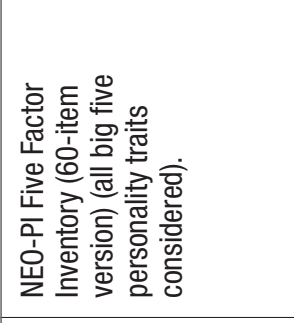 & 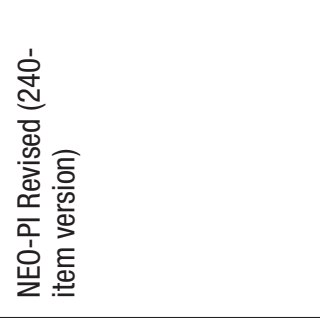 \\
\hline 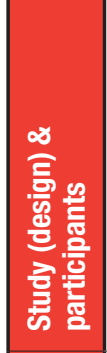 & 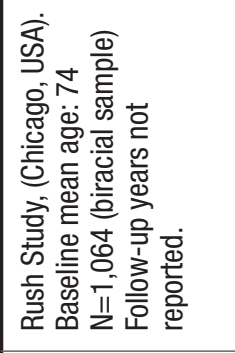 & 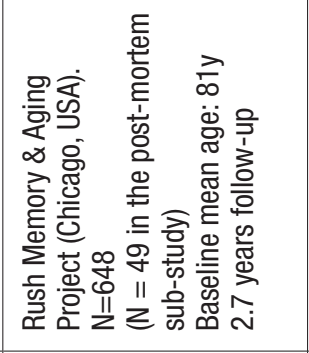 & 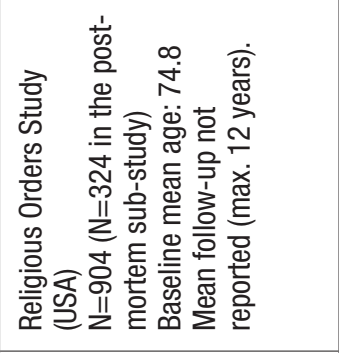 & 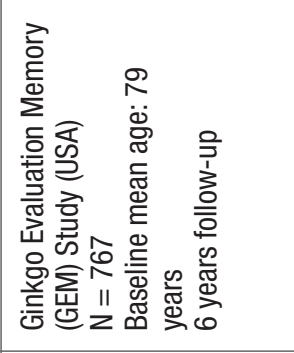 & 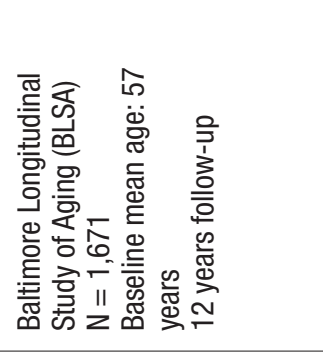 \\
\hline 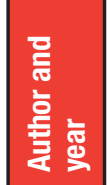 & 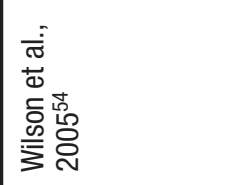 & 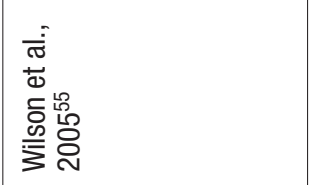 & 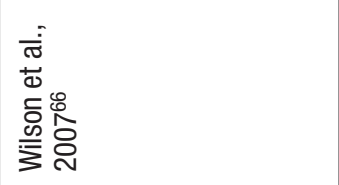 & 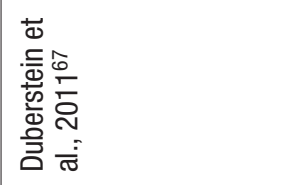 & 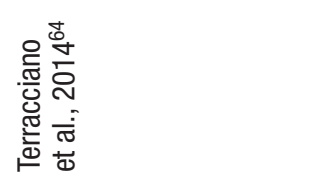 \\
\hline
\end{tabular}


Figure 3.3

Mid-life personality and risk of Alzheimer's disease (AD) in the Baltimore Longitudinal Study of Aging (BLSA) ${ }^{64}$ $(n=1,671)$. High neuroticism and low conscientiousness increased AD risk more than 12 years later

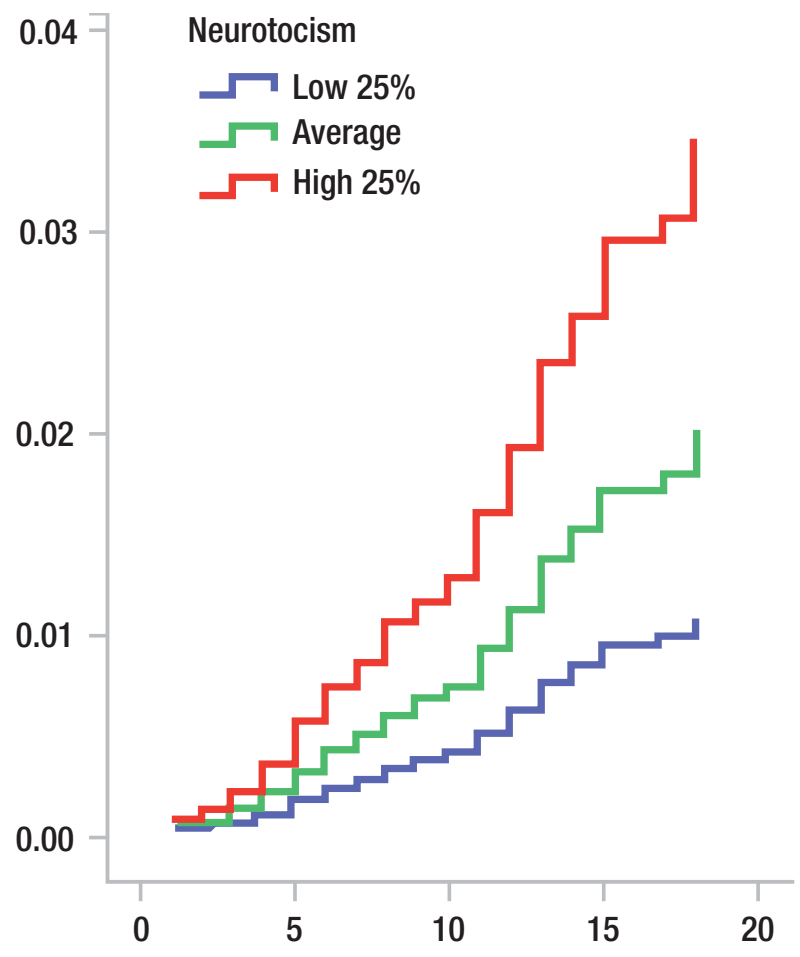

Time, years

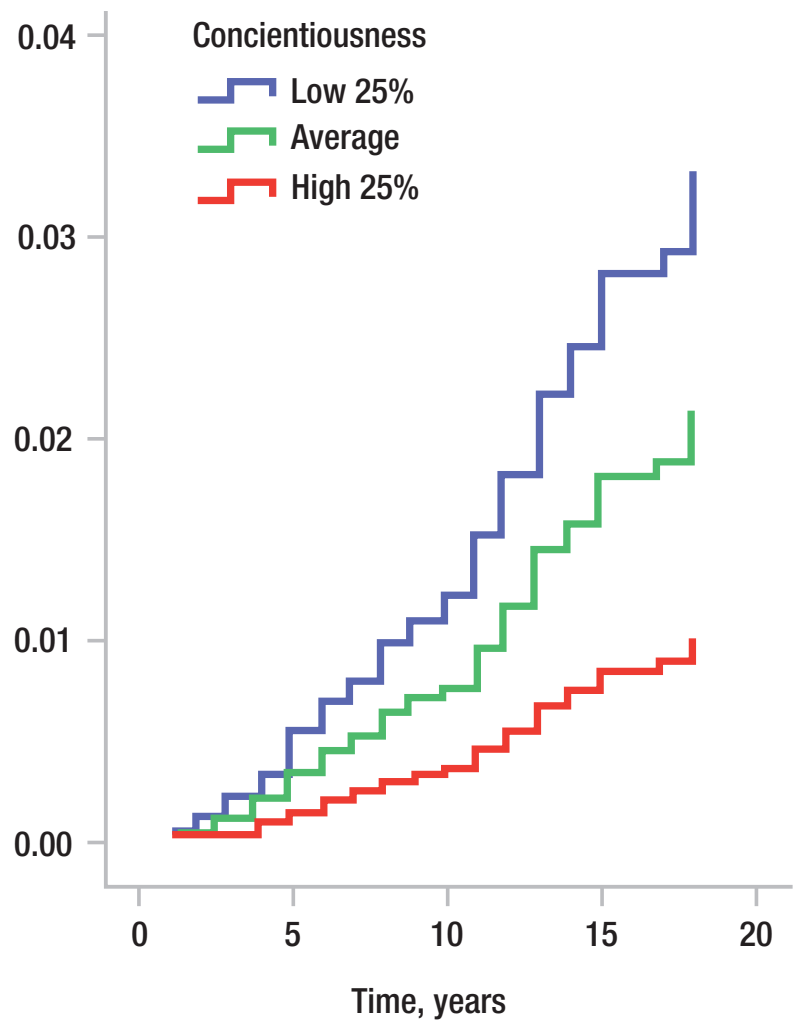

Cumulative hazard of incident Alzheimer's disease clinical dementia associated with the low 25\% and high $25 \%$ on neuroticism and conscientiousness, adjusted for age, sex, ethnicity and education. The group with average scores (25\%-75\%) was included in the analyses but is not shown in the figure. For neuroticism, the low $25 \%$ was $n=405$ and the high $25 \%$ was $n=436$. For conscientiousness, the low $25 \%$ was $n=422$ and the high $25 \%$ was $n=393$.

neurodegenerative lesions identified at autopsy post-mortem ${ }^{70-72}$.

The salient characteristics and main results of these studies are presented in Table 3.3.

These studies were conducted in Scandinavia (Sweden and Finland) ${ }^{68,73,74}$ and in the United States of America ${ }^{69-72}$. Samples sizes ranged from $219^{72}$ to $4,913^{69}$, and years of follow-up between assessment of personality and outcome ascertainment between $2.5^{72}$ and $25^{68}$

Neuroticism (also termed 'proneness to psychological distress'54), measured with the NEO-PI71 was the focus of the studies conducted in the USA ${ }^{70,72}$, except in the Chicago Health and Aging Project (CHAP) ${ }^{69}$ study where 'cynical distrust' was measured using a subset from the Coo-Medley Hostility Scale ${ }^{63}$. This scale was also used in the Cardiovascular Risk Factors, Aging and Dementia (CAIDE) Study in Scandinavia ${ }^{74}$. However, while in the CAIDE study the outcome was dementia diagnosis after 8.4 years of follow-up, in the CHAP study the main outcome measures were global cognitive function at baseline and cognitive decline over 4.4 years of follow-up. Cognitive decline over a 25-year period was the main outcome measure in the Swedish Twin Registry Study, in which neuroticism and extraversion measured with the Eysenck Personality Inventory (EPI-Q) ${ }^{61}$ were main predictors ${ }^{68}$. The EPI-Q was used also in the Kungsholmen Project in Stockholm (Sweden) with respect to risk of dementia after an average of 6 years.

The main findings of these additional studies are summarised in Table 3.3. The associations of all personality measures and risk of dementia/ Alzheimer's disease and cognitive decline were statistically significant, before and after adjustments for a large set of potential confounders and covariates. In addition to the consistency found, results from the available epidemiological studies seem to suggest that those with higher neuroticism or cynical distrust in combination with lower extraversion or conscientiousness may be at particulary high risk of developing dementia ${ }^{73}$, or experiencing more rapid cognitive decline ${ }^{68}$. This is clearly illustrated in Figure 3.3, from the BLSA study ${ }^{64}$.

Despite the consistency across studies in the observed link between personality and dementia risk, 
associations with dementia-related neurodegenerative lesions, including amyloid burden, neurofibrillary tangle density, Lewy bodies, and cerebral infarctions, were not significant before and after adjustments in all post-mortem studies conducted in subsamples of participants of the Religious Order Study and Rush Memory and Aging Project ${ }^{70-72}$.

\section{Conclusions}

Personality measures have been consistently found to be related to dementia. This body of evidence would support the hypothesis that higher psychological distress may increase dementia risk. However, the potential mechanisms underlying this association are yet to be understood because there is apparently no association between personality and dementia neuropathology. While the pattern of association with personality types is consistent with the hypothesis that prolonged exposure to psychological distress is the underlying causal mechanism, this has not been tested yet in randomised controlled trials that target psychological distress to reduce dementia risk.

There may be other non-causal explanations for the observed associations. Personality may be less stable than assumed. For example there is evidence that Neuroticism, Extraversion, and Openness may decline and Agreeableness and Conscientiousness increase with age, from college age to middle adulthood, across cultures $^{75}$. Personality is also markedly impacted by the emergence of symptoms of dementia and possibly dementia-related neuropathology, even prior to the clinical onset of the disease ${ }^{76}$. For instance the progressive reduction of hippocampal volume and alterations in its corticosteroid receptor composition may alter social behaviours and increase aggression ${ }^{77}$. As such, similarly to potential risk factors discussed in other chapters, associations between personality traits and dementia may be age-confounded, or accounted for by reverse causality (pre-clinical dementia leading to changes in personality) if personality is not assessed before old age and the follow-up time to dementia diagnosis is short. Only part of the available evidence comes from studies with long follow-ups and in which personality measures were assessed in mid-life.

In conclusion, at present the evidence remains insufficient to support interventions in the general population that target psychological distress to reduce dementia risk. However, smaller scale prevention programs may target very specific subgroups defined through personality assessment, which may have some value at an individual level.

\section{Sleep disorders}

Sleep disturbances are a collection of conditions strongly related to behavioural changes present in people with dementia. Symptoms such as increased time to fall asleep, increased number of awakenings, early awakening, diurnal naps and alterations in the circadian rhythm, which are commonly reported by older people, are exacerbated in people with dementia, leading to serious impairments in the quality of life of people with dementia and their caregivers. These are important risk factors for early institutionalisation ${ }^{78}$.

Evidence suggests that the relationship between sleep disturbances and dementia may in fact be bidirectional. Impairment of the neural pathways involved in the sleep-wake cycle caused by dementia might result in sleep disorders ${ }^{79}$; but the reverse is also possible, where sleep problems might also be a risk factor for cognitive decline ${ }^{80}$. Experimental evidence suggests various potential mechanisms; sleep disruption has been linked to abnormal myelin-related gene expression ${ }^{81}$, hippocampal neurogenesis and synapsis plasticity ${ }^{82}$ and neuronal susceptibility to ischaemic damage ${ }^{83}$. Also, the dynamics of amyloid- $\beta(A \beta)$ production and deposition, a key neuropathological feature of Alzheimer's disease that may contribute to neurocognitive decline, seems to be highly affected by acute and chronic sleep deprivation ${ }^{84,85}$. In wild-type mice and a mouse model of Alzheimer's disease, levels of $A \beta$ in brain interstitial fluid are increased during wakefulness and decreased during sleep. There is also some evidence in humans that shorter sleep duration and poorer sleep quality are associated with greater $A \beta$ burden, measured in vivo using ligands with positron emission tomography (PET) up to 5 years after selfreported sleep measures ${ }^{86}$.

It has been proposed that decreased sleep quality, especially in midlife where changes in sleep architecture are prominent, might increase neuronal activity and $A \beta$ release leading to an increased risk of amyloid plaque formation ${ }^{80}$. The deposition of amyloid plaques in regions of the central nervous system that control the sleep-wake cycle might in turn impair sleep quality. In addition, reduced sleep quality can itself contribute to the neurocognitive dysfunction present in symptomatic stages of Alzheimer's disease. In the late stages of the disease, environmental changes, such as institutionalisation and lack of regular daily activities including disrupted meals times and physical activity are also risk factors for reduced sleep quality ${ }^{80,87}$. This positive-feedback loop describes a series of events that may take place during the pathophysiology of Alzheimer's disease, highlighting the importance of behavioural treatments that involve sleep management, especially in the early stages of the disease. However, whether changes in the sleep-wake cycle contribute to, or reflect early stages in the development of Alzheimer's disease remains unclear.

Cross-sectional studies have reported that individuals showing particularly short or long sleep duration, and poor objective and subjective sleep quality, were more likely to have cognitive impairment and that these sleep disturbances were common among people with dementia ${ }^{88-91}$. Several longitudinal studies have also linked sleep disturbance with cognitive decline, most of which have used self-reported measures 
Table 3.3

Characteristics of epidemiological studies on the prospective association of personality traits with risk cognitive decline, dementia or Alzheimer's disease, and dementia-related neuropathology

\begin{tabular}{|c|c|c|c|}
\hline $\begin{array}{l}\text { Author and } \\
\text { year }\end{array}$ & Study (design) \& participants & Personality measure & Outcome measure(s) \\
\hline $\begin{array}{l}\text { Wilson et al., } \\
2003^{71}\end{array}$ & $\begin{array}{l}\text { Religious Orders Study (USA) } \\
\text { Baseline mean age: } 75 \\
\mathrm{~N}=800 \\
(\mathrm{~N}=141 \text { in the post-mortem sub- } \\
\text { study) } \\
4.9 \text { years follow-up }\end{array}$ & $\begin{array}{l}\text { NEO-PI } \\
\text { Only the Neuroticism trait was considered } \\
\text { (based on } 12 \text { items from the } 60 \text {-item } \\
\text { NEO-PI questionnaire). }\end{array}$ & $\begin{array}{l}\text { Clinical diagnosis of dementia/ Alzheimer's } \\
\text { disease (according to standard criteria) } \\
\text { AD-related neuro-pathology (global measure } \\
\text { of AD pathology combining neuritic and } \\
\text { diffuse plaques, and neurofibrillary tangles) }\end{array}$ \\
\hline $\begin{array}{l}\text { Crowe et al., } \\
2006^{68}\end{array}$ & $\begin{array}{l}\text { Swedish Twin Registry (middle } \\
\text { cohort) the Study of Dementia in } \\
\text { Swedish Twins } \\
\text { Baseline mean age: } \\
\mathrm{N}=4,039 \\
25 \text { years follow-up }\end{array}$ & $\begin{array}{l}\text { EPI-Q (18-item short version of the } \\
\text { Eysenck Personality Inventory) } \\
\text { Self-completed, mailed questionnaire. } \\
\text { Neuroticism and extraversion. }\end{array}$ & $\begin{array}{l}\text { Cognitive impairment (yes/no) based on the } \\
\text { pre-validated telephone-based cognitive } \\
\text { evaluation (TELE) assessment. }\end{array}$ \\
\hline $\begin{array}{l}\text { Wilson et al., } \\
2007^{66}\end{array}$ & $\begin{array}{l}\text { Religious Orders Study (USA) } \\
\mathrm{N}=219 \text { (all post-mortem) } \\
\text { Baseline mean age: not reported. } \\
\text { (mean age at death: } 88 \text { years) } \\
2.5 \text { years follow-up }\end{array}$ & $\begin{array}{l}\text { NEO-PI } \\
\text { Composite measure of 'chronic distress' } \\
\text { based on neuroticism (12 items from the } \\
\text { NEO-PI), anxiety Trait Sale (20-item State- } \\
\text { Trait Anxiety Inventory), and depressive } \\
\text { symptomatology (CES-D). }\end{array}$ & $\begin{array}{l}\text { Clinical diagnosis of dementia proximate to } \\
\text { death (according to standard criteria).. } \\
\text { Dementia-related } \\
\text { neuropathology (Amyloid burden; Tangle } \\
\text { density; Lewy bodies; Cerebral infarctions) }\end{array}$ \\
\hline $\begin{array}{l}\text { Barnes et al., } \\
2009^{69}\end{array}$ & $\begin{array}{l}\text { Chicago Health and Aging Project } \\
\text { Study (Chicago, USA). } \\
\text { (Biracial sample) } \\
\mathrm{N}=4,913 \\
\text { Baseline mean age: } 73 \text { years } \\
4.4 \text { mean follow-up }\end{array}$ & $\begin{array}{l}\text { 'Cynical Distrust Scale' (8 item scale part } \\
\text { of the Cook-Medley Hostility Scale). } \\
\text { CES-D } \\
\text { Leisure activities } \\
\text { Social engagement } \\
\text { Social network size } \\
\text { Chronic diseases. }\end{array}$ & $\begin{array}{l}\text { DSST } \\
\text { Memory (East Boston Story) } \\
\text { MMSE } \\
\text { (Z-scores averaged to a composite score, } \\
\text { cognitive decline in the analysis). }\end{array}$ \\
\hline $\begin{array}{l}\text { Wang et al., } \\
2009^{73}\end{array}$ & $\begin{array}{l}\text { Kungsholmen Project, (Stockholm, } \\
\text { Sweden) } \\
\mathrm{N}=506 \\
\text { Baseline mean age: } 83 \text { years } \\
6 \text { years follow-up }\end{array}$ & $\begin{array}{l}\text { Eysenck Personality Inventory (EPI). } \\
57 \text {-item scale for } \\
\text { Neuroticism and } \\
\text { Extraversion }\end{array}$ & $\begin{array}{l}\text { 3-step diagnostic procedure. } \\
\text { Clinical consensus dementia diagnosis } \\
\text { according to DSM-II-R (integrated by hospital } \\
\text { records and death certificates) }\end{array}$ \\
\hline $\begin{array}{l}\text { Wilson et al., } \\
2011^{70}\end{array}$ & $\begin{array}{l}\text { Rush memory and aging project } \\
\text { (Chicago, USA) } \\
\mathrm{N}=785 \text { (N=156 for the post- } \\
\text { mortem study). } \\
\text { Baseline mean age: } 81 \text { years } \\
3.4 \text { years follow-up }\end{array}$ & $\begin{array}{l}\text { NEO-PI Revised (240-item version) } \\
\text { Neuroticism ( } 48 \text { items), and its six facets } \\
\text { (anxiety; depression; self-consciousness; } \\
\text { impulsiveness; vulnerability) }\end{array}$ & $\begin{array}{l}\text { Extensive neuro-psychological tests scores, } \\
\text { standardized, averaged to five domains } \\
\text { composite and a global cognition measures. } \\
\text { Clinical diagnosis of dementia and } \\
\text { Alzheimer's disease (according to standard } \\
\text { criteria) } \\
\text { Dementia-related } \\
\text { neuropathology (Amyloid burden; Tangle } \\
\text { density; Lewy bodies). }\end{array}$ \\
\hline $\begin{array}{l}\text { Neuvonen et } \\
\text { al., } 2014^{74}\end{array}$ & $\begin{array}{l}\text { Cardiovascular Risk Factors, Aging } \\
\text { and Dementia (CAIDE) Study } \\
\mathrm{N}=622 \\
\text { Age: } 65 \text { to } 79 \text { years } \\
8.4 \text { years follow-up }\end{array}$ & $\begin{array}{l}\text { 'Cynical Distrust Scale' (8 item scale part } \\
\text { of the Cook-Medley Hostility Scale). }\end{array}$ & $\begin{array}{l}\text { 3-phase clinical diagnosis of Dementia } \\
\text { according to DSM-IV criteria }\end{array}$ \\
\hline
\end{tabular}


Sex, age and education, depressive symptoms (CES-D Scale)
Distress proneness (neuroticism) increased risk of AD (HR=1.05, 95\% Cl: 1.01-1.08).

Neuroticism was not associated with AD-pathology
Lifestyle or health characteristics were not adjusted for.

Not included in Terracciano's review.

High education: $18 \mathrm{y}+$
Age, sex, education, smoking, alcohol, self-reported health status.

Higher neuroticism ( $\mathrm{HR}=1.07,95 \% \mathrm{Cl}$ : 1.01-1.14) and lower extraversion ( $\mathrm{HR}=0.72 ; 95 \% \mathrm{Cl}$ : 0.50 -

1.01) were associated with cognitive impairment 25 years later.

The combination of high neuroticism/high extraversion conferred the highest risk ( $\mathrm{HR}=1.97$, $95 \%$ Cl: $1.30 ; 2.99)$.

Age at death, sex, education, and all indices of neuropathology.

Chronic distress (composite measure)

(OR=1.71, 95\% Cl: $1.20-2.44)$, neuroticism
$(\mathrm{OR}=1.08,95 \% \mathrm{Cl}: 1.03-1.14)$, trait anxiety

$(\mathrm{OR}=1.19,95 \% \mathrm{Cl}: 1.08-1.30)$ and depressive symptoms ( $\mathrm{OR}=1.42,95 \% \mathrm{Cl}: 1.12-1.80$ ) were all significantly associated with dementia proximate to death.

Age, sex, race, education, SES, depressive symptoms (CES-D), neuroticism (4 items from the NEO$\mathrm{PI})$, cognitive stimulating activities, social engagement, social network size, chronic diseases (hypertension, heart disease, diabetes, cancer, thyroid disease, stroke) cognition at baseline $[\beta=-0.025$ (SE: 0.004) $(p<0.001)]$

Hostility was not association with cognitive decline $[\beta=-0.001$ (SE: 0.001) $(p=0.29)]$
Hostility was negatively associated with global
The outcome was not dementia, but significant cognitive impairment.

Personality was assessed in mid-life 25 years prior to cognitive assessment.

Not included in Terracciano's review

Associations between chronic stress and dementia were independent of indices of neuropathology. Not included in Terracciano's 2014 review.

The outcome is cognitive decline in old age not dementia/ AD diagnosis.
Age, sex, education, APOE e4, cognitive functioning, vascular diseases, depressive symptoms.

Neither neuroticism nor extraversion increased dementia risk.

However, low neuroticism in combination with high extraversion was protective ( $70 \%$ less; $\mathrm{HR}=0.33$, $95 \% \mathrm{Cl}: 0.12-0.90$ ), as it was amongst those with an inactive or socially isolated lifestyle $(50 \%$ risk reduction; $\mathrm{HR}=0.51,95 \% \mathrm{Cl}$ : 0.27-0.96)

\section{Age, sex and education.}

Anxiety (HR=1.05, 95\% Cl: 1.01-1.09) and
Vulnerability ( $\mathrm{HR}=1.06,95 \% \mathrm{Cl}: 1.01-1.12)$ were associated with greater risk of Alzheimer's disease. Overall personality measures were not associated with cognitive decline.

All associations with dementia-related Neuropathology were null.

Those in the top tertile of cynical distrust had greater dementia risk ( $\mathrm{RR}=3.07,95 \% \mathrm{Cl}$ : 1.11 8.50) compared to those in the lowest tertile; the association was attenuated and close to statistical significance after adjustment for depressive symptoms ( $\mathrm{RR}=1.90,95 \% \mathrm{Cl}: 0.97-8.70$ ). Cynical distrust was not associated with mortality after adjustment.
Not included in Terracciano's 2014 review.

Adjustment was limited to age, sex and education. Not included in Terracciano's 2014 review.
Age, sex, SBP, serum total cholesterol, plasma glucose, $\mathrm{BMI}$, retirement status and educational level, smoking, alcohol, self-reported health, MMSE APOE (model 4).

Depressive symptoms (Beck Depression Inventory) in sensitivity analysis. 
of sleep disturbance, the most common being sleep duration ${ }^{91-95}$. Long sleep duration ( $>8 \mathrm{hrs}$ ) was associated with cognitive decline in a study with a one year follow up period ${ }^{94}$ and also in a study with a much longer follow up period of more than 20 years ${ }^{95}$. However, results have been inconsistent in other studies. For example, in a three year longitudinal study only substantial increase of sleep duration from baseline to follow up was associated with cognitive impairment ${ }^{96}$, and in a large cohort study of older women there was no association between snoring, sleep duration or any other sleep variables and cognitive decline over two years, although shorter sleep duration was associated with cognitive impairment at baseline ${ }^{91}$.

More recently, there have been a growing number of longitudinal studies looking at the association between sleep disturbances and the onset of dementia ${ }^{97-104}$. Despite the variety of measures used for sleep disturbances at baseline, in contrast with studies of cognitive decline, findings have been more consistent with an increased dementia risk. In a study of 2,346 Japanese American men aged 70 and over followed up for 3 years, there was no association between insomnia and incident dementia ${ }^{105}$; however participants with excessive daytime sleep at baseline had an increased risk of dementia at follow up. Taiwan's Longitudinal Health Insurance Database was used to identify all 5693 older people with a first diagnosis of insomnia from 2002 to 2007, and an age and sex matched comparison cohort of 28,465 people without insomnia. After adjusting for hypertension (high blood pressure), diabetes mellitus, hyperlipidaemia (high cholesterol), and stroke, those with long-term insomnia had significantly higher risks of dementia $(\mathrm{HR}=2.34$, 95\% Cl: 1.92-2.85). Patients with longterm insomnia and aged 50 to 65 years had a higher increased risk of dementia (HR=5.22, 95\% Cl: 2.62$10.41)$ than those older than 65 years $(H R=2.33,95 \%$ $\mathrm{Cl}$ : 1.90-2.88), and risk was further elevated for those taking hypnotics ${ }^{98}$. The Survey of Health Ageing and Retirement in Europe (SHARE study) ${ }^{102}$, conducted in several western Europe countries, also found a positive association of several self-reported measures of sleep disturbances, and the use of sleeping pills with increased risk of self-reported diagnosis of dementia and Alzheimer's disease at 4 years follow-up. Although most such studies rely on self-report of sleep disturbance, a few have used direct measures such as actigraphy ${ }^{101,103}$ or polissonagraphy ${ }^{104}$ and consistently found increased risk of mild cognitive impairment and/ or dementia among those with sleep disturbance.

The use of sleeping pills has been associated with an increased risk of dementia in several studies. However those studies in which the use of sleeping pills was accounted for in the analysis ${ }^{94-96,98,99}$, still found a strong association between sleep disturbance and dementia.
Sleep-disordered breathing, which is present in obstructive sleep apnoea syndrome (OSAS), a disorder affecting more than $60 \%$ of people aged over $60^{106}$, may also be a risk factor for dementia ${ }^{104}$, although there is evidence that this might operate through hypoxia and inflammation related mechanisms, predisposing particularly to vascular dementia. For instance, in a 10-year follow up study of 1986 males in the UK, excessive daytime sleepiness and restless legs syndrome predicted vascular dementia but not nonvascular sub-types of dementia ${ }^{99}$.

Insomnia symptoms are highly prevalent among people with depression, with three in four depressive patients reporting insomnia symptoms. Hypersomnia (excessive sleep) seems to be highly prevalent in people with depression, especially among women ${ }^{107,108}$. Depression has also been associated with increased risk for dementia ${ }^{109}$ and might be a confounder in the association between sleep disturbances and cognitive decline and dementia (see section above). A 3 year follow up study of 6444 people aged 65 and over found that depression was associated with cognitive decline, independently of self-reported insomnia at baseline, but insomnia was not associated with cognitive decline independently of depression ${ }^{92}$. In another recent study from Sweden ${ }^{100}$, the association between self-reported sleep problems and incident dementia was no longer apparent after adjusting for depressive symptoms. Alternatively, sleep disturbance might mediate the association between depression and dementia (depression causing sleep disturbance, causing dementia), or vice versa.

The cohort studies looking at sleep disturbances and dementia risk have varied substantially regarding the population studied (Japanese Americans ${ }^{105}$, only male ${ }^{99}$, only females $\left.{ }^{103}\right)$, studied a range of indicators of sleep disturbance (sleep-disordered breathing, nocturnal sleep duration, daily sleep duration, snoring, apnoea), and had different follow-up periods, although none of them may have been long enough to ensure that sleep disturbances had preceded the development of Alzheimer's disease pathology, which is thought to begin 10 to 15 years or more before the onset of the clinical symptoms. Therefore, despite the mechanistic evidence in animal models relating sleep loss and amyloid- $\beta$ production and deposition, it is still not clear whether changes in sleep are a cause or consequence of dementia and the underlying brain pathology that may precede its onset. The lack of well-designed long-term longitudinal studies, and the variety of sleep disturbance measures previously used, are important limiting factors which make it difficult to establish clearly whether sleep disturbance in early life increases the risk of late onset dementia. 


\section{Overall conclusions}

In this chapter we have reviewed the relationship between psychological factors and the onset of dementia. The majority of studies have focused on depression and sleep disorders, even though there is growing evidence regarding psychological distress.

In the meta-analysis we carried out, we found a positive association between depression and the onset of dementia, which is consistent within most of the literature. It is however not clear whether this is due to depression being a prodrome of dementia or an independent risk factor. There is more uncertainty as to whether sleep disorders are linked to the onset of dementia, as the majority of the studies are cross-sectional or have a relatively short-follow up time. There is also insufficient evidence to support any intervention targeting psychological distress to reduce the risk of dementia. Only a couple of studies have focused on anxiety disorders, and it is therefore difficult to meaningfully interpret and contextualise the results of these studies.

What transpires from this chapter is that more research is needed, in particular on the relationship between anxiety, sleep disorders and dementia, but also on the potential impact of mid-life psychological interventions to reduce risk or delay the onset of dementia. Although the effect of these interventions on dementia risk is not clear, addressing psychological problems throughout the life course is nonetheless of public health importance, as the social, medical and financial burden of these conditions is extremely high.

\section{References}

1 Beekman AT, Copeland JR, Prince MJ. Review of community prevalence of depression in later life. The British journal of psychiatry : the journal of mental science 1999; 174: 307-11.

2 Guerra M, Ferri CP, Sosa AL, et al. Late-life depression in Peru, Mexico and Venezuela: the 10/66 population-based study. The British journal of psychiatry : the journal of mental science 2009; 195(6): 510-5.

3 Ay-Woan P, Sarah CP, Lyinn C, Tsyr-Jang C, Ping-Chuan H. Quality of life in depression: predictive models. Quality of life research : an international journal of quality of life aspects of treatment, care and rehabilitation 2006; 15(1): 39-48.

4 Prina AM, Huisman M, Yeap BB, et al. Hospital costs associated with depression in a cohort of older men living in Western Australia. General hospital psychiatry 2014; 36(1): 33-7.

5 Prina AM, Huisman M, Yeap BB, et al. Association between depression and hospital outcomes among older men. CMAJ : Canadian Medical Association journal = journal de l'Association medicale canadienne 2013; 185(2): 117-23.

6 Ferrari AJ, Charlson FJ, Norman RE, et al. Burden of depressive disorders by country, sex, age, and year: findings from the global burden of disease study 2010. PLoS medicine 2013; 10(11): e1001547.

7 Murray CJ, Vos T, Lozano R, et al. Disability-adjusted life years (DALYs) for 291 diseases and injuries in 21 regions, 1990-2010: a systematic analysis for the Global Burden of Disease Study 2010. Lancet 2012; 380(9859): 2197-223.

8 Jajodia A, Borders A. Memory Predicts Changes in Depressive Symptoms in Older Adults: A Bidirectional Longitudinal Analysis. J Gerontol B-Psychol 2011; 66(5): 571-81.

9 Bennett S, Thomas AJ. Depression and dementia: Cause, consequence or coincidence? Maturitas 2014.

10 Boland RJ. Depression in Alzheimer's disease and other dementias. Current psychiatry reports 2000; 2(5): 427-33.

11 Wulsin LR, Singal BM. Do depressive symptoms increase the risk for the onset of coronary disease? a systematic quantitative review. Psychosomatic medicine 2003; 65: 201-10.

12 Prina AM, Ferri CP, Guerra M, Brayne C, Prince M. Co-occurrence of anxiety and depression amongst older adults in low- and middle-income countries: findings from the 10/66 study. Psychological medicine 2011; 41(10): 2047-56.

13 Butters MA, Young JB, Lopez O, et al. Pathways linking late-life depression to persistent cognitive impairment and dementia. Dialogues in clinical neuroscience 2008; 10(3): 345-57.

14 Prince M, Patel V, Saxena S, et al. No health without mental health. Lancet 2007; 370: 859-77.

15 Kessler RC, Birnbaum HG, Shahly V, et al. Age differences in the prevalence and co-morbidity of DSM-IV major depressive episodes: results from the WHO World Mental Health Survey Initiative. Depress Anxiety 2010; 27(4): 351-64.

16 Gao Y, Huang C, Zhao K, et al. Depression as a risk factor for dementia and mild cognitive impairment: a meta-analysis of longitudinal studies. International journal of geriatric psychiatry 2013; 28(5): 441-9.

17 Diniz BS, Butters MA, Albert SM, Dew MA, Reynolds CF, 3rd. Late-life depression and risk of vascular dementia and Alzheimer's disease: systematic review and meta-analysis of community-based cohort studies. The British journal of psychiatry : the journal of mental science 2013; 202(5): 329-35.

18 Ownby RL, Crocco E, Acevedo A, John V, Loewenstein D. Depression and risk for Alzheimer disease - Systematic review, meta-analysis, and metaregression analysis. Archives of general psychiatry 2006; 63(5): 530-8.

19 Nordstrom P, Nordstrom A, Eriksson M, Wahlund LO, Gustafson $Y$. Risk factors in late adolescence for young-onset dementia in men: a nationwide cohort study. JAMA internal medicine 2013; 173(17): 1612-8.

20 Zeki Al Hazzouri A, Vittinghoff E, Byers A, et al. Long-term cumulative depressive symptom burden and risk of cognitive decline and dementia among very old women. The journals of gerontology Series A, Biological sciences and medical sciences 2014; 69(5): 595-601.

21 Barnes DE, Yaffe K, Byers AL, McCormick M, Schaefer C Whitmer RA. Midlife vs late-life depressive symptoms and risk of dementia: differential effects for Alzheimer disease and vascula dementia. Archives of general psychiatry 2012; 69(5): 493-8. 
22 Burton C, Campbell P, Jordan K, Strauss V, Mallen C. The association of anxiety and depression with future dementia diagnosis: a case-control study in primary care. Family practice 2013; 30(1): 25-30.

23 Byers AL, Covinsky KE, Barnes DE, Yaffe K. Dysthymia and depression increase risk of dementia and mortality among older veterans. The American journal of geriatric psychiatry : official journal of the American Association for Geriatric Psychiatry 2012 20(8): 664-72.

24 Heser K, Tebarth F, Wiese B, et al. Age of major depression onset, depressive symptoms, and risk for subsequent dementia: results of the German study on Ageing, Cognition, and Dementia in Primary Care Patients (AgeCoDe). Psychological medicine 2013 43(8): 1597-610.

25 Luppa M, Luck T, Ritschel F, Angermeyer MC, Villringer A, Riedel-Heller SG. Depression and incident dementia. An 8-year population-based prospective study. PloS one 2013; 8(3): e59246.

26 Mirza SS, de Bruijn RF, Direk N, et al. Depressive symptoms predict incident dementia during short- but not long-term followup period. Alzheimer's \& dementia : the journal of the Alzheimer's Association 2014.

27 Richard E, Reitz C, Honig LH, et al. Late-life depression, mild cognitive impairment, and dementia. JAMA neurology 2013; 70(3): 374-82.

28 Tam CW, Lam LC. Association between late-onset depression and incident dementia in Chinese older persons. East Asian archives of psychiatry : official journal of the Hong Kong College of Psychiatrists = Dong Ya jing shen ke xue zhi: Xianggang jing shen ke yi xue yuan qi kan 2013; 23(4): 154-9.

29 Vilalta-Franch J, Lopez-Pousa S, Llinas-Regla J, Calvo-Perxas L, Merino-Aguado J, Garre-Olmo J. Depression subtypes and 5-year risk of dementia and Alzheimer disease in patients aged 70 years. International journal of geriatric psychiatry 2013; 28(4): 341-50.

30 Wallin K, Bostrom G, Kivipelto M, Gustafson Y. Risk factors for incident dementia in the very old. International psychogeriatrics / IPA 2013; 25(7): 1135-43.

31 Mihalopoulos C, Chatterton ML. Economic evaluations of interventions designed to prevent mental disorders: a systematic review. Early intervention in psychiatry 2014

32 Krishna M, Jauhari A, Lepping P, Turner J, Crossley D, Krishnamoorthy A. Is group psychotherapy effective in older adults with depression? A systematic review. International journal of geriatric psychiatry 2011; 26(4): 331-40.

33 Pinquart M, Duberstein PR, Lyness JM. Effects of psychotherapy and other behavioral interventions on clinically depressed older adults: A meta-analysis. Aging \& mental health 2007; 11(6): 64557.

34 Arroll B, Elley CR, Fishman T, et al. Antidepressants versus placebo for depression in primary care. The Cochrane database of systematic reviews 2009; (3): CD007954.

35 American Psychiatric Association. Diagnostic and Statistical Manual of Mental Disorders. Fourth edition revised. Washington, DC: American Psychiatric Association; 2000.

36 American Psychiatric Association. Diagnostic and Statistical Manual of Mental Disorders. Third edition revised. Washington, DC: American Psychiatric Association; 1987.

37 Van Hout HP, Beekman AT, de Beurs E, et al. Anxiety and the risk of death in older men and women. British Journal of Psychiatry 2004; 185: 399-404.

38 Prina AM, Ferri CP, Guerra M, Brayne C, Prince M. Prevalence of anxiety and its correlates among older adults in Latin America India and China: cross-cultural study. The British journal of psychiatry : the journal of mental science 2011; 199(6): 485-91.

39 Gallacher J, Bayer A, Fish M, et al. Does anxiety affect risk of dementia? Findings from the Caerphilly Prospective Study. Psychosomatic medicine 2009; 71(6): 659-66.

40 de Bruijn RF, Direk N, Mirza SS, et al. Anxiety Is Not Associated with the Risk of Dementia or Cognitive Decline: The Rotterdam Study. The American journal of geriatric psychiatry : official journal of the American Association for Geriatric Psychiatry 2014

41 McEwen BS. Protective and damaging effects of stress mediators: central role of the brain. Dialogues in clinical neuroscience 2006; 8(4): 367-81.

42 McEwen BS. Protective and damaging effects of stress mediators. N Engl J Med 1998; 338(3): 171-9.
43 Andrieu S, Aboderin I, Baeyens JP, et al. IAGG workshop: health promotion program on prevention of late onset dementia. The journal of nutrition, health \& aging 2011; 15(7): 562-75.

44 Krieger $N$. Shades of difference: theoretical underpinnings of the medical controversy on black/white differences in the United States, 1830-1870. International journal of health services : planning, administration, evaluation 1987; 17(2): 259-78.

45 Lupien SJ, Fiocco A, Wan N, et al. Stress hormones and human memory function across the lifespan. Psychoneuroendocrinology 2005; 30(3): 225-42.

46 Green KN, Billings LM, Roozendaal B, McGaugh JL, LaFerla FM. Glucocorticoids increase amyloid-beta and tau pathology in a mouse model of Alzheimer's disease. The Journal of neuroscience : the official journal of the Society for Neuroscience 2006; 26 (35): 9047-56.

47 Jeong $\mathrm{YH}$, Park $\mathrm{CH}$, Yoo J, et al. Chronic stress accelerates learning and memory impairments and increases amyloid deposition in APPV717I-CT100 transgenic mice, an Alzheimer's disease model. The FASEB journal : official publication of the Federation of American Societies for Experimental Biology 2006; 20(6): 729-31.

48 Lupien SJ, de Leon M, de Santi S, et al. Cortisol levels during human aging predict hippocampal atrophy and memory deficits. Nat Neurosci 1998; 1(1): 69-73.

49 Abercrombie HC, Jahn AL, Davidson RJ, Kern S, Kirschbaum C, Halverson J. Cortisol's effects on hippocampal activation in depressed patients are related to alterations in memory formation. J Psychiatr Res 2011; 45(1): 15-23.

50 Persson G, Skoog I. A prospective population study of psychosocial risk factors for late onset dementia. International journal of geriatric psychiatry 1996; 11: 15-22.

51 Johansson L, Guo X, Waern M, et al. Midlife psychological stress and risk of dementia: a 35-year longitudinal population study. Brain : a journal of neurology 2010; 133(Pt 8): 2217-24.

52 Ravona-Springer R, Beeri MS, Goldbourt U. Exposure to the Holocaust and World War II concentration camps during late adolescence and adulthood is not associated with increased risk for dementia at old age. Journal of Alzheimer's disease : JAD 2011; 23(4): 709-16.

53 Sulway MR, Broe GA, Creasey $\mathrm{H}$, et al. Are malnutrition and stress risk factors for accelerated cognitive decline? A prisoner of war study. Neurology 1996; 46(3): 650-5.

54 Wilson RS, Barnes LL, Bennett DA, et al. Proneness to psychological distress and risk of Alzheimer disease in a biracial community. Neurology 2005; 64(2): 380-2.

55 Wilson RS, Bennett DA, Mendes de Leon CF, Bienias JL, Morris $\mathrm{MC}$, Evans DA. Distress proneness and cognitive decline in a population of older persons. Psychoneuroendocrinology 2005; 30(1): 11-7.

56 Bolger N, Zuckerman A. A framework for studying personality in the stress process. Journal of personality and social psychology 1995; 69(5): 890.

57 Gunthert KC, Cohen LH, Armeli S. The role of neuroticism in daily stress and coping. Journal of personality and social psychology 1999; 77(5): 1087.

58 Larsen RJ, Ketelaar T. Personality and susceptibility to positive and negative emotional states. Journal of personality and social psychology 1991; 61(1): 132.

59 Innes J, Kitto S. Neuroticism, self-consciousness and coping strategies, and occupational stress in high school teachers. Personality and Individual Differences 1989; 10(3): 303-12.

60 Costa PTj, McCrae RR. Revised NEO personality inventory (NEO$\mathrm{PI}-\mathrm{R}$ ) and NEO Five-Factor Inventory (NEO-FFI) professional manual. Odessa: Florida; 1992.

61 Eysenck HJ. Eysenck personality inventory: Educational and Industrial Testing Service San Diego; 1968.

62 Goldberg LR. The development of markers for the Big-Five factor structure. Psychological assessment 1992; 4(1): 26.

63 Barefoot JC, Dodge KA, Peterson BL, Dahlstrom WG, Williams $\mathrm{RB}, \mathrm{Jr}$. The Cook-Medley hostility scale: item content and ability to predict survival. Psychosomatic medicine 1989; 51(1): 46-57.

64 Terracciano A, Sutin AR, An Y, et al. Personality and risk of Alzheimer's disease: new data and meta-analysis. Alzheimer's \& dementia : the journal of the Alzheimer's Association 2014; 10(2): 179-86.

65 Wilson RS, Arnold SE, Schneider JA, Kelly JF, Tang Y, Bennett DA. Chronic psychological distress and risk of Alzheimer's disease in old age. Neuroepidemiology 2006; 27(3): 143-53. 
66 Wilson RS, Schneider JA, Arnold SE, Bienias لJ, Bennett DA. Conscientiousness and the incidence of Alzheimer disease and mild cognitive impairment. Archives of general psychiatry 2007; 64(10): 1204-12.

67 Duberstein PR, Chapman BP, Tindle HA, et al. Personality and risk for Alzheimer's disease in adults 72 years of age and older: a 6-year follow-up. Psychology and aging 2011; 26(2): 351-62.

68 Crowe M, Andel R, Pedersen NL, Fratiglioni L, Gatz M. Personality and risk of cognitive impairment 25 years later. Psychology and aging 2006; 21(3): 573-80.

69 Barnes LL, Mendes de Leon CF, Bienias JL, Wilson RS, EversonRose SA, Evans DA. Hostility and change in cognitive function over time in older blacks and whites. Psychosomatic medicine 2009; 71(6): 652-8.

70 Wilson RS, Begeny CT, Boyle PA, Schneider JA, Bennett DA. Vulnerability to stress, anxiety, and development of dementia in old age. The American journal of geriatric psychiatry : official journal of the American Association for Geriatric Psychiatry 2011; 19(4): 327-34

71 Wilson RS, Evans DA, Bienias JL, Mendes de Leon CF, Schneider JA, Bennett DA. Proneness to psychological distress is associated with risk of Alzheimer's disease. Neurology 2003; 61(11): 1479-85

72 Wilson RS, Arnold SE, Schneider JA, Li Y, Bennett DA. Chronic distress, age-related neuropathology, and late-life dementia. Psychosomatic medicine 2007; 69(1): 47-53.

73 Wang HX, Karp A, Herlitz A, et al. Personality and lifestyle in relation to dementia incidence. Neurology 2009; 72(3): 253-9.

74 Neuvonen E, Rusanen M, Solomon A, et al. Late-life cynical distrust, risk of incident dementia, and mortality in a populationbased cohort. Neurology 2014; 82(24): 2205-12.

75 McCrae RR, Costa PT, Jr., Pedroso de Lima M, et al. Age differences in personality across the adult life span: parallels in five cultures. Developmental psychology 1999; 35(2): 466-77.

76 Ausen B, Edman G, Almkvist O, Bogdanovic N. Personality features in subjective cognitive impairment and mild cognitive impairment--early indicators of dementia? Dementia and geriatric cognitive disorders 2009; 28(6): 528-35.

77 van der Kooij MA, Fantin M, Kraev I, et al. Impaired Hippocampal Neuroligin-2 Function by Chronic Stress or Synthetic Peptide Treatment is Linked to Social Deficits and Increased Aggression. Neuropsychopharmacology 2013.

78 Pollak C, Perlick D, Linser J, Wenston J, Hsieh F. Sleep problems in the community elderly as predictors of death and nursing home placement. Journal of community health 1990; 15(2): 123-35.

79 Peter-Derex L, Yammine P, Bastuji H, Croisile B. Sleep and Alzheimer's disease. Sleep medicine reviews 2014.

80 Ju YE, Lucey BP, Holtzman DM. Sleep and Alzheimer disease pathology--a bidirectional relationship. Nature reviews Neurology 2014; 10(2): 115-9.

81 Cirelli C, Faraguna U, Tononi G. Changes in brain gene expression after long-term sleep deprivation. Journal of neurochemistry 2006; 98(5): 1632-45.

82 Tartar JL, Ward CP, McKenna JT, et al. Hippocampal synaptic plasticity and spatial learning are impaired in a rat model of sleep fragmentation. The European journal of neuroscience 2006; 23(10): 2739-48.

83 Gozal D, Daniel JM, Dohanich GP. Behavioral and anatomical correlates of chronic episodic hypoxia during sleep in the rat. The Journal of neuroscience: the official journal of the Society for Neuroscience 2001; 21(7): 2442-50.

84 Kang JE, Lim MM, Bateman RJ, et al. Amyloid-beta dynamics are regulated by orexin and the sleep-wake cycle. Science 2009; 326(5955): 1005-7.

85 Huang Y, Potter R, Sigurdson W, et al. Effects of age and amyloid deposition on Abeta dynamics in the human central nervous system. Archives of neurology 2012; 69(1): 51-8.

86 Spira AP, Gamaldo AA, An Y, et al. Self-reported Sleep and betaAmyloid Deposition in Community-Dwelling Older Adults. JAMA neurology 2013; 70(12): 1537-43.

87 Ancoli-Israel S, Klauber MR, Jones DW, et al. Variations in circadian rhythms of activity, sleep, and light exposure related to dementia in nursing-home patients. Sleep 1997; 20(1): 18-23.

88 Blackwell T, Yaffe K, Ancoli-Israel S, et al. Association of sleep characteristics and cognition in older community-dwelling men: the MrOS sleep study. Sleep 2011; 34(10): 1347-56.
89 Bombois S, Derambure P, Pasquier F, Monaca C. Sleep disorders in aging and dementia. The journal of nutrition, health \& aging 2010; 14(3): 212-7.

90 Faubel R, Lopez-Garcia E, Guallar-Castillon P, Graciani A, Banegas JR, Rodriguez-Artalejo F. Usual sleep duration and cognitive function in older adults in Spain. Journal of sleep research 2009; 18(4): 427-35.

91 Tworoger SS, Lee S, Schernhammer ES, Grodstein F. The association of self-reported sleep duration, difficulty sleeping, and snoring with cognitive function in older women. Alzheimer disease and associated disorders 2006; 20(1): 41-8.

92 Cricco M, Simonsick EM, Foley DJ. The impact of insomnia on cognitive functioning in older adults. Journal of the American Geriatrics Society 2001; 49(9): 1185-9.

93 Jelicic M, Bosma H, Ponds RW, Van Boxtel MP, Houx PJ, Jolles J. Subjective sleep problems in later life as predictors of cognitive decline. Report from the Maastricht Ageing Study (MAAS). International journal of geriatric psychiatry 2002; 17(1): 73-7.

94 Potvin O, Lorrain D, Forget H, et al. Sleep quality and 1-year incident cognitive impairment in community-dwelling older adults. Sleep 2012; 35(4): 491-9.

95 Virta JJ, Heikkila K, Perola M, et al. Midlife sleep characteristics associated with late life cognitive function. Sleep 2013; 36(10): 1533-41, 41A

96 Loerbroks A, Debling D, Amelang M, Sturmer T. Nocturnal sleep duration and cognitive impairment in a population-based study of older adults. International journal of geriatric psychiatry 2010; 25(1): 100-9.

97 Chang WP, Liu ME, Chang WC, et al. Sleep apnea and the risk of dementia: a population-based 5-year follow-up study in Taiwan. PloS one 2013; 8(10): e78655.

98 Chen PL, Lee WJ, Sun WZ, Oyang YJ, Fuh JL. Risk of dementia in patients with insomnia and long-term use of hypnotics: a population-based retrospective cohort study. PloS one 2012; 7(11): e49113.

99 Elwood PC, Bayer AJ, Fish M, Pickering J, Mitchell C, Gallacher JE. Sleep disturbance and daytime sleepiness predict vascular dementia. J Epidemiol Community Health 2011; 65(9): 820-4.

100 Hahn EA, Wang HX, Andel R, Fratiglioni L. A Change in Sleep Pattern May Predict Alzheimer Disease. The American journal of geriatric psychiatry : official journal of the American Association for Geriatric Psychiatry 2013.

101 Lim AS, Kowgier M, Yu L, Buchman AS, Bennett DA. Sleep Fragmentation and the Risk of Incident Alzheimer's Disease and Cognitive Decline in Older Persons. Sleep 2013; 36(7): 1027-32.

102 Sterniczuk R, Theou O, Rusak B, Rockwood K. Sleep disturbance is associated with incident dementia and mortality. Current Alzheimer research 2013; 10(7): 767-75.

103 Tranah GJ, Blackwell T, Stone KL, et al. Circadian activity rhythms and risk of incident dementia and mild cognitive impairment in older women. Annals of neurology 2011; 70(5): 722-32.

104 Yaffe K, Laffan AM, Harrison SL, et al. Sleep-disordered breathing, hypoxia, and risk of mild cognitive impairment and dementia in older women. JAMA : the journal of the American Medical Association 2011; 306(6): 613-9.

105 Foley D, Monjan A, Masaki K, et al. Daytime sleepiness is associated with 3 -year incident dementia and cognitive decline in older Japanese-American men. Journal of the American Geriatrics Society 2001; 49(12): 1628-32.

106 Tufik S, Santos-Silva R, Taddei JA, Bittencourt LR. Obstructive sleep apnea syndrome in the Sao Paulo Epidemiologic Sleep Study. Sleep medicine 2010; 11(5): 441-6.

107 Breslau N, Roth T, Rosenthal L, Andreski P. Sleep disturbance and psychiatric disorders: a longitudinal epidemiological study of young adults. Biological psychiatry 1996; 39(6): 411-8.

108 Stewart R, Besset A, Bebbington P, et al. Insomnia comorbidity and impact and hypnotic use by age group in a national survey population aged 16 to 74 years. Sleep 2006; 29(11): 1391-7.

109 Saczynski JS, Beiser A, Seshadri S, Auerbach S, Wolf PA, Au R. Depressive symptoms and risk of dementia: the Framingham Heart Study. Neurology 2010; 75(1): 35-41. 


\section{CHAPTER 4 \\ Lifestyle}

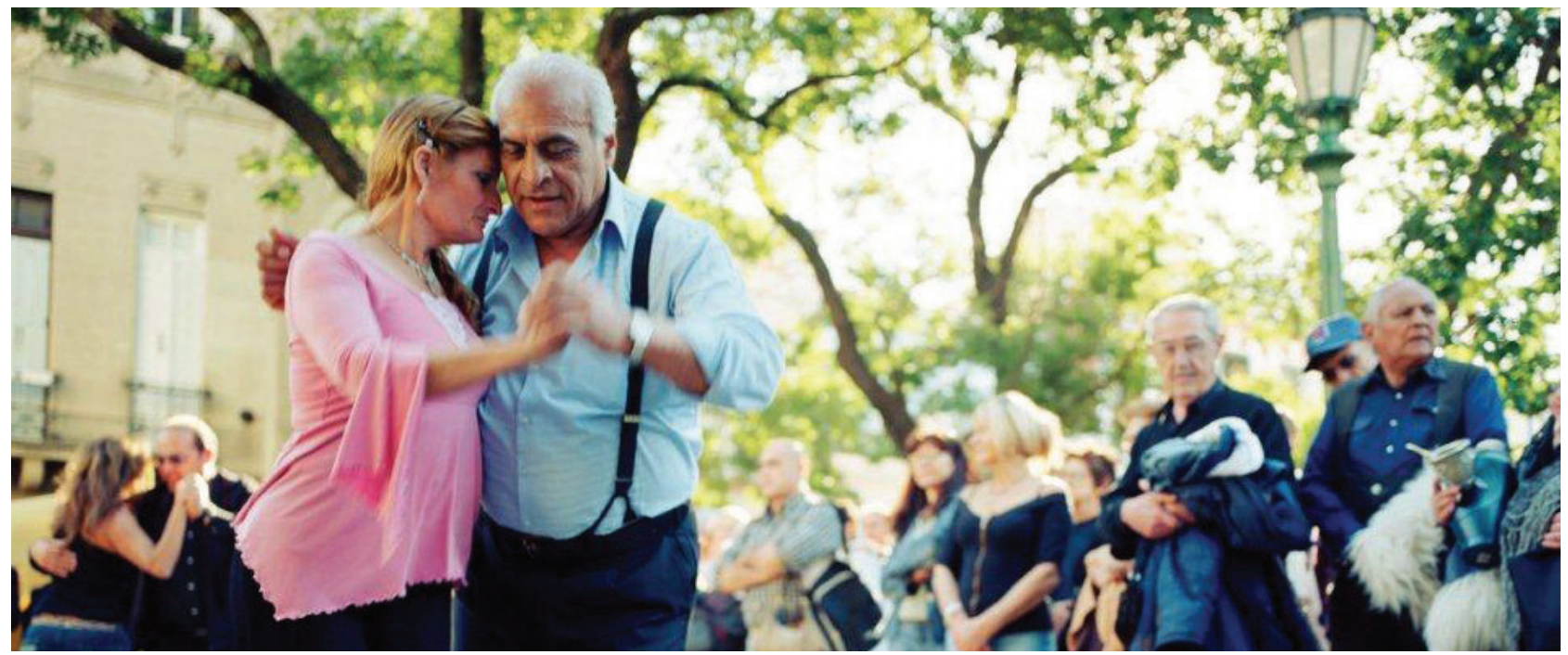

The interest in the relationship between lifestyles and dementia risk is extremely important for its potential impact on prevention. Lifestyles are modifiable and are typical targets of preventive programs and interventions. Interestingly, healthy and unhealthy lifestyles are closely interconnected, with observed clusters within some lifestyles. For instance cigarette smoking is strongly associated with alcohol consumption (and vice-versa). Low physical activity level is related to poorer diet, smaller social network and fewer social interactions. This means that separating out the potential effect on health of a specific lifestyle is challenging. Indeed, some have argued that to better inform preventive actions and programs, lifestyles factors should not be investigated separately but as clusters. For instance, the metabolic syndrome (defined as the combination of at least five amongst abdominal obesity, elevated blood pressure, elevated fasting plasma glucose, high serum triglycerides, and low high-density cholesterol (HDL) levels) is not only highly prevalent in the general population of high-income countries, but is also the strongest predictor of cardiovascular disease. However, the effort to explore the extent to which each of the components of the metabolic syndrome may be linked to specific diseases, such as diabetes and heart failure, has been also extremely important to understand causal pathways and develop specific preventive interventions and treatments for sub-groups of the population at greatest risk. Lifestyles, such as diet and physical activity, alcohol and smoking habits are strongly related to each other, and to the metabolic syndrome, and are the target of existing preventive programs that aim to improve health, particularly through the reduction of cardiovascular risk. There is, therefore, some potential overlap and synergy between factors considered in this chapter, and the 'cardiovascular risk factors' considered in chapter 5.

Our understanding of the causes and pathophysiology underpinning dementia is still limited. Therefore it is difficult to conceive whether a specific cluster of lifestyle exposures may be particularly detrimental for brain health. Because vascular mechanisms are thought to be implicated in the development of dementia, an improved cardiovascular risk profile may reduce dementia risk. However, some lifestyles may be related to dementia risk through nonvascular pathways. For instance, the term 'use it or lose it', which is often used colloquially to refer to the deleterious impact on cognitive performance of disengagement in old age, is somewhat supported by research evidence on the beneficial effects of intellectually stimulating activities on cognitive function.

In this section we will review the existing evidence on the association between dementia and a selected number of lifestyles. Here we focus on lifestyles that are targets of existing preventive programs and for which substantial epidemiologic evidence is available. We also considered those lifestyles that are targeted by multi-domain interventions in which efficacy to reduce cognitive decline is currently tested in a number randomised controlled trials in participants at risk ${ }^{1}$.

\section{Smoking}

Smoking is the chief preventable cause of death worldwide ${ }^{2}$. Fifty years have passed since the US Surgeon General's landmark report linking smoking with cancer ${ }^{3}$. However, the annual global deaths due to tobacco are still expected to increase from the current six million, to eight million people by $2030^{4}$. Cigarette smoking is causally related to a wide range of diseases 
including many forms of cancer, cardiovascular disease and diabetes as well as increased risk of dyslipidaemia ${ }^{5}$.

The most prevalent dementia subtypes, vascular dementia $(\mathrm{VaD})$ and Alzheimer's disease (AD), have been linked to underlying vascular mechanisms and neurovascular events ${ }^{6-8}$. Stroke, for example, increases the risk of developing vascular dementia ${ }^{9}$. Additionally, tobacco smoke contains a myriad of toxic substances favouring oxidative stress and inflammation, which potentially exacerbate AD pathology ${ }^{10}$. Smoking exerts effects on amyloid precursor protein processing, reduces $A \beta$ microglia clearance, enhances microglial proinflammatory response and induces neurodegenerative-related synaptic changes ${ }^{11}$. Transgenic AD animal model studies suggest cigarette smoke increases amyloidogenesis, neuroinflammation and tau phosphorylation ${ }^{12}$. All these findings suggest tobacco use could increase dementia incidence or progression.

Cigarette smoke contains many substances and although some of them may be involved in pathologic mechanisms related to neurodegenerative or neurovascular conditions, some others, such as nicotine, offer possible cholinergic protection, which could decrease AD incidence and symptoms ${ }^{13}$. Nicotine has antiamyloidogenic properties and could protect the brain against ischaemic and excitotoxic cell damage ${ }^{14-17}$. A neuropathological study found that lifetime smoking reduced Lewy-related pathology, potentially protecting against some neurodegenerative conditions, such as Parkinson's disease and Lewy Body dementia ${ }^{18}$. This one possible beneficial effect of nicotine is likely outweighed by the neuropathological damage and other harms caused by smoking, but specific nicotinic pharmacological therapies could be a future therapeutic strategy for cognitive disorders ${ }^{19}$.

Epidemiological data from case-control studies indicated a lower odds of smoking among dementia cases than controls ${ }^{20}$, reinforcing the belief among some academics and members of the general population that tobacco consumption might reduce dementia risk. Cigarette companies actively disseminated this information, and sought more evidence ${ }^{21}$. Evidence from a recent review suggests that this may have been a source of bias; studies conducted with tobacco industry affiliation were more likely to report a decreased $A D$ risk associated with smoking, although the associations from individual studies were generally not statistically significant ${ }^{22}$. This review, and one other also highlighted that case-control study designs were more likely than prospective cohort studies to indicate protective effects $^{20,22}$. In case-control studies recall and prevalence bias may have led to an underestimation of the odds of a smoking history among cases. Selection bias may have occurred if those with cardiovascular disease (linked to smoking) were strictly excluded from the $A D$ case group. For all these reasons, in recent years focus has shifted to cohort studies, as a less biased source of information.

\section{Previous systematic reviews}

The association of smoking with incident dementia in longitudinal studies has been considered in seven systematic reviews ${ }^{20,22-27}$, of which only four focused on this association $20,22,23,26$ and only four synthesised results by meta-analysis ${ }^{20,22-24}$. The way data was summarised in these systematic reviews varied greatly regarding the categories of exposures being compared. A very recent systematic review ${ }^{24}$ included nine studies ${ }^{28-36}$ that compared either current or ever smokers with never smokers for the risk of $A D$ and found a positive association (RR 1.37, 95\% Cl: 1.231.52). Anstey et al. ${ }^{23}$ conducted a more detailed review with meta-analyses summarising findings according to five different categories of smoking exposure for three different outcomes (Alzheimer's disease, vascular dementia and any dementia). However, this review, published in 2007 included only publications up to June 2005, and contained some errors in the transcription of effect sizes. We have therefore updated this review, using the same rigorous approach to distinguishing different types of smoking exposure contrasts (see Methods, below, for details).

\section{Methods}

\section{Literature search}

We searched MEDLINE for published literature until 31 August 2014 using the following search strategy limited to humans:

(("Smoking"[Mesh]) OR ("Tobacco Products"[Mesh] OR "Tobacco"[Mesh] OR "Tobacco Use"[Mesh] ) OR ("Nicotine"[Mesh]) OR ("Smoking"[AllFields])) AND ("Dementia"[Mesh] OR "Frontotemporal Dementia"[Mesh] OR "Dementia, Multi-Infarct"[Mesh] OR "Dementia, Vascular"[Mesh] OR "Alzheimer Disease"[Mesh] OR "Lewy Body Disease"[Mesh])

The references list of all published reviews identified with this search were carefully searched for further eligible publications. This same procedure was repeated with each of the eligible publications. Relevant publications were selected by CP and RP.

\section{Inclusion/exclusion criteria}

(i) population-based longitudinal studies or case control studies nested into a cohort study; (ii) studies which measured dementia at baseline and followed up those without dementia for any period of time to identify incident cases of dementia, (iii) studies which did not measure dementia at baseline, but measured exposure to tobacco up to the age 50; (iv) dementia diagnosis (any dementia, Alzheimer's disease or vascular dementia) was ascertained from direct and systematic assessment of cohort participants and not taken from health insurance records or death certificates. Publications from the same study were 
Figure 4.1

Classification of smoking exposure

\begin{tabular}{|l|l|l|l|l|}
\hline $\begin{array}{l}\text { Possible } \\
\text { contrasts } \\
\text { Current status }\end{array}$ & $\begin{array}{l}\text { 1. Ever smokers vs. never } \\
\text { smokers }\end{array}$ & $\begin{array}{l}\text { 2. Current-smokers vs. } \\
\text { current non-smokers }\end{array}$ & $\begin{array}{l}\text { 3. Current vs. never } \\
\text { smokers }\end{array}$ & $\begin{array}{l}\text { 4. Ex-smokers vs. never } \\
\text { smokers }\end{array}$ \\
\hline Never smoker & & & & \\
\hline Ex-smoker & & & & \\
\hline Current smoker & & & & \\
\hline
\end{tabular}

\begin{tabular}{|l|l|}
\hline Exposed category \\
\hline & Non-exposed (reference) category \\
\hline & Excluded from the comparison \\
\hline
\end{tabular}

examined and all relevant information extracted. If the same analyses were repeated, priority was given to the most recent publication.

\section{Classification of exposure}

In most studies current and previous smoking exposure was established by self-report, such that cohort members could be divided into three groups - those who had never smoked (never smoker), those who had smoked, but had given up (ex-smoker), and those who continued to smoke (current smoker). This categorisation can be recoded into at least four contrasts permitting different comparisons of interest to be made (see Figure 4.1).

In some studies participants who had ever smoked were asked at what age they had started smoking, their age at stopping smoking (for ex-smokers) and typical daily cigarette consumption. This enabled pack-years to be calculated, which is a composite measure of smoking dose and duration. It is calculated by multiplying the number of packs of cigarettes smoked per day by the number of years the person has smoked. Thus, one pack-year is equal to smoking 20 cigarettes (one pack) per day for one year, or 10 cigarettes per day for two years.

Data extraction was conducted by CP and RP. Data was extracted according to the following categories of comparison:

1. Current vs. never smokers

2. Ex-smokers vs. never smokers

3. Ever (current or ex-smokers) vs. never smokers

4. Current smokers vs. current non-smokers (ex-smokers or never smokers),

5. Pack-years

6. Any of these comparisons separately for APOE4 carriers and non-carriers. Preference was given for estimates adjusted for the largest number of variables.

\section{Statistical analysis}

Meta-analysis was conducted for group comparisons where two or more studies provided estimates.
Estimates were provided as OR, HR, RR. They were used as relative risks. Fixed effect meta-analyses were used to pool estimates. Heterogeneity was examined using $\chi^{2}$ test and quantified using Higgins $\mathrm{l}^{2}$.

\section{Results}

Our initial search identified 786 publications, of which 87 had looked at the association between smoking and dementia, and 28 were longitudinal studies or case-control studies nested in a cohort study. Three more studies were identified from the reference lists of the review papers. Fourteen of these 31 studies were considered fully eligible for inclusion 29,30,32,33,35,37-45 Two pairs of publications reported different analyses from the same study; the Finland CAIDE study ${ }^{30,43}$, and the North Manhattan study ${ }^{40,41}$; these were retained since they report on different exposures or outcomes.

Only six of the studies included in this review overlap with the Anstey review ${ }^{35,38-42}$. We excluded four studies that were included in the Anstey review; Broe et al. ${ }^{46}$, which in the published version, does not provide any relevant effect sizes; Launer et al. ${ }^{47}$, which provides a pooled estimate from four European cohort studies, two of which have been published separately and we have included; Yoshitake et al. ${ }^{48}$, which does not provide an adjusted estimate for the association of interest; and Laurin $2004^{49}$, which does not provide estimates on the association of smoking and dementia, but these are reported in another paper from the Honolulu Asia Aging Study (Tyas et al. ${ }^{29}$ ), which we have included. We also identified seven more eligible studies $^{30,32,33,37,43-45}$, published between 2006 and 2011 after the search conducted by Anstey (up to June 2005).

The characteristics of the 14 studies included in our updated review are summarised in Table 4.1.

The results of the meta-analyses are summarised in Table 4.2, for each of the four exposure contrasts, and for each of the three outcomes. For most of the studies, never smokers were the reference category, with relative risks reported for current smokers and exsmokers. For a smaller number of studies, current and 
ex-smokers were combined to compare ever smokers with never smokers. More rarely still, current smokers were compared with current non-smokers (ex-smokers and never smokers). There were relatively few studies of the effect of smoking upon the incidence of $\mathrm{VaD}$.

Only two of the 10 pooled effects suggested a statistically significant effect; of current smokers vs. never (RR 1.52, 95\% Cl: 1.18-1.86) and ever smokers vs never (RR 1.55, 95\% Cl: 1.15-1.95), both on incident AD. However, a pattern of association emerges in the tabulated effect sizes, with several strong but non-statistically significant trends toward an increased risk of dementia associated with smoking. Positive associations between smoking and dementia incidence were most apparent for the current vs. never contrast, and least apparent for the ex-smoker vs. never. However, for the few studies that had assessed the contrast for ever (pooling the higher risk current and lower risk former smoker groups) vs. never, relative risks were similar to those for current vs. never.

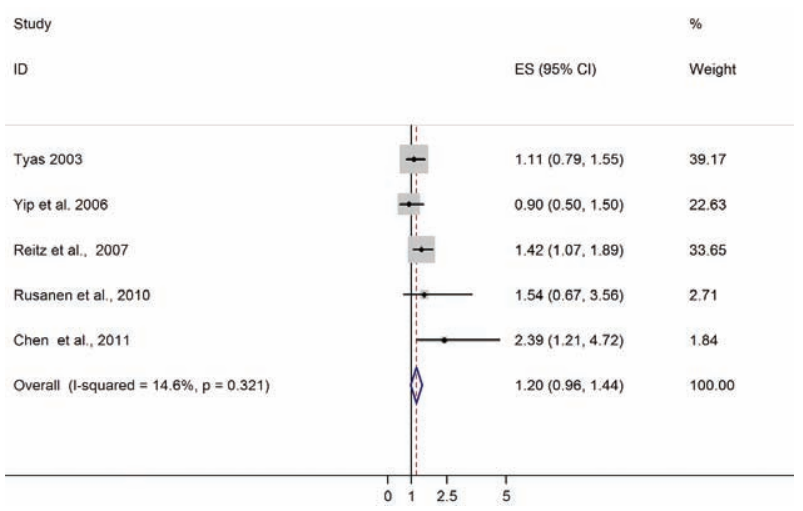

Figure 4.2

Forest plot for studies of the effect of current smokers versus never smokers on the outcome of incident any dementia

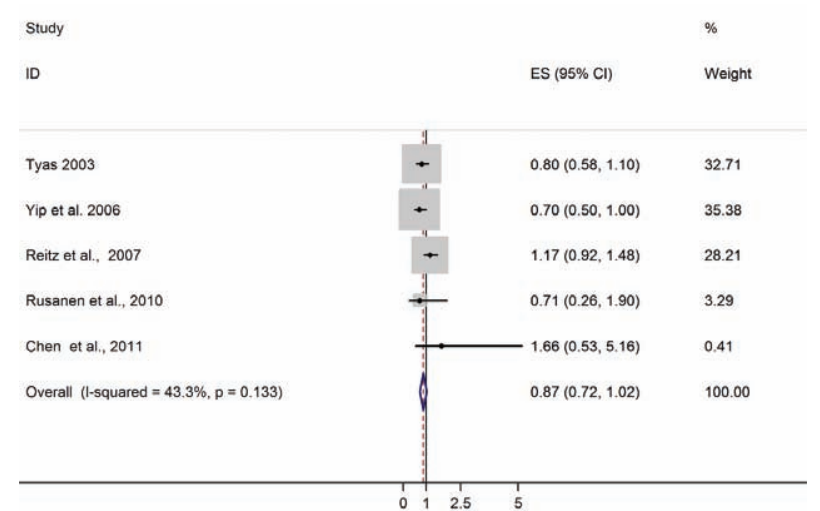

Figure 4.3

Forest plot for studies of the effect of ex-smokers versus never smokers on the outcome of incident any dementia

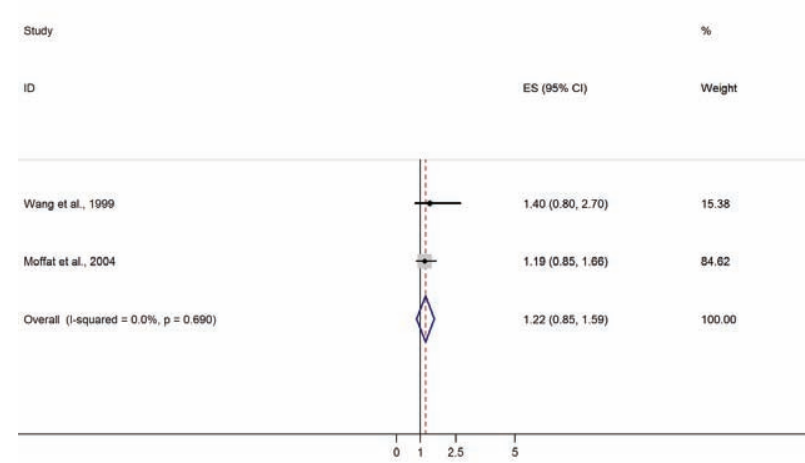

Figure 4.4

Forest plot for studies of the effect of ever smokers versus never smokers on the outcome of incident any dementia

\section{Dose-response}

Pack-years were used in four studies to quantify lifetime smoking exposure, and then to test for a dose-response effect among smokers $29,33,35,45$. In the Chicago Health and Aging Project cohort study 45 there was no association of pack-years with $A D$ among current smokers $(p=0.88)$, but among ex-smokers there was a significant trend towards a lower risk of incident $A D$ with increasing pack-years of exposure $(p=0.02)$; effect sizes were not reported. In the Rotterdam study ${ }^{33}$, authors report a non-significant trend towards a dose-response effect of pack-years among current smokers; however, the nature of the analyses conducted is unclear, and there seem to be errors in the reporting of effect sizes. In the Honolulu Asia Aging Study ${ }^{29}$, among current and ex-smokers combined, risks for incident $A D$ and any dementia increased monotonically with increasing pack-years of exposure up to 'heavy' smoking levels (>40.5 to 55.5 pack-years), but the risk in 'very heavy smokers' (> 55.5 pack-years) was similar to that in 'light' smokers ( $>0$ to $<26.7$ pack-years). No tests-for-trend were reported. This analysis was replicated exactly in the Chinese Chongqing study, with very similar results ${ }^{35}$. The test-for-trend for an increasing risk of $A D$ with increasing pack-years of exposure was statistically significant when 'very heavy' smokers were excluded. However, it is unclear whether these analyses focused upon 'ever' or 'current' smokers.

\section{Effect modification by APOE genotype}

In seven longitudinal studies the association between smoking and incident dementia (any of the three outcomes), was estimated separately for APOE e4 carriers and non-carriers ${ }^{29,30,32,33,40,43,45}$. Four of these studies tested explicitly for the statistical significance of an interaction, and in each case the null hypothesis could not be rejected $(p>0.05)^{30,41,43,45}$. We have meta-analysed the stratum specific effect sizes for the five studies ${ }^{29,30,32,33,43}$ that reported effect sizes for the association of smoking (variously defined) 
Table 4.1

Characteristics of the $\mathbf{1 4}$ studies included in this review

\begin{tabular}{|c|c|c|c|c|c|c|c|c|c|c|}
\hline 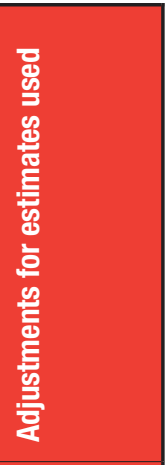 & 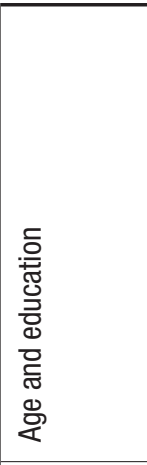 & 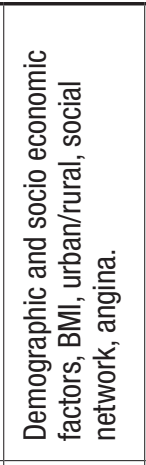 & 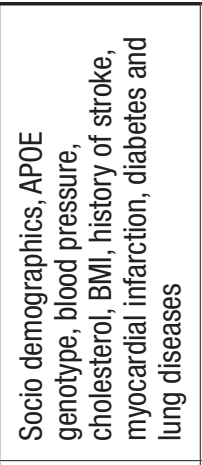 & 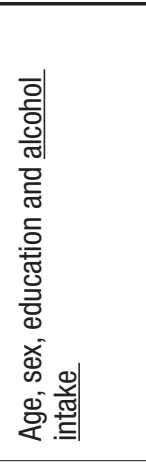 & 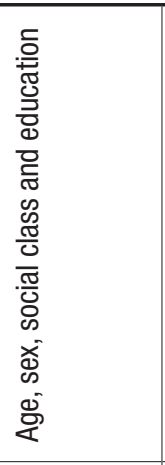 & 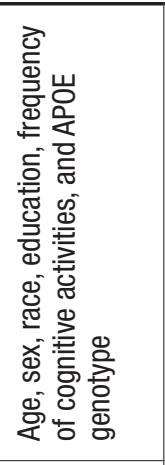 & 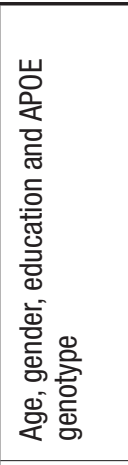 & 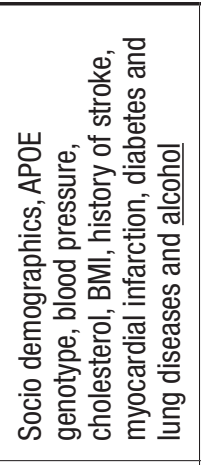 & 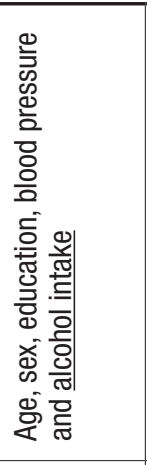 & 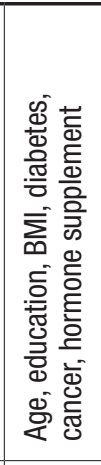 \\
\hline 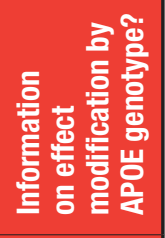 & $\stackrel{\infty}{\check{2}}$ & 2 & $\stackrel{\infty}{=}$ & 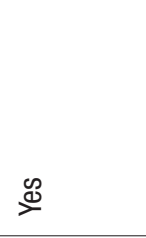 & 2 & $\stackrel{\mathscr{S}}{=}$ & $\stackrel{\mathscr{S}}{=}$ & $\stackrel{\mathscr{0}}{\rightleftharpoons}$ & 2 & 2 \\
\hline 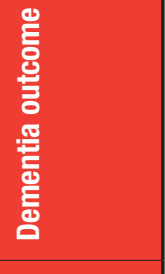 & 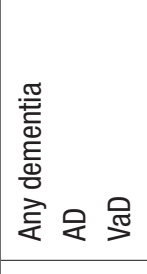 & 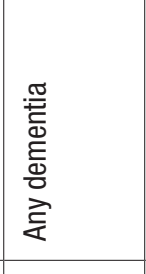 & 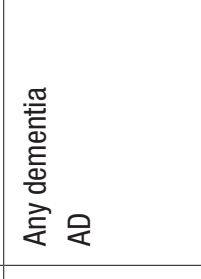 & 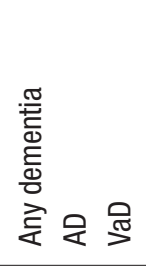 & 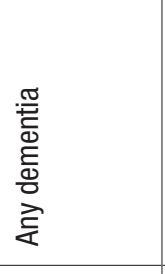 & \& & ₹ & 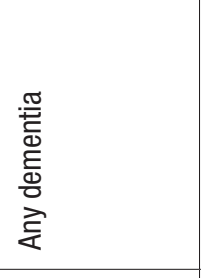 & 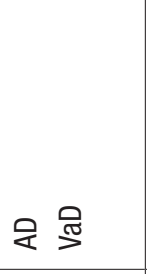 & 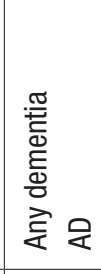 \\
\hline $\begin{array}{l}\text {. } \\
\text { 哥 }\end{array}$ & 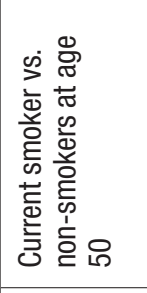 & 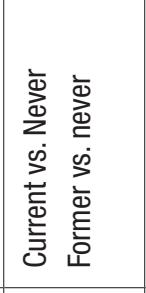 & 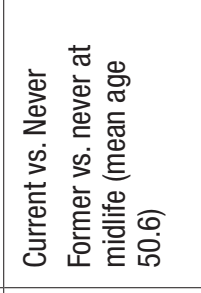 & 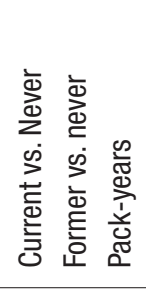 & 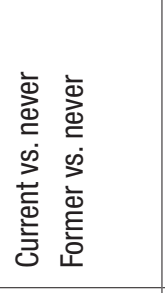 & 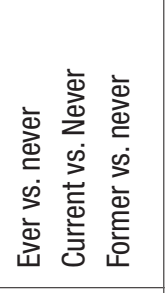 & 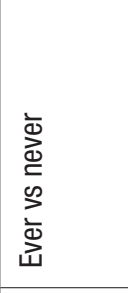 & 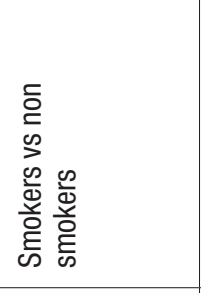 & 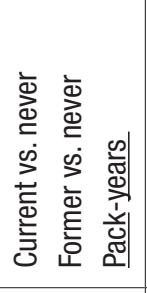 & 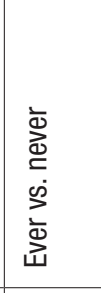 \\
\hline 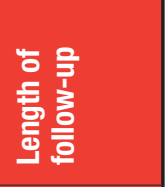 & 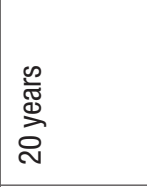 & 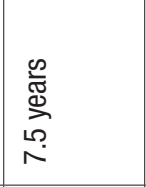 & 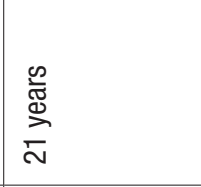 & 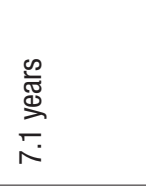 & 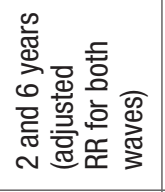 & $\begin{array}{l}\stackrel{\infty}{\mathbb{E}} \\
\stackrel{\tilde{W}}{\sigma}\end{array}$ & 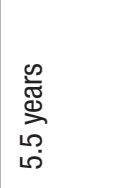 & 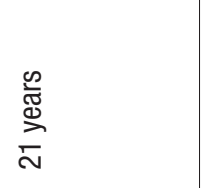 & $\underset{\stackrel{\infty}{\mathbb{W}}}{\stackrel{w}{\sim}}$ & 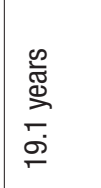 \\
\hline 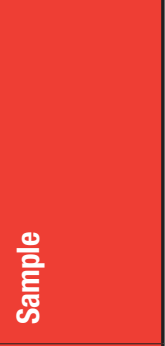 & 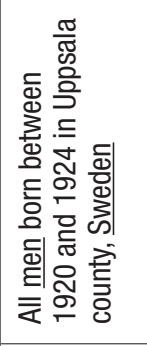 & 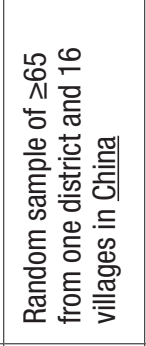 & 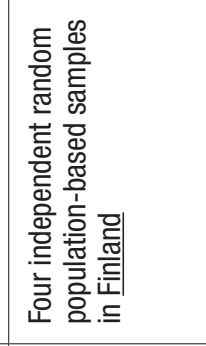 & 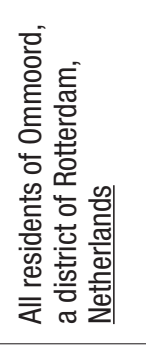 & 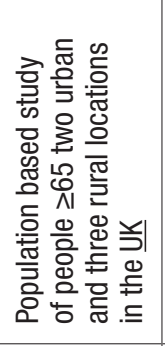 & 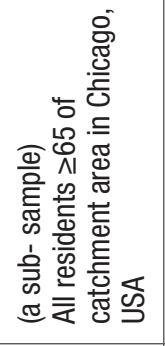 & 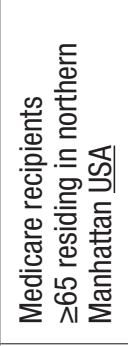 & 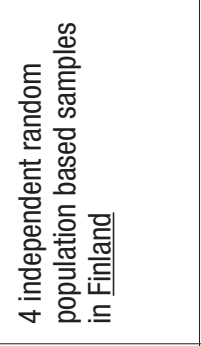 & 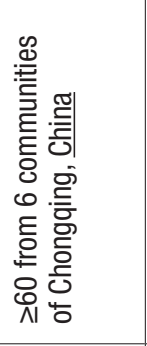 & 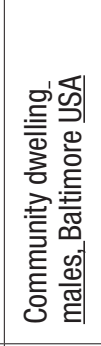 \\
\hline $\begin{array}{l}\text { 悬 } \\
\text { 吾 }\end{array}$ & 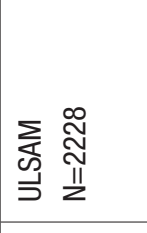 & 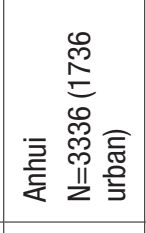 & 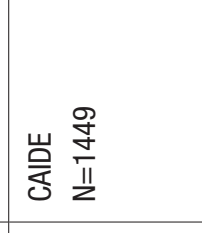 & 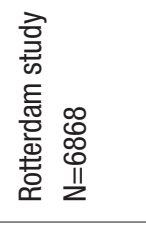 & 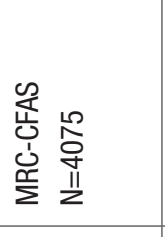 & 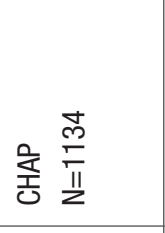 & $\begin{array}{l}\frac{\infty}{m} \\
\frac{m}{2} \\
2\end{array}$ & 容恋 & $\begin{array}{l}\text { ळ్ } \\
\text { II } \\
\end{array}$ & 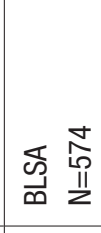 \\
\hline 을 & 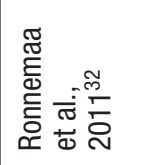 & 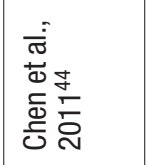 & 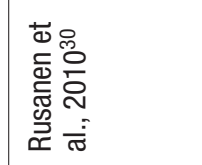 & 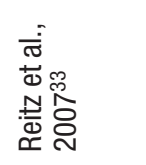 & 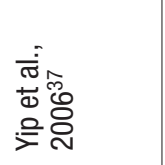 & 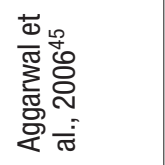 & 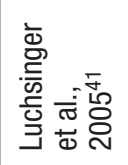 & 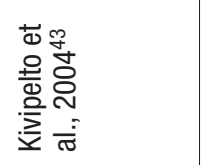 & 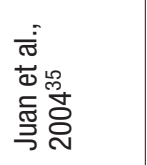 & 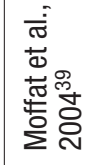 \\
\hline
\end{tabular}


Table 4.2

Results of the meta-analyses according to exposures and outcomes

\begin{tabular}{|c|c|c|c|}
\hline 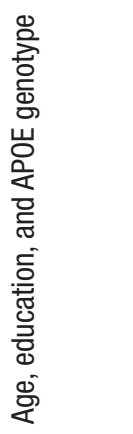 & 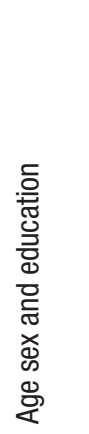 & 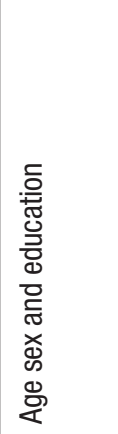 & 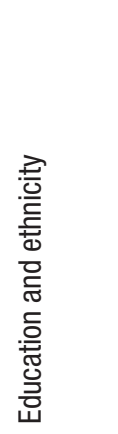 \\
\hline$\stackrel{0}{z}$ & 岕 & 2 & $\stackrel{\mathscr{0}}{\rightleftharpoons}$ \\
\hline 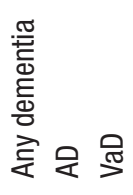 & 安 & 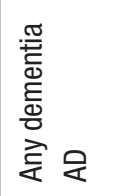 & 足 \\
\hline 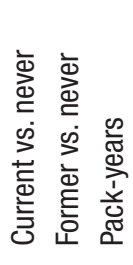 & 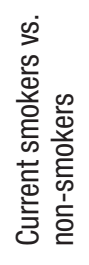 & 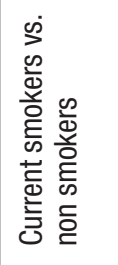 & 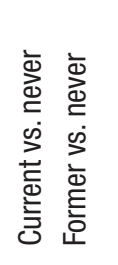 \\
\hline 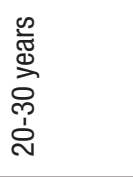 & 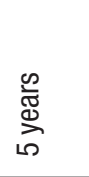 & 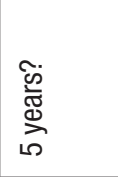 & $\begin{array}{l}\stackrel{\infty}{\mathbb{\#}} \\
\stackrel{\mathbb{N}}{\sim}\end{array}$ \\
\hline 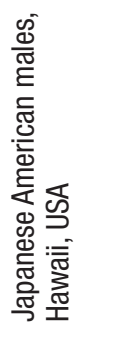 & 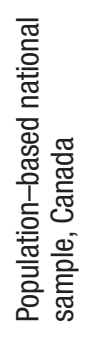 & 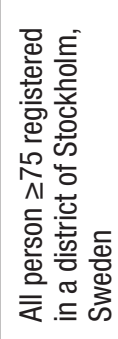 & 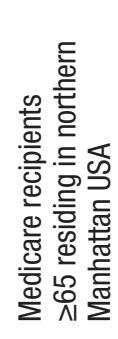 \\
\hline 空兽 & 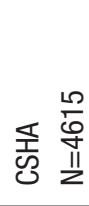 & 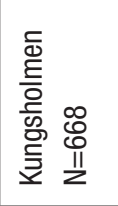 & $\begin{array}{l}\text { Ð } \\
\frac{11}{2}\end{array}$ \\
\hline 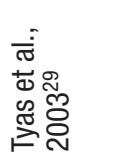 & 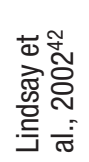 & 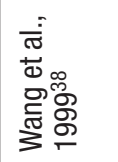 & 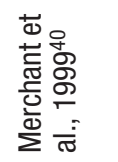 \\
\hline
\end{tabular}

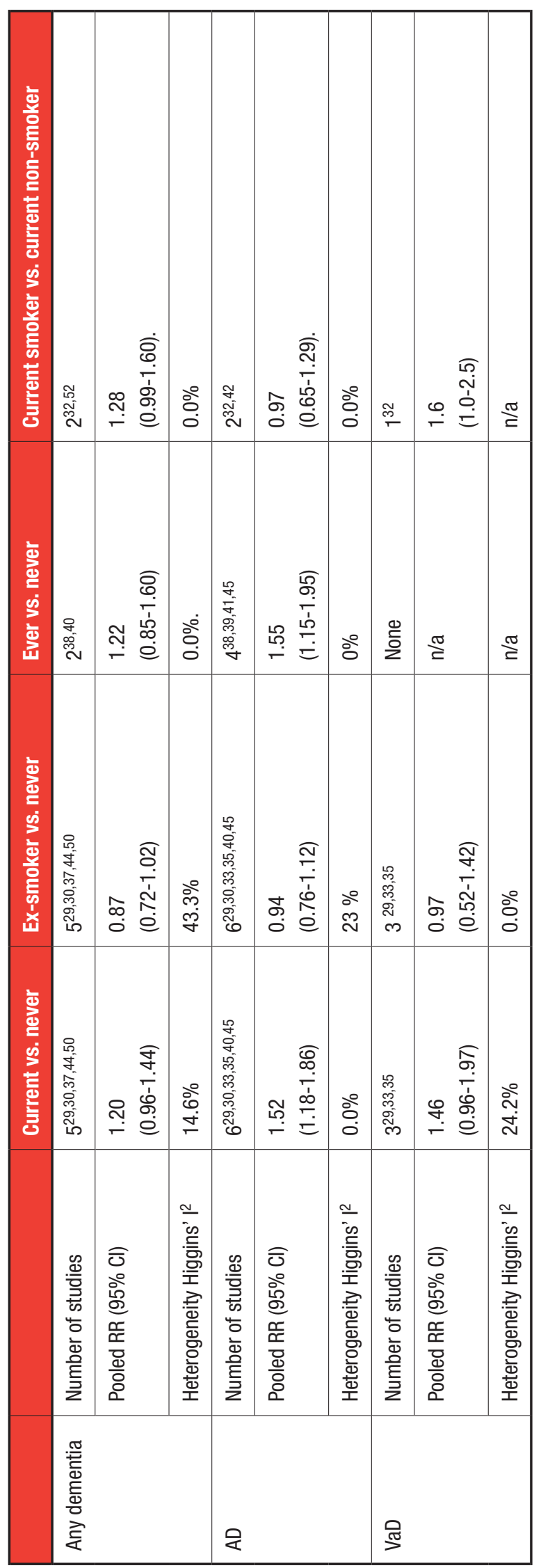


with the incidence of any dementia and these were similar for carriers (pooled RR 0.88, 95\% Cl: 0.56-1.19, heterogeneity $\mathrm{I}^{2}=0.0 \%$ ) and non-carriers (RR 1.16 , 95\% Cl: 0.59- 1.74). The pooled RR for non-carriers is from a random effects model given the high level of heterogeneity $\left(I^{2}=61.6 \%\right)$. In the four studies of the association of smoking with AD risk ${ }^{30,33,40,45}$ the pooled relative risk was slightly higher for non-carriers (RR $1.73,95 \% \mathrm{Cl}: 1.12-2.35)$ than for carriers $(R R=1.49$, 95\% Cl: 0.95-2.03).

\section{Conclusion}

Our systematic review and meta-analyses indicate that

- current smokers, compared to never smokers have a higher risk for the incidence of $A D$, with a nonsignificant trend in this direction for incident any dementia and $\mathrm{VaD}$;

- ex-smokers are at a similar risk to never smokers for the incidence of all types of incident dementia;

- these two groups combined (ever smokers), compared to never smokers have a higher risk for the incidence of $A D$ with a non-significant trend in this direction for incident any dementia;

- there is inconsistent evidence for a dose response effect among current smokers, with an increased risk of $A D$ (and, possibly, any dementia) with increasing pack-years exposure up to, but not including very heavy consumption (>55 pack-years);

- there is insufficient evidence to determine whether or not the association of smoking with incident dementia or AD is modified by APOE genotype.

\section{Discussion}

We believe that this is the most complete review yet of the evidence from longitudinal studies for the association of smoking with dementia risk. Inclusion and exclusion criteria have been chosen and applied carefully to avoid duplication and eliminate obvious sources of bias. The different categories of exposure have been distinguished and analysed separately. Nevertheless, with several recent publications identified, this updated review includes more studies than others on key exposure contrasts, particularly current vs. never smokers and ex-smokers vs. never smokers. There is now quite strong and consistent evidence to support an association between current smoking (vs. never smoking) and the incidence of AD, with tentative (non-statistically significant) evidence for a similar association with vascular dementia, and a smaller association with any dementia. Conversely, ex-smokers do not appear to be at increased risk. This is an encouraging finding for dementia prevention, suggesting, as with other adverse impacts of smoking, that the increased risk of dementia can be avoided by quitting smoking.

Limitations to the evidence-base constrain to some extent the inferences that can be drawn. The very different risks apparently experienced by current and ex-smokers highlight the importance of clarifying the nature of the exposure. However, the exposure contrasts that are compared vary among studies, reducing potential for meta-analysis. While in other sections of this report, we have drawn a distinction between 'midlife' and 'late-life' exposure, this does not apply in the same way to smoking exposure, since, when the information is collected at baseline, this aims to summarise exposure across the life course. However, when cohort inception is in late-life, errors in recall of lifetime smoking history may be particularly likely, and the future onset of dementia may influence recent changes in smoking behaviour. When inception is in mid-life, failure to assess and analyse the effect of subsequent changes in smoking behaviour may lead to underestimation of the impact of smoking on dementia incidence in late-life, perhaps accounting for the generally null associations observed in those studies. Adjustment for potential confounders is highly variable between studies (see Table 4.1); the role of alcohol consumption, physical exercise, and other cardiovascular risk factors may be particularly important to consider. Smoking habits, and their impacts on health, can be strongly gendered, and we have not estimated effect sizes for men and women separately, from studies where these are reported. While some studies have reported very different effects of smoking on dementia risk for APOE e4 carriers and non-carriers, these are highly variable between studies, few have tested formally for effect modification, and the results of the reported analyses are difficult to meta-analyse. Dose-response effects by pack-years of smoking have been assessed in several studies, but the resulting analyses are inadequately described and reported.

Smoking greatly reduces life expectancy, and there has been much discussion in the literature of the possible effects of the 'competing risk' of dementiafree death from smoking-related causes on the estimation of the 'true' effect of smoking on risk for dementia. Smokers who survive into late-life despite continuing to smoke are remarkable individuals, who are probably genetically and/or constitutionally robust in a variety of ways, including some that may reduce their risk of developing dementia. This may explain the tendency for effect sizes for the association of smoking with dementia to be closer to the null, or even inverse (suggesting a lower risk than for non-smokers) in cohorts with an inception in late-life, that therefore recruit only long-term survivors of their smoking habit. A similar mechanism may explain the attenuation of the dose-response effect for the 'very heavy' smoker category observed in two studies. When the competing risk of 'dementia-free death' is accounted for, the relative risk for the association of smoking with dementia is increased ${ }^{51,52}$. This is a little difficult to conceptualise, but, in essence, if these 'phantoms' who died early because of their smoking habit had not 
smoked, they would not only have lived longer (into the period of risk for developing dementia), but would also then have experienced a lower risk of dementia, consistent with their non-smoking status.

Despite some inconsistencies and uncertainties, our findings point to a possible and plausible positive risk association between smoking and the onset of dementia in late-life. It will be important to further clarify the nature and extent of this association both to quantify more accurately the total burden of disease and societal economic impact attributable to smoking, and to model the potential changes in future dementia incidence in different world regions where the prevalence of smoking has been decreasing (most high income countries) or increasing (many low and middle income countries) in recent years.

\section{Alcohol}

Alcohol is ranked fifth among the most important risk factors for death and disability worldwide ${ }^{53}$ and it has been implicated as a causal factor for more than 200 diseases and injuries ${ }^{54}$, including major noncommunicable diseases such as liver cirrhosis, some cancers and cardiovascular disease. A J-or U- shaped relationship with cardiovascular disease has been suggested, where moderate drinkers are at lower risk than abstainers and heavy drinkers ${ }^{55}$. The association of alcohol consumption with cognitive decline and dementia has been more controversial, but a J-shape has also been suggested, where moderate drinkers are at lower dementia risk than abstainers and heavy drinkers. Despite the controversy, there are biological mechanisms to explain both a protective and a risk effect.

The deleterious effects of alcohol in the brain are well known. It produces cerebral volume loss, especially from the white matter that is related to memory processing and visuospatial functioning ${ }^{56}$. Neuronal loss in alcoholics has been described, especially in the frontal association cortex, hypothalamus, cerebellum, hippocampus, amygdala and locus coeruleus ${ }^{57}$, although its repercussions on a functional level are controversial $^{58}$. The mechanisms involved in brain damage include nutritional factors that can exacerbate ethanol neurotoxicity, such as thiamine deficiency (vitamin B1), but there is insufficient evidence on the benefits of thiamine intake to recommend this as a prevention or treatment for Alzheimer's ${ }^{59}$.

The potential neuroprotective effects of alcohol can be explained by different mechanisms. Alcohol increases the insulin-sensitive glucose transporters ${ }^{57}$ that have been identified as being compromised in the medial temporal lobe in prodromal Alzheimer's disease, a disease associated with abnormal brain glucose metabolism ${ }^{60}$. Alcohol increases levels of high density lipoprotein cholesterol ${ }^{57}$; which in high concentrations could lower concentrations of low density lipoprotein cholesterol, which is related to cardiovascular disease ${ }^{61}$ and neurodegenerative diseases $^{62}$. Alcohol also produces a significant reduction in plasma viscosity, its increase is related to inflammatory mechanisms that can be linked with the cause of dementia ${ }^{63}$. In the same way, alcohol produces a reduction in fibrinogen concentration, which is an inflammatory marker ${ }^{63}$. Studies have linked abnormal coated-platelet synthesis with an increased risk of $A D$, hypothesizing a relationship with inflammatory processes ${ }^{64}$ and ethanol promotes a decrease in platelet aggregation, coagulation and other thrombotic factors ${ }^{57}$. Non-alcoholic elements of wine such as flavonoids and resveratrol with anti-oxidant and anti-inflammatory effects could also contribute to a protective effect on cognition 65 . In addition, there is experimental evidence of a potential direct effect of alcohol and wine on cognition by stimulating acetylcholine in the hippocampus ${ }^{66,67}$.

\section{Previous systematic reviews and beyond}

There are several reviews on the association between alcohol consumption and dementia, however only eight of them were systematic reviews ${ }^{25,68-74}$ and only three conducted a meta-analysis ${ }^{69,71,74}$. The way data was summarized in these systematic reviews varied greatly, especially regarding the categories of exposures being compared. Two of them looked at several other health behaviours and modifiable risk factors ${ }^{73,75}$ and in respect of alcohol concluded that findings are conflicting. The three narrative systematic reviews ${ }^{68,70,72}$ were cautious in their conclusion that light to moderate alcohol intake does not increase dementia risk ${ }^{72}$, advising that is not possible to define a specific harmless or beneficial level of alcohol intake ${ }^{70}$ and that alcohol should not be used as a means to decrease the risk of developing dementia ${ }^{68}$. Three systematic reviews ${ }^{69,71,74}$ conducted a meta-analysis, both Peters et al. ${ }^{69}$ and Neafsey \& Collins ${ }^{71}$ combined data with very different categories of alcohol intake levels and Neafsey \& Collins ${ }^{71}$ have also combined data for very different outcomes, including any dementia and cognitive decline to come up with a "cognitive risk". They both concluded that despite the heterogeneity in the data, there is some evidence that light to moderate drinking seems to reduce the risk of dementia in older adults. Anstey et al..$^{74}$ included a smaller number of studies in an attempt to combine similar data regarding the categories for light to moderate and heavy drinking, but still had a broad set of inclusion criteria. We updated their review and have been more conservative in how we combined data, distinguishing studies that had a more standard way of categorizing moderate and heavy drinking (categorising levels of consumption in the following way: moderate $=1-14$ units for women and 1-21 for men; and heavy = above these limits, or similar quantitative methods), from those including much lighter categories for moderate drinking (once a month, less than once a week, etc.). 
Based on these previous reviews and our own search we identified 38 longitudinal studies looking at the association between alcohol and dementia; 16 of them were eligible (longitudinal studies providing information for at least one of the groups compared, for directly measured incident dementia, AD or VaD, and which had measured and excluded dementia at baseline). Random effect meta-analyses were used to pool estimates. Heterogeneity was examined using $\chi^{2}$ test and quantified using Higgins $\mathrm{I}^{2}$.

\section{Drinkers versus abstainers}

\section{Alzheimer's disease}

We included four studies $37,42,76,77$ and found that drinkers are at lower risk for AD compared to nondrinkers (RR 0.66, 95\% Cl: 0.51-0.82). Heterogeneity was not statistically significant $\left(\chi^{2}=0.91 ; \mathrm{df}=3\right.$; $\left.p=0.824, I^{2}=0 \% ; 95 \% \mathrm{Cl}: 0-85 \%\right)$

\section{Any dementia}

We included two studies ${ }^{76,78}$ and found that drinkers were at lower dementia risk than non-drinkers (RR 0.68, 95\% Cl: 0.54-0.82). Heterogeneity was not statistically significant $\left(\chi^{2}=0.12 ; d f=1 ; p=0.724\right.$, $\left.\mathrm{I}^{2}=0.0 \%\right)$.

\section{Moderate drinkers versus abstainers}

For our meta-analysis we included only those studies that defined moderate drinkers according to numbers of units of alcohol consumed per week, 1-14 units for women and 1 to 21 for men (or similar).

\section{Alzheimer's disease}

We identified four studies ${ }^{79-82}$, and found that moderate drinkers were at lower risk of $A D$ than abstainers (RR 0.62, 95\% Cl: 0.54-0.69). Heterogeneity between studies was not statistically significant $\left(\chi^{2}=1.70, \mathrm{df}=3\right.$; $\left.\mathrm{p}=0.637, \mathrm{I}^{2}=0 \%\right)$.

\section{Any dementia}

We identified five studies ${ }^{79-83}$ and found that moderate drinkers were at lower risk of any dementia than abstainers (RR 0.54, 95\% Cl: 0.42-0.67) (Figure 4.5). Heterogeneity between studies was not statistically significant $\left(\chi^{2}=0.78 ; d f=4 ; p=0.941 ; l^{2}=0 \%\right)$.

\section{Heavy drinkers versus abstainers}

For our meta-analysis we have included only those studies that defined heavy drinking according to numbers of units of alcohol consumed per week, above 14 units for women and 21 for men (or similar).

\section{Alzheimer's disease}

We identified three studies ${ }^{79,80,82}$ and found no difference in the incidence of AD between heavy drinkers and abstainers (RR 1.02, 95\% Cl: 0.36-1.67). Heterogeneity between studies was not statistically significant $\left(\chi^{2}=0.14, d f=2 ; p=0.933, l^{2}=0 \%\right)$.

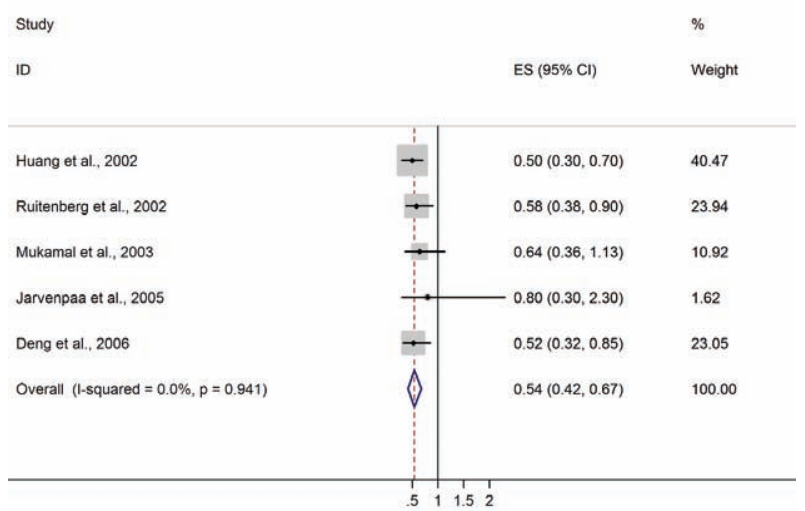

Figure 4.5

Forest plot for studies of the effect of moderate drinking versus abstainers on the outcome of incident any dementia

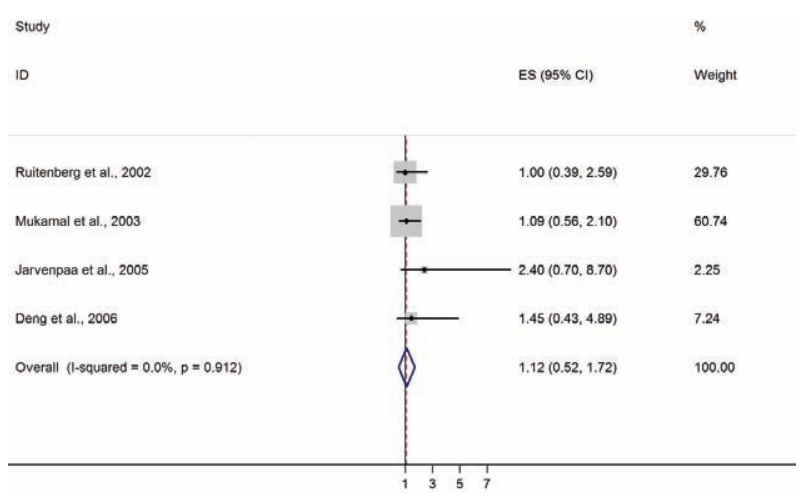

Figure 4.6

Forest plot for studies of the effect of heavy drinking versus abstainers on the outcome of incident any dementia

\section{Any dementia}

We identified four studies ${ }^{79,80,82,83}$ and found no difference in the incidence of any dementia between heavy drinkers and abstainers (RR 1.12, 95\% Cl: $0.52-1.72)$. Heterogeneity between studies was not statistically significant $\left(\chi^{2}=0.53 ; \mathrm{df}=3 ; \mathrm{p}=0.912\right.$; $\mathrm{I}^{2}=0 \%$ ).

\section{Type of beverage}

Weyerer et al. ${ }^{76}$ found similar AD and any dementia risk between those who reported drinking wine only or beer only compared to non-drinkers. Meligh et al. ${ }^{84}$ also found similar any dementia risk between those who reported drinking wine only or beer only, compared to non-drinkers.

Moderate and excessive wine, beer and spirits drinkers have been compared to abstainers in four studies $80,82,85,86$. All of them found a similar dementia risk, apart from Deng et $\mathrm{al}^{82}$ who found a lower dementia risk among moderate wine drinkers compared to abstainers. 


\section{APOE effect modification}

Only two studies looked at the interaction with APOE $^{79,80}$ and did not find differences between carriers and non-carriers when comparing dementia risk between drinkers (differing definitions) and nondrinkers.

\section{Conclusions}

Our pooled estimates show that:

- compared to abstainers, drinkers are at lower risk of AD (RR 0.66, 95\% Cl: 0.51-0.82) and any dementia (RR 0.68, 95\% Cl: 0.54-0.82)

- compared to abstainers, moderate drinkers are at lower risk of $A D(R R 0.62,95 \% \mathrm{Cl}: 0.54-0.69)$ and any dementia (RR $0.54,95 \% \mathrm{Cl}: 0.42-0.67$ )

- compared to abstainers, heavy/excessive drinkers are at similar risk of $A D(R R 1.02,95 \% \mathrm{Cl}: 0.36-1.67)$ and any dementia (RR 1.12, 95\% Cl: 0.52-1.72) risk

- there is no clear evidence that drinking wine is associated with a lower AD and/or dementia risk

- there is no evidence that the association between alcohol consumption and dementia is modified by APOE genotype

\section{Discussion}

Findings point to a lower incidence of any dementia and $A D$ among moderate drinkers compared with abstainers, and a similar incidence of any dementia and $A D$ among heavy drinkers compared with abstainers.

The fundamental problem with this evidence is the lack of detailed definition, and the heterogeneous nature of the 'abstainer' group that is used as the reference category in most studies. Lifetime abstainers include those who do not drink for cultural, religious or moral reasons, and/or who were brought up not to do so. Current abstainers also include those who have given up drinking, for health reasons (including recovering alcoholics), and following religious conversion. More detailed analysis of the literature on alcohol use and mortality has clarified that the 'abstainer' reference category actually combines low and high risk groups, and that more fine-grained classification based upon the reason/s for not drinking helps to explain more of the variance in mortality experience ${ }^{87}$. Mortality risk is low for those who abstain for religious and moral reasons, have a responsibility to family, were brought up not to drink, and are not social. Mortality risk is higher among former drinkers, and individuals who abstain because they do not like the taste of alcohol, are concerned that they will lose control, or are concerned about adverse consequences. In essence it is not the biological effects of zero alcohol intake that explains the increased mortality risk over moderate drinkers, so much as the reasons for not drinking among some non-drinkers. It seems highly likely that similar considerations apply to the association of drinking patterns with dementia incidence.

On the basis of the current evidence, one should not advise abstainers to adopt moderate consumption in the hope of reducing their risk of developing dementia. Likewise there are no health reasons for advising those who consume in moderation to alter their behaviours. While dementia risk seems to be similar in 'heavy' drinkers compared to abstainers, this should not be taken as reassurance, since,

- abstainers may themselves, overall, be at increased risk of developing dementia (see above);

- there is insufficient evidence to be clear as to whether heavy drinkers are at increased risk of dementia compared with moderate drinkers;

- the harmful effects of very heavy drinking on the brain are well established in clinical neuropsychiatric research (e.g. alcohol-related dementia, delirium tremens, Wernicke's encephalopathy and Korsakoff's syndrome);

- the potential impact on dementia incidence is insufficiently clarified in population-based studies, with a relatively low threshold applied in many studies, and few studies of the effects of alcohol dependence, harmful drinking, or binge drinking on the incidence of dementia;

- heavy drinking is associated with well-established hazards and harms to health, and is hence, for other reasons, an evidence-based priority target for health promotion and disease prevention.

Hence, despite much research interest, currently available evidence on the impact of alcohol consumption on dementia incidence is largely irrelevant to the formulation of public health policy. More research is needed, and this should focus upon a) lifetime histories of alcohol consumption, distinguishing lifetime abstainers (and their reasons for abstaining) from those who have given up drinking, b) reasons for changes in alcohol consumption, including reasons for stopping drinking, and c) more, and better studies of dose response effects among drinkers, seeking to identify risk conferring levels and patterns of drinking.

\section{Physical activity}

The ancient Latin aphorism mens sana in corpore sano (a healthy mind in a healthy body) testifies that the recognition of the key importance of physical health for mental health dates back thousands of years. This notion is still present and pervasive, with a contemporary focus on sport and physical exercise. Equally, ill health, including neurodegenerative diseases, reduce physical capability and engagement in leisure activities in general. Dementia is no exception and is associated with progressive isolation and 
functional impairments, which may precede and gradually progress after the onset of the disease. Therefore, as for many other modifiable factors, epidemiological studies and well-designed randomised controlled trials with sufficiently long follow-ups are needed to disentangle the direction of the association between physical activity and dementia. Moreover, physical activity is usually conceived as a leisure activity, which entails social and psychological engagement and interactions that are known to be important for mental health too. Therefore, valid measures of physical activities and appropriate consideration to potential confounding factors should be used to study the potential beneficial effects of physical activity. The independent association of physical activity with a lower dementia risk is plausible and has received growing attention in recent years. Epidemiological research, and animal models and basic research provide sound observational and mechanistic evidence that physical activity can be beneficial for brain health. There are both indirect and direct effects. Physical activity can help keep at bay hypertension, diabetes, hypercholesterolemia and obesity and thus can indirectly reduce dementia risk. Physical activity is also beneficial for the macro- and micro-structure and physiology of blood vessels, including those of the cerebrovascular system. Better perfusion translates into reduction of risk and burden of both diffuse and focal brain vascular damage, which is implicated in all forms of dementia and key in the vascular dementia subtype. Interestingly though, physical activity may also have a number of direct effects including reduction of amyloid burden, improvement and consolidation of neuronal structure, and enhancement of neurotransmitter synthesis. Potential mechanisms have been comprehensively reviewed by Rolland et al. in $2008^{88}$, as summarised in

\section{Box 4.1.}

Official recommendations for healthy adults ${ }^{89}$ and older adults on the types and amounts of physical activity needed to maintain and improve health have been updated in 2007 by the American Heart Association ${ }^{90}$. The evidence-base came primarily from longitudinal observational and (few) randomised controlled trials of the effects of regular physical activities on various outcomes, mainly cardiovascular risk factors and diseases, stroke, diabetes, and (breast and colon) cancers. However, two cohort studies were considered to also support the extension of recommendations to potential benefits on cognitive function ${ }^{91,92}$. In the next section we present the expanding evidence on the potential beneficial effects of physical activity to reduce risk of dementia and cognitive decline.

\section{Overview of available evidence}

\section{Evidence from the latest systematic reviews}

Numerous studies in the past decade have been conducted to explore the association between physical
Box 4.1

Beneficial effects of physical activity supported by epidemiologic and mechanistic evidence (adapted from Rolland et al. 2008 ${ }^{\mathbf{8}}$ )

\begin{tabular}{|c|c|}
\hline General mechanisms & Specific actions \\
\hline \multirow[t]{3}{*}{$\begin{array}{l}\text { Vascular and metabolic } \\
\text { pathways }\end{array}$} & $\begin{array}{l}\text { Lowering of blood pressure; better } \\
\text { glucose tolerance and reduced } \\
\text { insulin resistance; improved lipid } \\
\text { profile; healthier body weight. }\end{array}$ \\
\hline & $\begin{array}{l}\text { Improved brain perfusion (oxygen } \\
\text { and glucose) }\end{array}$ \\
\hline & $\begin{array}{l}\text { Anti-inflammatory and anti-oxidant } \\
\text { actions }\end{array}$ \\
\hline \multirow[t]{4}{*}{$\begin{array}{l}\text { Enhancement of brain } \\
\text { structure and function }\end{array}$} & $\begin{array}{l}\text { Improved dendritic, microglia and } \\
\text { vascular structure }\end{array}$ \\
\hline & $\begin{array}{l}\text { Increased neurogenesis (new } \\
\text { neurons) }\end{array}$ \\
\hline & $\begin{array}{l}\text { Reduced loss of neurons of the } \\
\text { hippocampus }\end{array}$ \\
\hline & $\begin{array}{l}\text { Improves synaptic function, and } \\
\text { neurotransmitters synthesis }\end{array}$ \\
\hline $\begin{array}{l}\text { Impact on dementia- } \\
\text { related neuropathology }\end{array}$ & Reduction of amyloid burden \\
\hline
\end{tabular}

activity and dementia/Alzheimer's disease risk, or cognitive decline, and a number of recent systematic reviews and meta-analyses are available (Table 4.3). The first comprehensive review was conducted in 2008 by Rolland and colleagues ${ }^{88}$. The authors included a very broad range of studies including animal studies (for mechanistic evidence), randomised controlled trials (conducted to test the efficacy of physical activity interventions in both cognitively healthy people and people with Alzheimer's disease to prevent dementia or reduce cognitive decline, respectively), and prospective cohort studies that examined whether physical activity level (typically self-reported) in people without dementia was associated with future dementia risk. A meta-analysis was not conducted.

One year later Hamer and colleagues conducted a new systematic review and meta-analysis on the topic ${ }^{93}$. This is a comprehensive systematic review of prospective cohort studies on risk of dementia or Alzheimer's disease as a function of physical activity level recorded in men and women who were cognitively healthy at baseline. In total 16 studies met inclusion criteria and could be included in the metaanalysis. Results clearly show that physical activity level is associated with a reduced risk of dementia (hazard ratio, $\mathrm{HR}=0.72,95 \% \mathrm{Cl}: 0.60-0.86$ ), and Alzheimer's disease ( $\mathrm{HR}=0.50,95 \% \mathrm{Cl}$ : 0.36-0.84). However, heterogeneity across studies was high and 
significant $(p<0.001)$ and overall quality of primary studies low. In a series of sensitivity analyses the authors also found more robust associations in men, and in studies of higher quality (i.e., that used more valid physical activity measures at baseline, had longer follow-ups, and adjusted for a greater number of confounders in the analysis). The authors concluded that although the type and level remain uncertain and understudied, physical activity may be protective for cognitive decline, dementia and Alzheimer's disease. The authors correctly remark that results might be, at least in part, age- and disease-confounded because reduced physical activity may be caused by dementia neuro-pathology and sub-clinical symptoms (including mild apathy) also before the onset of the disease. Indeed, in most studies included in this review participants were older than 65 years at baseline when physical activity was measured.

Finally, in a very recent systematic review published in 2014, Beydoun et al. ${ }^{24}$ retrieved 21 cohort studies on physical activity and risk of dementia, cognitive impairment or cognitive decline, which included also two newly published papers since the previous review $^{94,95}$. In the latter study, physical activity was continuously recorded, providing a more objective measure of physical activity level compared to self-reported questionnaires ${ }^{95}$. The authors metaanalysed the results of the eight studies using the more homogeneous study designs (including mean age at baseline, years of follow-up, physical activity measure, and $A D$ diagnosis). Compared to low, high physical activity level was associated with a $43 \%$ reduced risk of AD, consistently across all studies. Formal, quantitative quality assessment was not conducted, but those studies that were included in the metaanalysis were selected on the basis of their quality. As remarked for the previous reviews' findings, because physical activity level was assessed in old age also in the two additional studies included in this newer review (mean age at baseline was 77.2 years ${ }^{94}$ and 81.6 years $^{95}$ ), issues related to directionality may exist, with incipient dementia possibly causing reduction in physical activity level.

Other systematic reviews somewhat extend this evidence. For instance, Sofi et al. ${ }^{96}$ conducted a systematic review of epidemiological studies with a prospective design that assessed the association between physical activity (including levels and type) and risk of cognitive decline (not dementia diagnosis) in people without dementia or cognitive impairment at baseline. Fifteen studies met the inclusion criteria, and the relative risks from the meta-analysis clearly showed a lower risk of cognitive decline for those in the high ( $\mathrm{RR}=0.62,95 \% \mathrm{Cl}: 0.54-0.70)$, and moderate $(\mathrm{RR}=0.65,95 \% \mathrm{Cl}: 0.57-0.75)$ physical activity level groups compared to those in the low level group at baseline. A formal test for publication bias confirmed that this was unlikely, and heterogeneity was limited (Higgins' $\left.\left.\right|^{2}=33 \%\right)$ and not significant $(p=0.10)$. The authors concluded that physical activity level before dementia may reduce the risk of cognitive decline. The high variability in the measures used to assess both physical activity and cognitive decline amongst the studies included in the review was mentioned, but a series of sensitivity analyses supported the robustness of the main findings. Potential issues related to directionality in the observed associations were not discussed. As discussed above, it is possible that those who will go on to experience steeper decline in cognitive function may have involuntarily reduced their physical activity level already at baseline because of the subtle impact of sub-optimal cognitive aging on physical health, mood and lifestyles.

In another systematic review, studies that focused or at least reported findings on vascular dementia were separately considered. The Alzheimer's Society Systematic Review Group ${ }^{97}$ sought to conduct a systematic review and meta-analysis of published papers that reported findings on the association between level (and type) of physical activity and subsequent risk of developing vascular dementia (VaD), in people without cognitive impairment at baseline. Although the authors retrieved 24 studies that were potentially eligible, only five could be included in the meta-analysis. Primary studies were all conducted in older adults (70 years or more), and measures of physical activity included higher self-reported exercise level per week, derived energy expenditure per day or week, and distance walked per day. Follow-up between physical activity level and clinical diagnosis of $\mathrm{VaD}$ ranged between 4 and 7.3 years. The results of the meta-analysis clearly indicate a reduction of $\mathrm{VaD}$ risk of nearly $40 \%$. However, heterogeneity across studies was reasonably high (Higgins $\mathrm{I}^{2}=66 \%$ ) and statistically significant $(p=0.03)$, and publication bias was considered very likely (that is the likelihood that studies that might have reported null or negative results were not published). In addition to the quantitative results, the authors also report a narrative synthesis of studies that did not qualify for meta-analysis.

Overall, these studies did not report consistent significant associations between physical activity and incident dementia. Although the authors concluded that evidence supports the hypothesis that physical activity in cognitively healthy older adults may reduce risk of $\mathrm{VaD}$, caution is warranted in interpreting these results. Further longitudinal cohort studies are needed to interpret the high heterogeneity observed across the studies included in the meta-analysis. In fact, the pooled estimate may be largely influenced by the only primary study that did find a significant reduced risk of $\mathrm{VaD}$ in those with higher physical activity levels ${ }^{98}$. All the other four cohort studies included in the metaanalysis reported null associations. 
Table 4.3

Physical activity \& Cognitive function or decline - reviews

\begin{tabular}{|c|c|c|c|c|c|}
\hline 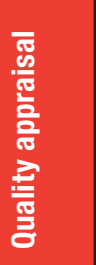 & 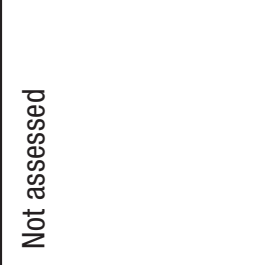 & 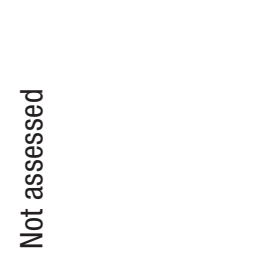 & 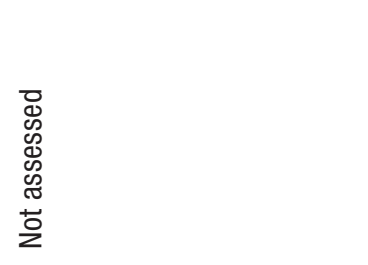 & 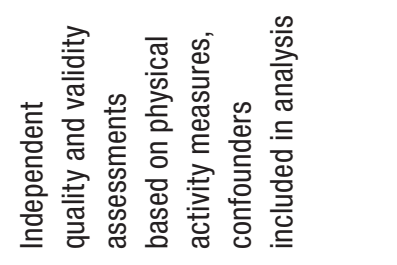 & 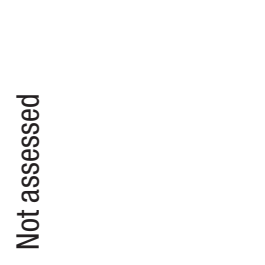 \\
\hline & 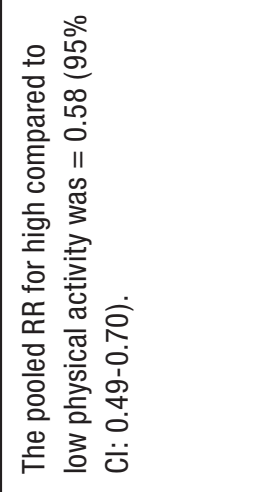 & 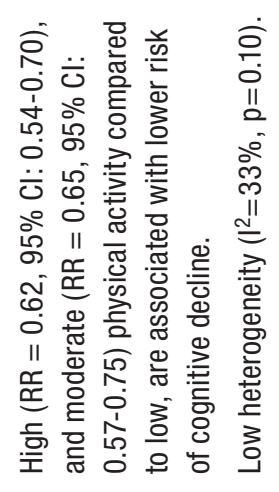 & 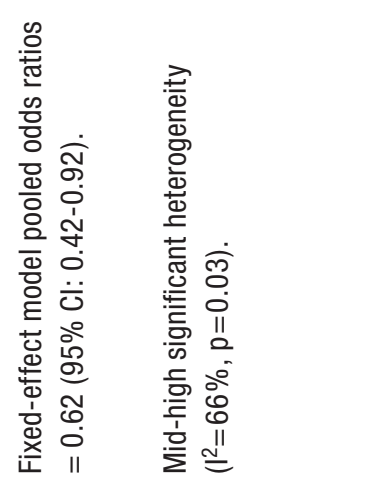 & 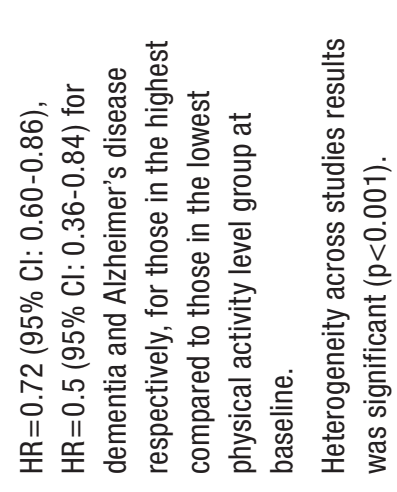 & 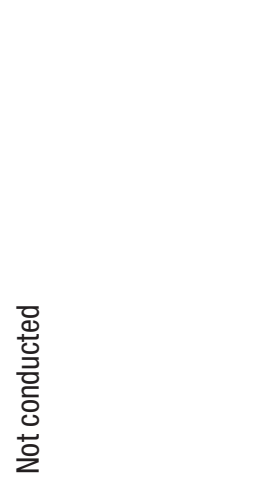 \\
\hline 음 & 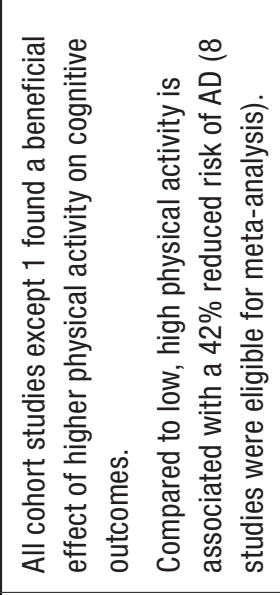 & 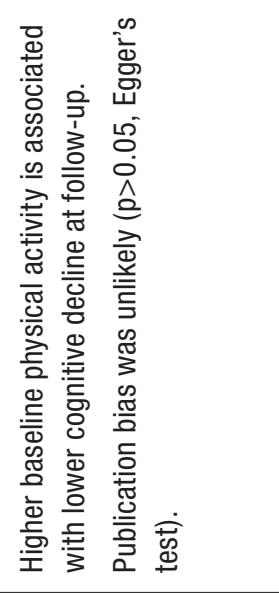 & 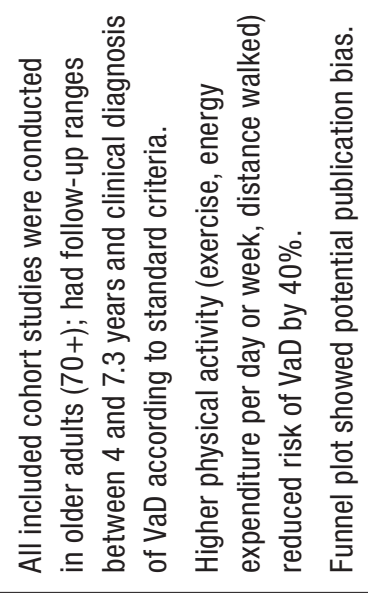 & 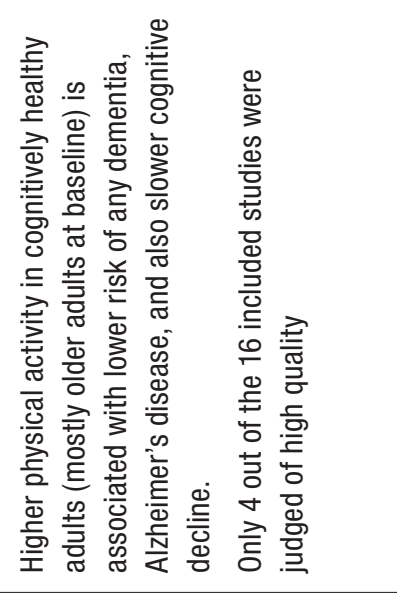 & 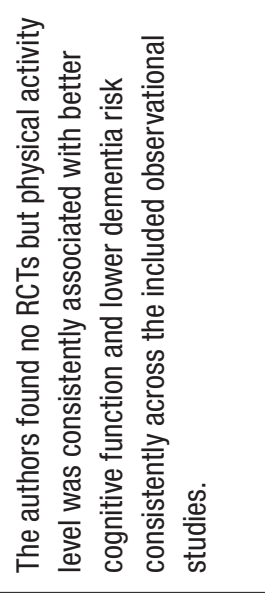 \\
\hline 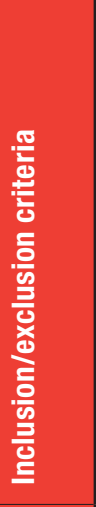 & 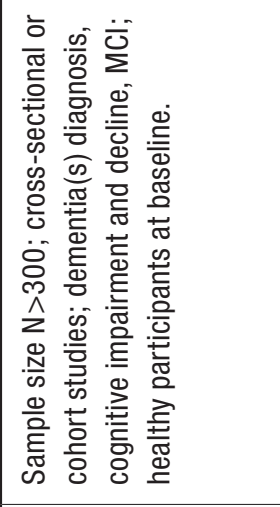 & 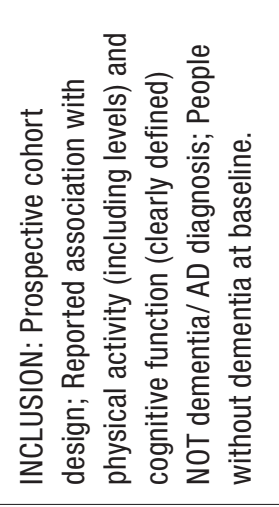 & 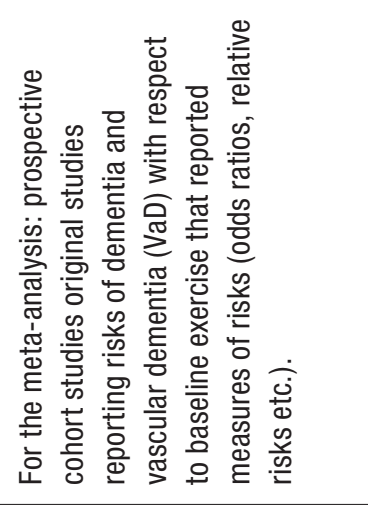 & 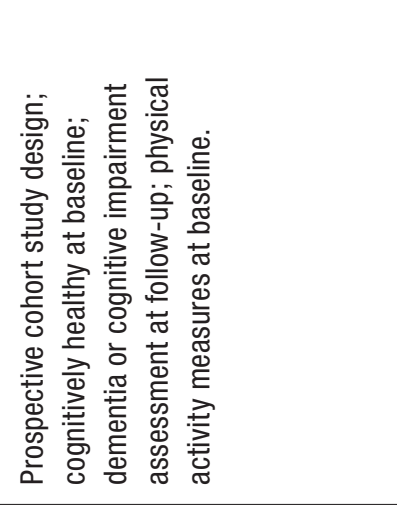 & 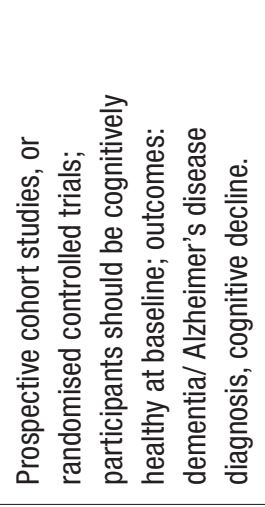 \\
\hline 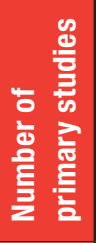 & 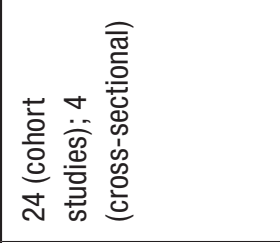 & $\stackrel{\circ}{\llcorner}$ & 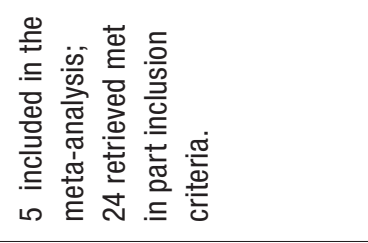 & $\stackrel{\varphi}{\circ}$ & $\stackrel{\sim}{ }$ \\
\hline 번 & 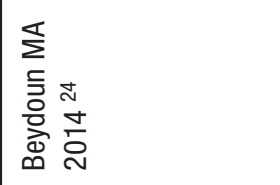 & 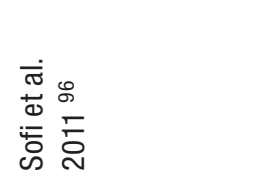 & 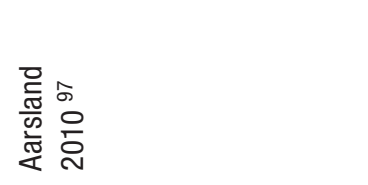 & 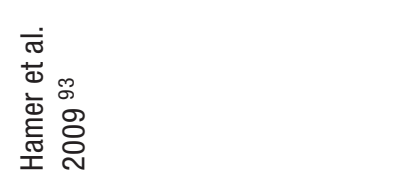 & 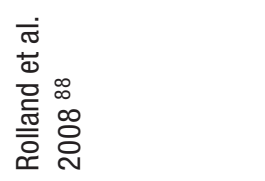 \\
\hline
\end{tabular}


Table 4.4

Physical activity \& risk of dementia - New evidence from observational studies

\begin{tabular}{|c|c|c|c|c|}
\hline & 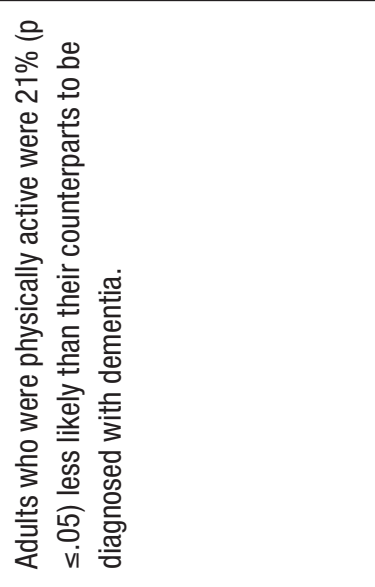 & 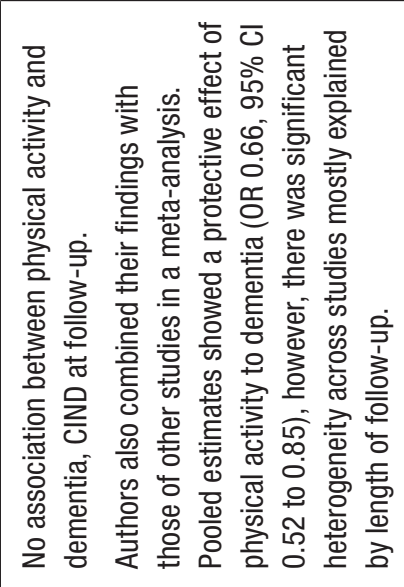 & 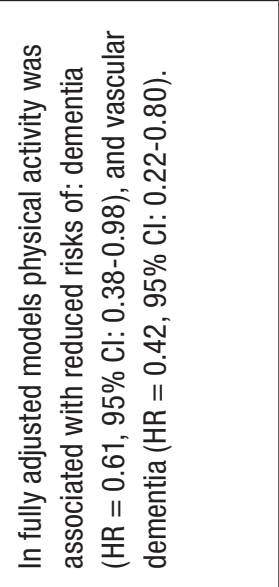 & 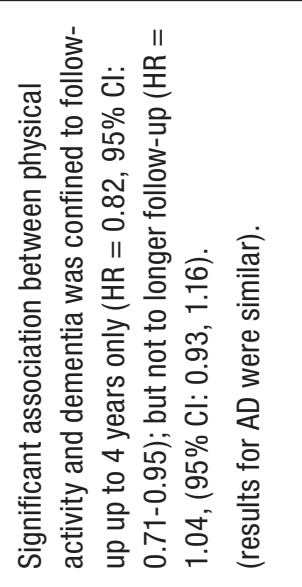 \\
\hline & 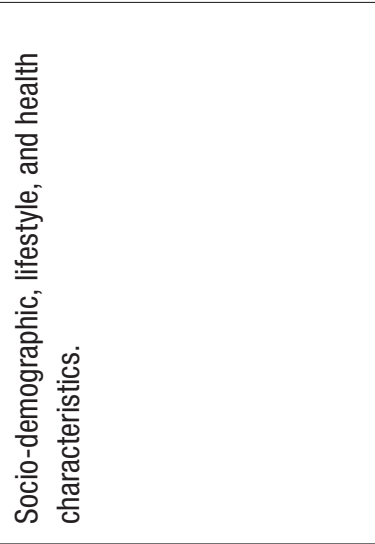 & 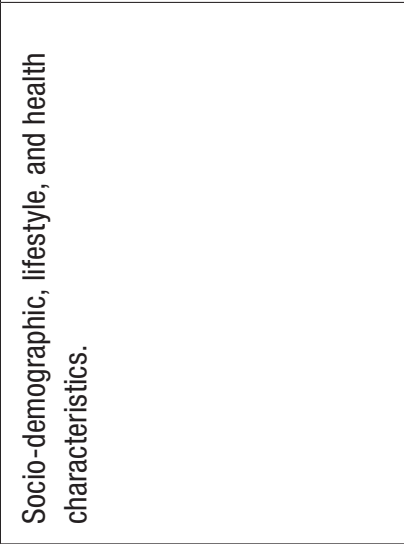 & 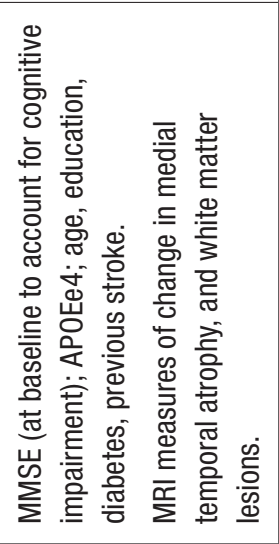 & 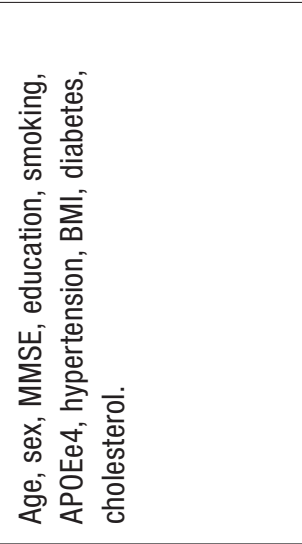 \\
\hline 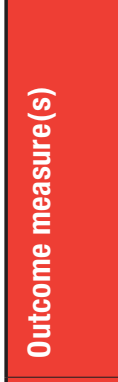 & 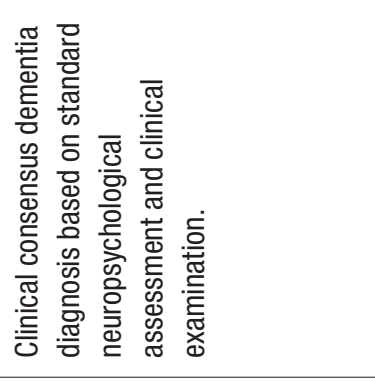 & 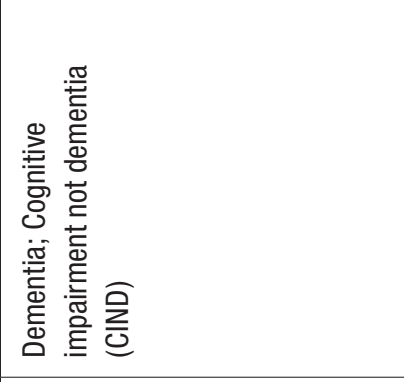 & 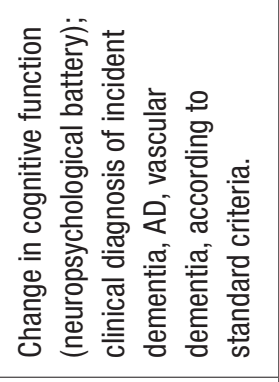 & 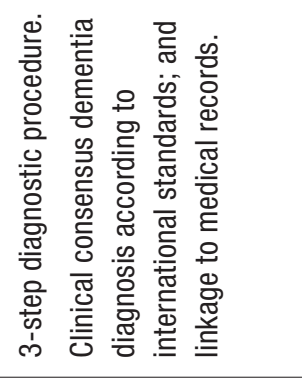 \\
\hline 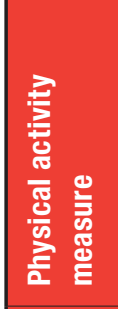 & 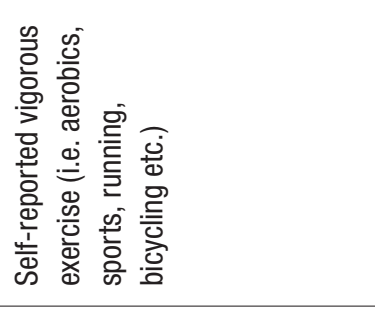 & 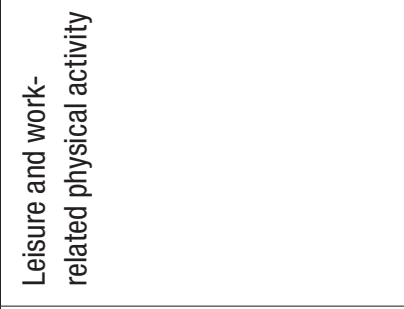 & 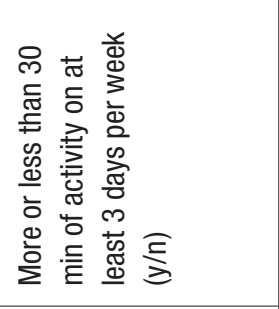 & 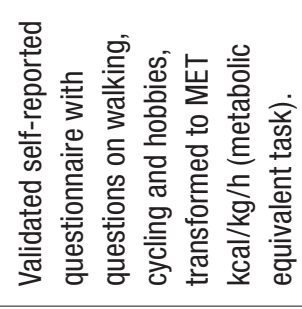 \\
\hline 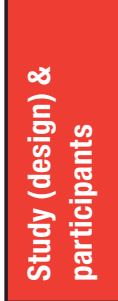 & 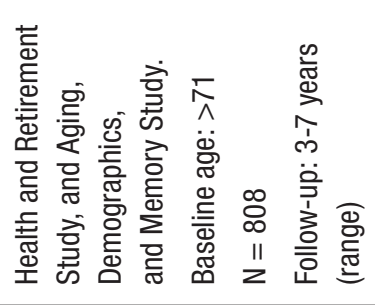 & 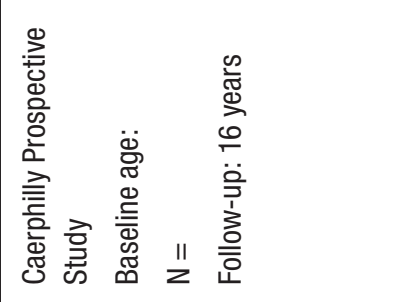 & 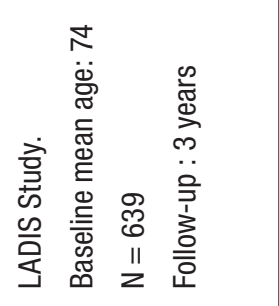 & 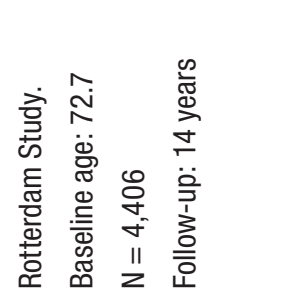 \\
\hline 音急 & 空。 & 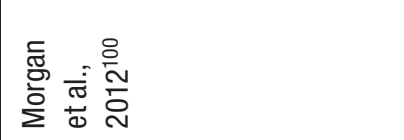 & 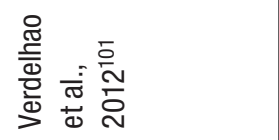 & 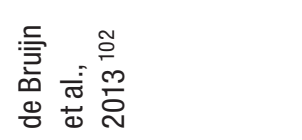 \\
\hline
\end{tabular}




\section{Evidence from new studies}

We identified four additional cohort studies that were not included in the systematic reviews described in the previous paragraph ${ }^{99-102}$. The main characteristics of these studies are presented in Table 4.4. All these were well designed prospective cohort studies with followup between baseline physical activity assessment (self-reported validated questionnaires) and cognitive outcomes ascertainment ranging between $3^{101}$ and 14 years $^{100,102}$. In all studies baseline physical activity was measured in old age, when participants were 70 years or older. Cognitive assessments were based on validated procedures, and diagnosis made according to standard international criteria. All studies controlled for socio-demographic and health characteristics in the analysis. In addition, in the LADIS Study MRI data were also available and were used in the analysis as covariates along with MMSE scores at baseline, to account for the potential reduction in physical activity caused by neuropathological burden or baseline cognitive level ${ }^{101}$. In the Rotterdam study and in the Caerphilly Prospective Study two follow-up periods were separately considered to account for potential reverse causality (i.e. cognitive impairment causing a reduction in physical activity) ${ }^{100,102}$. Results were consistent with those of recent systematic reviews for the two studies with shorter follow-up periods (3 years), with an average $40 \%$ reduction in dementia risk associated with high compared to low physical activity level at baseline 99,101 . Conversely, the association was not significant before and after adjustment in either in the Rotterdam study or in the Caerphilly Prospective Study, particularly when the longer follow-up period (more than 4 years) was analysed separately in the Rotterdam study ${ }^{102}$ and after 14 years in the Caerphilly Prospective Study ${ }^{100}$ (Table 4.4). In addition to the main results, Morgan et al. conducted a meta-analysis combining their findings with those of existing cohort studies. Although the pooled estimate showed a significant inverse association between physical activity and dementia (pooled OR of dementia for high compared to low physical activity $=0.66,95 \%$ $\mathrm{Cl}$ : 0.52-0.85), there was a marked and significant heterogeneity across studies that was largely explained by length of follow-up. The hypothesised potential protective effect of physical activity was consistently reported in studies with smaller samples and shorter follow-up periods, which represent the large majority of available studies to date. The authors concluded that "The apparent protective effects of physical activity on cognitive health may partially reflect reverse causation and current estimates may be overly optimistic in terms of cognitive benefits" 100 .

Finally, it is important to note that in only three studies physical activity was assessed in midlife $e^{103-105}$. Interestingly, in two of these the association between midlife physical activity and subsequent dementia risk (ascertained up to 30 years later) was statistically significant and of the same magnitude found in the available meta-analysis (around 40\%) in one study ${ }^{105}$ and even greater (more than 52\%) in the study with an average 20 years follow-up ${ }^{104}$. The third study with midlife physical activity did not find significant associations with dementia in late-life, but occupational physical activity was combined with leisure physical activity, which may confound results ${ }^{103}$.

\section{Evidence from randomised controlled trials}

We could not find any randomised controlled trial that tested the efficacy of physical activity to delay onset or reduce risk of dementia in cognitively healthy participants. However, numerous randomised controlled studies (RCTs) have been conducted to test whether physical exercise (typically aerobic) improves cognitive performance. Smith et al. ${ }^{106}$ recently carried out a systematic review and meta-analysis of RCTs conducted in people without dementia (but RCTs in those with $\mathrm{MCl}$ or comorbidities were also included) to test whether an aerobic exercise program (that lasted at least 1 month) had any effect on change in cognitive test performance (various tests) (Table 4.5). The review authors grouped neuropsychological tests by cognitive domain and reported results accordingly, and found that aerobic exercise was associated with small but significant improvements in cognitive test scores at follow up for executive function ( $p=0.02 ; 19$ RCTs), attention \& processing speed ( $p=0.003 ; 24 \mathrm{RCTs})$, memory $(p=0.03)$; but not working memory $(p=0.64$; 12 RCTs). However, pooled estimates were calculated with Hedge's $g$ but whether this was corrected $\left(g^{\star}\right)$ to account for the overall small sizes of primary studies was not reported. Therefore, pooled estimates may be over-estimates, and statistical significance may not be correct, with biased (i.e. too narrow) 95\% Cl. In conclusion, the small effect sizes found in this meta-analysis, coupled with the uncertainty regarding the appropriateness of the meta-analysis statistics, suggest extreme caution in drawing conclusions that short aerobic exercise programs may improve cognitive performance in adults (including elderly people, and people with $\mathrm{MCl}$ ). This is in line with evidence that suggest that there are potential beneficial effects for dementia when one is physically active for several years of one's life, because all mechanisms described above likely act gradually over long periods of time.

\section{Conclusions}

There are a very large number of observational studies that have explored the association between physical activity and dementia. Conversely, there are no RCTs that specifically tested the potential protective effect of physical activity programs to reduce dementia risk.

The evidence from observational studies is inconsistent, and although taken together the results of the available studies seem to suggest that physical 
Table 4.5

Characteristics of the systematic review on physical exercise and neurocognitive impairment

\begin{tabular}{|c|c|c|c|c|c|c|}
\hline $\begin{array}{l}\text { Author, } \\
\text { year }\end{array}$ & Title & $\begin{array}{l}\text { Number } \\
\text { of } \\
\text { primary } \\
\text { studies }\end{array}$ & $\begin{array}{l}\text { Inclusion/exclusion } \\
\text { criteria }\end{array}$ & Findings & Meta-analysis & $\begin{array}{l}\text { Quality } \\
\text { appraisal }\end{array}$ \\
\hline $\begin{array}{l}\text { Smith } \\
\text { et al., } \\
2010^{106}\end{array}$ & $\begin{array}{l}\text { Aerobic } \\
\text { Exercise and } \\
\text { Neurocognitive } \\
\text { Performance: a } \\
\text { meta-analysis } \\
\text { review of } \\
\text { randomised } \\
\text { controlled } \\
\text { trials. }\end{array}$ & $\begin{array}{l}29 \text { (only } \\
\text { RCTs) }\end{array}$ & $\begin{array}{l}\text { Young, middle aged } \\
\text { and older adults, } \\
\text { cognitively healthy or } \\
\text { with mild cognitive } \\
\text { impairment or } \\
\text { comorbid conditions; } \\
\text { randomised } \\
\text { clinical trial design } \\
\text { (RCT); randomised } \\
\text { treatment allocation; } \\
\text { intervention: } \\
\text { supervised aerobic } \\
\text { exercise that last at } \\
\text { least } 1 \text { month. }\end{array}$ & $\begin{array}{l}\text { Aerobic exercise was } \\
\text { associated with small but } \\
\text { significant improvements } \\
\text { in cognitive test scores } \\
\text { at follow up for executive } \\
\text { function ( } p=0.02 \text {; } \\
19 \text { RCTs); attention } \\
\& \text { processing speed } \\
\text { ( } p=0.003 ; 24 \text { RCTs); } \\
\text { memory ( } p=0.03) \text {; but not } \\
\text { working memory ( } p=0.64 \text {; } \\
12 \text { RCTs); }\end{array}$ & $\begin{array}{l}\text { Pooled effect sizes } \\
\text { (non-corrected } \\
\text { Hedge's G) were: } \\
0.158(0.05,0.260) ; \\
0.123(0.021,0.225) ; \\
0.032(0.103 ; \\
0.166) ; 0.128(0.015 \text {, } \\
0.241) \text { for attention, } \\
\text { executive function, } \\
\text { working memory and } \\
\text { memory, respectively }\end{array}$ & $\begin{array}{l}\text { Not } \\
\text { assessed }\end{array}$ \\
\hline
\end{tabular}

activity may be associated with up to a $40 \%$ reduction in dementia risk, more recent studies with longer follow-up reported consistently negative results. Although the evidence from the numerous RCTs that tested the short term effects of physical activity programs and aerobic exercise on cognitive function showed small but consistent encouraging results, recommendations cannot be made for physical activity as an effective way to prevent or delay onset of dementia. Randomised controlled trials are warranted, and the type, intensity and duration of physical activity interventions should be considered and possibly tested because the positive effects of physical activity on health, particularly on vascular risk factors and diseases, have been demonstrated, and these are in turn related to dementia.

\section{Cognitive stimulation}

\section{Introduction}

There is great interest in whether engaging in cognitively stimulating activities may exert benefits on the brain and preserve, or even improve cognitive function. The simple idea that cognitive activities may be as beneficial for brain function as exercise is for physical health is biologically plausible. Experimental studies in both animals and humans have shown that mentally stimulating activities are related to measurable improvements in brain vascular health ${ }^{107,108}$, and in both brain structure (i.e. neurogenesis) ${ }^{109,110}$ and function (i.e. formation and reactivity of synapses) $)^{111,112}$.

However, dementia has a significant impact on all leisure activities. A gradual reduction in cognitive activity level is very often a prodromal sign of dementia itself. This is due to the progressive difficulties caused by cognitive impairment and to early manifestations of neuropsychiatric symptoms including apathy and depression. Therefore, similarly to other risk and protective factors, studies that explore the association between cognitive activities in late-life and dementia risk are prone to bias, because causes and effects are not easily discernible. Nonetheless, cognitive stimulation may be beneficial for cognitive function in old age in both people with and without dementia. Specific intervention programs have been developed and tested in clinical trials. Moreover, because videogames are very popular, and one third of active players are baby-boomers who are now at risk of dementia, there is growing interest in computer-based cognitive stimulating interventions. Some videogames have already been marketed to older adults with the promise of maintaining cognitive health. Interestingly, the commercial success of these videogames may be seen as a scale up of a prevention program in a high-risk subgroup of the population, although the publicised potential beneficial effects remain to be demonstrated.

In the next paragraph we will focus on evidence from prospective epidemiological studies that investigated the relationship between cognitive activity and cognitive impairment or dementia measured at follow-up. This evidence relates directly to the cognitive reserve hypothesis, which suggests that cognitive activity may lead to structural and functional advantages, buffering the effects of neuropathology on cognition ${ }^{113}$. Computer based cognitive activities programs are components of multi-domain interventions of recently completed or still ongoing randomised controlled trials designed to test their potential to reduce risk of incident dementia in older adults at higher risk ${ }^{1}$. Results from these studies are awaited and should be reported in the coming 
months; this evidence will have a considerable impact on the development and scale up of secondary prevention programs mainly in older adults at risk of dementia. Here we focus primarily on those studies that investigated whether lifelong engagement in intellectual activity, mainly measured in mid-life, may prevent cognitive impairment and dementia later in life, reducing the occurrence or delaying the onset of clinical symptoms of dementia.

\section{Overview of available evidence}

\section{Evidence from the systematic reviews}

Thirteen observational studies have been included in a systematic review conducted in 2010 on the association between leisure cognitive activities and dementia risk ${ }^{114}$. Six studies measured cognitive activity in mid-life, five of these were case-control and only one a cohort study. Seven cohort studies focused on older adults. There was a large variety of type and duration across the leisure cognitive activities assessed in these studies, and comparisons between studies may not be appropriate, nor could results be pooled. However, most studies reported an overall inverse association between higher cognitive activities and lower dementia risk or slower cognitive decline. The type of activity seems to be very important. For instance, one study reported a reduction in dementia risk in people exposed to activities that required an active intellectual involvement, but an increased dementia risk in other type of activities, such as television watching ${ }^{115}$. Although results are extremely consistent across epidemiological studies, it is worth noting that evidence from studies with a prospective design remains extremely limited ${ }^{116,117}$. Stern and Munn who conducted this systematic review warned that caution is recommended in interpreting their results ${ }^{114}$.

\section{New studies}

In a recent report from the Rush Memory and Aging Project self-reported cognitive stimulating activities (including reading and writing) in a group of 300 cognitively healthy men and women were associated with a slower cognitive decline in the 6 years before death. The authors enquired about cognitive activity levels at different epochs in life at baseline, when participants were older than 55 years of age. Activities in childhood and midlife were significantly associated with slower cognitive decline in late-life. This was a clinic-pathological study in which post-mortem measures of brain pathology were also available and accounted for in the analysis, and all association between self-reported lifelong cognitive activity levels remained statistically significant ${ }^{118}$.

The association between level of intellectually engaging activities reported in old-age and lower dementia risk or slower cognitive decline has also been consistently reported in several other recent publications. We report here results from cohort studies, with prospective designs, carried out in regions or amongst ethnic groups that were previously little studied. This includes studies from Germany, China, and in ethnic minorities in the USA. Overall there seems to be a good geographical consistency in the association of self-reported level of cognitive activity and lower risk of dementia, better cognitive function or slower cognitive impairment, with only one recent study from Sweden reporting negative results ${ }^{119}$. The characteristics and main findings of these recent studies are reported in Table 4.6.

In a study conducted in the provinces of Sichuan and Shandong, lower level of mental activity, including board games and writing and reading, was linked to an increased probability of dementia diagnosis after a short follow-up period of 2.4 years. The engagement in cognitive activity was reported at baseline, when participants were 65 years or older, but a large number of covariates and potential confounders were included in the analysis, and baseline cognitive function did not modify the observed associations between mental activity and reduced dementia risk ${ }^{120}$.

In the German Interdisciplinary Longitudinal Study on Adult Development and Aging (ILSE) Study about 300 older adults were followed-up for 12 years. Participation in cognitively stimulating leisure activities, such as reading, writing, solving crosswords, courses and professional training attendance, was self-reported at baseline, when participants were on average 74 years old. A significant reduction in risk of Mild Cognitive Impairment or AD diagnosis in those who reported high compared to low level of cognitive activities (combined OR $=0.38,95 \% \mathrm{Cl}$ : 0.15-0.99). However, only sex and self-reported depressive symptomatology were adjusted for in the final statistical model, despite the availability of measures of educational achievement and socio-economic status $^{121}$.

A detailed, validated questionnaire about cognitive activity was used in the Memory and Aging Project (MAP), and Minority Aging Research Study (MARS) in older adults (70+) including men and women of Hispanic and black ethnicity ${ }^{122}$. A cross-sectional analysis showed that those who reported higher participation in cognitive stimulating activities had better cognitive performance in a large number of neuropsychological tests. Although both cognitive activity level and cognitive test scores were lower in Hispanics (reflecting the social disadvantage of this ethnic group), associations between past and current participation in intellectually stimulating activities and cognitive function did not vary across ethnic groups. The authors remarked that interventions to improve participation in cognitive stimulating activities throughout life, including the enrichment of the domestic environment, may be particularly beneficial in those who are most socially disadvantaged. 
Null findings have also been recently reported. The association between self-reported cognitive activity and risk of incident dementia was not significant in a Swedish study (the Betula prospective cohort Study) of 1,474 individuals (average age $=73.7$ years), who were assessed using a postal questionnaire for their engagement in activities, and who had a maximum follow up of 12 years ${ }^{119}$.

In another recent publication from the Rush Memory and Aging Project, a prospective population-based cohort study, the patterns of reduction in engagement in mentally stimulating activity and cognitive performance measured annually over five years were examined in more than 1,000 older adults who were 80 years or older at baseline. The authors conducted advanced statistical modelling to explore the reciprocal relationships between the two patterns of decline in order to determine the direction of this relationship. The main finding was that lower activity was associated with a subsequent steeper cognitive decline, but that lower cognitive performance did not predict reduction in cognitive activity. These results were robust to a number of alternative model specifications taking into account for cognitive impairment at baseline (i.e. those who met $\mathrm{MCl}$ diagnostic criteria were excluded from the analysis), and to explore associations in specific cognitive domains ${ }^{123}$.

In the Chicago Health and Aging Project study, cognitive activity was assessed at baseline when participants were free of dementia and its association with the progression of cognitive decline amongst those who subsequently received a diagnosis of $A D$ or $\mathrm{MCl}$ was investigated to explore the potential beneficial effect of pre-morbid cognitive activity on AD prognosis. The authors concluded that cognitive activity in old age, before dementia onset, may improve the prognosis of the disease slowing the progression of cognitive impairment ${ }^{124}$, probably through the enhancement of cognitive reserve.

\section{Conclusions}

Although evidence from prospective cohort studies is limited, consistent results from a large number of observational studies that measured cognitive activity in late-life seem to support the hypothesis that this may be beneficial for both brain structure and function. Dementia-related brain damage likely starts up to decades before the clinical onset of dementia, and the effects of incipient neuropathology on the level and type of intellectual activity is not known. As stated earlier, this is the main reason why the current corpus of evidence on cognitive activity and risk of dementia should be interpreted with caution. The observed lower cognitive activity levels in those who will go on to show clinical symptoms of dementia may in fact be a prodromal sign of the disease itself. However, evidence from randomised controlled trials that are being conducted on both cognitively healthy subjects and on people at greater risk of dementia will help to elucidate this unresolved issue, and support the development and implementation of primary and secondary prevention interventions. Finally, there are suggestions that the type of cognitive activity warrants further investigation. Although we were not able to retrieve any population-based prospective study that explored the association between playing video games and dementia risk there is an increasing interest as to whether computer-based cognitive stimulating activities may be beneficial. This is relevant, because the number of people who play video games in the past decades has steadily increased such that even small beneficial effects may have significant public health implications that need to be carefully studied to account for a likely reduction in physical activity levels due to the sedentary lifestyle, typically associated with video gaming.

\section{Diet}

The association of diet and nutrients with cognitive function, impairment and dementia has received much attention in past decades. Evidence from crosssectional studies showed that compared to adults with dementia, healthy older people tend to have a healthier diet, richer in fruits and vegetables, rather than meat, processed carbohydrates and fats. Because dementia alters dietary habits, these initial studies have been useful in generating hypotheses but could not prove any causal link. Prospective cohort studies with long follow-up intervals are needed to clarify the direction of the association under study. When associations are biologically plausible, reported consistently across numerous studies and independent of potential confounding factors, epidemiologic evidence can inform dietary recommendations to reduce risk of dementia in populations.

Experimental evidence from randomised controlled trials always provides the best basis for guiding treatment and prevention strategies. However, dementia is a multifactorial chronic disease, with a long latent period between the beginning of complex pathophysiological mechanisms and the clinical, detectable onset of symptoms. Definitive trials may therefore be difficult to conduct, particularly when treatment or prevention may need to be implemented in midlife to delay or prevent dementia onset in latelife, and their feasibility to test the effect of diet on dementia risk may be limited.

Earlier in the year we published a report on dementia \& nutrition ${ }^{126}$ and here we summarise the evidence specific to nutrient deficiencies and nutrient supplementation. For further details and all the references please see the published report.

\section{B Vitamins}

$B$ vitamins are organic, water-soluble, chemical compounds that cannot be synthesised in sufficient quantities by an organism and have to be acquired 
Table 4.6

Evidence from new studies or studies not included in published reviews.

\begin{tabular}{|c|c|c|c|c|c|c|c|}
\hline 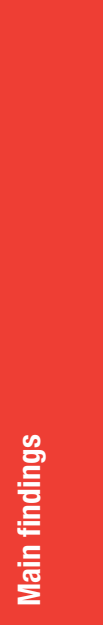 & 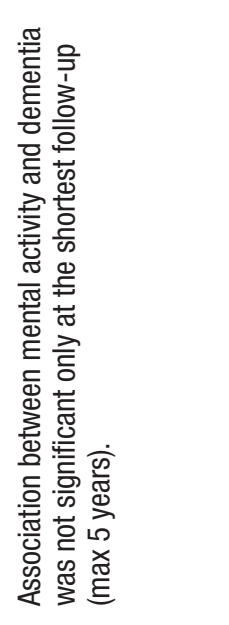 & 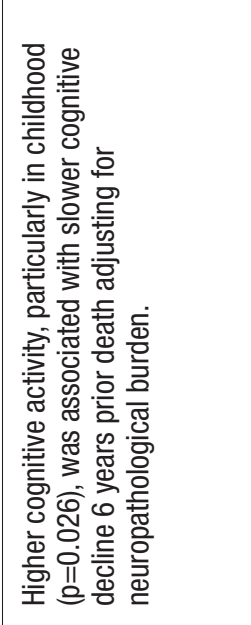 & 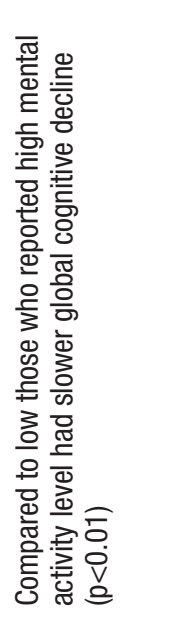 & 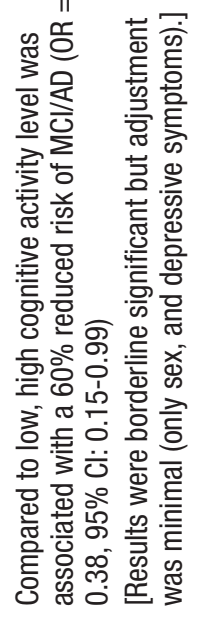 & 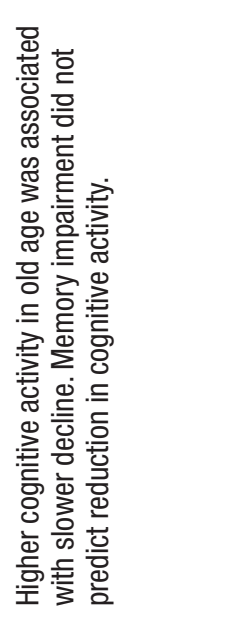 & 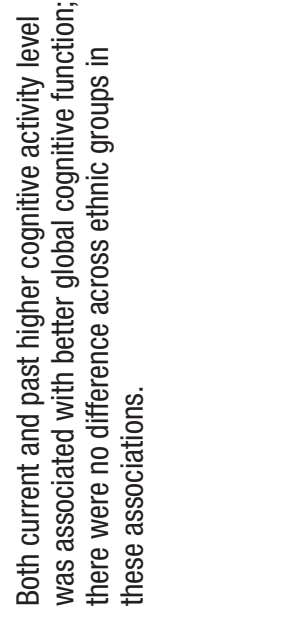 & 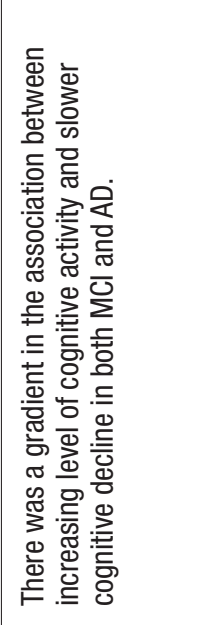 \\
\hline రें & & 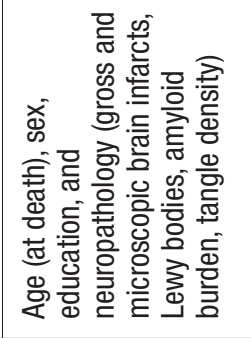 & 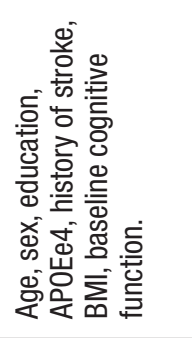 & 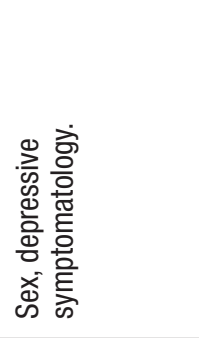 & 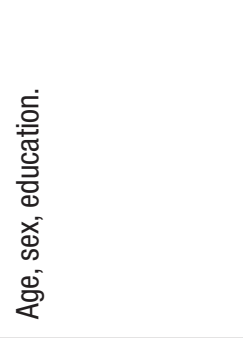 & 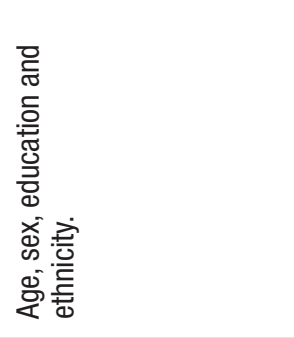 & 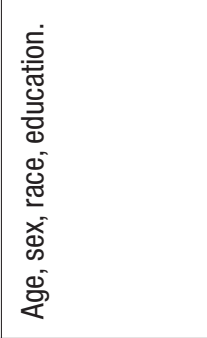 \\
\hline 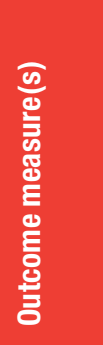 & 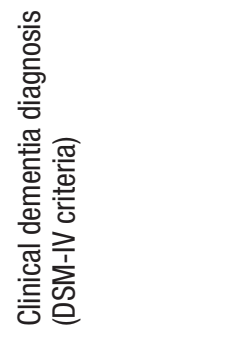 & 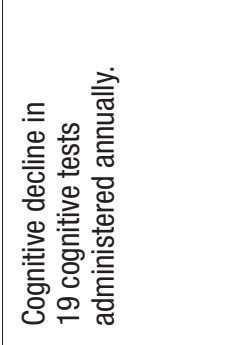 & 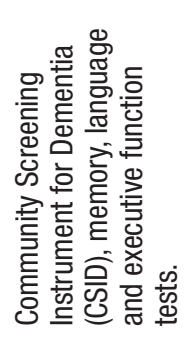 & 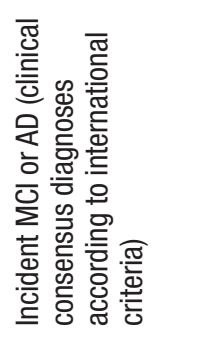 & 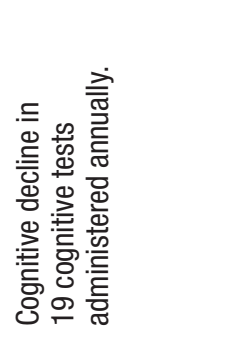 & 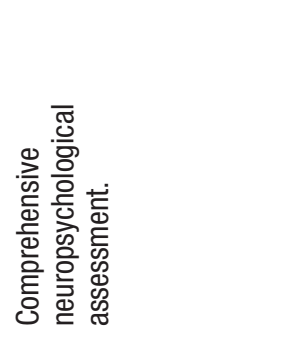 & 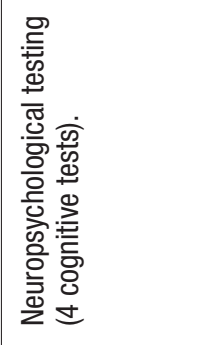 \\
\hline 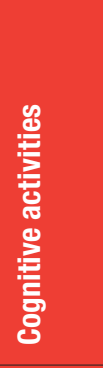 & 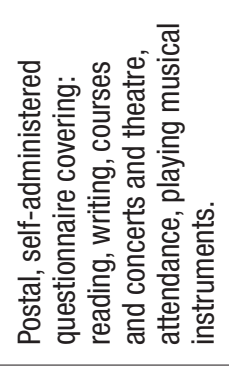 & 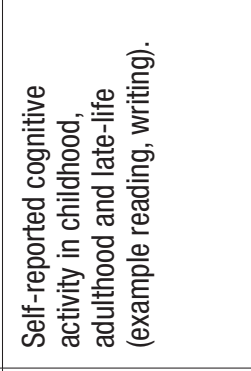 & 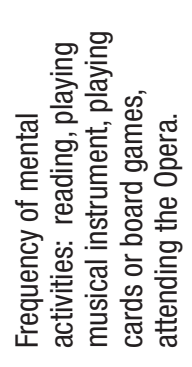 & 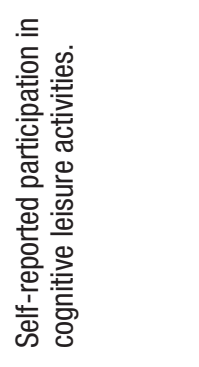 & 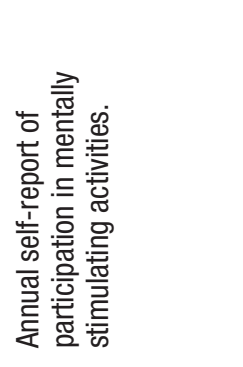 & 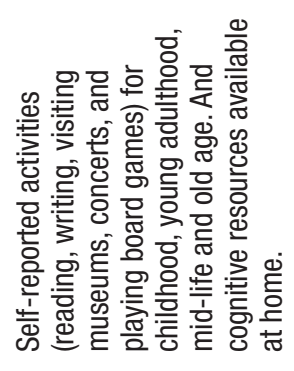 & 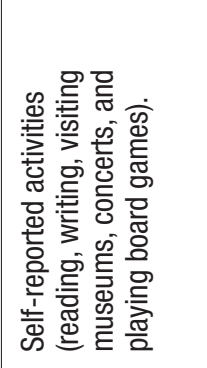 \\
\hline 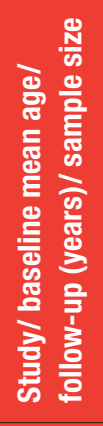 & 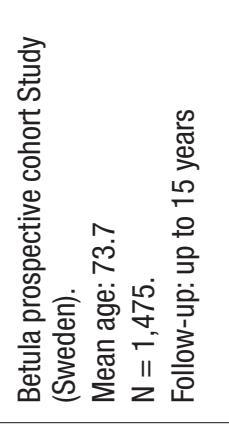 & 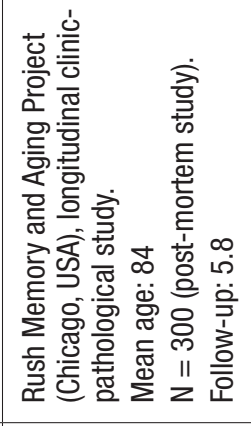 & 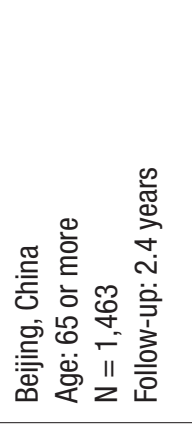 & 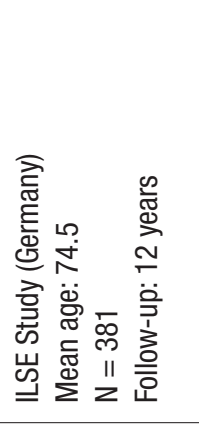 & 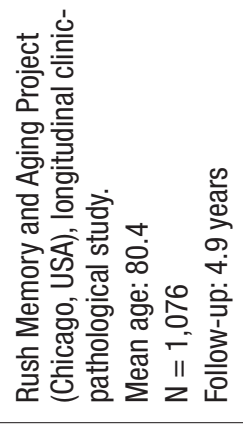 & 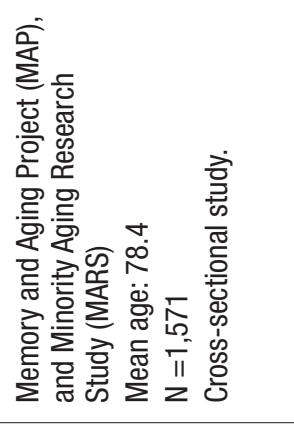 & 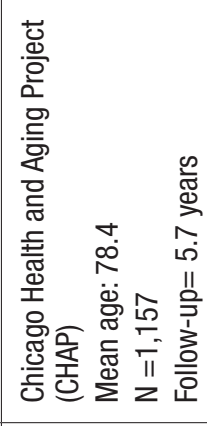 \\
\hline 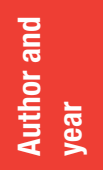 & 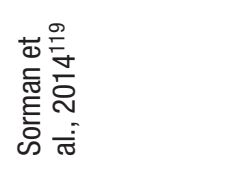 & 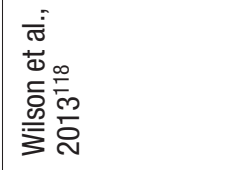 & 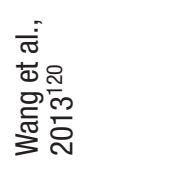 & 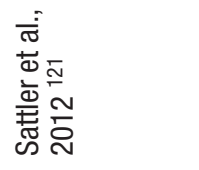 & 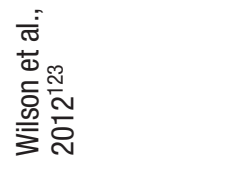 & 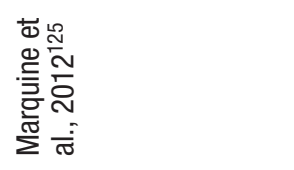 & 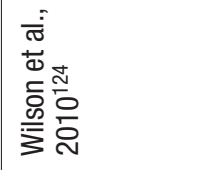 \\
\hline
\end{tabular}


through diet. B vitamins play key roles in cell metabolisms. There are eight different chemically distinct types of Vitamin B, with B6, B9 and B12 all being linked with protective roles in cognition. When folate or Vitamin $B_{12}$ are deficient, homocysteine levels rise, which may contribute to amyloid and tau protein accumulation and neuronal death. Homocysteine stimulates apoptosis and neurotoxicity (leading to nerve cell death), and platelet activation (contributing to white matter lesions, vascular injury and ischaemic strokes $^{127}$.

The association between $B$ vitamins and cognition has been the subject of several recent systematic reviews and since the latest reviews a number of new studies have been published. Cohort studies have produced inconclusive evidence on the association between vitamin-B deficiency and cognitive decline, but have seemed to confirm that high levels of homocysteine are associated with poorer cognition. Some new randomised controlled trials have also been published in the past couple of years with mixed results. Randomised controlled trials have shown that supplementation with $B$ vitamins can consistently reduce levels of homocysteine ${ }^{128-130}$, but that this does not necessarily translate into slower cognitive decline, improvement in cognitive function or reduction in dementia incidence. It is important to note that more encouraging findings have been reported in individuals with higher homocysteine levels at baseline ${ }^{131}$, suggesting that those with clear and defined deficiencies may be the ones who could actually benefit from vitamin supplementation.

\section{Antioxidants}

Antioxidants are thought to act against neurodegeneration by limiting the production of toxic substances and by reducing damage by free radicals $^{132}$. There are relatively fewer antioxidant enzymes specifically focused on neuronal protection, suggesting that antioxidant nutrients may have a more prominent role in older and ageing brains than in other organ systems ${ }^{133}$. There is currently insufficient evidence from either longitudinal studies or randomised controlled trials to support a role for antioxidants in cognition. The only consistent associations were reported in studies that have assessed vitamin E status using food frequency questionnaires, rather than biochemical measures, suggesting that more work is needed to better understand these nutrients and their relationship with dementia.

\section{Omega-3}

Omega-3 PUFA (polyunsaturated fatty acids) cannot be synthesised in the human body but are very important, particularly for the brain - they are an essential dietary constituent. Dietary omega-3 PUFA are important throughout life, from before birth (particularly during the third trimester of pregnancy), to older age when diets poor in omega-3 PUFA accelerate the physiological reduction of their concentration in cell membranes in the nervous system. Omega-3 PUFA may be implicated in the vascular, inflammatory and also the amyloid pathways of dementia, and are therefore potentially important in vascular dementia, Alzheimer's disease and mixed forms.

The evidence on the beneficial effects of fish consumption to prevent dementia incidence is, overall, conflicting, but a protective role does not seem to exist. Healthy lifestyles and life circumstances (including socio-economic and educational level) that are associated both to higher fish consumption and lower dementia risk may explain the positive results found by some studies ${ }^{134}$.

Evidence from experimental studies on the beneficial effects of omega-3 PUFA supplementation is insufficient to recommend their use in populations either for the prevention, or treatment or amelioration of dementia ${ }^{135,136}$. But dietary recommendations to increase the amount of the intake of omega-3 PUFA from foods and the use of supplements in those who be deficient in these fatty acids, particularly of DHA, seems indicated for other reasons.

Some issues related to experimental studies may exist that could explain the weak results reported so far. Longer follow-ups may be needed to observe significant changes in cognitive function in primary prevention trials because changes in cognitive function were somewhat minimal in both the treated and placebo arms of existing trials. An additional concern exists regarding the experimental integrity of these trials, because the absence of limitations in fish consumption may have diminished the difference in total dietary omega-3 PUFA intake between those who were given the supplement and those who receive placebo.

\section{Mediterranean diet}

The Mediterranean diet, which consists of a high intake of cereals, fruits, fish, legumes, and vegetables, has been associated with reduced risk for a number of outcomes, including cardiovascular disease, type 2 diabetes, some forms of cancer and overall mortality ${ }^{137}$. Three main biological mechanisms, relating to impact on the vascular system, oxidative stress and attenuation of the inflammatory pathway, have been proposed to support these associations. The Mediterranean diet could reduce the risk of dementia by affecting the vascular system, reducing cardiovascular disease, which in itself is a risk factor for dementia. The Mediterranean diet could increase the concentration of plasma neutrophins, which usually protect neurons against oxidative stress ${ }^{138}$. Furthermore, the Mediterranean diet could reduce the risk of dementia by limiting pro-inflammatory cascades $^{61,62}$. 
There is moderate evidence suggesting a positive link between adherence to the Mediterranean Diet and reduced dementia risk. Not all the studies did, however, report positive findings, in particular regarding cognitive decline. Only one study, the PREDIMED-NAVARRA randomised trial has attempted to test this association in an experimental design, by comparing a nutritional Mediterranean diet intervention supplemented with either extra-virgin olive oil (EVOO) or mixed nuts, with a low-fat control diet. The intervention, lasting 6.5 years showed encouraging results; participants that supplemented Mediterranean diet with EVOO but not with mixed nuts, had better cognitive function, and less incident mild cognitive impairment (MCl) than the control group (OR for $\mathrm{MCl}$ $=0.34,95 \% \mathrm{Cl}: 0.12-0.97)^{139}$. Implementing such an intervention on a large scale, and in a sustainable way, would be challenging. More intervention studies are needed to further understand the preventive role of Mediterranean diet, and the active ingredients for improving cognitive function and reducing dementia risk.

\section{Conclusions}

There is currently insufficient evidence to confirm a relationship between the micro- and macronutrients described above (vitamin B6, vitamin B12, folate, vitamin $\mathrm{C}$, vitamin $\mathrm{E}$, flavonoids, omega-3, Mediterranean diet) and cognitive function. Although some studies have shown positive results, particularly those using cross-sectional designs, the findings have not been consistently supported in prospective cohort studies, and preventive interventions have generally failed the critical test of randomised controlled trials.

\section{Overall conclusions}

We all of us have the potential to avoid starting, or stop smoking, moderate our alcohol intake, become more physically active, engage in more cognitively stimulating activities, and adopt a healthier, more balanced diet. All of these changes have the potential to improve brain health. As regards the prevention of dementia, only smoking cessation (or preferably, prevention) is strongly evidenced as a modifiable risk factor, with relatively consistent findings of an independent association across a number of cohort studies, and with some evidence for a dose-response effect. Increase physical and cognitive activity may also be beneficial, but these associations may be explained by reverse causality. Nevertheless, the risk reduction seen quite consistently in short latency cohort studies conducted in late-life is quite substantial. Causality can only be demonstrated clearly in randomised controlled trials, which should be feasible in older populations at risk for dementia. An association of deficiency of micronutrients, arising from a compromised diet, or malabsorption, or both is mechanistically plausible, and in some instances is (hyperhomocysteinaemia) quite strongly supported by observational data. However, with the possible exception of adopting a Mediterranean diet, there is as yet no evidence from randomised controlled trials, that correcting deficiencies through supplementation reduces the incidence of dementia. Again, more trials are required.

Although lifestyle changes could benefit more than one domain, and be beneficial for a reduction in dementia risk, it is also important to highlight that these lifestyle changes take time and they are often difficult to accomplish. 


\section{References}

1. Schneider N, Yvon C. A review of multidomain interventions to support healthy cognitive ageing. The journal of nutrition, health \& aging 2013; 17(3): 252-7.

2. Preventing Tobacco Use Among Youth and Young Adults: A Report of the Surgeon General. In: Services. USDoHaH, editor. Atlanta (GA): Centers for Disease Control and Prevention, National Center for Chronic Disease Prevention and Health Promotion, Office on Smoking and Health.; 2012.

3. (US) NCfCDPaHP, Health. OoSa. The Health Consequences of Smoking -50 Years of Progress: A Report of the Surgeon General. 2014/01/24 ed. Atlanta (GA): Centers for Disease Control and Prevention (US); 2014.

4. WHO global report. Mortality attributable to tobacco. 2012. http:// www.thehealthwell.info/node/115845 (accessed 1st August 2014

5. Alberg AJ, Shopland DR, Cummings KM. The 2014 Surgeon General's report: commemorating the 50th Anniversary of the 1964 Report of the Advisory Committee to the US Surgeon General and updating the evidence on the health consequences of cigarette smoking. Am J Epidemiol 2014; 179(4): 403-12.

6. Querfurth HW, LaFerla FM. Alzheimer's disease. N Engl J Med 2010; 362(4): 329-44.

7. Barnes DE, Yaffe K. The projected effect of risk factor reduction on Alzheimer's disease prevalence. Lancet neurology 2011; 10(9): 81928.

8. Bangen KJ, Nation DA, Delano-Wood L, et al. Aggregate effects of vascular risk factors on cerebrovascular changes in autopsyconfirmed Alzheimer's disease. Alzheimers Dement 2014.

9. Pendlebury ST. Stroke-related dementia: rates, risk factors and implications for future research. Maturitas 2009; 64(3): 165-71.

10. Sonnen JA, Larson EB, Gray SL, et al. Free radical damage to cerebral cortex in Alzheimer's disease, microvascular brain injury, and smoking. Annals of neurology 2009; 65(2): 226-9.

11. Ho YS, Yang X, Yeung SC, et al. Cigarette smoking accelerated brain aging and induced pre-Alzheimer-like neuropathology in rats. PloS one 2012; 7(5): e36752.

12. Moreno-Gonzalez I, Estrada LD, Sanchez-Mejias E, Soto C Smoking exacerbates amyloid pathology in a mouse model of Alzheimer's disease. Nat Commun 2013; 4: 1495.

13. Murray KN, Abeles N. Nicotine's effect on neural and cognitive functioning in an aging population. Aging \& mental health 2002 6(2): 129-38

14. Shimohama S, Greenwald DL, Shafron DH, et al. Nicotinic alpha 7 receptors protect against glutamate neurotoxicity and neuronal ischemic damage. Brain research 1998; 779(1-2): 359-63.

15. Akaike A, Tamura Y, Yokota T, Shimohama S, Kimura J. Nicotineinduced protection of cultured cortical neurons against $\mathrm{N}$-methyl-Daspartate receptor-mediated glutamate cytotoxicity. Brain research 1994; 644(2): 181-7.

16. Zeng $\mathrm{H}$, Zhang $\mathrm{Y}$, Peng $\mathrm{L}$, et al. Nicotine and amyloid formation. Biological psychiatry 2001; 49(3): 248-57.

17. Ono K, Hasegawa K, Yamada M, Naiki H. Nicotine breaks down preformed Alzheimer's beta-amyloid fibrils in vitro. Biological psychiatry 2002; 52(9): 880-6.

18. Tsuang D, Larson EB, Li G, et al. Association between lifetime cigarette smoking and lewy body accumulation. Brain pathology (Zurich, Switzerland) 2010; 20(2): 412-8.

19. Levin ED, McClernon FJ, Rezvani AH. Nicotinic effects on cognitive function: behavioral characterization, pharmacological specification, and anatomic localization. Psychopharmacology 2006; 184(3-4): 523-39.

20. Almeida OP, Hulse GK, Lawrence D, Flicker L. Smoking as a risk factor for Alzheimer's disease: contrasting evidence from a systematic review of case-control and cohort studies. Addiction 2002; 97(1): 15-28.

21. Cataldo JK, Glantz SA. Smoking cessation and Alzheimer's disease: facts, fallacies and promise. Expert review of neurotherapeutics 2010; 10(5): 629-31.

22. Cataldo JK, Prochaska JJ, Glantz SA. Cigarette smoking is a risk factor for Alzheimer's Disease: an analysis controlling for tobacco industry affiliation. Journal of Alzheimer's disease : JAD 2010; 19(2): 465-80.

23. Anstey KJ, von Sanden C, Salim A, O'Kearney R. Smoking as a risk factor for dementia and cognitive decline: a meta-analysis of prospective studies. Am J Epidemiol 2007; 166(4): 367-78.

24. Beydoun MA, Beydoun HA, Gamaldo AA, Teel A, Zonderman AB, Wang Y. Epidemiologic studies of modifiable factors associated with cognition and dementia: systematic review and meta-analysis. BMC public health 2014; 14(1): 643.
25. Di Marco LY, Marzo A, Munoz-Ruiz M, et al. Modifiable Lifestyle Factors in Dementia: A Systematic Review of Longitudinal Observational Cohort Studies. Journal of Alzheimer's disease : JAD 2014.

26. Hernan MA, Alonso A, Logroscino G. Cigarette smoking and dementia: potential selection bias in the elderly. Epidemiology 2008; 19(3): 448-50.

27. Purnell C, Gao S, Callahan CM, Hendrie HC. Cardiovascular risk factors and incident Alzheimer disease: a systematic review of the literature. Alzheimer disease and associated disorders 2009; 23(1): 1-10.

28. Whitmer RA, Sidney S, Selby J, Johnston SC, Yaffe K. Midlife cardiovascular risk factors and risk of dementia in late life. Neurology 2005; 64(2): 277-81.

29. Tyas SL, White LR, Petrovitch $\mathrm{H}$, et al. Mid-life smoking and late-life dementia: the Honolulu-Asia Aging Study. Neurobiology of aging 2003; 24(4): 589-96.

30. Rusanen M, Rovio S, Ngandu T, et al. Midlife smoking, apolipoprotein $\mathrm{E}$ and risk of dementia and Alzheimer's disease: a population-based cardiovascular risk factors, aging and dementia study. Dementia and geriatric cognitive disorders 2010; 30(3): 277 84.

31. Rusanen M, Kivipelto M, Quesenberry CP, Jr., Zhou J, Whitmer RA. Heavy smoking in midlife and long-term risk of Alzheimer disease and vascular dementia. Arch Intern Med 2011; 171(4): 333-9.

32. Ronnemaa E, Zethelius B, Lannfelt L, Kilander L. Vascular risk factors and dementia: 40-year follow-up of a population-based cohort. Dementia and geriatric cognitive disorders 2011; 31(6): 460-6.

33. Reitz C, den Heijer T, van Duijn C, Hofman A, Breteler MM. Relation between smoking and risk of dementia and Alzheimer disease: the Rotterdam Study. Neurology 2007; 69(10): 998-1005.

34. Ott A, Slooter AJ, Hofman A, et al. Smoking and risk of dementia and Alzheimer's disease in a population-based cohort study: the Rotterdam Study. Lancet 1998; 351(9119): 1840-3.

35. Juan D, Zhou DH, Li J, Wang JY, Gao C, Chen M. A 2-year followup study of cigarette smoking and risk of dementia. European journal of neurology : the official journal of the European Federation of Neurological Societies 2004; 11(4): 277-82.

36. Doll R, Peto R, Boreham J, Sutherland I. Smoking and dementia in male British doctors: prospective study. BMJ (Clinical research ed) 2000; 320(7242): 1097-102.

37. Yip AG, Brayne C, Matthews FE, Function MRCC, Ageing S. Risk factors for incident dementia in England and Wales: The Medical Research Council Cognitive Function and Ageing Study. A population-based nested case-control study. Age Ageing 2006; 35(2): 154-60.

38. Wang HX, Fratiglioni L, Frisoni GB, Viitanen M, Winblad B. Smoking and the occurrence of Alzheimer's disease: cross-sectional and longitudinal data in a population-based study. Am J Epidemiol 1999; 149(7): 640-4.

39. Moffat SD, Zonderman AB, Metter EJ, et al. Free testosterone and risk for Alzheimer disease in older men. Neurology 2004; 62(2): 18893.

40. Merchant C, Tang MX, Albert S, Manly J, Stern Y, Mayeux R. The influence of smoking on the risk of Alzheimer's disease. Neurology 1999; 52(7): 1408-12.

41. Luchsinger JA, Reitz C, Honig LS, Tang MX, Shea S, Mayeux R. Aggregation of vascular risk factors and risk of incident Alzheimer disease. Neurology 2005; 65(4): 545-51.

42. Lindsay J, Laurin D, Verreault R, et al. Risk factors for Alzheimer's disease: a prospective analysis from the Canadian Study of Health and Aging. Am J Epidemiol 2002; 156(5): 445-53.

43. Kivipelto M, Rovio S, Ngandu T, et al. Apolipoprotein E epsilon4 magnifies lifestyle risks for dementia: a population-based study. $J$ Cell Mol Med 2008; 12(6B): 2762-71.

44. Chen R, Hu Z, Wei L, Ma Y, Liu Z, Copeland JR. Incident dementia in a defined older Chinese population. PloS one 2011; 6(9): e24817.

45. Aggarwal NT, Bienias JL, Bennett DA, et al. The relation of cigarette smoking to incident Alzheimer's disease in a biracial urban community population. Neuroepidemiology 2006; 26(3): 140-6.

46. Broe GA, Creasey $H$, Jorm AF, et al. Health habits and risk of cognitive impairment and dementia in old age: a prospective study on the effects of exercise, smoking and alcohol consumption. Aust N Z J Public Health 1998; 22(5): 621-3.

47. Launer LJ, Andersen K, Dewey ME, et al. Rates and risk factors for dementia and Alzheimer's disease: results from EURODEM pooled analyses. EURODEM Incidence Research Group and Work Groups. European Studies of Dementia. Neurology 1999; 52(1): 78-84. 
48. Yoshitake T, Kiyohara Y, Kato I, et al. Incidence and risk factors of vascular dementia and Alzheimer's disease in a defined elderly Japanese population: the Hisayama Study. Neurology 1995; 45(6): 1161-8.

49. Laurin D, Masaki KH, Foley DJ, White LR, Launer LJ. Midlife dietary intake of antioxidants and risk of late-life incident dementia: the Honolulu-Asia Aging Study. Am J Epidemiol 2004; 159(10): 959-67.

50. Reitz C, Luchsinger J, Tang MX, Mayeux R. Effect of smoking and time on cognitive function in the elderly without dementia. Neurology 2005; 65(6): 870-5.

51. Chang CC, Zhao Y, Lee CW, Ganguli M. Smoking, death, and Alzheimer disease: a case of competing risks. Alzheimer disease and associated disorders 2012; 26(4): 300-6.

52. Debanne SM, Bielefeld RA, Cheruvu VK, Fritsch T, Rowland DY. Alzheimer's disease and smoking: bias in cohort studies. Journal of Alzheimer's disease : JAD 2007; 11(3): 313-21.

53. Lim SS, Vos T, Flaxman AD, et al. A comparative risk assessment of burden of disease and injury attributable to 67 risk factors and risk factor clusters in 21 regions, 1990-2010: a systematic analysis for the Global Burden of Disease Study 2010. Lancet 2012; 380(9859): 2224-60.

54. WHO. (2014). "Patterns of Consumption: Patterns of drinking score - by country." Global Information System on Alcohol and Health (GISAH), from http://apps.who.int/gho/data/node.main. A1048?lang=en\&showonly=GISAH

55. Ronksley PE, Brien SE, Turner BJ, Mukamal KJ, Ghali WA. Association of alcohol consumption with selected cardiovascula disease outcomes: a systematic review and meta-analysis. BMJ 2011; 342: d671.

56. Monnig MA, Tonigan JS, Yeo RA, Thoma RJ, McCrady BS. White matter volume in alcohol use disorders: a meta-analysis. Addiction biology 2013; 18(3): 581-92.

57. Brust JC. Ethanol and cognition: indirect effects, neurotoxicity and neuroprotection: a review. International journal of environmental research and public health 2010; 7(4): 1540-57.

58. Smith S, Fein G. Cognitive performance in treatment-naive active alcoholics. Alcoholism, clinical and experimental research 2010; 34(12): 2097-105.

59. Rodriguez-Martin JL, Qizilbash N, Lopez-Arrieta JM. Thiamine for Alzheimer's disease. The Cochrane database of systematic reviews 2001; (2): CD001498.

60. Watson GS, Craft $\mathrm{S}$. The role of insulin resistance in the pathogenesis of Alzheimer's disease: implications for treatment. CNS drugs 2003; 17(1): 27-45.

61. Stampfer MJ. Cardiovascular disease and Alzheimer's disease: common links. Journal of internal medicine 2006; 260(3): 211-23.

62. Vitali C, Wellington CL, Calabresi L. HDL and cholesterol handling in the brain. Cardiovascular research 2014; 103(3): 405-13.

63. Aras S, Tek I, Varli M, et al. Plasma viscosity: is a biomarker for the differential diagnosis of Alzheimer's disease and vascular dementia? American journal of Alzheimer's disease and other dementias 2013; 28(1): 62-8.

64. Prodan Cl, Ross ED, Stoner JA, Cowan LD, Vincent AS, Dale GL. Coated-platelet levels and progression from mild cognitive impairment to Alzheimer disease. Neurology 2011; 76(3): 247-52.

65. Kloner RA, Rezkalla SH. To drink or not to drink? That is the question. Circulation 2007; 116(11): 1306-17.

66. Perry E, Walker M, Grace J, Perry R. Acetylcholine in mind: a neurotransmitter correlate of consciousness? Trends in neurosciences 1999; 22(6): 273-80.

67. Fadda F, Rossetti ZL. Chronic ethanol consumption: from neuroadaptation to neurodegeneration. Progress in neurobiology 1998; 56(4): 385-431.

68. Piazza-Gardner AK, Gaffud TJ, Barry AE. The impact of alcohol on Alzheimer's disease: a systematic review. Aging Ment Health 2013; 17(2): 133-46.

69. Peters R, Peters J, Warner J, Beckett N, Bulpitt C. Alcohol, dementia and cognitive decline in the elderly: a systematic review. Age Ageing 2008; 37(5): 505-12.

70. Panza F, Capurso C, D'Introno A, et al. Alcohol drinking, cognitive functions in older age, predementia, and dementia syndromes. $J$ Alzheimers Dis 2009; 17(1): 7-31.

71. Neafsey EJ, Collins MA. Moderate alcohol consumption and cognitive risk. Neuropsychiatric disease and treatment 2011; 7: 46584.

72. Letenneur L, Larrieu S, Barberger-Gateau P. Alcohol and tobacco consumption as risk factors of dementia: a review of epidemiological studies. Biomedicine \& pharmacotherapy $=$ Biomedecine \& pharmacotherapie 2004; 58(2): 95-9.
73. Lee Y, Back JH, Kim J, et al. Systematic review of health behavioral risks and cognitive health in older adults. International psychogeriatrics / IPA 2010; 22(2): 174-87.

74. Anstey KJ, Mack HA, Cherbuin N. Alcohol consumption as a risk factor for dementia and cognitive decline: meta-analysis of prospective studies. The American journal of geriatric psychiatry : official journal of the American Association for Geriatric Psychiatry 2009; 17(7): 542-55.

75. Di Marco LY, Marzo A, Munoz-Ruiz M, et al. Modifiable lifestyle factors in dementia: a systematic review of longitudinal observational cohort studies. J Alzheimers Dis 2014; 42(1): 119-35.

76. Weyerer S, Schaufele M, Wiese B, et al. Current alcohol consumption and its relationship to incident dementia: results from a 3-year follow-up study among primary care attenders aged 75 years and older. Age Ageing 2011; 40(4): 456-63.

77. Gureje O, Ogunniyi A, Kola L, Abiona T. Incidence of and risk factors for dementia in the Ibadan study of aging. J Am Geriatr Soc 2011; 59(5): 869-74.

78. Simons LA, Simons J, McCallum J, Friedlander Y. Lifestyle factors and risk of dementia: Dubbo Study of the elderly. The Medical journal of Australia 2006; 184(2): 68-70.

79. Ruitenberg A, van Swieten JC, Witteman JC, et al. Alcohol consumption and risk of dementia: the Rotterdam Study. Lancet 2002; 359(9303): 281-6.

80. Mukamal KJ, Kuller LH, Fitzpatrick AL, Longstreth WT, Jr., Mittleman MA, Siscovick DS. Prospective study of alcohol consumption and risk of dementia in older adults. JAMA : the journal of the American Medical Association 2003; 289(11): 1405-13.

81. Huang W, Qiu C, Winblad B, Fratiglioni L. Alcohol consumption and incidence of dementia in a community sample aged 75 years and older. Journal of clinical epidemiology 2002; 55(10): 959-64.

82. Deng J, Zhou DH, Li J, Wang YJ, Gao C, Chen M. A 2-year followup study of alcohol consumption and risk of dementia. Clinical neurology and neurosurgery 2006; 108(4): 378-83.

83. Jarvenpaa T, Rinne JO, Koskenvuo M, Raiha I, Kaprio J. Binge drinking in midlife and dementia risk. Epidemiology 2005; 16(6): 766-71.

84. Mehlig K, Skoog I, Guo X, et al. Alcoholic beverages and incidence of dementia: 34-year follow-up of the prospective population study of women in Goteborg. Am J Epidemiol 2008; 167(6): 684-91.

85. Truelsen T, Thudium D, Gronbaek M, Copenhagen City Heart S. Amount and type of alcohol and risk of dementia: the Copenhagen City Heart Study. Neurology 2002; 59(9): 1313-9.

86. Luchsinger JA, Tang MX, Siddiqui M, Shea S, Mayeux R. Alcohol intake and risk of dementia. J Am Geriatr Soc 2004; 52(4): 540-6.

87. Rogers GR KP, Miech R, Lawrence EM. . Lifetime abstainers and mortality risk in the United States. : Boulder, USA, IBS Population Program, Institute of Behavioral Science, University of Colorado Boulder. Population Program POP2012-06., 2012.

88. Rolland $Y$, Abellan van Kan G, Vellas B. Physical activity and Alzheimer's disease: from prevention to therapeutic perspectives. $J$ Am Med Dir Assoc 2008; 9(6): 390-405.

89. Haskell WL, Lee I-M, Pate RR, et al. Physical activity and public health: updated recommendation for adults from the American College of Sports Medicine and the American Heart Association. Circulation 2007; 116(9): 1081.

90. Nelson ME, Rejeski WJ, Blair SN, et al. Physical activity and public health in older adults: recommendation from the American College of Sports Medicine and the American Heart Association. Circulation 2007; 116(9): 1094.

91. Weuve J, Kang JH, Manson JE, Breteler MM, Ware JH, Grodstein F. Physical activity, including walking, and cognitive function in older women. Jama 2004; 292(12): 1454-61.

92. Yaffe K, Barnes D, Nevitt M, Lui L-Y, Covinsky K. A prospective study of physical activity and cognitive decline in elderly women: women who walk. Archives of internal medicine 2001; 161(14): 1703-8.

93. Hamer M, Chida Y. Physical activity and risk of neurodegenerative disease: a systematic review of prospective evidence. Psychol Med 2009; 39(1): 3-11.

94. Scarmeas N, Luchsinger JA, Schupf N, et al. Physical activity, diet, and risk of Alzheimer disease. Jama 2009; 302(6): 627-37.

95. Buchman A, Boyle P, Yu L, Shah R, Wilson R, Bennett D. Total daily physical activity and the risk of $A D$ and cognitive decline in older adults. Neurology 2012; 78(17): 1323-9.

96. Sofi F, Valecchi $D$, Bacci $D$, et al. Physical activity and risk of cognitive decline: a meta-analysis of prospective studies. Journal of internal medicine 2011; 269(1): 107-17. 
97. Aarsland D, Sardahaee FS, Anderssen S, Ballard C, group tAsSSR Is physical activity a potential preventive factor for vascular dementia? A systematic review. Aging \& mental health 2010; 14(4): 386-95.

98. Ravaglia G, Forti P, Lucicesare A, et al. Physical activity and dementia risk in the elderly Findings from a prospective Italian study. Neurology 2008; 70(19 Part 2): 1786-94.

99. Bowen ME. A prospective examination of the relationship between physical activity and dementia risk in later life. American Journal of Health Promotion 2012; 26(6): 333-40.

100. Morgan GS, Gallacher J, Bayer A, Fish M, Ebrahim S, Ben-Shlomo Y. Physical activity in middle-age and dementia in later life: findings from a prospective cohort of men in Caerphilly, South Wales and a meta-analysis. Journal of Alzheimer's Disease 2012; 31(3): 569-80.

101. Verdelho A, Madureira S, Ferro JM, et al. Physical Activity Prevents Progression for Cognitive Impairment and Vascular Dementia Results From the LADIS (Leukoaraiosis and Disability) Study. Stroke 2012; 43(12): 3331-5

102. de Bruijn RF, Schrijvers EM, de Groot KA, et al. The association between physical activity and dementia in an elderly population: the Rotterdam Study. European journal of epidemiology 2013; 28(3): 277-83.

103. Yamada M, Kasagi F, Sasaki H, Masunari N, Mimori Y, Suzuki G. Association between dementia and midlife risk factors: the radiation effects research foundation adult health study. Journal of the American Geriatrics Society 2003; 51(3): 410-4.

104. Rovio S, Kåreholt I, Helkala E-L, et al. Leisure-time physical activity at midlife and the risk of dementia and Alzheimer's disease. The Lancet Neurology 2005; 4(11): 705-11.

105. Andel R, Crowe M, Pedersen NL, Fratiglioni L, Johansson B, Gatz M. Physical exercise at midlife and risk of dementia three decades later: a population-based study of Swedish twins. The Journals of Gerontology Series A: Biological Sciences and Medical Sciences 2008; 63(1): 62-6.

106. Smith PJ, Blumenthal JA, Hoffman BM, et al. Aerobic exercise and neurocognitive performance: a meta-analytic review of randomized controlled trials. Psychosomatic medicine 2010; 72(3): 239-52.

107. Black JE, Sirevaag AM, Greenough WT. Complex experience promotes capillary formation in young rat visual cortex. Neuroscience letters 1987; 83(3): 351-5.

108. Saczynski JS, Jonsdottir MK, Sigurdsson S, et al. White matter lesions and cognitive performance: the role of cognitively complex leisure activity. The Journals of Gerontology Series A: Biological Sciences and Medical Sciences 2008; 63(8): 848-54.

109. Brown J, Cooper-Kuhn CM, Kempermann G, et al. Enriched environment and physical activity stimulate hippocampal but not olfactory bulb neurogenesis. European Journal of Neuroscience 2003; 17(10): 2042-6.

110. Kempermann G, Kuhn HG, Gage FH. More hippocampal neurons in adult mice living in an enriched environment. Nature 1997; 386(6624): 493-5.

111. Cracchiolo JR, Mori T, Nazian SJ, Tan J, Potter H, Arendash GW. Enhanced cognitive activity-over and above social or physical activity - is required to protect Alzheimer's mice against cognitive impairment, reduce $A \beta$ deposition, and increase synaptic immunoreactivity. Neurobiology of learning and memory 2007; 88(3): 277-94.

112. Cabeza R, Anderson ND, Locantore JK, McIntosh AR. Aging gracefully: compensatory brain activity in high-performing older adults. Neuroimage 2002; 17(3): 1394-402.

113. Stern Y. Cognitive reserve in ageing and Alzheimer's disease. Lancet neurology 2012; 11(11): 1006-12.

114. Stern C, Munn Z. Cognitive leisure activities and their role in preventing dementia: a systematic review. International Journal of Evidence-Based Healthcare 2010; 8(1): 2-17.

115. Wang J, Zhou D, Li J, et al. Leisure activity and risk of cognitive impairment: the Chongqing aging study. Neurology 2006; 66(6): 911-3.

116. Crowe M, Andel R, Pedersen NL, Johansson B, Gatz M. Does participation in leisure activities lead to reduced risk of Alzheimer's disease? A prospective study of Swedish twins. The Journals of Gerontology Series B: Psychological Sciences and Social Sciences 2003; 58(5): P249-P55.

117. Carlson MC, Helms MJ, Steffens DC, Burke JR, Potter GG Plassman BL. Midlife activity predicts risk of dementia in older male twin pairs. Alzheimer's \& Dementia 2008; 4(5): 324-31.

118. Wilson RS, Boyle PA, Yu L, Barnes LL, Schneider JA, Bennett DA Life-span cognitive activity, neuropathologic burden, and cognitive aging. Neurology 2013; 81(4): 314-21.
119. Sörman DE, Sundström A, Rönnlund M, Adolfsson R, Nilsson L-G. Leisure Activity in Old Age and Risk of Dementia: A 15Year Prospective Study. The Journals of Gerontology Series B: Psychological Sciences and Social Sciences 2014; 69(4): 493-501.

120. Wang $\mathrm{H}-\mathrm{X}$, Jin $\mathrm{Y}$, Hendrie $\mathrm{HC}$, et al. Late life leisure activities and risk of cognitive decline. The Journals of Gerontology Series A: Biological Sciences and Medical Sciences 2013; 68(2): 205-13.

121. Sattler C, Toro P, Schönknecht P, Schröder J. Cognitive activity, education and socioeconomic status as preventive factors for mild cognitive impairment and Alzheimer's disease. Psychiatry research 2012; 196(1): 90-5.

122. Marquine MJ, Segawa E, Wilson RS, Bennett DA, Barnes LL. Association between cognitive activity and cognitive function in older Hispanics. Journal of the International Neuropsychological Society : JINS 2012; 18(6): 1041-51.

123. Wilson RS, Segawa E, Boyle PA, Bennett DA. Influence of late-life cognitive activity on cognitive health. Neurology 2012; 78(15): 1123

124. Wilson R, Barnes L, Aggarwal N, et al. Cognitive activity and the cognitive morbidity of Alzheimer disease. Neurology 2010; 75(11): 990-6.

125. Marquine MJ, Segawa E, Wilson RS, Bennett DA, Barnes LL. Association between cognitive activity and cognitive function in older Hispanics. Journal of the International Neuropsychological Society 2012; 18(06): 1041-51.

126. Prince M, Albanese E, Guerchet M, Prina M. Nutrition and Dementia: a review of available research. Alzheimer's Disease International. http://www.alz.co.uk/sites/default/files/pdfs/nutritionand-dementia.pdf. London, 2014.

127. Garcia A, Zanibbi K. Homocysteine and cognitive function in elderly people. CMAJ 2004; 171(8): 897-904.

128. Hankey GJ, Ford AH, Yi Q, et al. Effect of B vitamins and lowering homocysteine on cognitive impairment in patients with previous stroke or transient ischemic attack: a prespecified secondary analysis of a randomized, placebo-controlled trial and metaanalysis. Stroke; a journal of cerebral circulation 2013; 44(8): 2232-9.

129. de Jager CA, Oulhaj A, Jacoby R, Refsum H, Smith AD. Cognitive and clinical outcomes of homocysteine-lowering B-vitamin treatment in mild cognitive impairment: a randomized controlled trial. Int J Geriatr Psychiatry 2012; 27(6): 592-600.

130. Kwok T, Lee J, Law CB, et al. A randomized placebo controlled trial of homocysteine lowering to reduce cognitive decline in older demented people. Clin Nutr 2011; 30(3): 297-302.

131. Douaud G, Refsum H, de Jager CA, et al. Preventing Alzheimer's disease-related gray matter atrophy by B-vitamin treatment. Proceedings of the National Academy of Sciences of the United States of America 2013; 110(23): 9523-8.

132. Mao P. Oxidative Stress and Its Clinical Applications in Dementia Journal of Neurodegenerative Diseases 2013; 2013: 15.

133. Olanow CW. Oxidation reactions in Parkinson's disease. Neurology 1990; 40(10 Suppl 3): suppl 32-7; discussion 7-9.

134. Larrieu S, Letenneur L, Helmer C, Dartigues JF, Barberger-Gateau P. Nutritional factors and risk of incident dementia in the PAQUID longitudinal cohort. J Nutr Health Aging 2004; 8(3): 150-4.

135. Sydenham E, Dangour AD, Lim WS. Omega 3 fatty acid for the prevention of cognitive decline and dementia. Cochrane Database Syst Rev 2012; 6: CD005379.

136. Dangour AD, Andreeva VA, Sydenham E, Uauy R. Omega 3 fatty acids and cognitive health in older people. Br J Nutr 2012; 107 Suppl 2: S152-8.

137. Sofi F, Cesari F, Abbate R, Gensini GF, Casini A. Adherence to Mediterranean diet and health status: meta-analysis. Bmj 2008 337: a1344.

138. Sanchez-Villegas A, Galbete C, Martinez-Gonzalez MA, et al. The effect of the Mediterranean diet on plasma brain-derived neurotrophic factor (BDNF) levels: the PREDIMED-NAVARRA randomized trial. Nutritional neuroscience 2011; 14(5): 195-201.

139. Martinez-Lapiscina EH, Clavero $P$, Toledo $E$, et al. Virgin olive oil supplementation and long-term cognition: the PREDIMEDNAVARRA randomized, trial. The journal of nutrition, health \& aging 2013; 17(6): 544-52. 


\section{CHAPTER 5 \\ Cardiovascular risk factors}

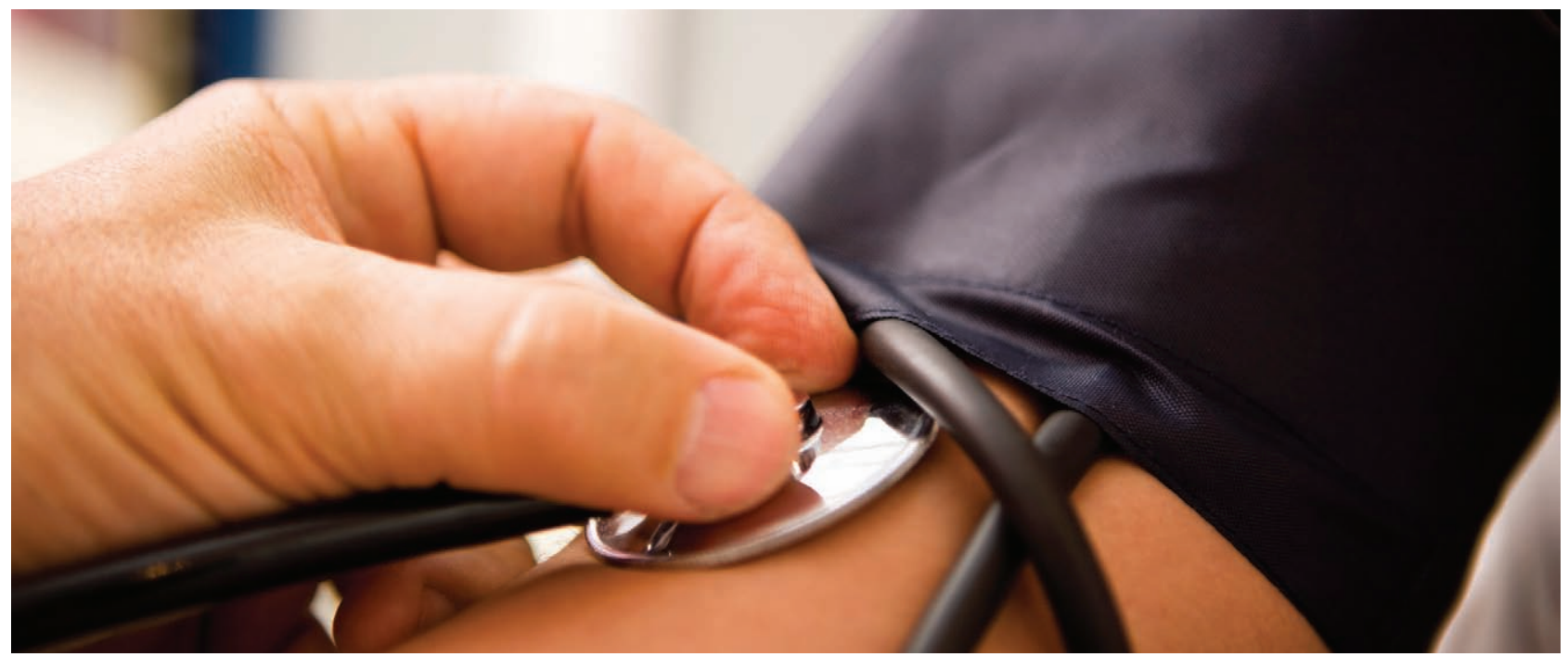

\section{Introduction}

Dyslipidaemia (an abnormal amount of cholesterol/ fat in the blood), hypertension (raised blood pressure), diabetes, smoking and obesity are the major modifiable risk factors for cardiovascular diseases (CVDs) including heart disease and stroke ${ }^{1 ; 2}$. These cardiovascular risk factors (CVRF) are already common by midlife, and their prevalence rises with increasing age thereafter. In the USA National Health and Nutrition Examination Survey (NHANES) 20032008, this pattern was apparent for physical inactivity, total cholesterol, fasting blood glucose and blood pressure ${ }^{3}$. Only smoking was less common among older adults. Several CVRF (obesity, hypertension, dyslipidaemia and type 2 diabetes) have a tendency to cluster together. This confluence of risk factors, called the metabolic syndrome, is associated with insulin resistance (leading to problems with energy utilisation and storage) and inflammation 4 .

Up to the 1980s and early 1990s, most of the evidence on the possible causes of dementia and Alzheimer's disease $(A D)$ had come from case-control studies. This line of research had been largely fruitless, particularly as regards cardiovascular factors; one of the few replicated findings being that a history of smoking was less common in AD cases than in controls. By the mid-1990s interest was reawakening in the relationship between CVRF, cognitive impairment and all cause dementia. Positive associations were identified in the cross-sectional and longitudinal phases of the Rotterdam study ${ }^{5-7}$. Strict application of the widely used NINCDS ADRDA case definition for probable AD might have biased results from case-control studies, by excluding those with cardiovascular disease or CVRF from the AD case group ${ }^{8}$.
In 1996 Skoog's seminal study of the long-term effects of hypertension in the Goteborg Longitudinal Population Study ${ }^{9}$ showed that those who developed dementia in late-life had had higher blood pressure levels 15 years earlier, but experienced a sharper drop than others thereafter, meaning that their blood pressure levels were lower than those of the same age who had not developed dementia by late-life. This suggested that researchers may have been looking in the wrong place - to understand the effects of CVRF on dementia one needed to look at these exposures in midlife, rather than in late-life just before dementia becomes clinically evident. This new insight led to a slew of historical cohort studies, exploiting pre-existing population-based studies with data already collected in the 1960s to 1990s on CVRF in middle-aged people, who could then be followed up in late-life (65 years and over) to determine the incidence of dementia and its subtypes. In addition to the Goteborg study, these included the Uppsala Longitudinal Study of Adult Men, the Cardiovascular Risk Factors Ageing and Dementia study (CAIDE - building on earlier WHO MONICA studies in Finland), the Honolulu-Asia Aging Study (HAAS - Japanese American men), the Framingham Heart Study, and the Hisayama Study from Japan. Such studies have clarified the relationship between CVRF (hypertension, obesity, and raised cholesterol) in midlife, changes in the levels of these exposures from midlife to late-life, and the subsequent incidence of dementia. The pattern identified in the Goteborg study has been broadly replicated in other studies, and for other CVRF. While midlife CVRF are somewhat inconsistent predictors of the late-life onset of dementia and $A D$, decline in blood pressure level, 
body mass and cholesterol precedes, and is a more consistent predictor of the onset of dementia.

Associations between CVRF and dementia are plausible, first, because hypertension, dyslipidaemia, obesity and type 2 diabetes all predispose to ischaemic heart disease and cerebrovascular disease, including cortical and sub-cortical infarcts and white matter lesions. In a systematic review of 16 studies of the association of stroke with all-cause dementia, those who experience a stroke are at approximately twice the risk of developing dementia, with most of the increased risk concentrated in the three years after the stroke event ${ }^{10}$. The effect is independent of CVRF and pre-stroke cognitive function ${ }^{10}$. In a recent publication from the Finnish Cardiovascular Risk Factors, Aging and Dementia (CAIDE) long-term cohort study, atrial fibrillation and heart failure, but not coronary artery disease, were associated with the onset of dementia and $A D^{11}$. Some other studies have found a specific association of heart disease with $A D^{12 ; 13}$, whereas for others the risk is confined to vascular dementia ${ }^{14}$.

Therefore, the impact of CVRF may not be limited to the vascular dementia subtype, since

- it is increasingly recognised that the neurodegenerative pathologies that contribute to the clinical expression of the dementia syndrome are frequently multiple and mixed, with 'pure' subtypes being relatively unusual ${ }^{15}$, and

- cerebrovascular disease may interact with other neurodegenerative pathologies, including $A D$, to predispose to the onset of dementia ${ }^{16}$, and

- other mechanisms, specific to particular CVRF, may initiate or exacerbate other neurodegenerative pathologies, particularly AD.

In the sections below we focus in on individual cardiovascular risk factors - hypertension, obesity, cholesterol and dyslipidaemia, and diabetes. We assess the salience of each of these risk factors both in terms of their current and future public health impact, and the evidence that they may be causal risk factors for dementia. When considering possible underlying mechanisms, it is taken as read that all of these factors may increase risk for dementia, jointly or severally, by increasing the risk for atherosclerosis ('hardening of the arteries'), and the inflammatory and thrombotic components of vascular disease. We concentrate particularly upon other, additional mechanisms that may be implicated. We summarise briefly current evidence ('What is known?'), and then present a detailed and critical analysis of the evidence-base to support a causal association, both from longitudinal epidemiological studies, and randomized controlled trials.

\section{Hypertension}

\section{Background}

Raised blood pressure is very common. In the USA around $30 \%$ of those aged $40-59$ years are affected ${ }^{17}$, rising to $60 \%$ of those aged $60-69,72 \%$ for those aged $70-79$, and $77 \%$ of those aged 80 and over ${ }^{18}$. In low and middle income countries prevalence also increases steadily with age, with half or more of those aged 60 and over affected ${ }^{21-25}$. Hypertension can be prevented by attention to lifestyle factors, particularly diet, weight and physical activity, and controlled with antihypertensive medication. These efforts must be sustained across the adult life course, since the adverse effects of hypertension are apparent well into old age. In the USA, hypertension among older people is an independent risk factor for mortality ${ }^{19}$, and is inversely associated with healthy ageing ${ }^{20}$. Although effect sizes are smaller than in younger people, lower blood pressure in older age is still strongly associated with reduced risk of stroke and mortality from ischaemic heart disease ${ }^{21}$. Meta-analysis of trials of hypertension treatment clearly show substantial benefit in reducing all deaths, cardiovascular morbidity and mortality ${ }^{22}$. Benefits are apparent for isolated systolic as well as diastolic hypertension ${ }^{22}$. Numbers needed to treat to avoid an event are much smaller than at younger ages ${ }^{23}$. Despite this, in the USA NHANES surveys 1999-2004, control of hypertension among those treated was particularly poor among older people, with only $47 \%$ controlled among those aged $60-79$ years, and $36 \%$ among those aged 80 years and over ${ }^{24}$. Control of hypertension is generally much worse in low and middle income countries ${ }^{25-27}$.

\section{Mechanisms}

Hypertension decreases the vascular integrity of the blood-brain barrier, resulting in protein extravasation into brain tissue ${ }^{28}$. This can lead to cell damage, a reduction in neuronal or synaptic function, and apoptosis (cell death). It may also increase the accumulation of insoluble $A \beta$ (beta amyloid), contributing directly to $A D$ pathology. In a recent systematic review of 28 studies exploring the link between hypertension and brain atrophy, nearly all studies showed a significant association of higher blood pressure levels and/or hypertension with total or regional reduction in brain volume ${ }^{29}$. The frontal and temporal lobes, particularly the hippocampus, were most affected. All eight longitudinal studies showed that hypertension predicted greater brain volume reduction. The authors concluded that the findings were most likely explained by a previously observed tendency for cerebrovascular atherosclerosis to lead to reduced perfusion specifically in the frontal and hippocampal regions. 


\section{What is known?}

Studies of the association of hypertension with the incidence of dementia have demonstrated clearly the importance of a life course perspective. Hypertension in midlife, not late-life, is associated with an increased risk of late-life dementia. In a review published in 2005, seven studies reported on the cross-sectional association between blood pressure and risk of prevalent $A D$ and dementia in late-life ${ }^{30}$. Five studies reporting an inverse association, with either blood pressure or self-reported or clinically diagnosed hypertension and dementia or $A D$, while two studies found no association. Skoog ${ }^{9}$, using data from the long-term Goteborg cohort study had earlier demonstrated that midlife hypertension was associated with an increased risk for later incidence of dementia, but blood pressure levels fell more rapidly among those who would go on to develop dementia, resulting in the inverse relationship generally observed in crosssectional and short latency incidence studies when blood pressure was measured in late-life, close to the incidence of dementia. These findings have since been replicated in the Honolulu Asia Aging Study (HAAS) ${ }^{31}$, with a greater midlife increase followed by a greater late-life decrease in systolic blood pressure levels among those who would go on to develop dementia. Similar patterns were seen with diastolic blood pressure but mainly for those with incident vascular dementia.

\section{Critical analysis of the evidence}

\section{Midlife hypertension and risk for any dementia (AnyDem)}

There is particularly strong evidence for an association of midlife hypertension with incident AnyDem. Of five studies to date 9;32-35, across four cohorts (Goteborg, Uppsala, Kuopio and Joensuu, and HAAS), all report consistent, positive and statistically significant associations.

\section{Midlife hypertension and risk for Alzheimer's disease (AD)}

According to a recent systematic review conducted for the AlzRisk AD Epidemiology Database of the Alzheimer Research Forum (Alzrisk.org) there is weak and inconsistent evidence to support an association between midlife hypertension and incident $A D^{36}$. A more recent review was flawed, due to incorrect interpretation of the results of some studies ${ }^{37}$. A third quantitative meta-analysis, reporting a pooled RR of 1.61 (95\% Cl: 1.16-2.24) for the association between midlife hypertension and incident $A D$, also has important limitations ${ }^{38 ; 39}$. For two of the included studies $^{40 ; 41}$, the effect of systolic hypertension was considered in three categories, but the effect size used for the meta-analysis compared the two extremes $\left(>160 \mathrm{~mm} \mathrm{Hg}\right.$ vs. $<=140 \mathrm{mmHg}^{40}$, and $>140 \mathrm{mmHg}$ vs $<120 \mathrm{mmHg}^{41}$ ) ignoring the intermediate categories.
This will lead to an overestimate of the overall effect size, and a miscalculation of the population attributable fraction since the exposure definition varies between pooled studies, and does not coincide with the definition used to determine the population prevalence of hypertension (>140 mm Hg). It should also be noted that a later paper from one of these studies reported somewhat lower effect sizes having adjusted also for APOE polymorphism ${ }^{34}$. This meta-analysis will also have been strongly influenced by two particularly large studies, not cited in other reviews ${ }^{42 ; 43}$. A Chinese cohort study $(n=16,488)$ with 16 years of followup reported a large and significant effect of midlife hypertension on incident $A D(A O R=1.97,95 \%$ $\mathrm{Cl}$ : 1.09-3.54); however, three-quarters of participants were aged 60 years or over at inception, so this cannot really be considered to be a study of midlife hypertension, and mixed (AD with $\mathrm{VaD}$ ) cases were included in the incident $A D$ group for analysis ${ }^{42}$. The other historical cohort study $(n=8,845)$, conducted in the USA, relied on linkage of midlife self-reports and diagnoses of hypertension to diagnoses of $A D$ recorded in Kaiser Permanente medical records ${ }^{43}$. Aside from the weakness of the exposure measure, as highlighted elsewhere, such studies are highly likely to be biased towards a positive association, since those with diagnosed hypertension may, for that reason, attend health care facilities more regularly, and are hence, perhaps, more likely to be identified with dementia at an early stage in the process.

Overall, the more robust AlzRisk meta-analyses suggest no association between hypertension, systolic blood pressure or diastolic blood pressure and the incidence of $A D^{36}$. However, there is a suggestion of an age-dependent relationship with regard to the timing of the ascertainment of the exposure, that is that hypertension in midlife may be positively associated with the incidence of $A D$, with a trend towards an inverse association when hypertension is ascertained in late-life. This tendency is particularly apparent for diastolic hypertension in midlife. However, relatively few of the included studies had specifically considered the association between midlife blood pressure and incident AD. Some more recent studies have suggested that associations with all case dementia are accounted for by associations with vascular dementia (see also next section), with no significant association with incident $A D^{35 ; 44}$. It is recommended that further research is necessary and should focus on the impact of blood pressure in midlife, on the potential modifying effect of anti-hypertensive drug use, and on quantifying the potential that bias might account for the observed associations $^{36}$. To improve the harmonisability of research findings (a particular problem with current evidence), it is recommended that studies should express effect sizes per $10 \mathrm{mmHg}$ for systolic and diastolic blood pressure, in addition to whatever standard diagnostic criteria may be in operation at the time. 
Midlife and late-life hypertension and vascular dementia (VaD)

There is strong evidence to support an association between hypertension and incident $\mathrm{VaD}$. Six cohort studies were identified in a recent systematic review as suitable for meta-analysis, these indicating a positive association between hypertension and incident vascular dementia (1.59, 95\% Cl: 1.29-1.95) with minimal heterogeneity ${ }^{45}$. However, the exposure for these studies was a self-reported history of hypertension, and the life period to which this exposure applied was unclear. For three other studies, not included in the meta-analysis, blood pressure level was measured directly, and the timing of the exposure clarified. All were conducted on Asian populations; the Honolulu Asia Aging Study (HAAS) ${ }^{46}$, and the Hisayama cohort study from Japan 44;47;48. Midlife hypertension was prospectively associated with risk for incident $\mathrm{VaD}$ in both HAAS (AOR 2.15, 95\% Cl: 1.253.71) and Hisayama (OR 3.09, 95\% Cl: 1.24-7.73) ${ }^{47}$, while in continued follow-up in the Hisayama study, late-life hypertension was also associated with incident VaD (systolic hypertension OR 1.53, 95\% Cl: 1.16-2.01; diastolic hypertension OR 1.46, 95\% Cl: 1.11-1.90) ${ }^{48}$.

\section{The impact of treatment with antihypertensive} drugs

In the 1980s and 1990s, a series of high profile clinical trials clarified that the benefits of treating hypertension (lower cardiovascular morbidity and mortality) extended to older people: Medical Research Council's Trial of Hypertension Treatment in the Elderly, the Systolic Hypertension in Europe (Syst-Eur), Study on Cognition and Prognosis in the Elderly (SCOPE), the Systolic Hypertension in the Elderly Program (SHEP). Although placebo controlled RCTs would no longer be considered ethical for most older people, more recently the evidence-base has been extended through the Hypertension in the Very Elderly Trial (HYVET), and the Perindopril Protection Against Recurrent Stroke Study (PROGRESS). These trials included assessment of cognitive function and/or dementia as secondary outcomes given the interest in the hypothesis that hypertension may increase the risk for dementia onset. Only two of these trials suggest cognitive benefits. In the Syst-Eur trial, treatment with nifedipine was associated with a $50 \%$ reduction in the incidence of dementia by from 7.7 to 3.8 cases per 1000 patientyears ( 21 vs 11 patients, $p=0.05)^{49}$. In PROGRESS ${ }^{50}$, blood pressure-lowering treatment with perindopril and indapamide did not affect the incidence of dementia, but was associated with a $19 \%$ reduction $(95 \% \mathrm{Cl}$ : $4 \%-32 \%$ ) in risk for cognitive decline. In a post-hoc subgroup analysis restricted to those with recurrent strokes, those randomised to blood pressure-lowering treatment did have a larger and statistically significant reduction in both outcomes.

The Cochrane review of blood pressure lowering for prevention of cognitive impairment and dementia with no prior cerebrovascular disease identified four trials including 15,936 hypertensive participants, with an average age of 75.4 years ${ }^{51}$. The four trials comparing treatment vs placebo for incidence of dementia (OR 0.89, 95\% Cl: 0.74-1.07) did not suggest a benefit from antihypertensive treatment. We believe that there may be an error in the meta-analysis of the three trials reporting change in Mini Mental State Examination, since the effect in the HYVET trial seems to have been misinterpreted. When this is corrected, there is a very small statistically significant effect in favour of the active treatment arms (Weighted Mean Difference +0.13 MMSE points, 95\% Cl: 0.00-0.25). However, this is only equivalent to a standardised mean difference of 0.05 , where SMD 0.2 are conventionally considered 'small', 0.5 'medium' and 0.8 'large'. The review authors' conclusion that "There is no convincing evidence from the trials identified that blood pressure lowering in late-life prevents the development of dementia or cognitive impairment in hypertensive patients with no apparent prior cerebrovascular disease" seems well justified.

\section{However,}

1. In all of the trials, for ethical reasons, alternative active antihypertensive treatment was provided to placebo participants to ensure that blood pressure reached target levels. Hence, none of the trials was strictly placebo controlled, and blood pressure differences between arms would have been attenuated, although still substantial and statistically significant.

2. In all but the PROGRESS trial, randomisation occurred in late-life. This may have been a case of 'too little, too late' since epidemiological evidence suggests that midlife, rather than latelife hypertension predicts the onset of late-life dementia. We do not know if treating hypertension in midlife may help to prevent dementia, since no suitable trials have been conducted.

3. Reassuringly, the accumulated evidence from the trials excludes the possibility of cognitive harm arising from blood pressure lowering in hypertensive older adults, which would otherwise be a theoretical concern given the decline in blood pressure observed, in late-life, before the clinical onset of dementia.

4. As previously noted, treatment of hypertension in older adults remains strongly evidence-based, in light of its proven benefits in reducing risk of cardiovascular morbidity and mortality.

A recent systematic review identified just six eligible trials of the treatment of hypertension among people with dementia, four of which were placebocontrolled ${ }^{52}$. Blood pressure reduction was achieved in the treatment compared with the placebo arms. The trials were generally small in size and of moderate quality. There was no clear evidence of either 
benefit or harm with respect to cognitive, physical or cardiovascular outcomes. There was inconsistent evidence of possible cognitive benefit, with one of the trials indicating less cognitive decline in those treated with brain-penetrating vs non-brain-penetrating ACE inhibitor antihypertensive drugs ${ }^{53}$.

\section{Conclusion}

There is strong and consistent evidence for an association of midlife hypertension and the incidence of any dementia in late-life. This is likely accounted for mainly by the even stronger association observed between midlife hypertension and incident vascular dementia. An association of midlife hypertension with incident $A D$ has not yet been convincingly demonstrated, and the size of possible effects has probably been over-estimated. Hypertension in late-life is not associated, or is even inversely associated with incident dementia because of the decline in blood pressure levels that precedes the clinical onset of dementia, particularly of the Alzheimer type. However, late-life hypertension is associated with an increased risk of $\mathrm{VaD}$ in some studies.

The failure, experimentally, to demonstrate a benefit of blood pressure lowering in RCTs that are conducted in late-life is likely to be explained by the specific salience of exposure to hypertension in midlife. Reducing this exposure through improved prevention, detection and control of hypertension is likely to have a substantial impact on the future prevalence of all forms of dementia.

\section{Obesity}

\section{Background}

While larger birth weight and high (optimal) body size in childhood may be associated with better cognition, overweight and obesity from an excess of nutrient/ energy intake and/or reduced physical activity level are notoriously harmful for health, and are associated with a high mortality risk ${ }^{54}$. Evidence, reviewed in this section, also suggests that they may contribute to neurodegenerative and cerebrovascular changes underlying late-life dementia, through both vascular and metabolic pathways. Over the last 30 years, problems of overweight and obesity have been on the rise in most world regions; in 2008 an estimated 1.46 billion adults had a higher than normal body mass index (BMI, $25 \mathrm{~kg} / \mathrm{m}^{2}$ or greater) of whom 205 million men and 297 million women would be considered obese $\left(30 \mathrm{~kg} / \mathrm{m}^{2} \text { or higher }\right)^{55}$. Thus, if there was a causal link with dementia, the public health impact would be considerable.

\section{Mechanisms}

Adiposity may have direct adverse effects on brain tissue through production of inflammatory cytokines, Advanced Glycosylation End Products (AGEs), and hyperinsulinaemia, some of which factors may be directly implicated in the promotion of AD pathology. For a more detailed account of possible mechanisms, see Box 5.1.

Box 5.1

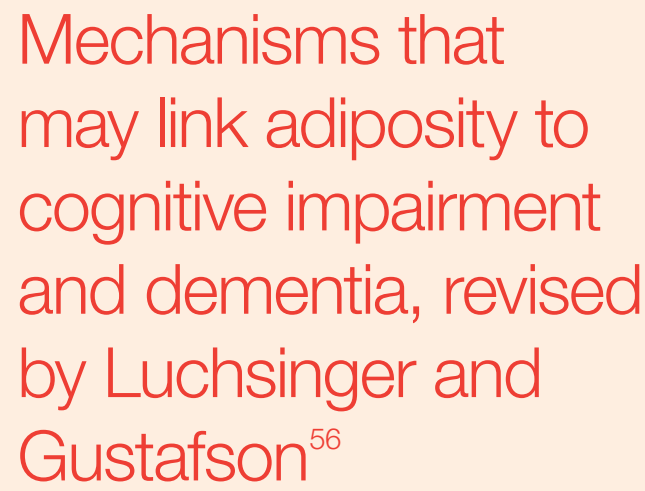

Hyperinsulineamia - insulin resistance and hyperinsulinaemia are caused by high adiposity. Excess of insulin can have direct effects in the brain, for instance it may interfere with the clearance of amyloid and contribute to brain damage.

Advanced glycosylation end products (AGEs) - AGEs are produced in excess in diabetes and are responsible for end organ damage. AGEs have been found both in both amyloid plaques and neurofibrillary tangles; the glycation of amyloid oligomers enhances their aggregation into insoluble plaques seen in Alzheimer's disease, and may facilitate neuronal damage.

Adipokines and cytokines - Adipose tissue produces inflammatory cytokines, which may increase the brain inflammatory state. It also acts as a diffuse endocrine organ secreting adipokines (adiponectin, leptin, and resistin), which have direct effects on brain regions implicated in dementia (e.g., the hippocampus) and may affect cognitive function.

\section{What is known?}

The association between adiposity and ensuing dementia is biologically plausible. However, similar to hypertension (see previous section), any excess risk seems to relate to obesity in midlife, with those going on to develop dementia experiencing greater relative decline in body mass before clinical onset. The existence of a causal association appears to be quite widely accepted; for example a recent review of modifiable risk factors for Alzheimer's disease estimated the relative risk associated with midlife obesity as 1.60 (95\% Cl: 1.34-1.92), and the population 
attributable fraction (the proportion of incident cases of $A D$ that might be prevented if the risk factor was completely removed from the population) as $2.0 \%{ }^{38}$. However, a critical overview of the evidence accumulated to date is necessary given the complexity of the research, the paucity of suitable studies to delineate the association, and a constantly developing literature.

Many prospective epidemiological studies have been conducted to test for associations of $\mathrm{BMI}$ and/or waist circumference in midlife with incident dementia. We have identified three reviews published in recent years ${ }^{57-59}$. The most recent of these, by Anstey and colleagues $^{59}$, is both the most comprehensive, and the most useful, in distinguishing between studies of the effects of midlife and late-life obesity, and their effects upon dementia and its subtypes.

\section{Critical analysis of the evidence}

\section{Studies of the association of body mass index with incident dementia}

In all, 15 prospective studies were identified of the relationship between $\mathrm{BMI}$ and dementia ${ }^{59}$. These comprised four studies of midlife and 11 of late-life exposures, with follow-up periods ranging from three to 36 years. BMI in late-life was not associated with dementia. However, pooled relative risks from metaanalyses indicated positive associations between adiposity in midlife and dementia risk. Those who were overweight in midlife had around a 30\% increased risk of dementia compared with those with normal BMI (AD RR 1.35, 95\% Cl: 1.19-1.54; Any Dementia RR 1.26, 95\% Cl: 1.10-1.44), while those who were obese had up to twice the risk (AD RR 2.04, 95\% Cl: 1.59-2.62, Any Dementia RR 1.64, 95\% Cl: 1.34-2.00). There was also a suggestion of a ' $U$-shaped' association, at least for $A D$ in that those with a low $B M I$ in midlife were also at twice the risk of developing dementia compared with those with a normal BMI (AD RR 1.96, 95\% Cl: 1.32-2.92). The authors highlight the relatively small numbers of studies that could be included in the midlife meta-analyses, and comment on the large heterogeneity of findings across the primary studies included in their review.

Close inspection of the midlife obesity studies included in the Anstey review indicates significant problems with three of them. Positive results were largely driven by the large effect sizes from a single study conducted on health plan members registered with the Kaiser Permanente medical care programme in northern California $60 ; 61$. Adiposity was rigorously and uniformly assessed in health checks conducted between 1964 and 1973 (at age 40-45), but dementia diagnoses were determined only from Kaiser Permanente medical records. This may have introduced an important ascertainment bias; since higher BMI predicts morbidity and hospitalization, those who were obese in midlife may have been more likely to be diagnosed with dementia simply because they were in more frequent and regular contact with health services. Another study included in the review, from the Swedish Primary Prevention Study, had the same limitation with incident dementia ascertained only through linkage to hospital discharge and mortality data ${ }^{62}$. Furthermore, educational level was not controlled for, and residual confounding seems likely because education is strongly associated with both BMI and dementia risk. Finally, in the Cardiovascular Health Study, 'midlife' obesity was ascertained by asking participants at the inception of the cohort (aged 65 years and over, mean 74.2 years) to recall their weight at age $50^{63}$.

Three population-based studies were not included in the review, although their data and methods were more robust than other included studies. In the Finnish Cardiovascular Risk Factors, Aging and Dementia (CAIDE) study ${ }^{64}$, there was a positive association between midlife obesity, but not overweight, and incident dementia (RR 2.44, 95\% Cl: 1.18-5.06), however this was diminished and not statistically significant after controlling for other CVRF, health status and APOE genotype (1.88, 95\% Cl: 0.76-4.53). Similar findings were reported from a later analysis from the same cohort, with more years of follow-up ${ }^{65}$. In the Prospective Population Study of Women in Sweden (PPSW) ${ }^{66}$ there was no association between any BMI indicators and incident dementia after 32 years of follow-up from mid- to late-life. No association between midlife BMI or weight and dementia incidence was detected in the Honolulu Asia Aging Study after 32 years of follow-up ${ }^{67}$.

In summary, the evidence regarding an association between midlife obesity and incident dementia is weak, conflicting, and likely to be subject to bias and residual confounding.

\section{Studies of the association of central obesity with incident dementia}

Waist circumference is less often measured than BMI in prospective, longitudinal epidemiological studies of the association with onset of dementia in late-life, and therefore this exposure was not assessed in the latest systematic review ${ }^{59}$. Nevertheless, in contrast with the conflicting evidence on BMI, the limited evidence on the association between central obesity and dementia risk is more consistent. It is striking that a positive, prospective association between a waist-to-hip ratio (WHR) greater than 0.80 and greater dementia risk was found in the Prospective Population Study of Women in Sweden (PPSW), in which BMI at the same age in midlife was not associated with dementia (see above ${ }^{66}$. Results were also unequivocal in the Kaiser Permanente study, in which those with highest central obesity in midlife were almost three times more likely to have been diagnosed with dementia three decades later ${ }^{68}$, this association being independent of BMI, and apparent also in those with normal BMI. A specific association with WHR rather than BMI, measured in 
late-life, and the incidence of AD was also reported in a cohort study of older adults in New York ${ }^{69}$. Because central adiposity captures associated metabolic changes better than total adiposity (i.e. BMI), these findings support the hypothesis that any link between adiposity and dementia may be best understood as a continuum through type 2 diabetes, possibly mediated through insulin resistance and hyperinsulinaemia ${ }^{56 ; 70}$.

\section{Conclusion}

There is currently inadequate evidence to confirm an association between midlife adiposity and incident dementia. The elucidation of the pattern of association is complicated by the decline in body mass that accompanies dementia, and may precede clinical onset by up to a decade ${ }^{65 ; 67}$. Indeed decline in $\mathrm{BMI}$ from mid- to late-life appears to be a stronger predictive factor than midlife obesity ${ }^{65}$, although it is unclear whether this represents a causal association or a prodromal aspect of dementia. The possibility that central obesity in midlife (e.g. waist circumference), rather than total obesity (e.g. BMI) better encapsulates the relationship between adiposity and future dementia risk warrants further research. An improved understanding of the critical pathways that may lead from high adiposity to greater dementia risk could have a significant impact on targeting of primary prevention strategies.

\section{Cholesterol (Dyslipidaemia)}

\section{Background}

Lipids comprise triglycerides, free fatty acids, sterols (cholesterol and cholesterol-related compounds) and phospholipids. Total cholesterol is made up of three subfractions; high density lipoproteins (HDL), low density lipoproteins (LDL) and very low density lipoproteins (VLDL). Dyslipidaemia occurs when levels of triglycerides or total cholesterol are high. HDL cholesterol ('good cholesterol') removes LDL ('bad cholesterol') from macrophages in the vascular endothelium where, if they accumulate, they can initiate the inflammatory process that can lead to formation of the plaques that lead to atherosclerosis ('hardening of the arteries'). Therefore dyslipidaemia is also diagnosed when LDL cholesterol levels are high, or HDL cholesterol levels are low. Dyslipidaemia is extraordinarily common in high income countries; $66.5 \%$ of middle-aged and $76.3 \%$ of older Americans have higher than ideal cholesterol levels ${ }^{3}$. It is an important independent risk factor for ischaemic heart disease and stroke, accounting, according to WHO estimates for the year 2000, for around $56 \%$ of ischaemic heart disease and $32 \%$ of ischaemic stroke burden, and 4.4 million deaths ${ }^{71}$. The class of drugs called statins (HMG-CoA reductase inhibitors) are effective in reducing levels of LDL cholesterol, and have been shown greatly to reduce risk of cardiovascular events and deaths, including for those aged 75 years and over ${ }^{72 ; 73}$. Current recommendations are that all those with a greater than $20 \%$ risk of a cardiovascular event within 5 years should take statins, although recent evidence suggests that this should be reduced to $10 \%{ }^{73}$. In the UK, this could imply an increase in the numbers of people taking statins from 7 million to 12 million.

\section{Mechanisms}

Lipids are the basic structural component of neuronal (nerve) cell membranes, and constitute the majority of brain dry weight. The brain is the most cholesterolrich organ, containing $30 \%$ of the body's total cholesterol. However, cholesterol does not cross the blood brain barrier, and brain cholesterol is therefore synthesised in the CNS. Brain cholesterol homeostasis is maintained through clearance via conversion into the metabolite (24S)-hydroxycholesterol, which can cross the blood brain barrier $-90 \%$ of circulating (24S)-hydroxycholesterol is of CNS origin. Cholesterol is an essential component of neuronal cell membranes and plays a crucial role in the development and maintenance of neuronal plasticity and function.

Several lines of research suggest that cholesterol may play an important part in $A D^{74}$.

1. Several genes involved in cholesterol metabolism or transport are susceptibility genes for $A D$, including apolipoprotein E (APOE), apolipoprotein J (APOJ, CLU), ATP-binding cassette subfamily A member 7(ABCA7), and sortilin-related receptor (SORL1). APOE plays an important role in brain cholesterol transport. The APOE $\varepsilon 2$ isoform, which confers a lower risk of $A D$, is associated with lower plasma cholesterol level. The $\varepsilon 4$ allele is associated with higher plasma concentrations of total and LDL cholesterol, and a higher risk of atherosclerosis, alongside a higher risk of AD. However, most studies concur that the effect of APOE genotype is not mediated through dyslipidaemia or cardiovascular disease.

2. The cleavage of $A \beta$ precursor protein (A $\beta P P)$ leading to generation of $A \beta$ protein occurs in the middle of the neuronal cell membrane. The cleavage by a-secretase results in soluble (nonamyloidogenic) $A \beta$, while cleavage by the membrane associated $\beta$-secretase and $\gamma$-secretase results in insoluble forms that aggregate as extracellular amyloid plaques. It is hypothesised that the brain lipid environment may influence the function of the cleavage enzymes, and hence $A \beta$ production and AD pathogenesis.

3. In animal studies, dietary cholesterol accelerates $A \beta$ deposition in the brain, whereas cholesterol lowering drugs decrease it. However, other evidence from in vitro studies suggest that the picture is more complex with the potential for higher levels of membrane cholesterol to promote or block different aspects of the AD neuropathological process. 


\section{What is known?}

The best explanation for the inconsistent findings on the association between cholesterol level and dementia seems to be that the association varies depending upon the age at which cholesterol level is assessed, and the follow-up interval. Studies where the exposure is assessed in midlife, are more likely to report a positive association than short latency studies where exposure is assessed in late-life shortly before the onset of dementia. Similar to body weight and blood pressure, cholesterol levels may decline more rapidly from midlife to late-life in those who go on to develop dementia, particularly AD.

While some epidemiological studies have suggested that high levels of total cholesterol in midlife may be associated with an increased risk of $A D^{75}$, the evidence to support this is limited and not completely consistent. Pharmacoepidemiologic studies suggest a modest reduced risk of the incidence of dementia and $A D$ among those taking statin drugs to reduce cholesterol levels ${ }^{76}$. However, Cochrane reviews of trials of statins to prevent ${ }^{77}$ or treat ${ }^{78}$ dementia strongly suggest no preventive or therapeutic effect. Therefore the apparent protective effect observed in the pharmacoepidemological studies was probably accounted for by confounding. The most recent review of the epidemiological evidence covered the period up to the end of $2006^{75}$. Our search in PubMed using the search terms "cholesterol and (dementia or Alzheimer ${ }^{\star}$ )" identified 1531 publications since $1 / 1 / 2007$, indicating an undiminished scientific interest in the hypothesis.

\section{Critical analysis of the evidence}

\section{Cholesterol in late-life and the incidence of dementia}

In the most recent review, by Anstey and colleagues ${ }^{75}$, five studies of the association between total cholesterol (TC) in late-life and the subsequent incidence of AD, and three studies of the incidence of any dementia consistently failed to identify any increased risk associated with higher levels of TC. There was a non-significant trend towards an increased risk of the incidence of $\mathrm{VaD}$ across quartiles of TC. In publications since then, there was also no association between late-life total cholesterol and the incidence of dementia, AD or VaD in the Uppsala Longitudinal Study of Adult Men ${ }^{35}$. In the Three Cities cohort study from France, no association was found over a 7 year follow-up period between total cholesterol or LDL cholesterol and incident dementia or $\mathrm{AD}^{79}$. However, complex patterns of association with triglyceride and HDL cholesterol were reported when the analyses were stratified by gender, and limited to participants without vascular pathologies. In the North Manhattan WHICAP Study (of over 65 year olds recruited 19992001) particularly high levels of HDL cholesterol were associated with a much lower incidence of
$A D^{80}$, although this association was not present to a statistically significant degree in the previous WHICAP cohort recruited seven years earlier.

\section{Cholesterol in midlife and the incidence of AD}

Anstey and colleagues identified four cohort studies assessing the association between total cholesterol in midlife and the onset of $A D$ in late-life. In two of these studies, both from Finland, elevated TC ( $>=6.5 \mathrm{mmol} / \mathrm{L})$ was strongly associated with $A D$ risk; the Finnish cohorts of the Seven Countries Study (OR 3.1, 95\% $\mathrm{Cl}: 1.2-8.5)^{81}$, and the CAIDE study (OR $2.8,95 \% \mathrm{Cl}$ : 1.2-6.7) ${ }^{34}$. In the Honolulu Asia Aging Study (HAAS) cohort it was reported that mean TC at baseline (mean age 50) did not differ by subsequent dementia status $^{82}$; however, the focus of this analysis was the change in cholesterol level over the 26 years of follow-up, with a much steeper decline noted in men who went on to develop dementia, preceding clinical onset by up to 15 years. In a separate publication from the same study, it is also reported that triglyceride levels were also not associated with the incidence of $A D^{83}$. In the Framingham Heart Study, TC levels were averaged across the first 15 biennial examinations (1948-1977), at the end of which period participants' ages ranged between 54 and 85 years ${ }^{84}$. While many of these assessments would have been collected in midlife, Anstey and colleagues are correct in stating that this could not be considered to be exclusively an assessment of the effect of midlife cholesterol. No association was observed between the risk for incident $A D$ and average cholesterol level at biennial examination cycles 1 to 15 (HR per $10 \mathrm{mg} / \mathrm{dL}$ [0.3mmol/L] rise, $0.95,95 \% \mathrm{Cl}: 0.87-1.04)$ or baseline total cholesterol level at examination 20 (HR 0.97, 95\% Cl: 0.90-1.05). The Kaiser Permanente historical cohort study was excluded from the Anstey review because the incidence of dementia was assessed through linkage to medical records. In this study, having a higher than desirable total cholesterol at baseline was associated with an increased risk of AD (borderline elevated TC HR 1.23, 95\% Cl: 0.97-1.55; high TC HR $1.57,95 \% \mathrm{Cl}: 1.23-2.01)$, while the association was less apparent for incident VaD (borderline TC HR 1.50, 95\% Cl: 1.01-2.23; high TC 1.26, 95\% Cl: 0.82-1.96) ${ }^{85}$.

We identified two further studies published since the Anstey review, both conducted in Sweden. In the Uppsala Longitudinal Study of Adult Men, total cholesterol measured at age 50 was not associated with risk for developing $A D$ in late-life (RR per SD increase in TC 1.0, 95\% Cl: 0.9-1.2) ${ }^{35}$. In the Prospective Population Study of Women ${ }^{86}$, there was a non-significant trend towards an increased risk of AD among those with elevated TC at baseline in 1968 who survived to and participated in a re-examination to assess dementia status in 2000-2001 (highest vs lowest TC quartile: HR 2.82, 95\% Cl: 0.94-8.43). However, the stronger predictive factor was a decline in 
TC over the 32 year follow-up period (HR 2.35, 95\% Cl: 1.22-4.58).

\section{Cholesterol in midlife and the incidence of dementia}

Anstey identified three studies of the effect of total cholesterol in midlife on the incidence of any dementia. Only one of these, the Finnish CAIDE study, reported a significantly increased incidence of any dementia associated with higher levels of TC at baseline (RR 2.6, $95 \% \mathrm{Cl}: 1.2-6.0$; the effect size is incorrectly reported in the review). No association was found between TC in midlife and incidence of dementia in $\mathrm{HAAS}^{82}$, or between either TC or HDL-C and incident dementia in the Israeli Ischaemic Heart Disease Study ${ }^{87}$. We identified two further relevant studies published since the Anstey review. In the Uppsala Longitudinal Study of Adult Men TC measured at age 50 was not associated with the incidence of any dementia (RR per SD increase 1.1, 95\% Cl: 1.0-1.2). In the Baltimore Longitudinal Study of Aging, participants were followed-up for a median of 25 years after cholesterol was measured at baseline when participants were aged 50 years ${ }^{88}$. There was no association between either TC or HDL-C and the subsequent incidence of dementia. Among men only, a pattern of decline in TC from first-visit was significantly associated with increased dementia risk (HR 4.21, 95\% Cl: 1.28-13.85).

\section{The impact of treatment with statins}

There have been two recently published systematic reviews and meta-analyses of the potential role of statin drugs in the prevention of dementia. The most comprehensive of these, by Wong and colleagues, identified 20 relevant studies, comprising 16 cohort studies, three case control studies, and one $\mathrm{RCT}^{76}$. The second, by Song et al, is much less comprehensive, contains multiple errors and should be disregarded ${ }^{89}$. In the Wong meta-analysis, there were modest protective effects of statin use for any dementia (random effects pooled RR 0.82, 95\% Cl: 0.69-0.97) and AD (random effects pooled RR $0.70,95 \% \mathrm{Cl}: 0.60-0.80)$. There was substantial heterogeneity in the effect sizes for any dementia, but not for AD. The authors note that effect sizes were generally smaller, and closer to the null (indicating no protective effect) in studies that had controlled for more confounders, and where a clinical diagnosis, as opposed to a linkage to health records was used to establish dementia incidence.

A Cochrane review of randomized controlled trials (RCTs) of the use of statins for the prevention of dementia $^{77}$, identified two relevant trials; HPS (simvastatin) ${ }^{90}$ and PROSPER (pravastatin) ${ }^{91 ; 92}$. Dementia and/or cognitive impairment were secondary outcomes in trials which were designed to assess the impact of statin treatment on cardiovascular morbidity and mortality. PROSPER recruited 5804 persons, and HPS included 5806 persons who were at least 70 years old at study entry. In both trials the randomised statin treatment was effective in reducing total and LDL cholesterol. Mean follow-up was 3.2 years in PROSPER, 5 years in HPS 2002. There was no difference in new diagnoses of dementia in HPS 31 cases in simvastatin group, 31 cases in placebo group, identified through event monitoring) nor in the prevalence of cognitive impairment at final follow-up. In PROSPER, cognitive function declined at the same rate in both treatment groups with no significant difference on performance of any of the cognitive test outcomes. The authors of the review conclude, reasonably, that "there is good evidence from RCTs that statins given in late-life to individuals at risk of vascular disease have no effect in preventing AD or dementia". The question as to whether statin treatment initiated earlier, in midlife, might have been effective in preventing cognitive decline or dementia, has not been addressed in any long-term trials, which would be very difficult to conduct for ethical and practical reasons.

Another Cochrane systematic review focused upon the evidence, from RCTs, for the possible cognitive benefits when statins were used to treat dementia ${ }^{78}$. Three trials were identified, with a total of 748 participants, all of whom had a diagnosis of probable or possible AD. Most patients were already taking a cholinesterase inhibitor. Change in Alzheimer's disease Assessment Scale cognitive subscale (ADAS-Cog) from baseline was the primary outcome, and change in MMSE a secondary outcome in all of the trials. The random effects pooled estimates (ADAS-Cog mean difference -1.12 points, $95 \% \mathrm{Cl}$ : -3.99 to $+1.75, \mathrm{p}=0.44$; MMSE mean difference $-1.53,95 \% \mathrm{Cl}:-3.28$ to $+0.21, p=0.08$ ) did not suggest a significant difference between statins and placebo.

\section{Conclusion}

The most recent review of prospective studies of cholesterol as a risk factor for dementia concluded that "consistent associations between high midlife TC and increased risk of $A D$... and any dementia were found" 75 . In fact, the evidence reported in that review was inconsistent, and the support for this conclusion has been weakened further with the publication of findings from more long-term cohort studies. Positive findings for an association between midlife TC and late-life $A D$ come principally from two Finnish Cohort studies. The North Karelia and Kuipio provinces were selected for the WHO MONICA studies because, in the 1960s and 1970s, Finland in general and these areas in particular experienced some of the highest ischaemic heart disease mortality rates in the world, attributed to a large extent to diets that were exceptionally rich in unsaturated fats, and to very high cholesterol levels in the population ${ }^{93}$. It remains possible, therefore, that there is a genuine association, but that increased risk for $A D$ is concentrated at very high levels of midlife TC.

The most consistent finding across cohorts is that a more rapid decline in TC from mid- to late-life predicts 
the onset of $A D$, and, possibly, dementia and cognitive decline. This has been demonstrated in $\mathrm{HAAS}^{82}$ and the Baltimore Longitudinal Study of Aging in the USA $^{88}$, the Prospective Population Study of Women in Sweden ${ }^{86}$, and CAIDE in Finland ${ }^{94}$. The only failure to replicate was in the Framingham Heart Study ${ }^{84}$. These trends explain the absence of an association, or even a protective effect, of hyperlipidaemia in late-life. The association between decline in TC and the subsequent incidence of dementia has yet to be satisfactorily explained. It could be causal (in which case acting to prevent the decline in cholesterol would reduce the risk of dementia), or reflect reverse causality (AD neuropathology or its consequences leading to a decline in TC), or be accounted for by confounding. A striking feature of the decline in TC is that it seems to be more prominent for $A D$ than for $\mathrm{VaD}$, and precedes the onset of $A D$ by around 15 years $^{82}$, much earlier than the decline in blood pressure ${ }^{31}$ or body mass ${ }^{67}$ that has also been reported. It may be that there is a common mechanism underlying each of these trends, but if so it has yet to be identified. It seems very unlikely that it would be secondary to cognitive or behavioural changes linked to dementia given the long interval between the onset of the trajectories and the clinical onset of dementia. Elucidation of the underlying mechanisms may improve our understanding of the neurobiology of $A D$, which may help to identify new therapeutic targets.

The evidence accumulated to date does not support the hypothesis that preventing or treating dyslipidaemia will help to prevent cognitive decline, AD or other forms of dementia. However, there are several important caveats:

1. It may be that the increased risk conferred by midlife hypercholesterolaemia may be concentrated at much higher than normal levels. This possibility could be explored further through re-analysis of existing data.

2. The possible benefits of statin treatment for preventing or treating vascular dementia have been little studied ${ }^{95}$, probably because of the focus on the cholesterol homeostasis mechanism that is specific for AD neuropathology. Dyslipidaemia is an important risk factor for stroke, and there may yet be therapeutic benefits through this mechanism.

3. The possibility that effective primary and secondary prevention of dyslipidaemia, initiated in midlife, may help to prevent AD or dementia has not been excluded. There is some evidence for example, from pharmacoepidemiologic studies, that longer term treatment with statins is associated with a greater protective effect ${ }^{96}$.

4. The generally negative findings from epidemiological and experimental research in no way negates the interesting findings from genetic research, animal models and in vitro studies that strongly suggest an important role for brain cholesterol metabolism and transport in AD neuropathology. This body of research should, and undoubtedly will, continue, in an effort to identify therapeutic targets.

\section{Diabetes}

\section{Background}

Type 2 diabetes is one of the more common chronic conditions in the world. In the United States alone, a third of the adult population has either type 2 diabetes or its antecedent, pre-diabetes ${ }^{97}$. The prevalence of diabetes increases sharply with age, from $2.4 \%$ in those aged $20-39$ years to $21.6 \%$ among those aged 65 years and over, and in recent years the largest increases have occurred in the oldest age groups ${ }^{98}$. The prevalence in emerging economies such as China ${ }^{99}$ and Mexico ${ }^{100}$ is already similar to that in the USA. The general trend, in both developed and developing countries, is towards an increasing prevalence of pre-diabetes and diabetes, linked to increases in obesity due to a sedentary life-style 101;102.

In contrast to type 1 diabetes, most cases of type 2 diabetes are brought on by lifestyle factors and are therefore preventable; taking exercise, losing weight, cutting fat and sugars in the diet, reducing alcohol consumption and stopping or avoiding smoking should all reduce risk. Diabetes can be treated with diet, oral hypoglycaemic drugs or insulin. The high prevalence of diabetes makes it potentially one of the most important modifiable risk factors for dementia.

\section{Mechanisms}

There are several possible mechanisms by which diabetes may act to increase the risk of dementia and AD. However, there is no clear consensus as yet on the mechanism or mechanisms that might support a causal association. As has been noted, diabetes is an important component of the metabolic syndrome. However, the association of the metabolic syndrome with dementia is inconsistent ${ }^{83 ; 103 ; 104}$ with some studies indicating a specific association with the diabetes component alone ${ }^{103 ; 104}$. Insulin resistance is an antecedent and correlate of diabetes, and thought by some to be a central mechanism in the metabolic syndrome, but few studies have demonstrated an association with dementia ${ }^{105 ; 106}$.

Several studies examined the relation between diabetes and dementia mechanisms, particularly surrogate markers of Alzheimer's disease, and found conflicting results. In a large population-based autopsy series from Finland, diabetes in late-life positively associated with the presence of cerebral infarcts (HR 1.88, 95\% Cl: 1.06-3.34), but not with either $\beta$-amyloid (HR $0.48,95 \% \mathrm{Cl}: 0.23-0.98$ ) or neurofibrillary tangles (HR 0.72, 95\% Cl: 0.39-1.33) ${ }^{107}$. Nevertheless, brain imaging studies of cognitively normal individuals indicate that insulin resistance ${ }^{108}$ and diabetes ${ }^{109}$ are related to a regional profile of reduced brain 
metabolism that is consistent with Alzheimer's disease. While, in the second of these imaging studies, there was no association between diabetes and amyloid accumulation ${ }^{109}$, one study from South Korea found that anti-amyloid $\beta$ antibodies were elevated in persons with diabetes, although possibly mediated by dyslipidaemia ${ }^{110}$.

Advanced glycation end products (AGEs) provide a particularly plausible link between diabetes and AD pathology. AGEs are elevated in diabetes, and are strongly implicated in end-organ damage. AGEs are also elevated in AD brains and it seems that they can stimulate beta-amyloid production. In rat experimental models, treatment with AGEs can induce tau hyperphosphorylation and impair synapse and memory through upregulation of the AGEs receptor (RAGE) activating glycogen synthase kinase-3 (GSK-3), these changes being reversed upon blockage of RAGE/GSK3 pathway ${ }^{111}$.

\section{What is known?}

We conducted a search of PubMed to update previously identified systematic reviews, and to explore mechanistic evidence. We used the search terms "diabetes and (dementia or Alzheimer* or Amyloid)" from 2010 to the present. This search yielded 176 articles. We prioritized epidemiological studies in humans and also accessed other relevant publications known to the authors.

There have been numerous longitudinal studies testing for a prospective association of diabetes and its related conditions with the onset of cognitive impairment and dementia, and these have been summarized in systematic reviews ${ }^{112-115}$. In general, most studies have found that diabetes is associated with an increased risk of dementia, and that this association is stronger for vascular dementia compared to Alzheimer's dementia. Diabetes is also relatively consistently associated with mild cognitive impairment $(\mathrm{MCl})$ and with cognitive impairment without dementia.

The association between diabetes and dementia has been shown across countries, continents and ethnic groups. The most disadvantaged demographic groups, such as minorities in the United States ${ }^{109}$, may be most heavily impacted by the association between diabetes and dementia ${ }^{116}$, and ethnic disparities in diabetes prevalence may account for some of the unequal distribution of incident cognitive impairment between ethnicities ${ }^{117}$.

It remains unclear whether diabetes may affect the amyloid cascade, as well as acting as a vascular risk factor ${ }^{118}$. To the extent that the association may be causal, it is also unclear whether prevention, or more effective treatment of diabetes can prevent dementia $^{119}$.

\section{Critical analysis of the evidence}

The two most recent meta-analyses, of 17 longitudinal studies (1966-2010) published in $2012^{120}$ and of 28 longitudinal studies (up to Jan 2012) published in $2013^{121}$, concur that diabetes is associated with incident AD, VD, and dementia in general. However, they are problematic, first and foremost since only nine studies are common between the two reviews, partly explained by duplicate and overlapping publications. However, there are also some apparent omissions and limitations. Both reviews included studies that used health service or hospital registers to ascertain dementia outcome, and some which had used the same approach to identify diabetes exposure. Neither review makes a clear distinction between midlife and late-life exposure to diabetes. Most critically, the way in which the diabetes exposure was ascertained was not classified. For many studies, this was 'diagnosed diabetes' (a self-reported or servicerecorded diagnosis, or use of medication prescribed for diabetes). This would miss many exposed to 'undiagnosed (and hence untreated) diabetes', who would have been correctly classified only in those studies that had used fasting glucose estimation, or Oral Glucose Tolerance Tests (OGTT) in addition to the measures used to identify diagnosed diabetes.

We therefore carried out a new review, merging studies from both recent reviews, checking carefully for duplication, and adding any further eligible studies identified in the course of the new search. We applied the same inclusion and exclusion criteria as the previous reviews ${ }^{120 ; 121}$ (prospective or historical population-based cohort studies reporting on the association of diabetes with any dementia (AnyDem), Alzheimer's disease (AD) or vascular dementia (VaD)), but excluded health record linkage studies other than for narrative description and discussion. We found 19 eligible studies ${ }^{14 ; 87 ; 104 ; 122-136}$. We stratified the meta-analyses by the stage in the life course at which the exposure had been ascertained (midlife or latelife), and as a sensitivity analysis, restricted inclusion to those studies in which undiagnosed as well as diagnosed diabetes had been ascertained. 
The association between diabetes and the incidence of any dementia (AnyDem)

Eleven studies provided data on the association between diabetes in late-life and incident AnyDem. The pooled RR was 1.50 (95\% Cl: 1.33-1.70), with no heterogeneity $\left(\mathrm{I}^{2}=0.0 \%\right)$. When restricted to the seven of these studies ${ }^{104 ; 124 ; 127-130 ; 135}$ that had also ascertained undiagnosed diabetes, the pooled RR was 1.50 (95\% Cl: 1.30-1.73), again with no heterogeneity of effect.

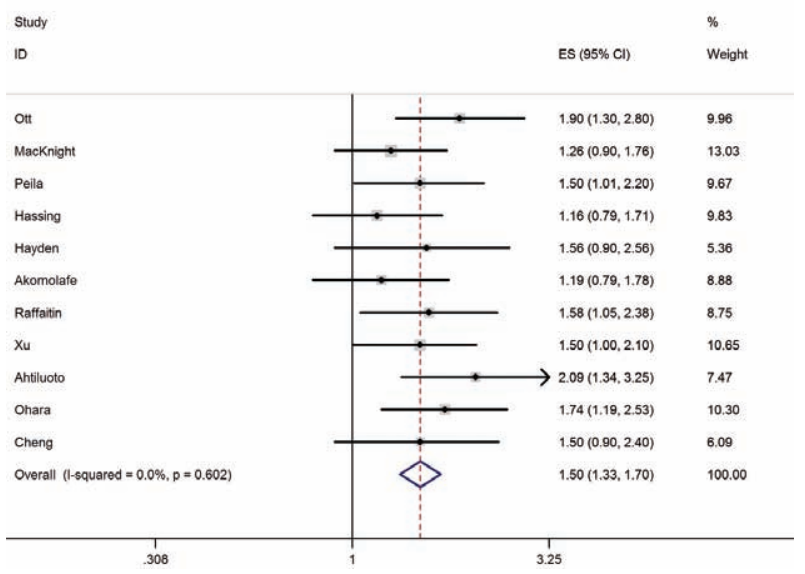

Figure 5.1

Forest plot for the association of diabetes in late-life with the incidence of any dementia (AnyDem)

Just three studies included estimates of the association between midlife (diagnosed) diabetes and incident AnyDem ${ }^{87 ; 122 ; 123}$. There was substantial heterogeneity of effect between them $\left(\mathrm{I}^{2}=68.8 \%\right.$, $\mathrm{Chi}^{2}$ $6.4,2 \mathrm{df}, \mathrm{p}=0.04)$. The random effect pooled $\mathrm{RR}$ was 1.37 (95\% Cl: 0.64-2.91). See section below on health record linkage studies for further information on this association.

\section{The association between diabetes and the incidence of Alzheimer's disease (AD)}

Fifteen studies provided data on the association between diabetes in late-life and incident AD. The pooled RR was 1.40 (95\% Cl: 1.22-1.61), $\mathrm{I}^{2}=0.0 \%$. When restricted to the seven of these studies $104 ; 124 ; 127-$ $130 ; 135$ that had also ascertained undiagnosed diabetes, the pooled RR was 1.46 (95\% Cl: 1.21-1.75), again with no heterogeneity of effect.

The Honolulu Asia Aging Study (HAAS) ${ }^{123}$ was the only study to have assessed the association of midlife (diagnosed) diabetes with incident AD. None was found, either from the baseline assessment (1965-68, 25 years prior to dementia ascertainment) RR 0.98 (95\% Cl: 0.48-1.99), or the interim assessment (1976-

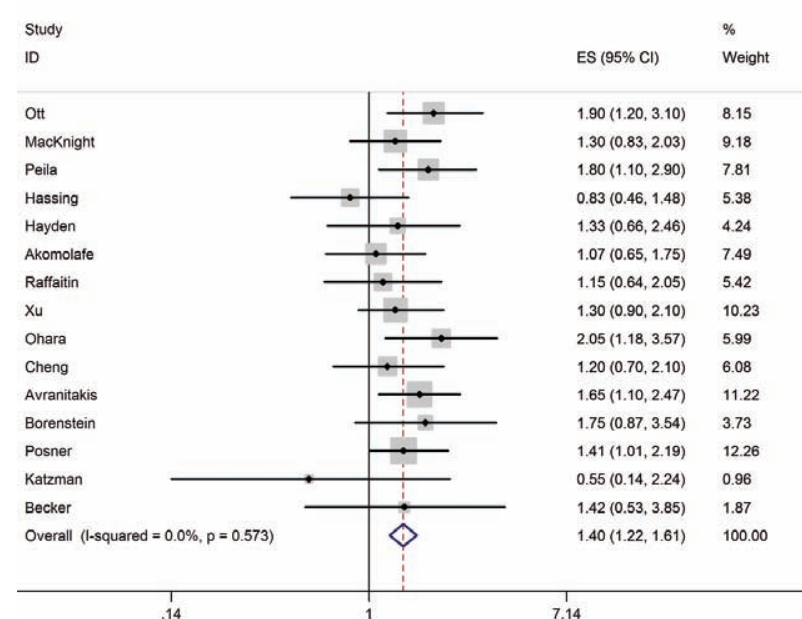

Figure 5.2

Forest plot for the association of diabetes in late-life with the incidence of Alzheimer's disease (AD)

78,15 years prior to dementia ascertainment follow up period) RR 1.00 (95\% Cl: 0.58-1.72).

\section{The association between diabetes and the incidence of vascular dementia (VaD)}

12 studies provided data on the association between diabetes in late-life and incident vascular dementia.

The pooled RR was 2.39 ( $95 \% \mathrm{Cl}: 1.92-2.98$ )

$\mathrm{I}^{2}=0.0 \%$. When restricted to the seven of these studies $^{104 ; 124 ; 127-130 ; 135}$ that had also ascertained undiagnosed diabetes, the pooled RR was 2.14 (95\% $\mathrm{Cl}: 1.60-2.86)$, again with no heterogeneity of effect.

The Honolulu Asia Aging Study (HAAS) ${ }^{123}$ was the only study to have assessed the association of midlife (diagnosed) diabetes with incident $\mathrm{VaD}$. None was

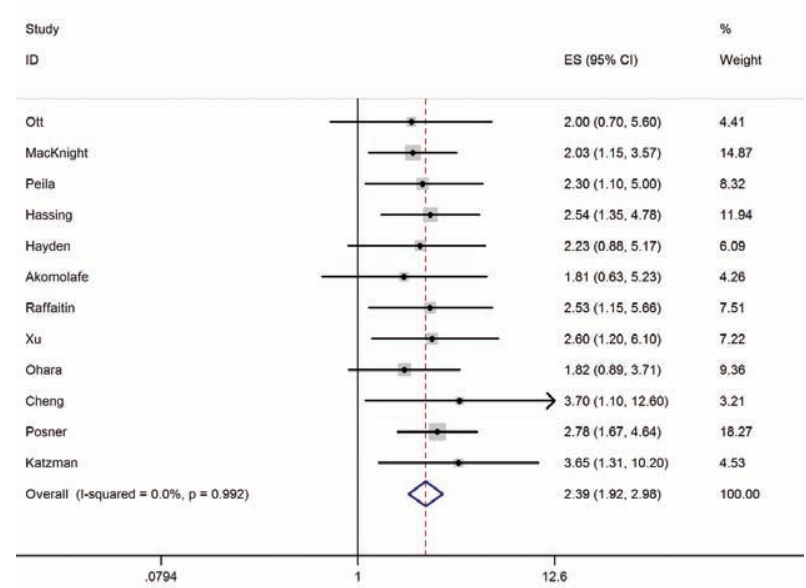

Figure 5.3

Forest plot for the association of diabetes in late-life with the incidence of vascular dementia (VaD) 
Table 5.1

The association of diabetes with incident dementia. Characteristics of eligible studies

\begin{tabular}{|c|c|c|c|c|c|c|c|c|c|c|c|}
\hline$\frac{\mathscr{c}}{2}$ & $\begin{array}{l}\text { 흐 } \\
\text { 产 }\end{array}$ & 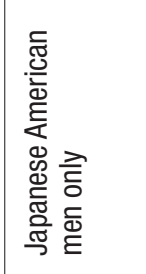 & 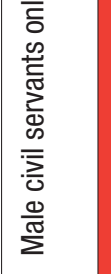 & & & & & 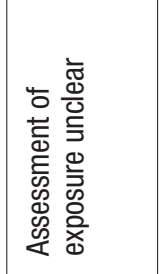 & 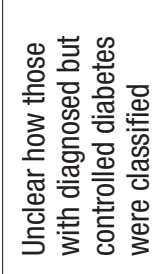 & & 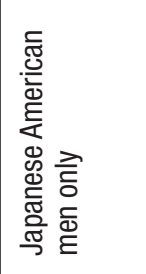 \\
\hline 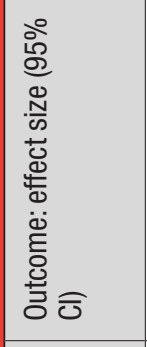 & 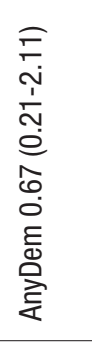 & 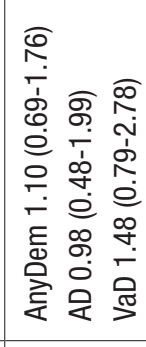 & 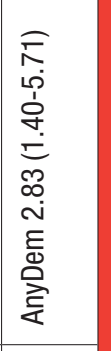 & 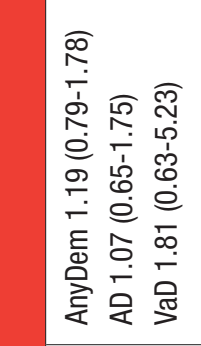 & 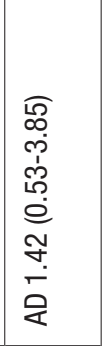 & 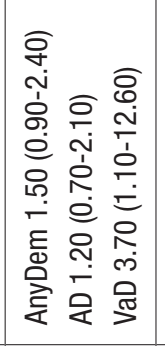 & 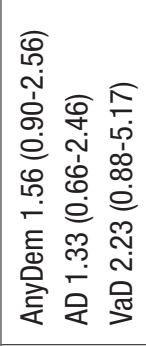 & 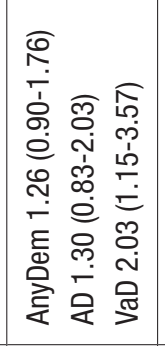 & 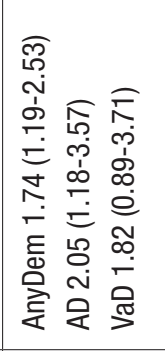 & 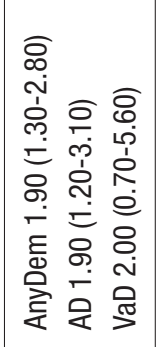 & 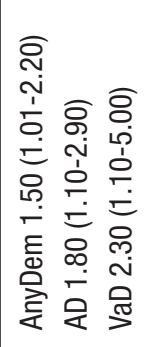 \\
\hline 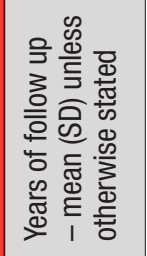 & 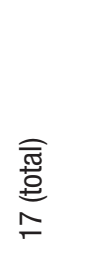 & 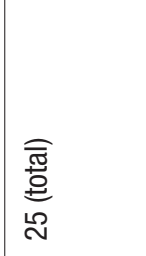 & 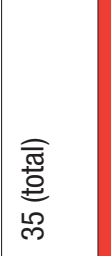 & 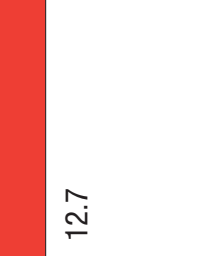 & $\bar{r}$ & $\stackrel{\rho}{\dot{m}}$ & $\underset{\substack{\tilde{S}\\
}}{\stackrel{f}{n}}$ & م & 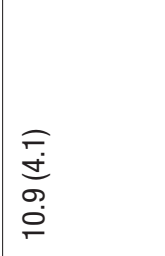 & $\bar{i}$ & 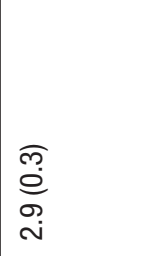 \\
\hline 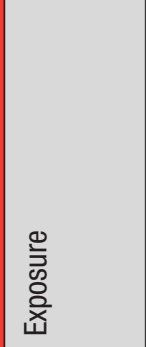 & 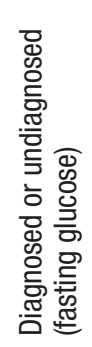 & 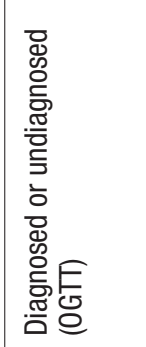 & 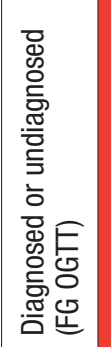 & 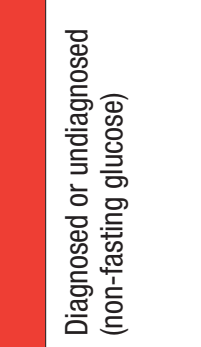 & 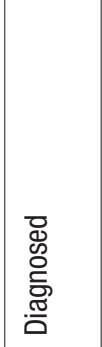 & 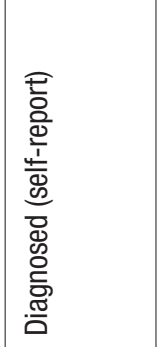 & 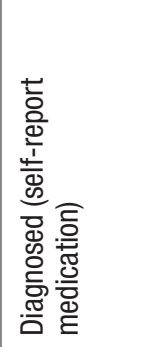 & 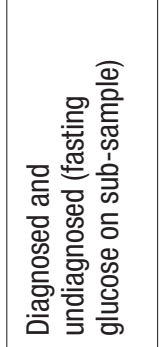 & 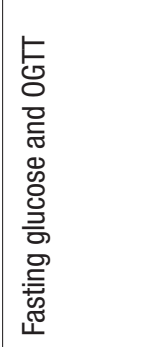 & 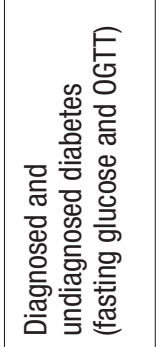 & 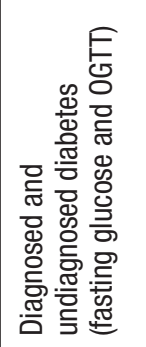 \\
\hline 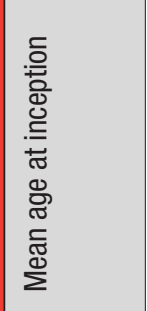 & 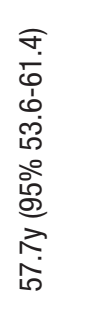 & 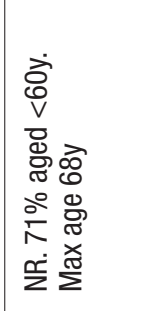 & $\stackrel{\infty}{\stackrel{f}{f}}$ & হ̀ & 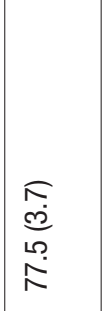 & 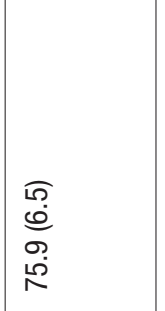 & 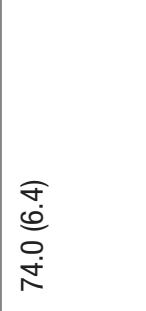 & 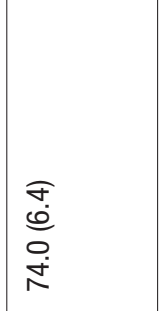 & 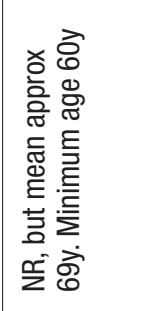 & 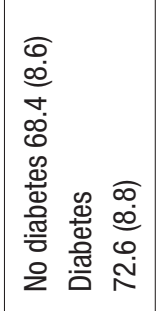 & 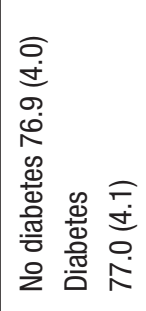 \\
\hline 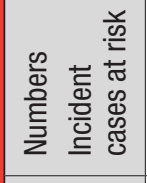 & 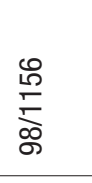 & $\begin{array}{c}\underset{N}{N} \\
\hat{N} \\
\stackrel{N}{\Sigma}\end{array}$ & 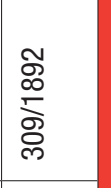 & $\begin{array}{l}\stackrel{0}{N} \\
\text { N. } \\
\frac{\mathrm{D}}{5}\end{array}$ & 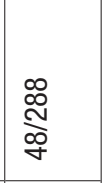 & 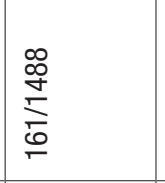 & 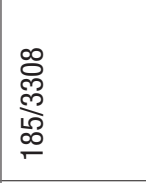 & 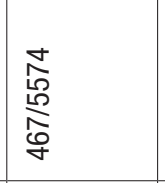 & $\hat{\bar{\sigma}}$ & 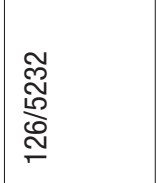 & 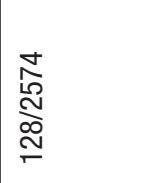 \\
\hline 咅 & 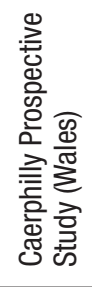 & 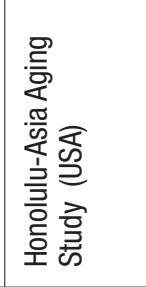 & 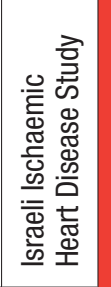 & 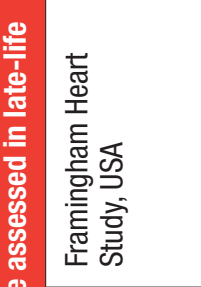 & 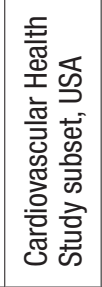 & 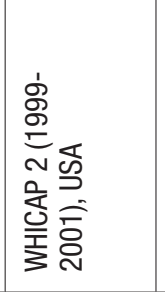 & 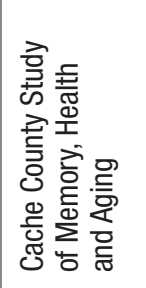 & 茎 & 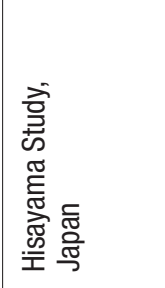 & 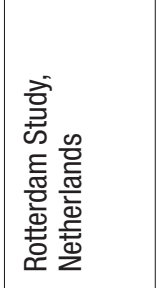 & 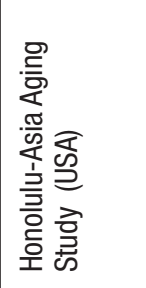 \\
\hline 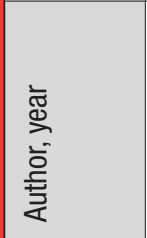 & 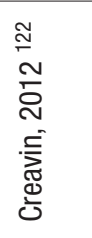 & 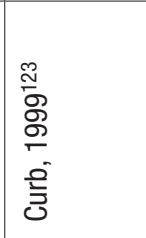 & 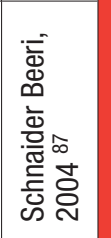 & 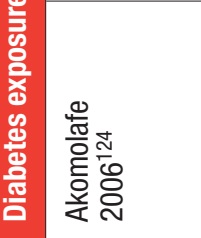 & 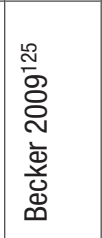 & 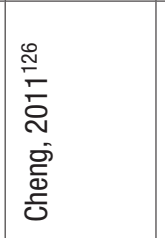 & 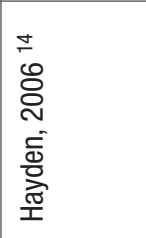 & 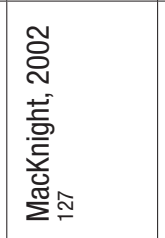 & 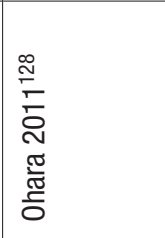 & 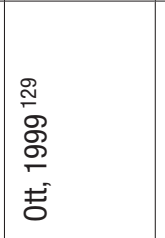 & 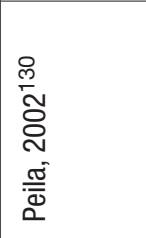 \\
\hline
\end{tabular}




\begin{tabular}{|c|c|c|c|c|c|c|c|}
\hline & & & 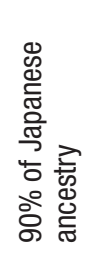 & & & & 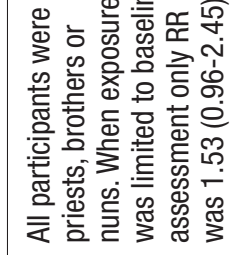 \\
\hline \multirow[t]{2}{*}{ 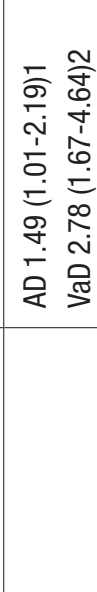 } & 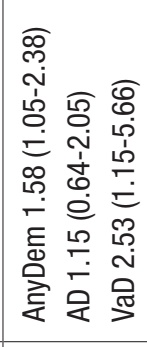 & 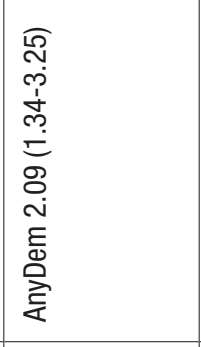 & 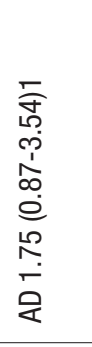 & 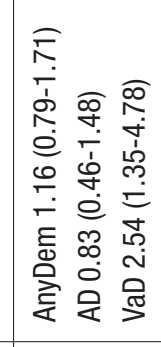 & 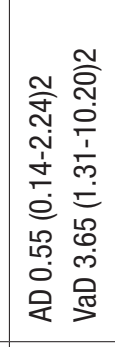 & 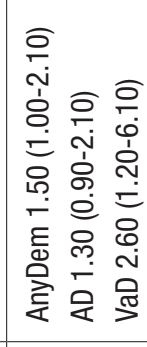 & 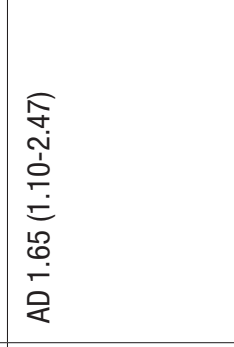 \\
\hline & $\stackrel{\text { L }}{\text { m }}$ & $\hat{m}$ & 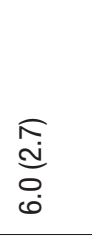 & 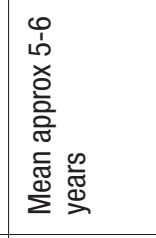 & 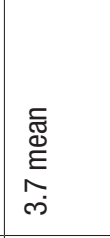 & 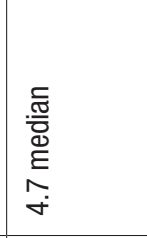 & $\begin{array}{l}\text { i } \\
\text { L }\end{array}$ \\
\hline 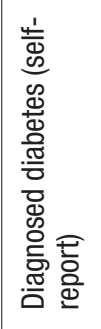 & 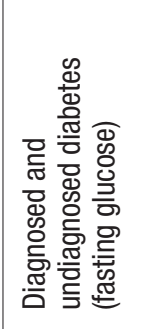 & 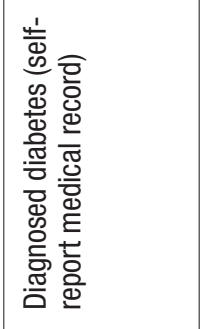 & 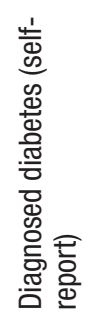 & 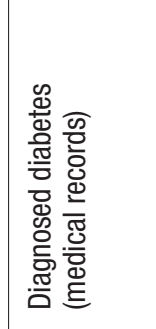 & 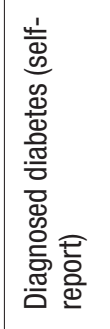 & 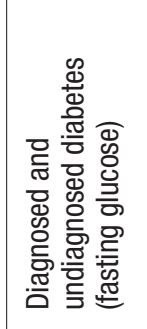 & 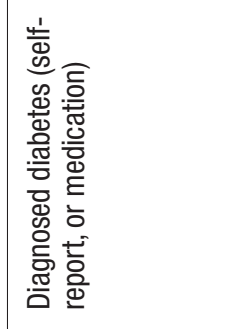 \\
\hline$\hat{\kappa}$ & 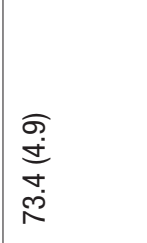 & 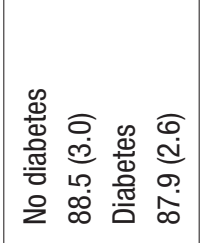 & 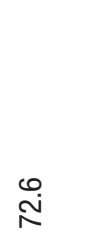 & ஜ & 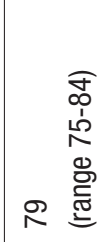 & 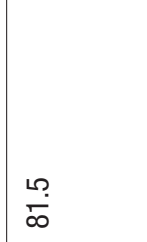 & 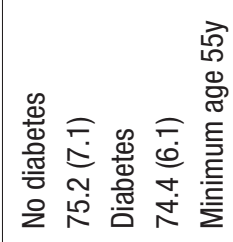 \\
\hline 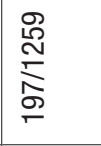 & 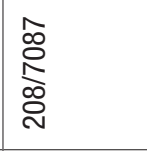 & 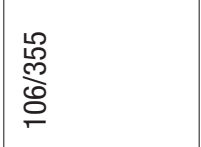 & $\begin{array}{l}\text { 品 } \\
\text { 品 } \\
\text { ò }\end{array}$ & 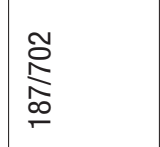 & 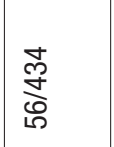 & 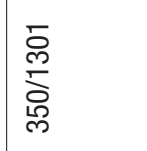 & 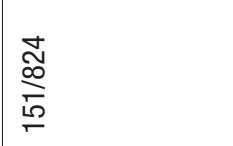 \\
\hline 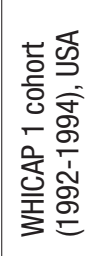 & 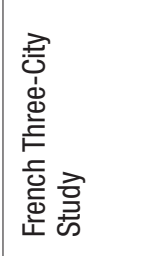 & 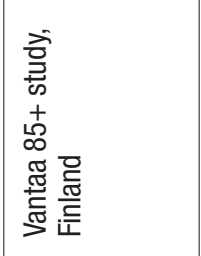 & 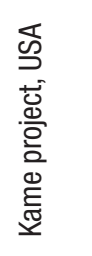 & 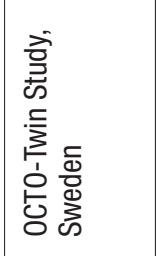 & 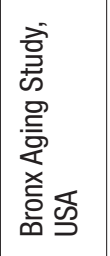 & 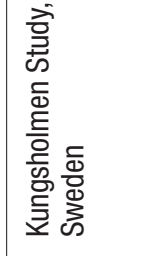 & 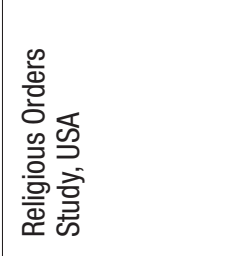 \\
\hline 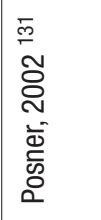 & 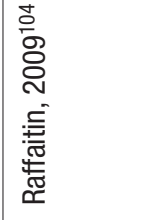 & 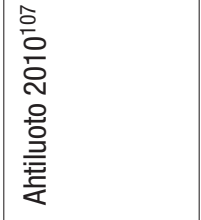 & 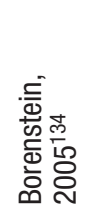 & 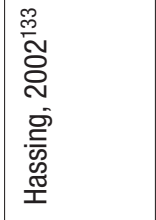 & 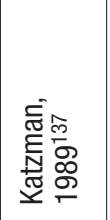 & 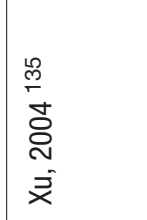 & 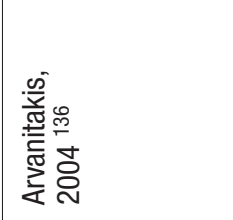 \\
\hline
\end{tabular}


found, either 25 years (RR 1.48, 95\% Cl: 0.79-2.78), or 15 years prior to dementia ascertainment (RR 1.53, 95\% Cl: 0.93-2.54).

\section{Health record linkage studies (excluded from the meta-analysis)}

Health record linkage studies may over-estimate the true association between an exposure such as diabetes and dementia incidence, since the exposure may make it more likely that a diagnosis of dementia is ascertained and recorded, regardless of any true difference in incidence between the exposure groups. Such studies may yet help us to clarify the association between diabetes in midlife and the subsequent incidence of dementia and $A D$, where, as results in previous paragraphs indicate, few other studies are available. Three studies, conducted in USA ${ }^{43}$, Korea ${ }^{138}$ and Finland ${ }^{139}$ all indicate an association between midlife diabetes and dementia risk, which may be even stronger than for diabetes diagnosed in late-life. In the Kaiser Permanente Health Maintenance Organisation, periodic multiphasic health assessment including diabetes status was carried out when enrolled members of the health plan were aged 40-44 years (1964-1973), and these data were then linked to diagnoses of dementia recorded 30 years later (1994-2003) ${ }^{43}$. Diabetes in midlife was strongly associated with a dementia diagnosis in late-life (RR 1.46, 95\% Cl: 1.19-1.79). In a similar linkage study from the National Health Insurance Corporation in Korea, diabetes (diagnosed or undiagnosed assessed from fasting glucose) identified in a compulsory biennial medical evaluation (1992-1995) was associated with subsequent (1993-2006) first admission to hospital with a diagnosis of AnyDem, VaD and AD (1993-2006) 138. However, effect sizes, particularly for $\mathrm{VaD}$, were slightly higher for those in whom the medical evaluation was carried out in midlife ( $<65$ years), than late-life ( $>=65$ years). In a Finnish case-control study, health records of people starting medication for Alzheimer's disease in 2005, and matched AD-free controls were compared for a diagnosis of diabetes over the preceding 33 years ${ }^{139}$. Those with AD were more likely to have had a preceding diagnosis of diabetes after adjusting for cardiovascular diseases (OR 1.31, 95\% Cl: 1.22-1.41). However, these associations were stronger for diabetes diagnosed at midlife (OR 1.60, $95 \% \mathrm{Cl}: 1.34-1.84)$ than for diabetes diagnosed in latelife (OR 1.25, 95\% Cl: 1.16-1.36).

\section{Other studies excluded from the meta- analysis}

In the Sacramento Area Latino Study on Aging, of Mexican Americans aged 60 years and over followed up for 10 years, both treated diabetes (RR 2.05, 95\% Cl: 1.41-2.97) and untreated diabetes (RR 1.55, 95\% Cl: 0.93-2.58) were associated with an increased risk of developing either AnyDem or cognitive impairment. AnyDem was not studied as a separate outcome, and hence these results could not be incorporated into the meta-analysis. This was an important finding given that Mexican Americans are known to have a high burden of diabetes. Findings from the HYVET randomised controlled trial of the treatment of hypertension in those aged 80 years or over could not be included in the meta-analysis since only volunteers with hypertension were included in the trial ${ }^{140}$. Among over 3000 participants followed up for a mean of two years, there was no association between baseline fasting glucose level and the subsequent incidence of AnyDem or cognitive impairment.

\section{The impact of the treatment of diabetes}

Among people with diabetes, factors associated with cognitive decline or the onset of dementia may provide some clues as to potential underlying mechanisms. Worse glycaemic control is an important predictor of cognitive decline ${ }^{141}$. Diabetes complications are linked to poor glycaemic control, and diabetic retinopathy ${ }^{142}$, microvascular disease, diabetic foot, cerebrovascular and cardiovascular disease ${ }^{143}$ are all associated with an increased risk of dementia. In principle, therefore, better glycaemic control might be expected to reduce the incidence of cognitive decline and dementia. Two trials give somewhat conflicting evidence. In the ACCORD MIND trial people with diabetes and elevated cardiovascular risk who were randomized to tighter than normal glycaemic control had similar cognitive function after 40 months to the control arm receiving standard care (although neuroimaging suggested less brain atrophy) ${ }^{144}$. In another clinical trial among diabetics aged 55 years and over, those randomized to a telemedicine intervention that improved glycaemic control experienced less global cognitive decline, an effect that seemed to be mediated by changes in $\mathrm{HbA}_{1} \mathrm{c}^{145}$. Hypoglycaemic attacks, which can be an unintended consequence of aiming for tight glycaemic control, may explain these discrepancies. Rapid improvement in glycaemic control (falling HbA1c levels, from a high baseline level) seems to be associated with worse cognitive outcomes than either stable good or bad control ${ }^{146}$, and hypoglycaemic attacks strongly predict the onset of dementia ${ }^{147}$. Evidence would therefore support a cautious approach to optimizing glycaemic control in older diabetics, avoiding hypoglycaemia where possible.

Findings on the impact of particular treatments for diabetes (e.g. different types of oral hypoglycaemic drugs and insulin) are inconsistent between studies ${ }^{148-150}$. The clinical indication for use of a particular treatment approach, often linked to diabetes severity, rather than the treatment itself, may account for observed differences in dementia risk. Management of cardiovascular comorbidities is also likely to be important. Studies have suggested that the incidence of dementia may be lower among those with diabetes who are also treated with statin (cholesterol lowering) medications ${ }^{150}$. Hypertension seems to 
increase the risk of dementia among people with diabetes, and treatment may lower the risk, particularly with angiotensin-converting enzyme inhibitors and angiotensin receptor blockers ${ }^{151}$.

While the focus of this report is modifiable risk factors for dementia, it is also important to note that the onset of cognitive impairment and dementia greatly complicates diabetes self-management and treatment ${ }^{152}$. Hypoglycaemia, a complication of diabetes treatment, may be a consequence, as well as a cause of dementia ${ }^{147}$.

\section{Conclusion}

Evidence reviewed in this section confirms a particularly strong and consistent association between diabetes in late-life and the subsequent onset of dementia. This is in contrast to the pattern observed for hypertension, obesity and dyslipidaemia, where the increased risk, if it exists, is only apparent for midlife exposures. Clearly this may have important implications for prevention. However, in contrast to other CVRF, relatively few randomized controlled trials have been conducted to assess if improved diabetes control results in a lower incidence of dementia. Evidence from health record linkage studies also suggests that diabetes in midlife may have an equivalent or even greater effect, and it may be that the duration of diabetes is an important risk determinant. The primary prevention of diabetes should also therefore be targeted. Diabetes seems to be a much stronger risk factor for vascular dementia than for Alzheimer's disease, and cerebrovascular disease is likely to be an important mediating mechanism. However, other causal mechanisms may also be involved, including direct influences on $A D$ neuropathological processes. It remains possible that processes or genetic predispositions that underlie both diabetes and $A D^{153}$, could explain a link that is not causal. It is also possible that diabetes decreases brain resilience, but does not directly cause Alzheimer's disease.

Improved understanding of causal mechanisms will help to shape diabetes treatment and prevention strategies to prevent dementia. It is also important to know whether Alzheimer's based dementia treatment and prevention strategies could also be useful in people with diabetes, or whether other strategies should be pursued. In the meantime, the rising and overlapping epidemics of diabetes and dementia mean that older people with diabetes are increasingly likely to have cognitive impairment, affecting their self-care, and potentially resulting in more adverse dementia and diabetes outcomes. This will pose a challenge for healthcare systems worldwide.

\section{Overall conclusion}

\section{Summary of findings}

We have identified particularly strong and consistent epidemiological evidence that

- Hypertension in midlife increases the risk of dementia, particularly vascular dementia

- Diabetes in late-life (and probably in midlife) is associated with an increased risk of all forms of dementia, particularly vascular dementia

- Hypertension, obesity and dyslipidaemia (high tota cholesterol) in late-life are not associated with the incidence of dementia

- A decline in blood pressure level, body mass index and total cholesterol precedes and predicts the onset of dementia, particularly Alzheimer's disease, by five to 15 years.

There is weak and inconsistent evidence that

- Obesity in midlife may increase the risk of dementia and Alzheimer's disease

- Dyslipidaemia in midlife (high total cholesterol) may increase the risk of dementia, particularly Alzheimer's disease.

\section{Implications for public health}

The possible associations of midlife obesity and high total cholesterol with dementia, and the decline in blood pressure, body mass index and cholesterol that precede dementia, are relatively specific to AD. Given the plausible links between these CVRF and aspects of $A D$ neurobiology, it may be that these associations are of greater importance to our understanding of underlying disease mechanisms than they are to public health prevention programmes.

The robust associations of diabetes and hypertension with dementia do give much cause for optimism that a significant proportion of the incidence of dementia could be prevented through more effective prevention, detection and control of these CVRF. This is currently sub-optimal in all world regions, but particularly in low and middle income countries where the prevalence of these exposures is increasing due to lifestyle change. The absence of clear evidence from RCTs conducted in late-life that lowering blood pressure prevents dementia is consistent with predictions from epidemiological research findings, and should not discourage prevention efforts. There is currently too little evidence from RCTs to reach clear conclusions regarding the effect of the treatment of diabetes on cognitive outcomes.

Obesity is an important determinant of risk for hypertension and type 2 diabetes, and, for that reason, should also be targeted in primary prevention programs. It is possible that an important part of any effect of midlife obesity is mediated through hypertension and diabetes. Available evidence 
suggests that the increased propensity for vascular disease is the most important mechanism for the effect of hypertension and diabetes on dementia risk, but influences on $A D$ pathology, or at least the clinical expression of $A D$, are also possible.

\section{Implications for research}

\section{Observational epidemiological studies}

While sub-classification of dementia outcomes into $\mathrm{AD}$ and $\mathrm{VaD}$ subtypes may be clinically informative, and assist in elucidation of underlying mechanisms, it may be less helpful in informing public health prevention programs. Different approaches to subtype classification may account for some of the heterogeneity in the strength of the association observed between studies, particularly the extent to which the presence of CVRF is used to exclude individuals from the AD subtype. The distinctiveness and validity of the subtypes is a matter of debate, given the importance of co-existing pathologies in determining the clinical expression of the dementia syndrome. In the domain of public health, we are ultimately interested in preventing dementia, regardless of contributory pathologies. Therefore, it would be helpful if future epidemiological studies always included 'any dementia' as an outcome, in addition to $\mathrm{AD}$ and/or VaD. Likewise, modelling exercises that assess the possible impact of future changes in risk factor profile on dementia incidence or prevalence, and studies of secular trends should, most usefully, focus on this outcome.

The epidemiological evidence is constantly developing, and difficult to track. While systematic reviews are increasing in number, their quality and comprehensiveness cannot always be assured. Many are uncritical in their approach with too little attention given to potential issues of bias and confounding. There would be a strong case for a Cochranelike consortium to be established to carry out and document this work, applying consistent standards. As we have pointed out, much of the available evidence cannot currently be meta-analysed, due to differing approaches between studies for operationalising CVRF exposures, which if standardised could greatly increase the yield of information. This would argue for a wider collaboration of research groups to permit secondary data analysis of individual participant data, and to establish reporting guidelines for future studies.

\section{Experimental evidence}

Some previous reviews have concluded, on the basis of lack of experimental evidence to support the hypothesis, that the evidence for potential for prevention by targeting CVRF is weak ${ }^{154}$. This may be technically correct, but largely misses the point. There is no point in setting a standard of proof that can never be met.
It is no longer ethically possible to conduct a placebocontrolled RCT of the effectiveness of the treatment of diabetes or hypertension for any outcome. Given the low levels of detection, treatment and control of both conditions, it would be possible to trial new health system or service level approaches to improve these parameters, probably in a cluster-randomised controlled design. There are recent examples of such studies in the hypertension ${ }^{155}$ and diabetes literature. Such trials have been used to test for the shortlatency effect of improving diabetic control on the prevention of cognitive decline among older people with diabetes ${ }^{144 ; 145}$ and more should be conducted. There is also a recent upsurge in interest in multicomponent interventions among older people at risk of cardiovascular disease, that include simultaneous attention to multiple CVRF, nutrition, physical and cognitive activity ${ }^{156 ; 157}$ - see also the European Dementia Prevention Initiative www.edpi.org. The potential value and interest of this work is discussed in more detail in the final chapter of this report.

However, it would not be feasible for ethical and practical reasons to maintain randomisation for long enough, meaningfully to assess the effect of improved control of CVRF in midlife on the prevention of dementia in late-life. Nonetheless, current evidence, attesting to the importance of a life course perspective, suggests that it is from targeting this 'sensitive period' that the greatest yield from dementia prevention efforts will accrue.

The most persuasive evidence that modifying CVRF may reduce the risk of dementia will come from 'the real world'. As behaviours change and public health messages impact to different degrees in different countries, we will have the conditions in place for a natural experiment that will allow us to correlate changes in putative risk factor exposures with changes in the incidence and prevalence of dementia. Such evidence has strongly supported the causality of the association between cigarette smoking and lung cancer ${ }^{158}$, which has never been, and for obvious reasons never will be, demonstrated in randomised controlled trials in humans. 


\section{References}

1 Yusuf S, Hawken S, Ounpuu S, Dans T, Avezum A, Lanas F et al. Effect of potentially modifiable risk factors associated with myocardial infarction in 52 countries (the INTERHEART study): case-control study.[see comment]. Lancet 2004; 364(9438):937952.

2 O'Donnell MJ, Xavier D, Liu L, Zhang H, Chin SL, Rao-Melacini P et al. Risk factors for ischaemic and intracerebral haemorrhagic stroke in 22 countries (the INTERSTROKE study): a case-control study. Lancet 2010; 376(9735):112-123.

3 Shay CM, Ning H, Allen NB, Carnethon MR, Chiuve SE, Greenlund $\mathrm{KJ}$ et al. Status of cardiovascular health in US adults: prevalence estimates from the National Health and Nutrition Examination Surveys (NHANES) 2003-2008. Circulation 2012; 125(1):45-56.

4 Grundy SM, Cleeman JI, Daniels SR, Donato KA, Eckel RH Franklin BA et al. Diagnosis and Management of the Metabolic Syndrome: An American Heart Association/National Heart, Lung, and Blood Institute Scientific Statement. 2005; 112:2735-2752.

5 Breteler MM, van Swieten JC, Bots ML, Grobbee DE, Claus JJ, van den Hout $\mathrm{JH}$ et al. Cerebral white matter lesions, vascular risk factors, and cognitive function in a population-based study: the Rotterdam Study. Neurology 1994; 44:1246-1252.

6 Hofman A, Ott A, Breteler MM, Bots ML, Slooter AJ, van Harskamp F et al. Atherosclerosis, apolipoprotein E, and prevalence of dementia and Alzheimer's disease in the Rotterdam Study [see comments]. Lancet 1997; 349(9046):151-154.

7 Breteler MM, Claus JJ, Grobbee DE, Hofman A. Cardiovascular disease and distribution of cognitive function in elderly people: the Rotterdam Study. BMJ 1994; 308(6944):1604-1608.

8 Prince MJ. Vascular risk factors and atherosclerosis as risk factors for cognitive decline and dementia. J Psychosom Res 1995; 39(5):525-530.

9 Skoog I, Lernfelt B, Landahl S, Palmertz B, Andreasson LA, Nilsson $L$ et al. 15-year longitudinal study of blood pressure and dementia [see comments]. Lancet 1996; 347(9009):1141-1145.

10 Savva GM, Stephan BC. Epidemiological studies of the effect of stroke on incident dementia: a systematic review. Stroke 2010; 41(1):e41-e46.

11 Rusanen M, Kivipelto M, Levalahti E, Laatikainen T, Tuomilehto J, Soininen $\mathrm{H}$ et al. Heart Diseases and Long-Term Risk of Dementia and Alzheimer's Disease: A Population-Based CAIDE Study. J Alzheimers Dis 2014; 42(1):183-191.

12 Luchsinger JA, Reitz C, Honig LS, Tang MX, Shea S, Mayeux R. Aggregation of vascular risk factors and risk of incident Alzheimer disease. Neurology 2005; 65(4):545-551.

13 Newman AB, Fitzpatrick AL, Lopez O, Jackson S, Lyketsos C Jagust $W$ et al. Dementia and Alzheimer's disease incidence in relationship to cardiovascular disease in the Cardiovascular Health Study cohort. J Am Geriatr Soc 2005; 53(7):1101-1107.

14 Hayden KM, Zandi PP, Lyketsos CG, Khachaturian AS, Bastian LA, Charoonruk $G$ et al. Vascular risk factors for incident Alzheimer disease and vascular dementia: the Cache County study. Alzheimer Dis Assoc Disord 2006; 20(2):93-100.

15 Neuropathology Group.Medical Research Council Cognitive Function and Aging Study. Pathological correlates of lateonset dementia in a multicentre, community-based population in England and Wales. Neuropathology Group of the Medical Research Council Cognitive Function and Ageing Study (MRC CFAS). [comment]. Lancet 2001; 357(9251):169-175.

16 Snowdon DA, Greiner LH, Mortimer JA, Riley KP, Greiner PA, Markesbery et al. Brain infarction and the clinical expression of Alzheimer disease. The Nun Study [see comments]. JAMA 1997; 277(10):813-817.

17 Egan BM, Zhao Y, Axon RN. US trends in prevalence, awareness, treatment, and control of hypertension, 1988-2008. JAMA 2010; 303(20):2043-2050.

18 Ostchega Y, Dillon CF, Hughes JP, Carroll M, Yoon S. Trends in hypertension prevalence, awareness, treatment, and control in older U.S. adults: data from the National Health and Nutrition Examination Survey 1988 to 2004. J Am Geriatr Soc 2007; 55(7):1056-1065.

19 Fried LP, Kronmal RA, Newman AB, Bild DE, Mittelmark MB, Polak JF et al. Risk factors for 5-year mortality in older adults: the Cardiovascular Health Study. JAMA 1998; 279(8):585-592.

20 Reed DM, Foley DJ, White LR, Heimovitz H, Burchfiel CM, Masak $\mathrm{K}$. Predictors of healthy aging in men with high life expectancies. Am J Public Health 1998; 88(10):1463-1468.
21 Lewington S, Clarke R, Qizilbash N, Peto R, Collins R. Agespecific relevance of usual blood pressure to vascular mortality: a meta-analysis of individual data for one million adults in 61 prospective studies. Lancet 2002; 360(9349):1903-1913.

22 Musini VM, Tejani AM, Bassett K, Wright JM. Pharmacotherapy for hypertension in the elderly. Cochrane Database Syst Rev 2009;(4):CD000028.

23 Sanderson S. Hypertension in the elderly: pressure to treat? Health Trends 1996; 28:71-75.

24 Ostchega Y, Hughes JP, Wright JD, McDowell MA, Louis T. Are demographic characteristics, health care access and utilization, and comorbid conditions associated with hypertension among US adults? Am J Hypertens 2008; 21(2):159-165.

25 Hypertension Study Group. Prevalence, awareness, treatment and control of hypertension among the elderly in Bangladesh and India: a multicentre study. Bull World Health Organ 2001; 79(6):490-500.

26 Gu D, Reynolds K, Wu X, Chen J, Duan X, Muntner P et al. Prevalence, awareness, treatment, and control of hypertension in china. Hypertension 2002; 40(6):920-927.

27 Prince MJ, Ebrahim S, Acosta D, Ferri CP, Guerra M, Huang Y et al. Hypertension prevalence, awareness, treatment and control among older people in Latin America, India and China: a 10/66 cross-sectional population-based survey. J Hypertens 2012; 30(1):177-187.

28 Kalaria RN. Vascular basis for brain degeneration: faltering controls and risk factors for dementia. Nutr Rev 2010; 68 Suppl 2:S74-87. doi: 10.1111/j.1753-4887.2010.00352.x.:S74-S87.

29 Beauchet O, Celle S, Roche F, Bartha R, Montero-Odasso M, Allali $\mathrm{G}$ et al. Blood pressure levels and brain volume reduction: a systematic review and meta-analysis. J Hypertens 2013; 31(8):1502-1516.

30 Qu C, Winblad B, Fratiglioni L. The age-dependent relation of blood pressure to cognitive function and dementia. Lancet Neurol 2005; 4(8):487-499.

31 Stewart R, Xue QL, Masaki K, Petrovitch H, Ross GW, White LR et al. Change in blood pressure and incident dementia: a 32-year prospective study. Hypertension 2009; 54(2):233-240.

32 Launer LJ, Ross GW, Petrovitch H, Masaki K, Foley D, White LR et al. Midlife blood pressure and dementia: the Honolulu-Asia aging study. Neurobiol Aging 2000; 21(1):49-55

33 Freitag MH, Peila R, Masaki K, Petrovitch H, Ross GW, White LR et al. Midlife pulse pressure and incidence of dementia: the Honolulu-Asia Aging Study. Stroke 2006; 37(1):33-37.

34 Kivipelto M, Helkala EL, Laakso MP, Hanninen T, Hallikainen M, Alhainen $\mathrm{K}$ et al. Apolipoprotein $\mathrm{E}$ epsilon4 allele, elevated midlife total cholesterol level, and high midlife systolic blood pressure are independent risk factors for late-life Alzheimer disease. Ann Intern Med 2002; 137(3):149-155

35 Ronnemaa E, Zethelius B, Lannfelt L, Kilander L. Vascular risk factors and dementia: 40-year follow-up of a population-based cohort. Dement Geriatr Cogn Disord 2011; 31(6):460-466.

36 Power MC, Weuve J, Gagne JJ, McQueen MB, Viswanathan A, Blacker $\mathrm{D}$. The association between blood pressure and incident Alzheimer disease: a systematic review and meta-analysis. Epidemiology 2011; 22(5):646-659.

37 Meng XF, Yu JT, Wang HF, Tan MS, Wang C, Tan CC et al. Midlife Vascular Risk Factors and the Risk of Alzheimer's Disease: A Systematic Review and Meta-Analysis. J Alzheimers Dis 2014.

38 Barnes DE, Yaffe K. The projected effect of risk factor reduction on Alzheimer's disease prevalence. Lancet Neurol 2011; 10(9):819-828.

39 Norton S, Matthews FE, Barnes DE, Yaffe K, Brayne C. Potential for primary prevention of Alzheimer's disease: an analysis of population-based data. Lancet Neurol 2014; 13(8):788-794.

40 Kivipelto M, Helkala EL, Laakso MP, Hanninen T, Hallikainen M, Alhainen $\mathrm{K}$ et al. Midlife vascular risk factors and Alzheimer's disease in later life: Iongitudinal, population based study. BMJ 2001; 322(7300):1447-1451.

41 Freitag MH, Peila R, Masaki K, Petrovitch H, Ross GW, White LR et al. Midlife pulse pressure and incidence of dementia: the Honolulu-Asia Aging Study. Stroke 2006; 37(1):33-37.

42 Wu C, Zhou D, Wen C, Zhang L, Como P, Qiao Y. Relationship between blood pressure and Alzheimer's disease in Linxian County, China. Life Sci 2003; 72(10):1125-1133.

43 Whitmer RA, Sidney S, Selby J, Johnston SC, Yaffe K. Midlife cardiovascular risk factors and risk of dementia in late life. Neurology 2005; 64(2):277-281. 
44 Ninomiya T, Ohara T, Hirakawa Y, Yoshida D, Doi Y, Hata J et al. Midlife and late-life blood pressure and dementia in Japanese elderly: the Hisayama study. Hypertension 2011; 58(1):22-28.

45 Sharp SI, Aarsland D, Day S, Sonnesyn H, Ballard C. Hypertension is a potential risk factor for vascular dementia: systematic review. Int J Geriatr Psychiatry 2011; 26(7):661-669.

46 Ross GW, Petrovitch H, White LR, Masaki KH, Li CY, Curb JD et al. Characterization of risk factors for vascular dementia: the Honolulu-Asia Aging Study. Neurology 1999; 53(2):337-343.

47 Ueda K, Kawano H, Hasuo Y, Fujishima M. Prevalence and etiology of dementia in a Japanese community. Stroke 1992; 23(6):798-803.

48 Yoshitake T, Kiyohara Y, Kato I, Ohmura T, Iwamoto H, Nakayama $\mathrm{K}$ et al. Incidence and risk factors of vascular dementia and Alzheimer's disease in a defined elderly Japanese population: the Hisayama Study. Neurology 1995; 45(6):1161-1168.

49 Forette F, Seux M-L, Staessen JA, Thijs L, Birkenhager WH, Babarskiene M-R et al. Prevention of dementia in randomised double-blind placebo-controlled Systolic Hypertension in Europe (Syst-Eur) trial. Lancet 1998; 352:1347-1351.

50 Tzourio C, Anderson C, Chapman N, Woodward M, Neal B, MacMahon S et al. Effects of blood pressure lowering with perindopril and indapamide therapy on dementia and cognitive decline in patients with cerebrovascular disease. Arch Intern Med 2003; 163(9):1069-1075.

51 McGuinness B, Todd S, Passmore P, Bullock R. Blood pressure lowering in patients without prior cerebrovascular disease for prevention of cognitive impairment and dementia. Cochrane Database Syst Rev 2009;(4):CD004034.

52 Beishon LC, Harrison JK, Harwood RH, Robinson TG, Gladman JR, Conroy SP. The evidence for treating hypertension in older people with dementia: a systematic review. J Hum Hypertens 2014; 28(5):283-287.

53 Ohrui T, Tomita N, Sato-Nakagawa T, Matsui T, Maruyama M, Niwa K et al. Effects of brain-penetrating ACE inhibitors on Alzheimer disease progression. Neurology 2004; 63(7):1324-1325.

54 Berrington de GA, Hartge P, Cerhan JR, Flint AJ, Hannan L, Maclnnis RJ et al. Body-mass index and mortality among 1.46 million white adults. N Engl J Med 2010; 363(23):2211-2219.

55 Finucane MM, Stevens GA, Cowan MJ, Danaei G, Lin JK, Paciorek $\mathrm{CJ}$ et al. National, regional, and global trends in body-mass index since 1980: systematic analysis of health examination surveys and epidemiological studies with 960 country-years and 9.1 million participants. Lancet 2011; 377(9765):557-567.

56 Luchsinger JA, Gustafson DR. Adiposity and Alzheimer's disease. Curr Opin Clin Nutr Metab Care 2009; 12(1):15-21.

57 Gorospe EC, Dave JK. The risk of dementia with increased body mass index. Age Ageing 2007; 36(1):23-29.

58 Beydoun MA, Beydoun HA, Wang Y. Obesity and central obesity as risk factors for incident dementia and its subtypes: a systematic review and meta-analysis. Obes Rev 2008; 9(3):204218.

59 Anstey KJ, Cherbuin N, Budge M, Young J. Body mass index in midlife and late-life as a risk factor for dementia: a meta-analysis of prospective studies. Obes Rev 2011; 12(5):e426-e437.

60 Whitmer RA, Gunderson EP, Quesenberry CP, Jr., Zhou J, Yaffe $\mathrm{K}$. Body mass index in midlife and risk of Alzheimer disease and vascular dementia. Curr Alzheimer Res 2007; 4(2):103-109.

61 Whitmer RA, Gunderson EP, Barrett-Connor E, Quesenberry CP, Jr., Yaffe K. Obesity in middle age and future risk of dementia: a 27 year longitudinal population based study. BMJ 2005; 330(7504):1360.

62 Rosengren A, Skoog I, Gustafson D, Wilhelmsen L. Body mass index, other cardiovascular risk factors, and hospitalization for dementia. Arch Intern Med 2005; 165(3):321-326.

63 Fitzpatrick AL, Kuller LH, Lopez OL, Diehr P, O'Meara ES Longstreth WT, Jr. et al. Midlife and late-life obesity and the risk of dementia: cardiovascular health study. Arch Neurol 2009; 66(3):336-342

64 Kivipelto M, Ngandu T, Fratiglioni L, Viitanen M, Kareholt I, Winblad B et al. Obesity and vascular risk factors at midlife and the risk of dementia and Alzheimer disease. Arch Neurol 2005; 62(10):1556-1560.

65 Tolppanen AM, Ngandu T, Kareholt I, Laatikainen T, Rusanen M, Soininen $\mathrm{H}$ et al. Midlife and late-life body mass index and late-life dementia: results from a prospective population-based cohort. J Alzheimers Dis 2014; 38(1):201-209.
66 Gustafson DR, Backman K, Waern M, Ostling S, Guo X, Zandi P et al. Adiposity indicators and dementia over 32 years in Sweden. Neurology 2009; 73(19):1559-1566.

67 Stewart R, Masaki K, Xue QL, Peila R, Petrovitch H, White LR et al. A 32-year prospective study of change in body weight and incident dementia: the Honolulu-Asia Aging Study. Arch Neurol 2005; 62(1):55-60.

68 Whitmer RA, Gustafson DR, Barrett-Connor E, Haan MN, Gunderson EP, Yaffe K. Central obesity and increased risk of dementia more than three decades later. Neurology 2008; 71(14):1057-1064

69 Luchsinger JA, Cheng D, Tang MX, Schupf N, Mayeux R. Central obesity in the elderly is related to late-onset Alzheimer disease. Alzheimer Dis Assoc Disord 2012; 26(2):101-105.

70 Luchsinger JA, Gustafson DR. Adiposity, type 2 diabetes, and Alzheimer's disease. J Alzheimers Dis 2009; 16(4):693-704.

71 Lawes CMM, Hoorn SV, Law MR, Rodgers A. High Cholesterol. In: Ezzati M, Lopez AD, Rodgers A, Murray CJL, editors. Comparative quantification of health risks. Geneva: World Health Organization; 2004. 391-496.

72 Baigent C, Keech A, Kearney PM, Blackwell L, Buck G, Pollicino $\mathrm{C}$ et al. Efficacy and safety of cholesterol-lowering treatment: prospective meta-analysis of data from 90,056 participants in 14 randomised trials of statins. Lancet 2005; 366(9493):1267-1278.

73 Mihaylova B, Emberson J, Blackwell L, Keech A, Simes J, Barnes $\mathrm{EH}$ et al. The effects of lowering LDL cholesterol with statin therapy in people at low risk of vascular disease: meta-analysis of individual data from 27 randomised trials. Lancet 2012; 380(9841):581-590.

74 Reitz C. Dyslipidemia and the risk of Alzheimer's disease. Curr Atheroscler Rep 2013; 15(3):307-0307.

75 Anstey KJ, Lipnicki DM, Low LF. Cholesterol as a risk factor for dementia and cognitive decline: a systematic review of prospective studies with meta-analysis. Am J Geriatr Psychiatry 2008; 16(5):343-354.

76 Wong WB, Lin VW, Boudreau D, Devine EB. Statins in the prevention of dementia and Alzheimer's disease: a meta-analysis of observational studies and an assessment of confounding. Pharmacoepidemiol Drug Saf 2013; 22(4):345-358.

77 McGuinness B, Craig D, Bullock R, Passmore P. Statins for the prevention of dementia. Cochrane Database Syst Rev 2009;(2):CD003160.

78 McGuinness B, O'Hare J, Craig D, Bullock R, Malouf R, Passmore P. Cochrane review on 'Statins for the treatment of dementia'. Int J Geriatr Psychiatry 2013; 28(2):119-126.

79 Ancelin ML, Ripoche E, Dupuy AM, Barberger-Gateau P Auriacombe S, Rouaud O et al. Sex differences in the associations between lipid levels and incident dementia. J Alzheimers Dis 2013; 34(2):519-528.

80 Reitz C, Tang MX, Schupf N, Manly JJ, Mayeux R, Luchsinger JA. Association of higher levels of high-density lipoprotein cholestero in elderly individuals and lower risk of late-onset Alzheimer disease. Arch Neurol 2010; 67(12):1491-1497.

81 Notkola IL, Sulkava R, Pekkanen J, Erkinjuntti T, Ehnholm C, Kivinen $\mathrm{P}$ et al. Serum total cholesterol, apolipoprotein $\mathrm{E}$ epsilon 4 allele, and Alzheimer's disease. Neuroepidemiology 1998; 17(1):14-20.

82 Stewart R, White LR, Xue QL, Launer LJ. Twenty-six-year change in total cholesterol levels and incident dementia: the HonoluluAsia Aging Study. Arch Neurol 2007; 64(1):103-107.

83 Kalmijn S, Foley D, White L, Burchfiel CM, Curb JD, Petrovitch H et al. Metabolic cardiovascular syndrome and risk of dementia in Japanese-American elderly men. The Honolulu-Asia aging study. Arterioscler Thromb Vasc Biol 2000; 20(10):2255-2260.

84 Tan ZS, Seshadri S, Beiser A, Wilson PW, Kiel DP, Tocco M et al. Plasma total cholesterol level as a risk factor for Alzheimer disease: the Framingham Study. Arch Intern Med 2003; 163(9):1053-1057.

85 Solomon A, Kivipelto M, Wolozin B, Zhou J, Whitmer RA. Midlife serum cholesterol and increased risk of Alzheimer's and vascular dementia three decades later. Dement Geriatr Cogn Disord 2009; 28(1):75-80.

86 Mielke MM, Zandi PP, Shao H, Waern M, Ostling S, Guo X et al. The 32-year relationship between cholesterol and dementia from midlife to late life. Neurology 2010; 75(21):1888-1895.

87 Schnaider BM, Goldbourt U, Silverman JM, Noy S, Schmeidler J, Ravona-Springer $\mathrm{R}$ et al. Diabetes mellitus in midlife and the risk of dementia three decades later. Neurology 2004; 63(10):19021907. 
88 Beydoun MA, Beason-Held LL, Kitner-Triolo MH, Beydoun HA Ferrucci L, Resnick SM et al. Statins and serum cholesterol's associations with incident dementia and mild cognitive impairment. J Epidemiol Community Health 2011; 65(11):949-957.

89 Song Y, Nie H, Xu Y, Zhang L, Wu Y. Association of statin use with risk of dementia: a meta-analysis of prospective cohort studies. Geriatr Gerontol Int 2013; 13(4):817-824.

$90 \mathrm{MRC} / \mathrm{BHF}$ Heart Protection Study of cholesterol lowering with simvastatin in 20,536 high-risk individuals: a randomised placebocontrolled trial. Lancet 2002; 360(9326):7-22.

91 Trompet S, van VP, de Craen AJ, Jolles J, Buckley BM, Murphy $\mathrm{MB}$ et al. Pravastatin and cognitive function in the elderly. Results of the PROSPER study. J Neurol 2010; 257(1):85-90.

92 Shepherd J, Blauw GJ, Murphy MB, Bollen EL, Buckley BM Cobbe SM et al. Pravastatin in elderly individuals at risk of vascular disease (PROSPER): a randomised controlled trial. Lancet 2002; 360(9346):1623-1630.

93 Vartiainen E, Puska P, Pekkanen J, Tuomilehto J, Jousilahti $P$. Changes in risk factors explain changes in mortality from ischaemic heart disease in Finland. BMJ 1994; 309(6946):23-27.

94 Solomon A, Kareholt I, Ngandu T, Winblad B, Nissinen A, Tuomilehto $\mathrm{J}$ et al. Serum cholesterol changes after midlife and late-life cognition: twenty-one-year follow-up study. Neurology 2007; 68(10):751-756.

95 Giannopoulos S, Katsanos AH, Kosmidou M, Tsivgoulis G. Statins and Vascular Dementia: A Review. J Alzheimers Dis 2014.

96 Chen PY, Liu SK, Chen CL, Wu CS. Long-term statin use and dementia risk in taiwan. J Geriatr Psychiatry Neurol 2014; 27(3):165-171.

97 National diabetes fact sheet: national estimates and general information on diabetes and prediabetes in the United States. 2011.

98 Cowie CC, Rust KF, Byrd-Holt DD, Eberhardt MS, Flegal KM, Engelgau MM et al. Prevalence of diabetes and impaired fasting glucose in adults in the U.S. population: National Health And Nutrition Examination Survey 1999-2002. Diabetes Care 2006; 29(6):1263-1268.

99 Yang W, Lu J, Weng J, Jia W, Ji L, Xiao J et al. Prevalence of diabetes among men and women in China. N Engl J Med 2010; 362(12):1090-1101.

100 Aguilar-Salinas CA, Velazquez MO, Gomez-Perez FJ, Gonzalez $\mathrm{CA}$, Esqueda AL, Molina C, $V$ et al. Characteristics of patients with type 2 diabetes in Mexico: Results from a large population-based nationwide survey. Diabetes Care 2003; 26(7):2021-2026.

101 Green A, Christian HN, Pramming SK. The changing world demography of type 2 diabetes. Diabetes Metab Res Rev 2003; 19(1):3-7.

102 Prentice AM. The emerging epidemic of obesity in developing countries. 2006; 2005/12/06:93-99.

103 Muller M, Tang MX, Schupf N, Manly JJ, Mayeux R, Luchsinger JA. Metabolic syndrome and dementia risk in a multiethnic elderly cohort. Dement Geriatr Cogn Disord 2007; 24(3):185-192.

104 Raffaitin C, Gin H, Empana JP, Helmer C, Berr C, Tzourio C et al. Metabolic syndrome and risk for incident Alzheimer's disease or vascular dementia: the Three-City Study. Diabetes Care 2009; 32(1):169-174.

105 Luchsinger JA, Tang MX, Shea S, Mayeux R. Hyperinsulinemia and risk of Alzheimer disease. Neurology 2004; 63(7):1187-1192.

106 Peila R, Rodriguez BL, White LR, Launer LJ. Fasting insulin and incident dementia in an elderly population of Japanese-American men. Neurology 2004; 63(2):228-233.

107 Ahtiluoto S, Polvikoski T, Peltonen M, Solomon A, Tuomilehto $\mathrm{J}$, Winblad B et al. Diabetes, Alzheimer disease, and vascular dementia: a population-based neuropathologic study. Neurology 2010; 75(13):1195-1202.

108 Baker LD, Cross DJ, Minoshima S, Belongia D, Watson GS, Craft $\mathrm{S}$. Insulin resistance and Alzheimer-like reductions in regional cerebral glucose metabolism for cognitively normal adults with prediabetes or early type 2 diabetes. Arch Neurol 2011; 68(1):5157.

109 Roberts RO, Knopman DS, Cha RH, Mielke MM, Pankratz VS Boeve BF et al. Diabetes and elevated hemoglobin A1c levels are associated with brain hypometabolism but not amyloid accumulation. J Nucl Med 2014; 55(5):759-764.

110 Kim I, Lee J, Hong HJ, Jung ES, Ku YH, Jeong IK et al. A relationship between Alzheimer's disease and type 2 diabetes mellitus through the measurement of serum amyloid-beta autoantibodies. J Alzheimers Dis 2010; 19(4):1371-1376.
111 LiXH, Lv BL, Xie JZ, Liu J, Zhou XW, Wang JZ. AGEs induce Alzheimer-like tau pathology and memory deficit via RAGEmediated GSK-3 activation. Neurobiol Aging 2012; 33(7):14001410

112 Cukierman T, Gerstein HC, Williamson JD. Cognitive decline and dementia in diabetes--systematic overview of prospective observational studies. Diabetologia 2005; 48(12):2460-2469.

113 Biessels GJ, Staekenborg S, Brunner E, Brayne C, Scheltens P. Risk of dementia in diabetes mellitus: a systematic review. Lancet Neurol 2006; 5(1):64-74

114 Luchsinger JA. Diabetes, related conditions, and dementia. J Neurol Sci 2010; 299(1-2):35-38.

115 Profenno LA, Porsteinsson AP, Faraone SV. Meta-analysis of Alzheimer's disease risk with obesity, diabetes, and related disorders. Biol Psychiatry 2010; 67(6):505-512.

116 Luchsinger JA, Tang MX, Stern Y, Shea S, Mayeux R. Diabetes mellitus and risk of Alzheimer's disease and dementia with stroke in a multiethnic cohort. Am J Epidemiol 2001; 154(7):635-641.

117 Noble JM, Manly JJ, Schupf N, Tang MX, Luchsinger JA. Type 2 diabetes and ethnic disparities in cognitive impairment. Ethn Dis 2012; 22(1):38-44.

118 Luchsinger JA. Insulin resistance, type 2 diabetes, and AD: cerebrovascular disease or neurodegeneration? Neurology 2010; 75(9):758-759.

119 Luchsinger JA. Type 2 diabetes, related conditions, in relation and dementia: an opportunity for prevention? J Alzheimers Dis 2010 20(3):723-736.

120 Cheng G, Huang C, Deng H, Wang H. Diabetes as a risk factor for dementia and mild cognitive impairment: a meta-analysis of longitudinal studies. Intern Med J 2012; 42(5):484-491.

121 Gudala K, Bansal D, Schifano F, Bhansali A. Diabetes mellitus and risk of dementia: A meta-analysis of prospective observational studies. J Diabetes Investig 2013; 4(6):640-650.

122 Creavin ST, Gallacher J, Bayer A, Fish M, Ebrahim S, Ben-Shlomo Y. Metabolic syndrome, diabetes, poor cognition, and dementia in the Caerphilly prospective study. J Alzheimers Dis 2012; 28(4):931-939.

123 Curb JD, Rodriguez BL, Abbott RD, Petrovitch H, Ross GW Masaki $\mathrm{KH}$ et al. Longitudinal association of vascular and Alzheimer's dementias, diabetes, and glucose tolerance. Neurology 1999; 52(5):971-975.

124 Akomolafe A, Beiser A, Meigs JB, Au R, Green RC, Farrer LA et al. Diabetes mellitus and risk of developing Alzheimer disease: results from the Framingham Study. Arch Neurol 2006; 63(11):1551-1555.

125 Becker JT, Chang YF, Lopez OL, Dew MA, Sweet RA, Barnes D et al. Depressed mood is not a risk factor for incident dementia in a community-based cohort. Am J Geriatr Psychiatry 2009; 17(8):653-663.

126 Cheng D, Noble J, Tang MX, Schupf N, Mayeux R, Luchsinger JA. Type 2 diabetes and late-onset Alzheimer's disease. Dement Geriatr Cogn Disord 2011; 31(6):424-430.

127 MacKnight C, Rockwood K, Awalt E, McDowell I. Diabetes mellitus and the risk of dementia, Alzheimer's disease and vascular cognitive impairment in the Canadian Study of Health and Aging 2002; 14:77-83.

128 Ohara T, Doi Y, Ninomiya T, Hirakawa Y, Hata J, Iwaki T et al Glucose tolerance status and risk of dementia in the community: the Hisayama study. Neurology 2011; \%20;77(12):1126-1134.

129 Ott A, Stolk RP, van HF, Pols HA, Hofman A, Breteler MM Diabetes mellitus and the risk of dementia: The Rotterdam Study. Neurology 1999; 53(9):1937-1942.

130 Peila R, Rodriguez BL, Launer LJ. Type 2 diabetes, APOE gene, and the risk for dementia and related pathologies: The HonoluluAsia Aging Study. Diabetes 2002; 51(4):1256-1262.

131 Posner HB, Tang MX, Luchsinger J, Lantigua R, Stern Y, Mayeux $R$. The relationship of hypertension in the elderly to $A D$, vascular dementia, and cognitive function. Neurology 2002; 58(8):11751181.

132 Ahtiluoto S, Polvikoski T, Peltonen M, Solomon A, Tuomilehto $J$ Winblad B et al. Diabetes, Alzheimer disease, and vascular dementia: a population-based neuropathologic study. Neurology 2010; 2010/08/27:1195-1202

133 Hassing LB, Johansson B, Nilsson SE, Berg S, Pedersen NL, Gatz $M$ et al. Diabetes mellitus is a risk factor for vascular dementia, but not for Alzheimer's disease: a population-based study of the oldest old. Int Psychogeriatr 2002; 14(3):239-248. 
134 Borenstein AR, Wu Y, Mortimer JA, Schellenberg GD, McCormick WC, Bowen JD et al. Developmental and vascular risk factors for Alzheimer's disease. Neurobiol Aging 2005; 26(3):325-334.

135 Xu WL, Quu CX, Wahlin A, Winblad B, Fratiglioni L. Diabetes mellitus and risk of dementia in the Kungsholmen project: a 6-year follow-up study. Neurology 2004; 63(7):1181-1186.

136 Arvanitakis Z, Wilson RS, Bienias JL, Evans DA, Bennett DA. Diabetes mellitus and risk of Alzheimer disease and decline in cognitive function. Arch Neurol 2004; 61(5):661-666.

137 Katzman R, Aronson M, Fuld P, Kawas C, Brown T, Morgenstern $\mathrm{H}$ et al. Development of dementing illnesses in an 80-year-old volunteer cohort. Ann Neurol 1989; 25:317-324.

138 Kimm H, Lee PH, Shin YJ, Park KS, Jo J, Lee Y et al. Mid-life and late-life vascular risk factors and dementia in Korean men and women. Arch Gerontol Geriatr 2011; 52(3):e117-e122.

139 Tolppanen AM, Lavikainen P, Solomon A, Kivipelto M, Uusitupa $\mathrm{M}$, Soininen $\mathrm{H}$ et al. History of medically treated diabetes and risk of Alzheimer disease in a nationwide case-control study. Diabetes Care 2013; 36(7):2015-2019.

140 Peters R, Poulter R, Beckett N, Forette F, Fagard R, Potter J et al. Cardiovascular and biochemical risk factors for incident dementia in the Hypertension in the Very Elderly Trial. J Hypertens 2009; 27(10):2055-2062.

141 Yaffe K, Falvey C, Hamilton N, Schwartz AV, Simonsick EM, Satterfield $S$ et al. Diabetes, glucose control, and 9-year cognitive decline among older adults without dementia. Arch Neurol 2012; 69(9):1170-1175.

142 Bruce DG, Davis WA, Starkstein SE, Davis TM. Mid-Life Predictors of Cognitive Impairment and Dementia in Type 2 Diabetes Mellitus: The Fremantle Diabetes Study. J Alzheimers Dis 2014; $\% 19$.

143 Exalto LG, Biessels GJ, Karter AJ, Huang ES, Katon WJ, Minkoff $\mathrm{JR}$ et al. Risk score for prediction of 10 year dementia risk in individuals with type 2 diabetes: a cohort study. Lancet Diabetes Endocrinol 2013; 1(3):183-190.

144 Launer LJ, Miller ME, Williamson JD, Lazar RM, Gerstein HC Murray AM et al. Effects of intensive glucose lowering on brain structure and function in people with type 2 diabetes (ACCORD MIND): a randomised open-label substudy. Lancet Neurol 2011; 10(11):969-977.

145 Luchsinger JA, Palmas W, Teresi JA, Silver S, Kong J, Eimicke JP et al. Improved diabetes control in the elderly delays global cognitive decline. J Nutr Health Aging 2011; 15(6):445-449.

146 Ravona-Springer R, Heymann A, Schmeidler J, Moshier E, Godbold J, Sano M et al. Trajectories in glycemic control over time are associated with cognitive performance in elderly subjects with type 2 diabetes. PLoS ONE 2014; 9(6):e97384.

147 Yaffe K, Falvey CM, Hamilton N, Harris TB, Simonsick EM, Strotmeyer ES et al. Association between hypoglycemia and dementia in a biracial cohort of older adults with diabetes mellitus. JAMA Intern Med 2013; 173(14):1300-1306.

148 Cheng C, Lin CH, Tsai YW, Tsai CJ, Chou PH, Lan TH. Type 2 Diabetes and Antidiabetic Medications in Relation to Dementia Diagnosis. J Gerontol A Biol Sci Med Sci 2014; glu073.

149 Moore EM, Mander AG, Ames D, Kotowicz MA, Carne RP, Brodaty $\mathrm{H}$ et al. Increased risk of cognitive impairment in patients with diabetes is associated with metformin. Diabetes Care 2013; 36(10):2981-2987.

150 Parikh NM, Morgan RO, Kunik ME, Chen H, Aparasu RR, Yadav RK et al. Risk factors for dementia in patients over 65 with diabetes. Int J Geriatr Psychiatry 2011; 26(7):749-757.

151 Johnson ML, Parikh N, Kunik ME, Schulz PE, Patel JG, Chen H et al. Antihypertensive drug use and the risk of dementia in patients with diabetes mellitus. Alzheimers Dement 2012; 8(5):437-444.

152 Feil DG, Lukman R, Simon B, Walston A, Vickrey B. Impact of dementia on caring for patients' diabetes. Aging Ment Health 2011; 15(7):894-903.

153 Lane RF, Raines SM, Steele JW, Ehrlich ME, Lah JA, Small SA et al. Diabetes-associated SorCS1 regulates Alzheimer's amyloidbeta metabolism: evidence for involvement of SorL1 and the retromer complex. The Journal of neuroscience : the official journal of the Society for Neuroscience 2010; 2010/10/01:1311013115.

154 Daviglus ML, Plassman BL, Pirzada A, Bell CC, Bowen PE, Burke JR et al. Risk factors and preventive interventions for Alzheimer disease: state of the science. Arch Neurol 2011; 68(9):1185-1190.
155 Jafar TH, Hatcher J, Poulter N, Islam M, Hashmi S, Qadri Z et al. Community-based interventions to promote blood pressure control in a developing country: a cluster randomized trial. Ann Intern Med 2009; 151(9):593-601.

156 Kivipelto M, Solomon A, Ahtiluoto S, Ngandu T, Lehtisalo J, Antikainen $\mathrm{R}$ et al. The Finnish Geriatric Intervention Study to Prevent Cognitive Impairment and Disability (FINGER): study design and progress. Alzheimers Dement 2013; 9(6):657-665.

157 Richard E, Van den Heuvel E, Moll van Charante EP, Achthoven L, Vermeulen M, Bindels PJ et al. Prevention of dementia by intensive vascular care (PreDIVA): a cluster-randomized trial in progress. Alzheimer Dis Assoc Disord 2009; 23(3):198-204.

158 Bray Fl, Weiderpass E. Lung cancer mortality trends in 36 European countries: secular trends and birth cohort patterns by sex and region 1970-2007. Int J Cancer 2010; 126(6):1454-1466. 


\section{CHAPTER 6}

\section{Summary and conclusion}

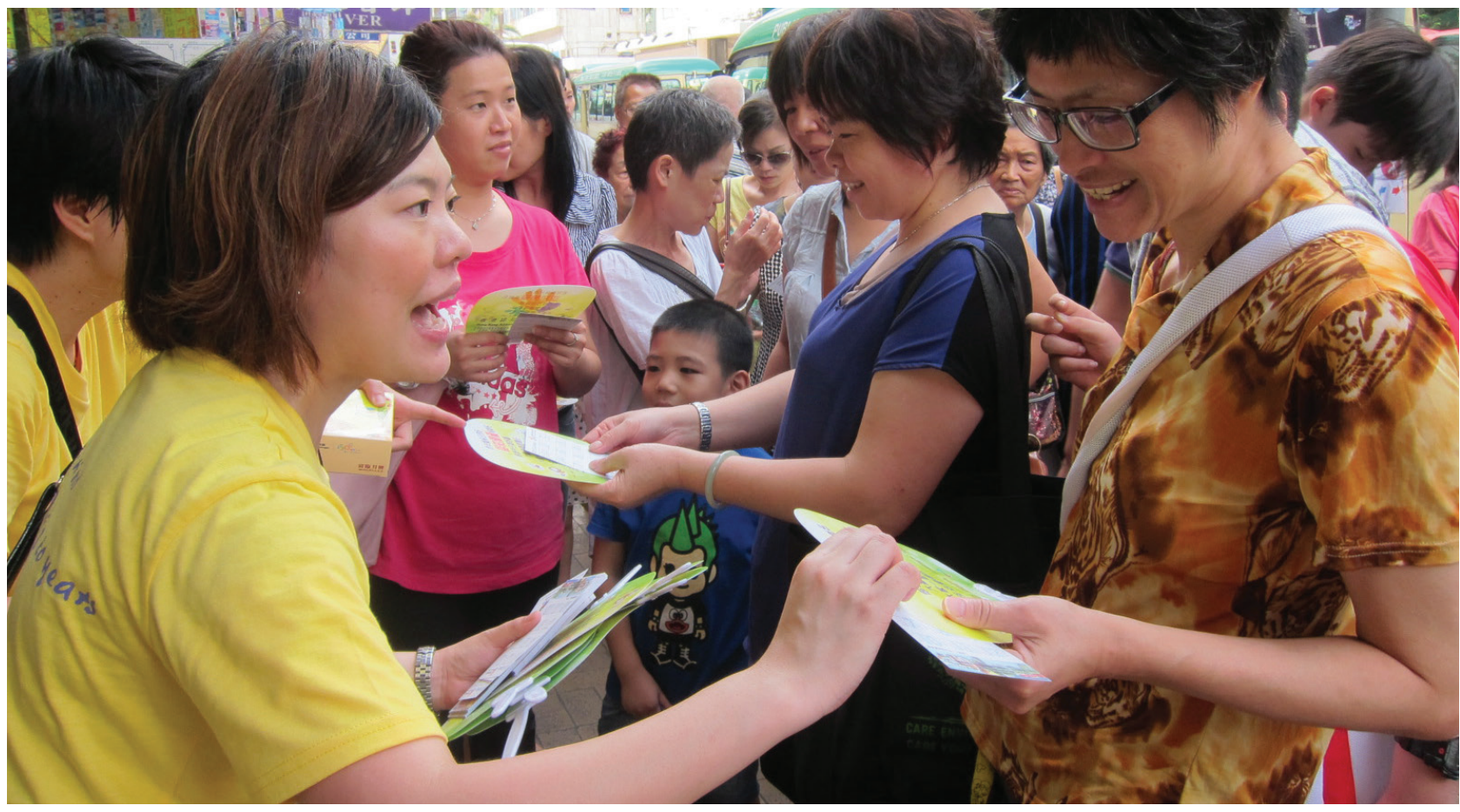

\section{Summary of findings}

In the course of this review, to inform health promotion and disease prevention strategies, we have examined critically the evidence for the existence of modifiable risk factors for dementia.

This has involved an intensive collaborative effort of a large team of experienced dementia researchers and systematic reviewers in the Global Observatory for Ageing and Dementia Care at King's College London, University of Geneva, Columbia University, and the Federal University of São Paulo. We have accessed systematic reviews and assessed their quality, making a point of reading the full text of all included studies. We have updated the evidence contained in those reviews, and where necessary conducted new fully systematic reviews (of the effects of education, occupation, depression, smoking, alcohol consumption, and diabetes). In the course of this work, we have read and critically appraised hundreds of reviews and original research articles.

What do we mean by a modifiable risk factor? 'Factor $x^{\prime}$ would be considered to be a modifiable risk factor for dementia when

a) the presence or absence Factor $\mathrm{x}$, or higher or lower levels of exposure to Factor $x$ was independently and consistently associated with a higher incidence of dementia, or one or more of its specific subtypes;

b) the observed association was likely to be causal; c) exposure to Factor $x$ could feasibly be modified in the desirable (lower risk) direction for individuals and at the population level; and

d) thereby, the risk of dementia onset might be reduced for the individual, and the incidence of dementia reduced in the population (this last criterion only being established with confidence in the presence of evidence from randomised controlled trials, see below for further discussion).

We have focused upon sets of potential modifiable risk factors in four key domains

1. Developmental factors

2. Psychological and psychosocial factors

\section{Lifestyle-related factors}

\section{Cardiovascular risk factors}

We have, throughout, addressed brain health promotion and dementia prevention from a developmental and life course perspective. One of the key issues to be considered was whether, for certain risk factors, there might be critical life periods during which the factor exerted the greatest impact on future risk of dementia. The developmental factors (Chapter 2) arise, mainly, during early life (education, nutrition [growth and development], early life events) and might reasonably be construed as impacting positively or negatively on brain and cognitive development. Education, and cognitive development are positive resources across the lifecourse ${ }^{1}$, that also create opportunities for occupational advancement, which 
in turn might confer additional protection against the onset of dementia. Nearly all of the other factors considered (in chapters 3-5) might influence dementia risk in midlife, or in late-life, or both, or neither. Therefore, in summarising the evidence for modifiable risk factors, we have considered this separately for exposures that are assessed in midlife and late-life (Tables 6.1). For example, there is robust evidence that hypertension in midlife is associated with an increase in the risk for dementia in late-life. Conversely, in latelife, lower blood pressure levels are associated with the incidence of dementia, although this latter effect is likely to be an example of reverse causality with no options for dementia prevention arising from the observed association.

Summarising the evidence in Tables 6.1, we have provided information on the general direction of the observed association, the extent and adequacy of the evidence-base to inform policy and practice (yes/ no), the consistency of the evidence between studies (high, moderate, low), and the overall strength of the evidence (robust, moderate, insufficient). These ratings are to some extent subjective, and we were not able, other than from an informal consensus among authors, to examine the reliability of the ratings and conclusions drawn. While there are several more formal and structured systems that have been proposed for the grading of evidence, these rely strongly on a presumed hierarchy of evidence from case studies, to single and multiple observational studies, to experimental studies (randomised controlled trials). Since, as will be discussed, experimental evidence was not, and never would be available to support or refute hypothesised risk associations for many of the risk factors considered in this report, these grading systems were considered inappropriate for our purpose.

The strongest evidence for possible causal associations with dementia (plausible, consistent, strong associations, relatively free of bias and confounding) are those of low education in early life, hypertension in midlife, and smoking and diabetes across the life course.

In addition there is consistent evidence from several studies for an inverse association between both physical and cognitive activity and dementia incidence - however, these associations cannot be considered robust, since reverse causality has not been excluded, and is a very plausible explanation for the observed associations.

This pattern of association suggests two important general mechanisms that may be in operation. The first is cognitive, or possibly brain reserve. Education and occupational attainment have been posited to lead to advantages in brain structure or function, or both, that modify the impact of neurodegenerative brain damage in late-life ${ }^{2}$. The second is vascular pathology, through which the effects of midlife hypertension, smoking and diabetes may be mediated. The associations of midlife hypertension and diabetes with incident any dementia and $\mathrm{VaD}$ are generally stronger than those with AD. The same is not necessarily true for smoking, although the cardiovascular disease risks of that exposure are very clearly established. While the risk associations with obesity and dyslipidaemia were less clear cut, these are important risk factors for hypertension and diabetes and also contribute independently to cardiovascular risk.

\section{Contextualising these findings with other research}

The US National Institutes of Health conducted a stateof-the-science conference review in 2010 to provide healthcare providers, patients, and public with an assessment of currently available data on prevention of Alzheimer's disease and cognitive decline ${ }^{3}$. Their headline finding that "firm conclusions cannot be drawn about the association of any modifiable risk factor with cognitive decline or Alzheimer's disease", if viewed in isolation from the evidence presented, may have led to unwarranted pessimism regarding the potential for primary prevention. It is true that very few primary prevention randomised controlled trials (RCTs) have been conducted, and that the results do not support potential for risk reduction. However, many of these trials recruited older people, and follow-up periods were relatively short. Given that neurodegeneration may precede the onset of dementia by several decades, this may have been a case of 'too little too late'. There is, however, a strong evidence-base from population-based cohort studies attesting to the potential risk reduction benefits of better cardiovascular health and more education, and, possibly physical activity and cognitive stimulation.

Following the NIH state-of-the-science review, another group working in the US conducted systematic reviews into the epidemiological evidence for risk reduction focusing on seven risk factors for which there was strong evidence of independent effects on the incidence of Alzheimer's disease; diabetes, midlife hypertension and obesity, depression, physical inactivity, smoking and low education; assessing evidence pertaining to the USA and populations worldwide ${ }^{4}$. Having meta-analysed the evidence base to estimate the relative risk (RR), they combined this with the prevalence of the risk factor in the population to compute a population attributable risk (PAR) - the proportion of cases of Alzheimer's disease in the population that might be prevented if the risk factor could be removed entirely. This exercise was repeated this year, seeking to address problems with the original analysis; that the risk exposures were correlated and hence interdependent in their effects, and that the population attributable fractions should be applied to incidence rather than prevalence ${ }^{5}$. From the worldwide perspective the meta-analysed RR and PAR were as follows - diabetes RR 1.46 (95\% Cl: 1.20-1.77), PAR 
Table 6.1.a and b

Summary of evidence for risk factors of dementia. $\downarrow$ signifies decreased risk with higher levels of exposure $\uparrow$ signifies increased risk $\rightarrow$ signifies varying risk, or null findings

\begin{tabular}{|l|l|l|l|l|l|}
\hline & $\begin{array}{l}\text { Direction of } \\
\text { Association }\end{array}$ & $\begin{array}{l}\text { Sufficient } \\
\text { number of cohort } \\
\text { studies to draw } \\
\text { meaningful } \\
\text { conclusions }\end{array}$ & $\begin{array}{l}\text { Consistency } \\
\text { across } \\
\text { studies }\end{array}$ & $\begin{array}{l}\text { Evidence type } \\
\text { (robust, } \\
\text { moderate, } \\
\text { insufficient) }\end{array}$ & Notes \\
\hline Developmental factors & No & Moderate & Insufficient & $\begin{array}{l}\text { Indirect evidence from proxies for early } \\
\text { life nutrition and development (leg } \\
\text { length and skull circumference inversely } \\
\text { associated with dementia prevalence) }\end{array}$ \\
\hline $\begin{array}{l}\text { Nutrition (growth } \\
\text { and development) }\end{array}$ & $\downarrow$ & Yes & Moderate & Robust & $\begin{array}{l}\text { Consistently protective effect, but with a } \\
\text { variable effect size, in a large number of } \\
\text { cohort studies, across cultures }\end{array}$ \\
\hline Education & $\downarrow$ & Yes & Low & Moderate & $\begin{array}{l}\text { Effects are attenuated when controlling } \\
\text { for education, hence apparent protective } \\
\text { effect may not be causal }\end{array}$ \\
\hline $\begin{array}{l}\text { Occupational } \\
\text { status }\end{array}$ & $\downarrow \rightarrow$ & No & Moderate & Insufficient & $\begin{array}{l}\text { Suggestive evidence that death of a } \\
\text { parent may increase dementia incidence, } \\
\text { but few studies, and potential for recall } \\
\text { bias }\end{array}$ \\
\hline Early life events & $\uparrow$ & & &
\end{tabular}

\begin{tabular}{|c|c|c|c|c|c|}
\hline & $\begin{array}{l}\text { Direction of } \\
\text { Association }\end{array}$ & $\begin{array}{l}\text { Sufficient number } \\
\text { of cohort studies to } \\
\text { draw meaningful } \\
\text { conclusions }\end{array}$ & $\begin{array}{l}\text { Consistency } \\
\text { across } \\
\text { studies }\end{array}$ & $\begin{array}{l}\text { Evidence type } \\
\text { (robust, } \\
\text { moderate, } \\
\text { insufficient) }\end{array}$ & Notes \\
\hline \multicolumn{6}{|c|}{ Psychological factors - midlife } \\
\hline Depression & $\uparrow$ & No & $\mathrm{n} / \mathrm{a}$ & Insufficient & $\begin{array}{l}\text { Metaregression indicates smaller effect } \\
\text { sizes (closer to the null) for studies } \\
\text { with longer follow-up periods. However, } \\
\text { limited evidence on midlife exposure }\end{array}$ \\
\hline Anxiety & $\uparrow$ & No & $\mathrm{n} / \mathrm{a}$ & Insufficient & $\begin{array}{l}\text { One cohort study suggesting possible } \\
\text { increased risk }\end{array}$ \\
\hline Sleep disorders & $\uparrow$ & No & $\mathrm{n} / \mathrm{a}$ & Insufficient & Very few long-term cohort studies \\
\hline $\begin{array}{l}\text { Psychological } \\
\text { distress }\end{array}$ & $\uparrow$ & No & High & Insufficient & $\begin{array}{l}\text { Indirect evidence using personality } \\
\text { type as a lifelong stable proxy for the } \\
\text { likely intensity and duration of stress } \\
\text { response. Neuroticism positively } \\
\text { associated and conscientiousness } \\
\text { negatively associated with dementia/ } \\
\text { AD risk }\end{array}$ \\
\hline \multicolumn{6}{|c|}{ Psychological factors - late life } \\
\hline Depression & $\uparrow$ & Yes & High & Moderate & $\begin{array}{l}\text { A strong and consistent association } \\
\text { observed across many studies. However, } \\
\text { this may reflect reverse causality (see } \\
\text { midlife above) }\end{array}$ \\
\hline Anxiety & $\rightarrow$ & No & $\mathrm{n} / \mathrm{a}$ & Insufficient & $\begin{array}{l}\text { One case-control and one cohort study - } \\
\text { no association observed }\end{array}$ \\
\hline Sleep disorders & $\uparrow$ & No & $\mathrm{n} / \mathrm{a}$ & Insufficient & $\begin{array}{l}\text { Suggestive evidence from a small } \\
\text { number of cohort studies. Various self- } \\
\text { reported exposures. Short follow-up. } \\
\text { Reverse causality not excluded. }\end{array}$ \\
\hline $\begin{array}{l}\text { Psychological } \\
\text { distress }\end{array}$ & $\uparrow$ & No & $\mathrm{n} / \mathrm{a}$ & Insufficient & See midlife (above) \\
\hline
\end{tabular}


Table 6.1.c

Summary of evidence for risk factors of dementia. $\downarrow$ signifies decreased risk with higher levels of exposure $\uparrow$ signifies increased risk $\rightarrow$ signifies varying risk, or null findings

\begin{tabular}{|c|c|c|c|c|c|}
\hline & $\begin{array}{l}\text { Direction of } \\
\text { Association }\end{array}$ & $\begin{array}{l}\text { Sufficient number } \\
\text { of cohort studies to } \\
\text { draw meaningful } \\
\text { conclusions }\end{array}$ & $\begin{array}{l}\text { Consistency } \\
\text { across } \\
\text { studies }\end{array}$ & $\begin{array}{l}\text { Evidence type } \\
\text { (robust, } \\
\text { moderate, } \\
\text { insufficient) }\end{array}$ & Notes \\
\hline \multicolumn{6}{|c|}{ Lifestyle factors - midlife } \\
\hline Smoking & $\uparrow$ & No & Low & Moderate & $\begin{array}{l}\text { Late-life studies include retrospective } \\
\text { assessment of lifetime smoking } \\
\text { history, and support hypothesis. Midlife } \\
\text { exposure in long-term cohort studies } \\
\text { may underestimate effect due to } \\
\text { mortality/ competing risk }\end{array}$ \\
\hline Alcohol & $\rightarrow$ & No & $\mathrm{n} / \mathrm{a}$ & Insufficient & Very few studies \\
\hline $\begin{array}{l}\text { Micro- and } \\
\text { macronutrient } \\
\text { deficiency }\end{array}$ & $\rightarrow$ & No & $\mathrm{n} / \mathrm{a}$ & Insufficient & Very few studies \\
\hline Physical activity & $\downarrow \rightarrow$ & No & High & Insufficient & $\begin{array}{l}\text { Only three long-term cohort studies with } \\
\text { mixed results }\end{array}$ \\
\hline $\begin{array}{l}\text { Cognitive } \\
\text { stimulation }\end{array}$ & $\downarrow$ & No & $\mathrm{n} / \mathrm{a}$ & Insufficient & $\begin{array}{l}\text { Supportive evidence from case-control } \\
\text { studies, prone to bias. Only one long- } \\
\text { term cohort study, with high attrition and } \\
\text { imprecise exposure measures }\end{array}$ \\
\hline \multicolumn{6}{|c|}{ Lifestyle factors - late life } \\
\hline Smoking & $\uparrow$ & Yes & Moderate & Moderate & $\begin{array}{l}\text { Dose response effect for incidence of } \\
\text { AD. Possible effect on VaD and any } \\
\text { dementia. }\end{array}$ \\
\hline Alcohol & $\rightarrow$ & No & Moderate & Insufficient & $\begin{array}{l}\text { Moderate drinkers have a lower risk } \\
\text { of dementia and AD than abstainers. } \\
\text { Unclear if this is causal or reflects } \\
\text { confounding by reason for abstaining. } \\
\text { Upper safe limit of 'moderate' drinking } \\
\text { and impact of heavy drinking is unclear }\end{array}$ \\
\hline $\begin{array}{l}\text { Micro- and } \\
\text { macronutrient } \\
\text { deficiency }\end{array}$ & $\rightarrow$ & Yes & Moderate & Insufficient & $\begin{array}{l}\text { With the exception of Mediterranean diet } \\
\text { (one positive trial), suggestive evidence } \\
\text { from observational cohort studies has } \\
\text { not been confirmed in supplementation } \\
\text { trials. However, RCTs are few in } \\
\text { number and often of poor quality. They } \\
\text { do not always focus on those with } \\
\text { micronutrient deficiencies }\end{array}$ \\
\hline Physical activity & $\downarrow \rightarrow$ & Yes & High & Insufficient & $\begin{array}{l}\text { Duration of follow-up is a major } \\
\text { determinant of heterogeneity of effect, } \\
\text { with inverse association seen mainly in } \\
\text { short follow-up studies. High probability } \\
\text { of reverse causality. RCTs needed to } \\
\text { clarify this }\end{array}$ \\
\hline $\begin{array}{l}\text { Cognitive } \\
\text { stimulation }\end{array}$ & $\downarrow$ & Yes & High & Insufficient & $\begin{array}{l}\text { Consistent risk reduction associated } \\
\text { with performance of cognitively } \\
\text { stimulating activities. Reverse causality } \\
\text { remains to be excluded. RCTs needed to } \\
\text { clarify this. }\end{array}$ \\
\hline
\end{tabular}


Table 6.1.d

Summary of evidence for risk factors of dementia. $\downarrow$ signifies decreased risk with higher levels of exposure $\uparrow$ signifies increased risk $\rightarrow$ signifies varying risk, or null findings

\begin{tabular}{|c|c|c|c|c|c|}
\hline & $\begin{array}{l}\text { Direction of } \\
\text { Association }\end{array}$ & $\begin{array}{l}\text { Sufficient number } \\
\text { of cohort studies to } \\
\text { draw meaningful } \\
\text { conclusions }\end{array}$ & $\begin{array}{l}\text { Consistency } \\
\text { across studies }\end{array}$ & $\begin{array}{l}\text { Evidence type } \\
\text { (robust, } \\
\text { moderate, } \\
\text { insufficient) }\end{array}$ & Notes \\
\hline \multicolumn{6}{|c|}{ Cardiovascular risk factors - midlife } \\
\hline Hypertension & $\uparrow$ & Yes & High & Robust & $\begin{array}{l}\text { Consistent evidence from } 5 \text { studies } \\
\text { across four cohorts. Evidence } \\
\text { stronger for any dementia, and VaD, } \\
\text { than for AD. }\end{array}$ \\
\hline Obesity & $\uparrow \rightarrow$ & No & Low & Insufficient & $\begin{array}{l}\text { Inconsistent findings for association } \\
\text { with midlife BMI. Problems with bias } \\
\text { and residual confounding. Possibly } \\
\text { more consistent association with } \\
\text { central obesity. }\end{array}$ \\
\hline Cholesterol & $\uparrow$ & No & Low & Insufficient & $\begin{array}{l}\text { Inconsistent findings. Hypothesis } \\
\text { supported mainly by two Finnish long- } \\
\text { term cohort studies }\end{array}$ \\
\hline Diabetes & $\uparrow$ & No & Moderate & Moderate & $\begin{array}{l}\text { Evidence is somewhat indirect, from } \\
\text { health care record linkage studies, } \\
\text { and subject to bias. However, longer } \\
\text { duration of diabetes is associated } \\
\text { with higher dementia risk. Only one } \\
\text { long-term cohort study, with no } \\
\text { association. }\end{array}$ \\
\hline \multicolumn{6}{|c|}{ Cardiovascular risk factors - late life } \\
\hline Hypertension & $\downarrow \rightarrow$ & Yes & High & Robust & $\begin{array}{l}\text { Cross-sectional studies show lower } \\
\text { BP level in people with dementia and } \\
\text { AD relative to controls. Decline in BP } \\
\text { predicts the onset of dementia and } \\
\text { AD, but this is unlikely to be causal. } \\
\text { RCTs suggest no cognitive benefit or } \\
\text { harm associated with the treatment } \\
\text { of hypertension in older people in } \\
\text { general, or those with dementia. }\end{array}$ \\
\hline Obesity & $\rightarrow$ & Yes & High & Robust & $\begin{array}{l}\text { Several studies. No association. } \\
\text { However, decline in BMI from mid- to } \\
\text { late-life predicts dementia onset but } \\
\text { this is unlikely to be causal. }\end{array}$ \\
\hline Cholesterol & $\rightarrow$ & Yes & Moderate & Moderate & $\begin{array}{l}\text { No effect of cholesterol lowering with } \\
\text { statins on cognitive outcomes. No } \\
\text { association of total cholesterol (TC) } \\
\text { with incident dementia, but effects } \\
\text { of cholesterol subfractions need to } \\
\text { be explored further. However, decline } \\
\text { in TC from mid- to late-life predicts } \\
\text { dementia onset. }\end{array}$ \\
\hline Diabetes & $\uparrow$ & Yes & High & Robust & $\begin{array}{l}\text { Highly consistent evidence for a } \\
\text { strong association between diabetes } \\
\text { and the incidence of any dementia, } \\
\text { AD and VaD. Particularly strong } \\
\text { effect on VaD. Possibly mediated } \\
\text { through poor glycemic control. Mixed } \\
\text { evidence for cognitive benefits of } \\
\text { optimising glycemic control }\end{array}$ \\
\hline
\end{tabular}


2.9\% (95\% Cl: 1.3-4.7); midlife hypertension RR 1.61 (95\% Cl: 1.16-2.24), PAR 5.1\% (95\% Cl: 1.4-9.9); midlife obesity RR 1.60 (95\% Cl: 1.34-1.92), PAR 2.0\% (95\% Cl: 1.1-3.0); depression RR 1.65 (95\% Cl: 1.421.92), PAR 7.9\% (95\% Cl: 5.3-10.8); physical inactivity RR 1.82 (95\% Cl: 1.19-2.78), PAR 12.7\% (95\% Cl: 3.3-24.0); smoking RR 1.59 (95\% Cl: 1.15-2.20), PAR 13.9\% (95\% Cl: 3.9-24.7) and low education RR 1.59 (95\% Cl: 1.35-1.86), PAR 19.1\% (95\% Cl: 12.3-25.6). Thus, in principle, the most promising strategies for prevention were the elimination of physical inactivity (12.7\% of AD cases prevented), smoking (13.9\%) and low education (19.1\%). This is because these factors are both relatively common and strongly associated with incident $A D$. If all of the risk factors were eliminated, accounting for their interdependence, then a total of up to $28.2 \%$ of all cases of $A D$ worldwide might be prevented. Of course, this is implausible. The authors therefore modelled the effect of a more realistic $10 \%$ or $20 \%$ reduction in the prevalence of the risk exposures on the prevalence of dementia through to 2050 - an $8.3 \%$ reduction assuming a $10 \%$ reduction in exposure prevalence, and a $15.3 \%$ reduction assuming a $20 \%$ reduction in exposure prevalence $^{5}$.

There is an underlying assumption in all such calculations that the associations observed in the epidemiological research studies that the risk factor has caused the onset of dementia. This may not necessarily be the case. Confounding may have occurred; other factors associated with, for example, midlife obesity may have been the true causal risk factor; under these circumstances, eliminating obesity would have no preventive effect. In epidemiological studies one tries to 'adjust' for the effect of such confounding variables, but this strategy may not be completely successful. Bias may also be a problem, as discussed in previous chapters, arising from selective patterns of mortality or other losses to follow-up, from an increased likelihood in health care record linkage studies of detection of dementia in the presence of chronic diseases requiring long-term health care, and from information bias where recall of exposure may be affected by the coming onset of dementia. Reverse causality also needs to be considered - the early pre-clinical effects of dementia may include a tendency to be less physically active or to become depressed - hence the disease may cause the 'risk factor' rather than the risk factor causing the disease. These aspects have been given insufficient attention in many published systematic reviews, which have been insufficiently critical of the internal validity of the observed associations. These issues are discussed, briefly, in the course of these modelling exercises ${ }^{5}$, but their implications have not been followed through. The causality of the observed associations of incident AD with depression, physical activity and midlife obesity are thinly evidenced, and open to considerable doubt.
It is for these reasons that policymakers and advisors (such as the recent $\mathrm{NIH}$ state-of-the-science expert panel ${ }^{3}$ are reluctant to act on the basis of epidemiological evidence alone. Randomised controlled trials of the effects of removing or reducing the risk factor are considered to provide the strongest evidence. However, these are sometimes difficult if not impossible to conduct given the long latency between the period over which the risk factor exerts an influence on the underlying mechanisms that lead to dementia (early to mid-life), and the onset of dementia in late life. This stricture applies to the possible effects of education (which is not, in any case, amenable to experimental control), and midlife hypertension and midlife hypercholesterolaemia (where placebo-controlled trials would, in any case, no longer be ethical). One of the complicating factors for interventions in this area is that evidence suggests that while hypertension, raised cholesterol, and obesity in midlife increase the risk for later onset of dementia, blood pressure levels ${ }^{6}$, cholesterol ${ }^{7}$ and body mass index ${ }^{8}$ fall progressively before the onset of the disease. Hence people with dementia have lower blood pressure levels, cholesterol and body mass than others. Therefore, early primary prevention may be the most effective intervention. Preventive trials indicate that statins ${ }^{9}$ and antihypertensive treatment ${ }^{10}$ do not seem to lower the incidence of dementia when initiated in older people, but there have not been, and can no longer be, any long-term trials from midlife onwards.

\section{Implications - Where do we go from here?}

\section{Randomised controlled trials}

There are outstanding questions highlighted in this review, and linked hypotheses, that would, in principle, be testable in randomised controlled trials involving experimental manipulation of lifestyles and control of risk factors.

- Are increases in physical activity in late-life, particularly aerobic exercise, associated with a reduced incidence of cognitive impairment and dementia?

- Are particular types of cognitive activity in late-life, performed regularly, associated with a reduced incidence of cognitive impairment and dementia?

- Among older people with established micronutrient deficiency (for example, of B12 and folate, with associated hyperhomocysteinaemia) is supplementation to correct the deficiency associated with a reduced incidence of cognitive impairment and dementia? See ADI's 'Nutrition and Dementia' report for further detailed recommendations on potential for clinical trials in this area. 
- Epidemiological studies suggest that diabetes in late-life increases the risk of all forms of dementia. Are health system enhancements to improve detection, treatment and control of diabetes associated with a lower incidence of dementia in cluster-randomised controlled trials? And are any such reductions mediated through improved glycaemic control? What would be the optimum policy for diabetes control to minimise risk for dementia, in the light of the concern that tighter control might increase risk because of more frequent hypoglycaemic attacks?

Aggregated cardiovascular risk indices incorporating hypertension, diabetes, hypercholesterolaemia and smoking incrementally increase risk for dementia incidence whether exposure is measured in midlife ${ }^{11}$ or a few years before dementia onset ${ }^{12}$. Therefore, among older people at increased risk of cardiovascular disease, does optimization of risk profile, through simultaneous attention to hypertension, diabetes, hyperlipidaemia, obesity smoking and physical underactivity, reduce the incidence of cognitive impairment and dementia? Such multi-component prevention trials are currently underway in several European countries under the umbrella of the European Dementia Prevention Initiative (EDPI - www.edpi.org). The FINGER trial in Finland (Finnish Geriatric Intervention Study to Prevent Cognitive Impairment and Disability), comprising multi-domain life-style intervention including nutritional guidance, exercise, cognitive training, increased social activity, and intensive monitoring and management of metabolic and vascular risk factors for 60-77 year old persons at an increased dementia risk ${ }^{13}$ has recently demonstrated cognitive benefits at the 2-year interim endpoint, and will now go on to assess impact on dementia incidence over seven years.

At the same time we must recognise the limitations of the randomised controlled trial methodology. There are several potential modifiable risk factors for dementia for which it would not be ethically possible to randomise modification, since the benefits of doing so are already clearly established for other important health outcomes. The examples suggested above all refer to risk exposures that might have an impact in late-life. If the critical period for an exposure, for example hormonal replacement therapy in women, was in midlife shortly after the menopause, a randomised controlled trial would not be feasible, since it would probably not be possible to maintain the intervention on a randomised basis for long enough, and would not be cost-effective or practical to follow-up participants for the 20 years that it would require to determine the effect of the randomised allocation on dementia incidence. We must, therefore, also explore other sources of evidence.

\section{Enhancing the quality and relevance of evidence from observational studies}

Several valuable lessons have been learnt from the systematic reviews conducted in the course of the preparation of this report

- We identified errors in many of the published systematic reviews that we accessed. These included: inclusion of studies that were not relevant; misinterpretation and/or incorrect reporting of study designs and findings; incorrect transcription and reporting of effect sizes; incorrect referencing, and untraceability of included studies. We have tried to correct these errors where we identified them, by contacting study authors and journal editors. Sometimes the errors were sporadic and unlikely to have a major impact on conclusions. Occasionally, they were widespread and/or serious in their implications. As the number of systematic reviews increase, journal editors may struggle to find peer reviewers who can allocate sufficient time to give each submitted review the detailed scrutiny it requires. For this report we have read and carefully assessed each individual cited paper. This is likely to be a systemic problem across the field of systematic review, and in our view requires a new policy and approach from biomedical journals. Given the complex and time consuming nature of the task when done properly, reviewers may need to be paid for their work, and provided with a complete set of electronic copies of included publications.

- Having clarified the nature of the existing evidence, it would be a cost-effective and valuable service to future systematic reviewers if these data were documented in a publicly accessible archive. Such an initiative has been attempted for genetic and environmental risk factors for Alzheimer's disease, through the AlzRisk consortium (www.alzrisk.org). However, see 'An integrated approach...', below.

- Much of the relevant evidence generated in wellconducted studies could not be included in metaanalyses because of the non-harmonisability of exposures and/or outcomes. A collaborative network of relevant cohort studies could be established, to share existing data and work together on re-analysis using common exposure definitions. This would be of particular value when assessing the impact of continuously distributed variables (e.g. blood pressure level, total cholesterol, fasting glucose, body mass index, waist circumference and waist/hip circumference ratio, pack-years of tobacco consumption and units of alcohol consumed), which are often categorised in different ways. Such an approach has been of tremendous value in clarifying risk associations in the cardiovascular disease field $^{14 ; 15}$. Recommendations could be made for a standardised approach for the operationalisation of 
risk exposures, and the analysis and presentation of findings in future studies.

- Many studies look at risk factors for 'any dementia' and $A D$ and $V a D$ subtypes. A relatively large number of studies only assess risk factors for AD. A few studies focus on $\mathrm{VaD}$ alone. In most of the metaanalyses that we have conducted, the number of studies providing risk estimates for AD exceed the number of studies reporting risk estimates for any dementia. As discussed in chapter 5 , in the domain of public health, it is dementia, regardless of cause or subtype, which is the most relevant outcome. While risk factors can, and do according to the evidence that we have assembled, impact differently on different dementia subtypes, the insights that this may give to clinical aspects and potential underlying mechanisms are largely irrelevant to the overall potential for prevention at the population level. All of the key modifiable risk factors that we have identified; education, midlife hypertension, smoking and diabetes; may influence both $A D$ and cerebrovascular pathology. Atherosclerosis and AD are linked disease processes ${ }^{16}$ with plausible common pathophysiological and aetiologic underpinnings (APOE e4 polymorphism, hypercholesterolaemia, hypertension, hyperhomocysteinaemia, diabetes, metabolic syndrome, smoking, systemic inflammation, increased fat intake and obesity). They may also be directly interactive through damage to the vascular integrity of the blood brain barrier. They certainly co-occur commonly, particularly in late-onset dementia ${ }^{17}$, and are likely to have an additive effect in determining whether and when total neurodegenerative burden translates into the clinical expression of the dementia syndrome ${ }^{18}$. A radical, but evidence-based view would be that $A D$ pathology and cerebrovascular disease are best considered as independent but interactive risk factors for dementia, rather than necessary or sufficient causes, or defining characteristics of distinct subtype entities. Therefore, it would be helpful if future epidemiological studies always included 'any dementia' as an outcome, in addition to $A D$ and/or VaD. This would not involve additional work, since NINCDS-ADRDA and DSM diagnostic criteria for the $A D$ subtype first require that individuals meet criteria for the dementia syndrome. Hence, neglecting to report associations with 'any dementia' involves discarding data that has already been collected.

\section{Modelling the 'real world' effect of changes in putative risk exposures on the incidence and prevalence of dementia}

Our best hope of ascertaining the likely impact of increasing levels of education, and improvements in cardiovascular health may be to observe populations in which such trends are prominent, to see whether these are associated with a decline over time in the age-specific incidence of dementia. Detection and treatment of diabetes and hypertension, reduction in levels of obesity, smoking cessation, increased physical activity, and better education are already public health priorities for most countries worldwide. Nevertheless, the message that dementia, alongside heart disease, stroke and cancer may be prevented through increased adoption and more effective implementation of these public health strategies is one that policymakers and public need to hear.

All current projections of the scale of the coming dementia epidemic, including those published by Alzheimer's Disease International ${ }^{19 ; 20}$ assume that the age- and gender-specific prevalence of dementia will not vary over time, and that population ageing alone (increasing the number of older people at risk) drives the projected increases ${ }^{19-22}$. The basis for this assumption was already uncertain at the time of the World Alzheimer Report 2009, since, as we acknowledged at the time, prevalence is a product of incidence and survival with dementia, and a fall in either or both of these indicators would lead to a fall in age-specific prevalence ${ }^{19}$. A decline in age-specific incidence, at least in high income countries, was theoretically possible, driven by changes in exposure to suspected developmental, lifestyle and cardiovascular risk factors for dementia. Thus, each generation is better educated than the one before. Although trends differ between countries, genders, age groups and time periods, there has been a general trend in high income countries towards less smoking, falling total cholesterol and blood pressure levels, and increasing physical activity. On the other hand, the prevalence of obesity and diabetes has been increasing in most developed countries. These changes can be attributed to a variety of factors, including increased prosperity, public health campaigns, legislation, and improvements in health care. After a lag period, to the extent that these factors are genuinely causally associated with dementia, one would expect to see corresponding reductions in the incidence of dementia. The net effect of these changes on survival with dementia is harder to estimate, and other factors; for example, standards of health and social care for people with dementia, and provision of life-prolonging critical interventions; might also be expected to have an influence.

In 2009, what very few data were available from certain high income countries did not suggest any clear 
pattern of a decline or increase over time in either the incidence or prevalence of dementia. Just a few years later, and linked to a greatly increased interest in the potential for prevention of dementia by targeting modifiable risk factors ${ }^{4 ; 23}$, the quality and extent of the evidence has expanded greatly.

In England, the MRC Cognitive Function and Ageing Study (MRC CFAS) surveys were repeated at two time points (1990-1993, CFAS I; 2008-2011, CFAS II) using identical random sampling in catchment areas in Nottingham, Cambridgeshire, and Newcastle ${ }^{24}$. A near one-third (30\%) reduction in prevalence was observed over this period, adjusting for any differences in age, sex and deprivation status. If a similar fall in prevalence had occurred across the whole of the UK, this would have been sufficient to have almost completely averted the increase in national numbers of people with dementia, anticipated from the ageing of the population ${ }^{24}$. A similar trend towards declining prevalence was observed in a study from Zaragoza, Spain ${ }^{25}$, this has not been replicated in all other studies of this type ${ }^{26-28}$. More compelling evidence comes from the long-term USA Health and Retirement Survey ${ }^{29}$, in which there was a substantial decline in the prevalence of cognitive impairment between survey waves conducted in 1993 and 2004, accompanied by a higher relative mortality risk for those who had developed cognitive impairment. There is also evidence consistent with a recent decline in incidence in Sweden and the Netherlands ${ }^{27 ; 30}$. Preliminary findings from two important studies were presented at the Alzheimer's Association International Conference in July 2014 (see footnote*). In the US Framingham study dementia incidence was tracked over thirty years in four five-year periods. Compared to the first five-year period, incidence had fallen by $17 \%, 32 \%$ and $42 \%$ respectively. Reductions were largest in the younger age groups, suggesting that dementia incidence was being delayed or deferred to older ages. The second study used claims data of the largest German public health insurance company to track the incidence and mortality of dementia in 2007-2010, compared with 2004-2007. Age-specific incidence fell by around 20\% in only five years, while mortality among those with dementia had increased for women but remained stable in men.

Evidence from these studies, collectively, presents a more consistent pattern of declining incidence, with onset of dementia deferred to progressively older ages. If the onset of dementia occurs close to the end of the natural life span, fewer years will be lived with dementia. Langa described this phenomenon as 'the compression of cognitive morbidity' ${ }^{29}$, a desirable outcome for public health and individual

\footnotetext{
* Alzheimer's Association International Conference

Source references: Satizabal C, et al "Temporal trends in dementia incidence in the Framingham Study" AAIC 2014; Abstract O5-0305/ Doblhammer G, et al "Short-term trends in German dementia prevalence, incidence, and mortality" AAIC 2014; Abstract 04-13-05.
}

quality of life, resulting in longer, healthier lives, with fewer years spent in a state of reduced independence and needing care. The authors of the UK MRC CFAS study noted that observed reduction in prevalence was "in line with major reductions in risk factors in higher income countries, which have been modified by societal changes such as improvements in education, and prevention and treatment strategies in recent decades" 24 . They speculated that the impact of factors that may have led to an increased dementia prevalence (diabetes, survival after stroke, and vascular incidents), must have been outweighed by those likely to lead to a reduction (improved prevention of vascular morbidity and higher levels of education). This was echoed in the direct observation from the Framingham study that a decline in the incidence of dementia over a 30-year period was accompanied by improvements in educational status, more use of antihypertensive and statin medication, lower blood pressure and cholesterol levels, and reductions in prevalence of smoking, heart disease and stroke, whereas the prevalence of obesity and diabetes had increased.

However, evidence from China and other east Asian countries suggests a worrying trend toward an increase in the prevalence of dementia over the last 20 years ${ }^{31 ; 32}$. While cardiovascular health is improving in many high income countries, it is deteriorating elsewhere. Many low and particularly middle income countries show a pattern of increasing stroke ${ }^{33}$ and ischaemic heart disease ${ }^{34-36}$ morbidity and mortality, linked to an epidemic of obesity, and increasing blood pressure levels ${ }^{37}$. A recent modelling exercise assessed the likely impact of recent increases in obesity among middle-aged Chinese on dementia prevalence, assuming a causal link with dementia; it concluded that future dementia prevalence in China may have been underestimated by up to $19 \%$ given the additional impact of epidemiologic transition ${ }^{38}$.

The future course of the global dementia epidemic, through to 2050, will therefore depend crucially upon the success or otherwise of continuing efforts to improve public health. Those who will be old in 2050 were born around the 1970s, and have already received their basic education. They are now in their third and fourth decades of life, a crucial 'sensitive period' where, evidence suggests, efforts to prevent, detect and control obesity, hypertension, diabetes and dyslipidaemia (high cholesterol) are likely to have maximum positive impact upon brain health and dementia risk in late-life 23

The Lancet Neurology ${ }^{5}$ and China obesity ${ }^{38}$ modelling exercises described above sought to predict what might happen to the prevalence of dementia, given our best estimates of risk associations, and possible changes in those risk factor profiles over time. An alternative approach is to observe and correlate actual changes in risk factor profiles and dementia incidence over time. This is a well-established modelling approach in the cardiovascular disease field and 
has contributed greatly to our understanding of the potential for prevention, and the attribution of changes in disease incidence to specific factors. Hence, between 1980 and 2000, age standardised ischaemic heart disease mortality rates nearly halved in the USA, nearly three-quarters of the deaths prevented or postponed being among those aged 65 years and over $^{39}$. This was evenly attributed to improvements in medical care and reduced risk factor exposure, despite increases in obesity and diabetes. In the late 1960s, ischaemic heart disease mortality among Finnish men was the highest in the world. Risk factor trends have been monitored since 1972 in the North Karelia Project, over which period there has been a remarkable decline in serum cholesterol levels, a decline in blood pressure level, which levelled off in 2002, a decrease in smoking among men but an increase among women, and an increase in body mass index in both sexes ${ }^{40}$. Given knowledge of risk associations, the decline in cholesterol among men would have been predicted to result in around a $40 \%$ reduction in mortality, the decline in BP around a $20 \%$ reduction, and the changes in smoking habit around a $15 \%$ reduction. The combine defect of the risk factor changes would be a $60 \%$ reduction in mortality. In fact the observed mortality reduction for men was a remarkable $80 \%$. Observed and predicted mortality reductions tracked each other closely until the mid 1980s. The subsequent additional decline in mortality over and above that predicted was attributed to the increased availability of secondary prevention and invasive revascularization procedures for coronary patients ${ }^{41}$.

Similar studies could, in the future, be carried out to monitor the impact of prevention programs on the future scale of the dementia epidemic. To do this, renewed efforts would need to be made in all regions to monitor trends in incidence and prevalence of dementia and to associate these with changes in public health, and in medical and social care. Unfortunately, studies of the prevalence of dementia have been conducted less frequently in high income countries since the $1990 \mathrm{~s}^{19}$, and there have been surprisingly few studies of the incidence of dementia in any world regions ${ }^{42}$. For the purposes of the risk modelling exercises described above, risk exposures should ideally be assessed in the same population sample. Governments need to commit to the funding of such monitoring activities, over the longer term.

\section{An integrated approach to the prevention of dementia and other chronic diseases}

The number of people with dementia is increasing worldwide, and there is growing evidence that suggests that attention to lifestyle and health factors may substantially reduce the risk of developing dementia. Combining efforts to tackle the global burden and threat of non-communicable disease is important and will contribute to efficient use of resources and funds. In September 2011 the United
Nations General Assembly met with Heads of State and Government to discuss the global impact of noncommunicable diseases (NCDs). In article 18 of the adopted political declaration ${ }^{43}$ mental and neurological disorders including Alzheimer's disease are mentioned as important contributors to the global NCD burden. The declaration states the importance of recognising that these conditions share common risk factors, including tobacco use, harmful use of alcohol, an unhealthy diet, and lack of physical activity, that can benefit from common prevention responses targeting priority NCDs (cancer, diabetes, cardiovascular disease and chronic respiratory diseases). It is the case that the profile of lifestyle-related risk factors is similar across the most burdensome conditions for older people. Dyslipidaemia, hypertension, diabetes, smoking and obesity are the major modifiable risk factors for CVDs ${ }^{44}$. Smoking is also the main modifiable risk factor for cataract and age-related macular degeneration ${ }^{45}$, Chronic Obstructive Pulmonary Disease ${ }^{46}$ and lung cancer ${ }^{47}$ in later life.

The current agenda for chronic disease prevention prioritises a simple five-point plan that would have the potential to reduce the risk of dying from one of the four main NCDs by $25 \%$ by 2025 (the 25 by 25 program) ${ }^{48)}$. The plan focuses, mainly, on primary prevention through population-level interventions -

1. A $40 \%$ reduction in prevalence of tobacco use, achieved through full implementation of the WHO Framework Convention on Tobacco Control (including price and tax measures to reduce demand; protection from exposure to tobacco smoke in public spaces; control of packaging and labelling; control of advertising, promotion and sponsorship).

2. Reduction in population levels of salt consumption (to reduce population blood pressure) from the current average global daily salt intake of about $9-12 \mathrm{~g}$ to $5 \mathrm{~g}$ of salt per adult per day.

3. A $10 \%$ relative reduction in per capita adult alcohol consumption; achieved by cost-effective interventions, principally measures to make alcohol more expensive and less available.

4. A $10 \%$ relative reduction in adult inactivity levels (this is acknowledged to be a challenging target requiring engagement with non-health sectors such as transport, energy, and urban planning).

And one treatment target, simplifying access to therapeutic management of cardiovascular risk factors:

5. An increase in the coverage of multidrug therapy, preferably fixed dose combination therapy, to at least $50 \%$ of people older than 50 years whose risk of a heart attack or stroke in the next 10 years is $30 \%$ or more, or for anyone who has already had a heart attack or stroke. Fixed dose combination therapy uses a 'polypill' comprising low doses of diuretic, beta-blocker, statin and aspirin, and is as 
effective in lowering blood pressure as different combinations of blood pressure-lowering drugs given separately, and nearly as effective in lowering LDL cholesterol as simvastatin alone ${ }^{49}$.

While dementia prevention was certainly not a prime consideration in the minds of those who developed this strategy, it could not, given the main findings of this report, be much better designed to suit this purpose. One could ask, given the development of this plan, and the considerable support that it has received from governments worldwide, and intergovernmental agencies such as $\mathrm{WHO}$ and the UN, what more now needs to be done?

\section{Towards a dementia-focused prevention strategy}

Consideration needs to be given to ways in which a more dementia-specific approach might complement and add value to the broader NCD prevention initiative. This focuses mainly upon population level interventions, particularly the use of legislation, fiscal measures, and voluntary agreements with industry, or regulation to achieve its desired ends. Much less attention is given to health promotion activities, to publicise risk associations and achieve change through the aggregated modification of individual lifestyles and behaviours. Nevertheless, in the past, such programmes have proved to be remarkably effective in improving cardiovascular health ${ }^{40}$. In the UK, people over the age of 55 years fear the onset of dementia more than any other condition, including cancer * There may therefore be potential to add to people's motivation to make and maintain changes in their physical activity, diet and smoking habit, to test for hypertension, cholesterol and diabetes, and adhere to prescribed treatments, if they understand that by doing so they may significantly reduce their risk of developing dementia in later life.

An important component of this message is that 'it is never too late'. The NCD prevention strategy focuses upon middle-aged people, and the prevention of 'premature mortality'. However, evidence presented in our report suggests that control of diabetes, smoking cessation, and, possibly, increases in physical and cognitive activity, have the potential to reduce the risk of dementia even in late-life.

There is also little emphasis in the NCD strategy on the role of the health sector in providing accessible and equitable treatment for the primary and secondary prevention of cardiovascular disease. The detection, treatment and control of hypertension ${ }^{50-53}$ and diabetes $^{54-56}$ is currently woefully inadequate among older people, particularly, but not exclusively in low and middle income countries. Earlier plans emphasised the need for an integrated approach to the management of chronic diseases, comprising assessment of risk factors, identification and active management of high risk status, early disease detection, and long-term follow-up with regular monitoring and promotion of adherence to treatment, and, to achieve this, the need for primary health care to be strengthened substantially ${ }^{57}$. Trials such as the Finnish FINGER trial described above, may, over time, develop an evidencebase that will reinvigorate interest in the targeted intensive treatment of at risk individuals in later-life, with the specific aim of promoting brain health, and preventing cognitive decline and dementia.

Hence, while the message is becoming clear, the optimal prevention strategy, and the 'messaging' to achieve the desired objectives remain obscure. We are, in truth, at the foothills with a mountain to climb, in particular in comparison to the evidencebase developed over the last 50 years to guide cardiovascular disease prevention and health promotion. Alzheimer's Disease International intends to follow this report with a selection of 'early adopter' case studies of brain health promotion and dementia prevention programmes, in an attempt to learn from these experiences, and understand which approaches are most likely to gain traction.

If we can all enter old age with better developed, healthier brains we are likely to live longer, happier and more independent lives with a much reduced chance of developing dementia. With an estimated global societal economic cost of dementia of over $\$ 600$ billion ${ }^{58}$, and rising, the stakes could hardly be higher.

\footnotetext{
* Alzheimer's Research Trust, YouGov Poll, May 2008; Alzheimer's Society survey, September 2008
} 


\section{References}

1 Beddington J, Cooper CL, Field J, Goswami U, Huppert FA, Jenkins $R$ et al. The mental wealth of nations. Nature 2008; 455(7216):10571060.

2 Jones RN, Manly J, Glymour MM, Rentz DM, Jefferson AL, Stern Y. Conceptual and Measurement Challenges in Research on Cognitive Reserve. J Int Neuropsychol Soc 2011;1-9.

3 Daviglus ML, Bell CC, Berrettini W, Bowen PE, Connolly ES, Jr., Cox NJ et al. National Institutes of Health State-of-the-Science Conference statement: preventing alzheimer disease and cognitive decline. Ann Intern Med 2010; 153(3):176-181.

4 Barnes DE, Yaffe K. The projected effect of risk factor reduction on Alzheimer's disease prevalence. Lancet Neurol 2011; 10(9):819-828.

5 Norton S, Matthews FE, Barnes DE, Yaffe K, Brayne C. Potential for primary prevention of Alzheimer's disease: an analysis of population-based data. Lancet Neurol 2014; 13(8):788-794.

6 Skoog I, Lernfelt B, Landahl S, Palmertz B, Andreasson LA, Nilsson $L$ et al. 15-year longitudinal study of blood pressure and dementia [see comments]. Lancet 1996; 347(9009):1141-1145

7 Stewart R, White LR, Xue QL, Launer LJ. Twenty-six-year change in total cholesterol levels and incident dementia: the Honolulu-Asia Aging Study. Arch Neurol 2007; 64(1):103-107.

8 Stewart R, Masaki K, Xue QL, Peila R, Petrovitch H, White LR et al. A 32-year prospective study of change in body weight and incident dementia: the Honolulu-Asia Aging Study. Arch Neurol 2005; 62(1):55-60.

9 McGuinness B, Craig D, Bullock R, Passmore P. Statins for the prevention of dementia. Cochrane Database Syst Rev 2009;(2):CD003160.

10 McGuinness B, Todd S, Passmore P, Bullock R. The effects of blood pressure lowering on development of cognitive impairment and dementia in patients without apparent prior cerebrovascular disease. Cochrane Database Syst Rev 2006;(2):CD004034.

11 Whitmer RA, Sidney S, Selby J, Johnston SC, Yaffe K. Midlife cardiovascular risk factors and risk of dementia in late life. Neurology 2005; 64(2):277-281.

12 Luchsinger JA, Reitz C, Honig LS, Tang MX, Shea S, Mayeux R. Aggregation of vascular risk factors and risk of incident Alzheimer disease. Neurology 2005; 65(4):545-551.

13 Kivipelto M, Solomon A, Ahtiluoto S, Ngandu T, Lehtisalo J, Antikainen $\mathrm{R}$ et al. The Finnish Geriatric Intervention Study to Prevent Cognitive Impairment and Disability (FINGER): study design and progress. Alzheimers Dement 2013; 9(6):657-665.

14 Lewington S, Whitlock G, Clarke R, Sherliker P, Emberson J, Halsey $\mathrm{J}$ et al. Blood cholesterol and vascular mortality by age, sex, and blood pressure: a meta-analysis of individual data from 61 prospective studies with 55,000 vascular deaths. Lancet 2007 ; 370(9602):1829-1839.

15 Lewington S, Clarke R, Qizilbash N, Peto R, Collins R. Age-specific relevance of usual blood pressure to vascular mortality: a metaanalysis of individual data for one million adults in 61 prospective studies. Lancet 2002; 360(9349):1903-1913.

16 Casserly I, Topol E. Convergence of atherosclerosis and Alzheimer's disease: inflammation, cholesterol, and misfolded proteins. Lancet 2004; 363(9415):1139-1146.

17 Neuropathology Group.Medical Research Council Cognitive Function and Aging Study. Pathological correlates of late-onset dementia in a multicentre, community-based population in England and Wales. Neuropathology Group of the Medical Research Council Cognitive Function and Ageing Study (MRC CFAS). [comment]. Lancet 2001; 357(9251):169-175.

18 Snowdon DA, Greiner LH, Mortimer JA, Riley KP, Greiner PA, Markesbery et al. Brain infarction and the clinical expression of Alzheimer disease. The Nun Study [see comments]. JAMA 1997; 277(10):813-817

19 Alzheimer's Disease International. World Alzheimer Report 2009. Prince M.J., Jackson J, editors. 2009. London, Alzheimer's Disease International.

20 Alzheimer's Disease International. Policy Brief for G8 Heads of Government. The Global Impact of Dementia 2013-2050. 2013. London, UK, Alzheimer's Disease International.
21 Prince M, Bryce R, Albanese E, Wimo A, Ribeiro W, Ferri CP. The global prevalence of dementia: a systematic review and metaanalysis. Alzheimers Dement 2013; 9(1):63-75.

22 Ferri CP, Prince M, Brayne C, Brodaty H, Fratiglioni L, Ganguli M et al. Global prevalence of dementia: a Delphi consensus study. Lancet 2005; 366(9503):2112-2117.

23 Lincoln P, Fenton K, Alessi C, Prince M, Brayne C, Wortmann M et al. The Blackfriars Consensus on brain health and dementia. Lancet 2014; 383(9931):1805-1806.

24 Matthews FE, Arthur A, Barnes LE, Bond J, Jagger C, Robinson $L$ et al. A two-decade comparison of prevalence of dementia in individuals aged 65 years and older from three geographical areas of England: results of the Cognitive Function and Ageing Study I and II. Lancet 2013; 382(9902):1405-1412.

25 Lobo A, Saz P, Marcos G, Dia JL, De-la-Camara C, Ventura T et al. Prevalence of dementia in a southern European population in two different time periods: the ZARADEMP Project. Acta Psychiatr Scand 2007; 116(4):299-307.

26 Mathillas J, Lovheim H, Gustafson Y. Increasing prevalence of dementia among very old people. Age Ageing 2011; 40(2):243-249.

27 Qiu C, von SE, Backman L, Winblad B, Fratiglioni L. Twenty-year changes in dementia occurrence suggest decreasing incidence in central Stockholm, Sweden. Neurology 2013; 80(20):1888-1894.

28 Rocca WA, Petersen RC, Knopman DS, Hebert LE, Evans DA, Hall $\mathrm{KS}$ et al. Trends in the incidence and prevalence of Alzheimer's disease, dementia, and cognitive impairment in the United States. Alzheimers Dement 2011; 7(1):80-93.

29 Langa KM, Larson EB, Karlawish JH, Cutler DM, Kabeto MU, Kim SY et al. Trends in the prevalence and mortality of cognitive impairment in the United States: is there evidence of a compression of cognitive morbidity? Alzheimers Dement 2008; 4(2):134-144.

30 Schrijvers EM, Verhaaren BF, Koudstaal PJ, Hofman A, Ikram MA Breteler MM. Is dementia incidence declining?: Trends in dementia incidence since 1990 in the Rotterdam Study. Neurology 2012; 78(19):1456-1463.

31 Chan KY, Wang W, Wu JJ, Liu L, Theodoratou E, Car J et al. Epidemiology of Alzheimer's disease and other forms of dementia in China, 1990-2010: a systematic review and analysis. Lancet 2013; 381(9882):2016-2023.

32 Wu YT, Lee HY, Norton S, Prina AM, Fleming J, Matthews FE et al. Period, birth cohort and prevalence of dementia in mainland China, Hong Kong and Taiwan: a meta-analysis. Int J Geriatr Psychiatry 2014;10.

33 Feigin VL, Lawes CM, Bennett DA, Barker-Collo SL, Parag V. Worldwide stroke incidence and early case fatality reported in 56 population-based studies: a systematic review. Lancet Neurol 2009; 8(4):355-369

34 Critchley J, Liu J, Zhao D, Wei W, Capewell S. Explaining the increase in coronary heart disease mortality in Beijing between 1984 and 1999. Circulation 2004; 110(10):1236-1244.

35 Gupta R, Joshi P, Mohan V, Reddy KS, Yusuf S. Epidemiology and causation of coronary heart disease and stroke in India. Heart 2008; 94(1):16-26.

36 Gaziano TA, Bitton A, Anand S, brahams-Gessel S, Murphy A. Growing epidemic of coronary heart disease in low- and middleincome countries. Curr Probl Cardiol 2010; 35(2):72-115.

37 Anand SS, Yusuf S. Stemming the global tsunami of cardiovascular disease. Lancet 2011; 377(9765):529-532.

38 Loef M, Walach H. Midlife obesity and dementia: Meta-analysis and adjusted forecast of dementia prevalence in the US and China. Obesity (Silver Spring) 2012.

39 Ford ES, Ajani UA, Croft JB, Critchley JA, Labarthe DR, Kottke TE et al. Explaining the decrease in U.S. deaths from coronary disease, 1980-2000. N Engl J Med 2007; 356(23):2388-2398.

40 Vartiainen E, Laatikainen T, Peltonen M, Juolevi A, Mannisto S, Sundvall $\mathrm{J}$ et al. Thirty-five-year trends in cardiovascular risk factors in Finland. Int J Epidemiol 2010; 39(2):504-518.

41 Laatikainen T, Critchley J, Vartiainen E, Salomaa V, Ketonen M, Capewell S. Explaining the decline in coronary heart disease mortality in Finland between 1982 and 1997. Am J Epidemiol 2005; 162(8):764-773. 
42 World Health Organization. Dementia: a public health priority. 2012. Geneva, World Health Organization.

43 United Nations General Assembly. Political declaration of the High-level Meeting of the General Assembly on the Prevention and Control of Non-communicable Diseases. A/66/L.1. 2011. New York, United Nations.

44 Yusuf S, Hawken S, Ounpuu S, Dans T, Avezum A, Lanas F et al. Effect of potentially modifiable risk factors associated with myocardial infarction in 52 countries (the INTERHEART study): casecontrol study.[see comment]. Lancet 2004; 364(9438):937-952.

45 Cong R, Zhou B, Sun Q, Gu H, Tang N, Wang B. Smoking and the risk of age-related macular degeneration: a meta-analysis. Ann Epidemiol 2008; 18(8):647-656.

46 van Durme YM, Verhamme KM, Stijnen T, van Rooij FJ, Van Pottelberge GR, Hofman A et al. Prevalence, incidence, and lifetime risk for the development of COPD in the elderly: the Rotterdam study. Chest 2009; 135(2):368-377.

47 Peto R, Darby S, Deo H, Silcocks P, Whitley E, Doll R. Smoking, smoking cessation, and lung cancer in the UK since 1950: combination of national statistics with two case-control studies. BMJ 2000; 321(7257):323-329.

48 Beaglehole R, Bonita R, Horton R, Ezzati M, Bhala N, AmuyunzuNyamongo $\mathrm{M}$ et al. Measuring progress on NCDs: one goal and five targets. Lancet 2012; 380(9850):1283-1285.

49 Yusuf S, Pais P, Afzal R, Xavier D, Teo K, Eikelboom J et al. Effects of a polypill (Polycap) on risk factors in middle-aged individuals without cardiovascular disease (TIPS): a phase II, double-blind, randomised trial. Lancet 2009; 373(9672):1341-1351.

50 Ostchega Y, Hughes JP, Wright JD, McDowell MA, Louis T. Are demographic characteristics, health care access and utilization, and comorbid conditions associated with hypertension among US adults? Am J Hypertens 2008; 21(2):159-165

51 Hypertension Study Group. Prevalence, awareness, treatment and control of hypertension among the elderly in Bangladesh and India: a multicentre study. Bull World Health Organ 2001; 79(6):490-500.

52 Gu D, Reynolds K, Wu X, Chen J, Duan X, Muntner P et al. Prevalence, awareness, treatment, and control of hypertension in china. Hypertension 2002; 40(6):920-927.

53 Prince MJ, Ebrahim S, Acosta D, Ferri CP, Guerra M, Huang Y et al. Hypertension prevalence, awareness, treatment and control among older people in Latin America, India and China: a 10/66 crosssectional population-based survey. J Hypertens 2012; 30(1):177187.

54 Cowie CC, Rust KF, Byrd-Holt DD, Eberhardt MS, Flegal KM, Engelgau MM et al. Prevalence of diabetes and impaired fasting glucose in adults in the U.S. population: National Health And Nutrition Examination Survey 1999-2002. Diabetes Care 2006; 29(6):1263-1268

55 Yang W, Lu J, Weng J, Jia W, Ji L, Xiao J et al. Prevalence of diabetes among men and women in China. N Engl J Med 2010; 362(12):1090-1101.

56 Olaiz G, Rojas R, Barquera S, Shamah T, Aguilar C, Cravioto P et al. Encuesta Nacional de Salud 2000. 2. La salud de los adultos. Sepulveda J, editor. 2003. Mexico City, Instituto Nacional de Salud Pública.

57 Beaglehole R, Epping-Jordan J, Patel V, Chopra M, Ebrahim S, Kidd $\mathrm{M}$ et al. Improving the prevention and management of chronic disease in low-income and middle-income countries: a priority for primary health care. Lancet 2008; 372(9642):940-949.

58 Wimo A, Prince M. World Alzheimer Report 2010; The Global Economic Impact of Dementia. 2010. London, Alzheimer's Disease International. 


\section{World Alzheimer's Month}

September

Alzheimer's Disease International

\section{Can we reduce the risk?}

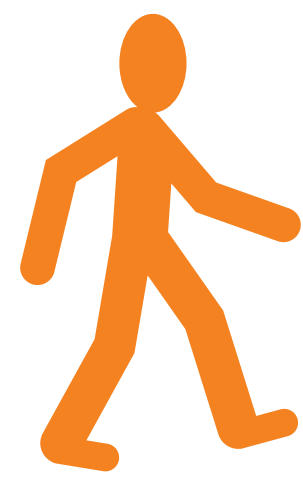

2

Be physically active

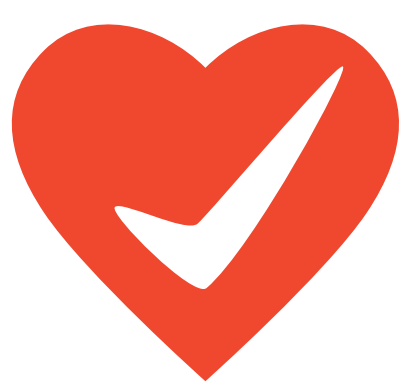

1

Look after your heart

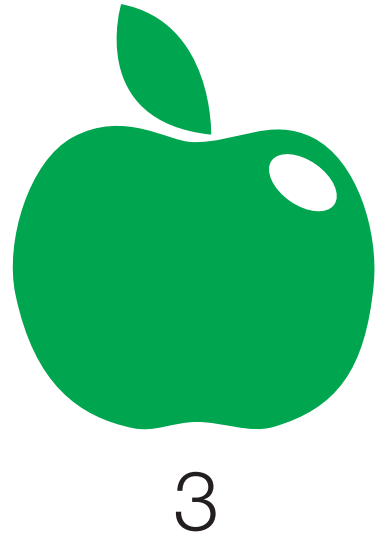

Follow a healthy diet

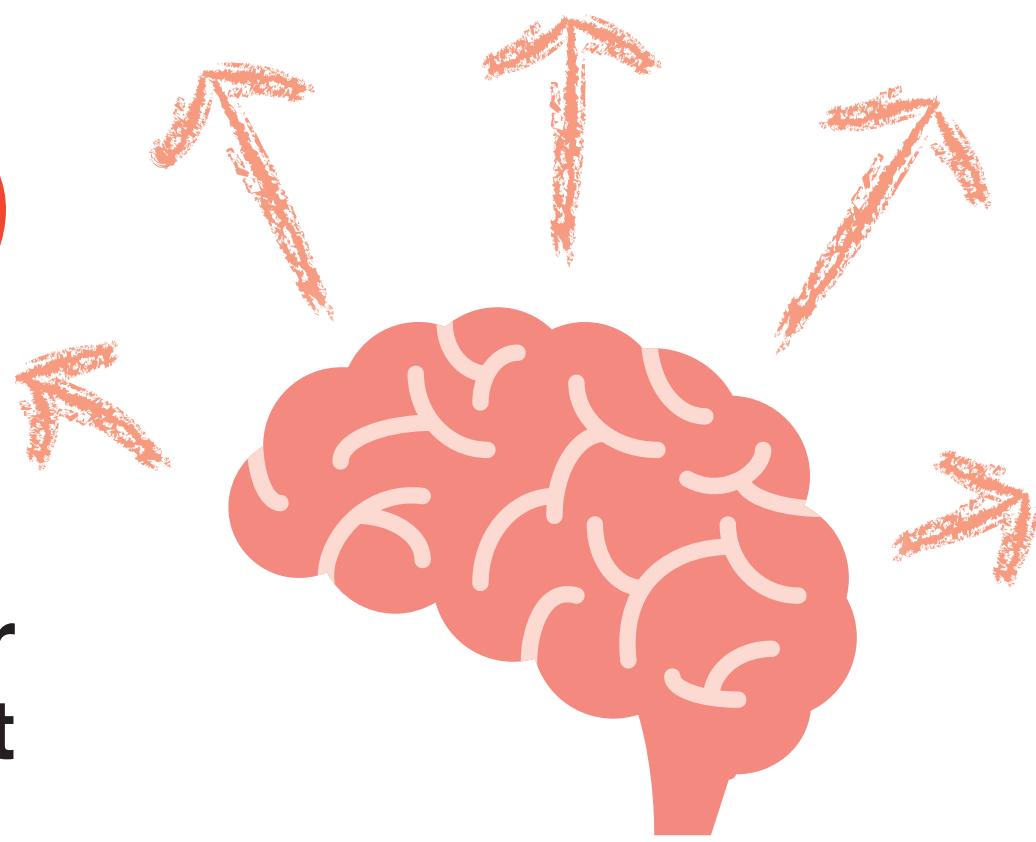

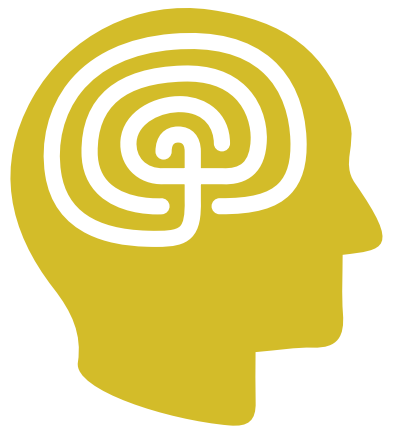

4

Challenge your brain

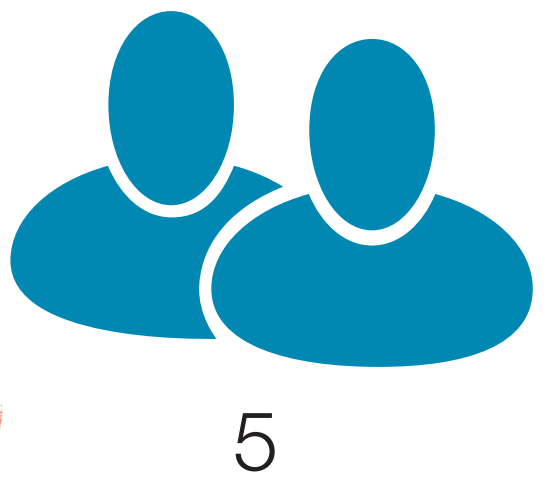

Enjoy social activity

To find out more visit:

www.alz.co.uk/WAM

y @AlzDisInt \#WAM2014

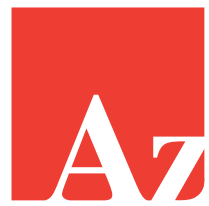

Alzheimer's Disease International

The global voice on dementia 
$A$

Alzheimer's Disease

International

\section{About ADI}

Alzheimer's Disease International (ADI) is the international federation of Alzheimer associations throughout the world. Each of our 84 members is a non-profit Alzheimer association supporting people with dementia and their families.

ADl's vision is an improved quality of life for people with dementia and their families throughout the world. ADI aims to make dementia a global health priority, to build and strengthen Alzheimer associations, and to raise awareness about dementia worldwide. Stronger Alzheimer associations are better able to meet the needs of people with dementia and their carers.

\section{What we do}

- Support the development and activities of our member associations around the world.

- Encourage the creation of new Alzheimer associations in countries where there is no organization.

- Bring Alzheimer organizations together to share and learn from each other.

- Raise public and political awareness of dementia

- Stimulate research into the prevalence and impact of Alzheimer's disease and dementia around the world.

- Represent people with dementia and families in international platforms at the UN and WHO

\section{Key activities}

- Raising global awareness through World Alzheimer's Month $^{\mathrm{TM}}$ (September every year).

- Providing Alzheimer associations with training in running a non-profit organization through our Alzheimer University programme.

- Hosting an international conference where staff and volunteers from Alzheimer associations meet each other as well as medical and care professionals, researchers, people with dementia and their carers.

- Disseminating reliable and accurate information through our website and publications.

- Supporting the 10/66 Dementia Research Group's work on the prevalence and impact of dementia in developing countries.

- Support global advocacy by providing facts and figures about dementia and monitor as well as influence dementia policies.

$\mathrm{ADI}$ is based in London and is registered as a nonprofit organization in the USA. ADI was founded in 1984 and has been in official relations with the World Health Organization since 1996. You can find out more about $\mathrm{ADI}$ at www.alz.co.uk.

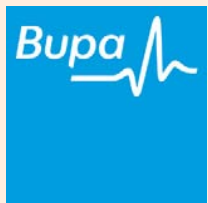

\section{About Bupa}

Bupa's purpose is longer, healthier, happier lives.

As a leading international healthcare group, we offer health insurance and medical subscription products, run care homes, retirement villages, hospitals, primary care centres and dental clinics. We also provide workplace health services, home healthcare, health assessments and long-term condition management services.

We have over $22 \mathrm{~m}$ customers in 190 countries. With no shareholders, we invest our profits to provide more and better healthcare and fulfil our purpose.

We employ more than 70,000 people, principally in the UK, Australia, Spain, Poland, New Zealand and Chile, as well as Saudi Arabia, Hong Kong, India, Thailand, and the USA.

For more information, visit www.bupa.com.

\section{About Bupa's social care services around the world}

During any given year, Bupa cares for more than 65,000 people in nearly 460 care homes and retirement villages in the UK, Spain, Australia, New Zealand and Poland.

We are the leading international provider of specialist dementia care. Of our care home residents, around three quarters have dementia.

In the UK, Bupa Care Services is providing care to nearly 29,000 residents during 2014 in 287 homes.

In Australia, Bupa Aged Care Australia is the largest private operator of residential aged care facilities. Caring for around 8,000 residents across 62 homes.

In New Zealand, Bupa Care Services New Zealand cares for more than 4,600 people in 48 homes, 21 care villages. It also operates 25 retirement villages and seven brain rehabilitation sites and provides support via a personal medical alarm network to over 14,000 people.

In Spain, Bupa (Sanitas Residencial) is one of the biggest geriatric care companies. It now has 41 care homes, caring for around 6,700 residents during 2014.

In Poland, Bupa (LUX MED) has a large nursing and residential care home.

We combine experience and expertise to care for our residents living with the dementia, providing a safe, comfortable and stimulating environment in our care homes. Our expertise in dementia care includes an innovative 'Person First' approach where our care revolves around each person's own needs and life history. 
Alzheimer's Disease International: The International Federation of Alzheimer's Disease and Related Disorders Societies, Inc. is incorporated in Illinois, USA, and is a $501(c)(3)$ not-for-profit organization
Alzheimer's Disease International 64 Great Suffolk Street London SE1 OBL

www.alz.co.uk

\section{$\sqrt[B u p a]{h}$} International 